Edith Cowan University

Research Online

$1-1-2005$

\title{
Living beyond the unanticipated sudden death of a partner : A phenomenological study
}

Martin L. Rodger

Edith Cowan University

Follow this and additional works at: https://ro.ecu.edu.au/theses

Part of the Social and Behavioral Sciences Commons

\section{Recommended Citation}

Rodger, M. L. (2005). Living beyond the unanticipated sudden death of a partner : A phenomenological study. https://ro.ecu.edu.au/theses/647

This Thesis is posted at Research Online.

https://ro.ecu.edu.au/theses/647 


\section{Edith Cowan University}

\section{Copyright Warning}

You may print or download ONE copy of this document for the purpose of your own research or study.

The University does not authorize you to copy, communicate or otherwise make available electronically to any other person any copyright material contained on this site.

You are reminded of the following:

- Copyright owners are entitled to take legal action against persons who infringe their copyright.

- A reproduction of material that is protected by copyright may be a copyright infringement. Where the reproduction of such material is done without attribution of authorship, with false attribution of authorship or the authorship is treated in a derogatory manner, this may be a breach of the author's moral rights contained in Part IX of the Copyright Act 1968 (Cth).

- Courts have the power to impose a wide range of civil and criminal sanctions for infringement of copyright, infringement of moral rights and other offences under the Copyright Act 1968 (Cth). Higher penalties may apply, and higher damages may be awarded, for offences and infringements involving the conversion of material into digital or electronic form. 
EDITH COWAN UNWVERSTY LIBPARY

\title{
LIVING BEYOND THE UNANTICIPATED SUDDEN DEATH OF A PARTNER: A PHENOMENOLOGICAL STUDY
}

\author{
BY
}

\section{MARTIN L. RODGER}

A thesis submitted for the award of:

Doctor of Philosophy (Nursing)

Faculty of Regional Professional Studies

Edith Cowan University, Bunbury, Western Australia

Year of submission: 2005 


\section{TABLE OF CONTENTS}

Use of thesis

Copyright and access declaration

Abstract

Acknowledgements

CHAPTER ONE

INTRODUCTION

Background

Significance of the study

Purpose of the study

The research question and objectives $\quad 5$

Definition of terms $\quad 5$

$\begin{array}{lc}\text { Structure of the thesis } & 6\end{array}$

CHAPTER TWO

HUSSERLIAN PHENOMENOLOGY - PHILOSPHICAL FOUNDATIONS

Introduction

Qualitative research methodology

Phenomenology as a philosophy

Husserlian phenomenology

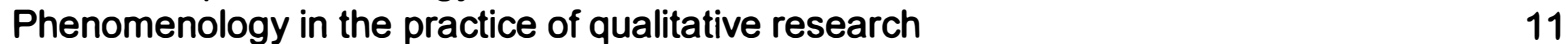

Phenomenological research and nursing $\quad 12$

Phenomenological research and thanatology 14

$\begin{array}{lr}\text { Conclusion } & 16\end{array}$

\section{CHAPTER THREE}

PHENOMENOLOGY AS A RESEARCH METHODOLOGY

Introduction

The phenomenological methodological process 17

Participant selection

$\begin{array}{ll}\text { Recruitment of participants } & 20\end{array}$

Ethical considerations $\quad 21$

$\begin{array}{ll}\text { The interview procedure } & 21\end{array}$

\begin{tabular}{ll} 
Transcription & 22 \\
\hline
\end{tabular}

Idiographic analysis $\quad 23$

Nomothetic analysis $\quad 24$

Participants' responses to the interview experience $\quad 25$

$\begin{array}{ll}\text { Rigour and phenomenological research } & 27\end{array}$

$\begin{array}{ll}\text { Conclusion } & 30\end{array}$

\section{CHAPTER FOUR}

PARTICIPANT PROFILES

Introduction

The participants

Overview of participants 


\section{CHAPTER FIVE}

\section{THE SURVIVING PARTNER'S RELATIONSHIP WITH SELF, WHILST EXPERIENCING A}

SHATTERED LIFE

Introduction

The surviving partner's experience of shock in relationship to discovering that his or her partner has died

The surviving partner's experience of confusion and chaos in relationship to the

sudden death of his or her partner

The surviving partner's experience of denial in relationship to the sudden death of

his or her partner

The surviving partner's experience of being with the dead partner's body

The surviving partner's experience of his or her dead partner's funeral and wake

The surviving partner's experience of emotional lability in relationship to the sudden death

of his or her partner

The surviving partner's experience of anger and frustration in relationship to the sudden

death of his or her partner

The surviving partner's experience of sleeping disturbances related to the sudden death of his or her partner

The surviving partner's experience of being bereft in relationship to the sudden death of his or her partner

Phenomenological explication of the participants' experiences

\section{CHAPTER SIX}

\section{THE SURVIVING PARTNER'S RELATIONSHIP WITH SELF WHILST}

\section{EXPERIENCING THE RECLAMATION OF HIS OR HER LIFE}

Introduction

The surviving partner's previous experience with the death of someone close

The surviving partner's experience of endurance whilst participating in everyday life

The surviving partner's experience of his or her own health and well-being

The surviving partner's experience with the use of alcohol and other drugs

The surviving partner's experience of creating diversions as a method for filling the void left by his or her deceased partner

The surviving partner's attempts at maintaining previous shared experiences

The surviving partner's experience of the use of music, and poetry as aesthetic therapy

The surviving partner's experience with the presence of the deceased partner

The surviving partner's experiences with the need to have time and space to grieve

The surviving partner's use of humour and laughter as a therapeutic device

The surviving partner's experience of significant dates and anniversaries

The surviving partner's relationship with the deceased partner's personal items

The surviving partner's experience with rituals and the memorialisation of the deceased partner

The surviving partner's experience of holidaying following the sudden and unexpected death of his or her partner

The surviving partner's experience with the integration of the death of his or her partner, whilst reclaiming his or her life

Phenomenological explication of the participants' experiences

\section{CHAPTER SEVEN}

THE SURVIVING PARTNER'S RELATIONSHIP WITH OTHERS WHILST EXPERIENCING DEPENDENCE ON AND REQUIRING SUPPORT FROM OTHERS

Introduction

The surviving partner's experience of children giving support and comfort 
The surviving partner's experience of creating an environment of mutual support

between themselves and his or her children

The surviving partner's experience of the relationship with his or her family $\quad 121$

The surviving partner's experiences with friends ' 125

The surviving partner's experience with community support $\quad 131$

The surviving partner's experience with loneliness, aloneness and social isolation 136

The surviving partner's experiences with pets as support and comfort 140

Phenomenological explication of the participants' experiences 141

\section{CHAPTER EIGHT}

\section{THE SURVIVING PARTNER'S RELATIONSHIP WITH OTHERS WHILE REGAINING INDEPENDENCE}

Introduction

The surviving partner's experience with children needing his or her support and comfort 143

The surviving partner's experience with his or her children in distress

The surviving partner's experience with allowing his or her children to develop his or her independence

The surviving partner's experience with his or her children's desire for a replacement father or mother

The surviving partner's experience of relating to the deceased partner's children

The surviving partner's experiences with bereavement counselling

The surviving partner's experiences with support groups

The surviving partner's experience of returning to work

The surviving partner's experience with the prospect of a new relationship

The surviving partner's experience of continuing to feel married to the deceased partner 164

The surviving partner's experience with perceived barriers to forming a new relationship 165

The surviving partner's experience with gaining family permission to form a

new relationship

The surviving partner's experience with missing the emotional and physical intimacy

of the relationship

The surviving partner's experience with taking the tentative steps of having outings with members of the opposite sex

The surviving partner's experience with a new relationship

The surviving partner's experience with his or her children relating to the new partner's children

Phenomenological explication of the participants' experiences

\section{CHAPTER NINE}

\section{THE SURVIVING PARTNER'S RELATIONSHIP WITH THE WORLD WHILST EXPERIENCING THE MAZE OF OFFICIALDOM}

Introduction

The surviving partner's experiences with being informed of the death or injury of his or her partner by the police

The surviving partner's experience with the nursing profession relation to the care and/or death of his or her partner

The surviving partner's experience with the medical profession in relation to the care and/or death of his or her partner

The surviving partner's experience with pastoral and social care

The surviving partner's experience with the Coronial Enquiries Section and hospital administration 
The surviving partner's experience managing financial affairs following the death of his or her partner

The surviving partner's experience with insurance companies

Phenomenological explication of the participants' experiences

\section{CHAPTER TEN}

\section{THE SURVIVING PARTNER'S RELATIONSHIP WITH THE WORLD WHILST EXPERIENCING THE EMERGENCE OF A NEW LIFE ORDER}

Introduction

The surviving partner's experience of reconciling his or her displaced position in the world following the death of his or her partner

The surviving partner's experience with developing a new social status

The surviving partner's experience with his or her spiritual belief system

207

The surviving partner's experience with facing his or her own mortality and the future

Phenomenological explication of the participants' experiences

\section{CHAPTER ELEVEN}

\section{OVERVIEW OF EXPERIENCES: ADSPICE, RESPICE AND PROSPICE}

Introduction

Phenomenological explication of the participants' experiences

Limitations of the study

Participants' updates on their lives since being interviewed

In conclusion

\section{CHAPTER TWELVE}

\section{RECOMMENDATIONS AND OPPORTUNITIES FOR FUTURE RESEARCH}

\section{Recommendations}

Informing of the death and the immediate support of the newly bereaved 225

Maintaining the health and well being of the surviving partner $\quad 226$

Bereavement follow-up for the newly bereaved person

Grief and bereavement education an ongoing support for the health and caring

Professions

Coronial Enquiries Section and hospital administration

Bereavement support for children

Funeral directors

Government and non-govemment agencies, banks and insurance companies

Opportunities for future thanatological research

REFERENCES

APPENDIX A Letter to participant

APPENDIX F Permission request to include a participant profile, a case study and an individual transcript analysis

APPENDIX G Case study 


\section{USE OF THESIS}

The Use of Thesis statement is not included in this version of the thesis. 


\section{COPYRIGHT AND ACCESS DECLARATION}

I certify that this thesis does not, to the best of my knowledge and belief:

(i) incorporate without acknowledgement any material previously submitted for a degree or diploma in any institution of higher degrees;

(ii) contain any material previously published or written by another person except where due reference is made in the text; or

(iii) contain any defamatory material.

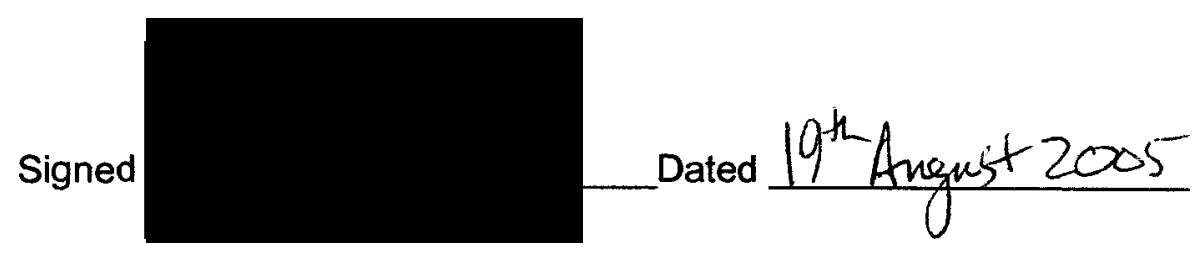




\section{ABSTRACT}

This research project used a Husserlian phenomenological approach to explore grief and its impact upon men and women who have experienced the sudden and unanticipated death of his or her partner. The use of Husserlian phenomenological research into thanatological study is a valuable method of exposing the experiences of bereaved people in a vibrant and deep manner. Husserlian phenomenology allowed the surviving partner to reveal every aspect of his or her everyday life and experiences. It included what grief meant to them, how it was manifested in their everyday lives and how their partner's death had impacted upon his or her relationship with themselves, with others and the world. The stories told by the surviving partner were unique, however shared common themes.

The researcher used in-depth open-ended interviews, which were informal conversations about the person's experiences and perceptions related to the death of their partner. A predetermined list of questions was used in order to prompt the interviewer and to gain some semblance of continuity.

This study involved interviewing 10 women and five men whose partner had died up to five years prior to the interview. Other parameters of this research project were: the partner who died was aged between 18 - 65 years of age, had no known pre-existing life threatening illness, had not worked in a high risk occupation, and did not regularly take part in high risk recreational pursuits. The death of the partner was not due to suicide or homicide. The participants were gathered using the media, and other formal and informal methods of communication.

The sudden and unexpected death of a partner shattered the life of the surviving partner leading the surviving partner to experience shock, denial and numbness. The surviving partner required family and friends to support them whilst they attempted to reconcile and integrate the death of their partner into his or her life. The need for the surviving partner to continue to participate in everyday life placed great strain upon the internal resources of the surviving partner, sometimes resulting in eating disorders, increased use of alcohol or the need for prescription medications.

Exposure to officialdom whilst coming to terms with the new social status of widow or widower reinforced the reality of the surviving partner's new life. The 
surviving partner needed to reinvent him or herself, in an attempt to become independent and regain functionality, whilst dealing with the sadness and loss that they had experienced. The surviving partner discovered that a new life order emerged that included hope, optimism, planning for the future and perhaps the prospect of a new relationship. The death of a partner left the surviving partner with a loss that would always be a part of them, with the memories of his or her relationship being maintained within them that will never be replaced by somebody else.

The results of this research project reinforce the need for ongoing education of the community in grief and bereavement issues in order to increase the awareness of the support needs of the bereaved person. The length of time and amount of energy required to incorporate the experience into the survivor's life, is greatly underestimated by the community, and perhaps by some of the health and caring professionals. The notion of being able to reconcile the sudden and unexpected death of a partner may actually be unachievable, with the surviving partner not being able to make sense of a "senseless" death. This may lead the surviving partner to encapsulate or compartmentalise the loss into his or her life in order to progress with future relationships between themselves, others and the world.

It is hoped that the health and caring professions that deal with the newly bereaved may gain greater insight and understanding into the way people live with this type of loss in order to provide appropriate support. Health providers need to be cognizant of the detrimental effect that profound grief experiences can have on the psychological and physical well being of the surviving partner. The impact that grief has upon the health and wellbeing of the survivors can be profound, which also has an impact upon the greater community with a financial cost associated with grief related psychological and physical problems.

Coronial and hospital based bereavement support services need to be established and proactive using outreach programmes, actively offering the suddenly bereaved partner and family support and information. The bereaved person may decide not to take up the offer of support, however will no doubt appreciate that his or her bereavement experience was recognised as a significant event. 


\section{Acknowledgements}

I would like to acknowledge with gratitude the men and women who volunteered to take part in this project. These people were willing to talk to me about their life experiences following a devastating event, the sudden and unexpected death of their partner. Their willingness to talk candidly and in depth is what made this thesis what it is, a testament to the strength of people who can continue to live beyond adversity, whilst using the memory of their partner to bring fulfilment into their lives.

I wish to acknowledge the commitment that I have had from my family and friends who journeyed with me over the six years it took to complete the Master and $\mathrm{PhD}$ level of this thesis. To my wife Ellen who was steadfastly supportive of this project, lending me her strength and wisdom, whilst providing me with the love and comfort that helped me survive the rigours of such a project. To my children, Luke and Bethany, thanks for going without my time, energy and tolerating my moods when this project was weighing me down. I'll make it up to you both! To my family and friends thanks for putting up with me! Thanks also to my father for performing the onerous task of the final proof read.

I wish to thank the 'professionals' involved in this project. To Myra, Emma and Lisa who transcribed the recorded conversations, thank you very much, I would never have survived if I had to do it myself! To all the support staff at Edith Cowan University, thank you for facilitating this process and making it happen as smoothly as possible. To the Nurses Board of Western Australia, who recognised the importance of the subject matter by awarding me the Postgraduate Research Award to help fund the project.

Finally, I would like to thank my supervision team. Over the six years several people have been part of this team, and have all given tremendous support and advice. Ricky Maltby, who was there at the start helping me get my initial proposal together, with Maxine Serrell taking over when Ricky left ECU, guiding me through the initial difficulties of finding men to participate in the project. Then when Maxine took study leave, it was over to Yvonne Hauck who was invaluable in helping me write my PhD proposal and upgrade from Master to PhD level. Associate Professor Gavin Leslie was then brought in to help with the editing of the thesis when $\mathrm{Dr}$ Yvonne went onto do other projects. To Dr Trish Sherwood who is a 
phenomenologist extraordinaire, thank you for your expertise and patience in helping me to understand the fundamentals and intricacies of phenomenology. Finally I would like to thank Dr Moira O Connor who has been an integral part of this journey from the start, always giving me cheerful, positive encouragement throughout. Moira was always able to give me insightful guidance whilst being able to help me develop the thesis to a professional academic level while maintaining empathy and thoughtfulness. Thanks everyone!

Lastly I would like to thank Professor Linda Kristjansen and Associate Professor Bronwyn Jones for their friendship and professional support over the years. People such as yourselves gave me the inspiration and resolve to undertake this study. 


\section{INTRODUCTION}

Life is not a problem to be solved, but a mystery to be lived.

Gabriel Marcel, (Miller \& Hrycyniak, 1996, p.83)

\section{Background}

When each of us approaches a new day, we make assumptions based upon our previous experiences. The major 'taken for granted for' assumption is that if we are living an ordinary life and we are anticipating an ordinary day, the probability is that each of us, as well as people close to us, will live to complete the day. Every day, however, somewhere in the world, this assumption is shattered by the sudden unanticipated death of a partner.

It has been well documented that people living in the so-called 'Western World' are by and large a death denying society (Kellehear, 2000). As a collective group we do not regularly discuss (or perhaps even think about) the inevitability of our death. Many people do not have up to date Wills or funeral plans organised (Kellehear, 2000).

The reality of life is that it will eventually end. People whose partners have a degenerative illness or a malignant disease are aware that his or her partner's life may be shortened and are more likely to be prepared for their impending death. People whose partners are fit and well and are not partaking in life threatening occupations or recreational pursuits are more likely to be unprepared for their death (Duke, 1998; Gilliland \& Fleming, 1997; Hogan, Greenfield, \& Schmidt, 2001; Levy, 1991; Sweeting \& Gilhooly, 1990).

Following the sudden and unexpected death of his or her partner the surviving partner's life has been thrown totally out of kilter and infused with sadness and loss. The grief that is experienced inhabits the life of the surviving partner every minute of the day, which affects how he or she views himself or herself, how he or she relates to others and his or her relationships with the world. 


\section{Significance of the study}

Nurses and other health professionals are becoming increasingly aware of the need for greater knowledge in the area of grief and bereavement as well as the need for active support of the bereaved person. The morbidity and mortality rates of the bereaved person are greater than the general population, ongoing psychosocial problems may impact upon the ability of the bereaved person to function in the work place and the personal realm to a satisfactory level, as well as ongoing relationship and interfamily problems may adversely affect the bereaved person (Baker, 1987; Buchanan, Geubtner, \& Snyder, 1996; Burgess, 1992; Coolican, Vassar, \& Grogan, 1989; G. Costello, 1995; Davidhizar \& Kirk, 1993; Davies, 1991; Feinstein \& Ramatowski, 1995; Fraser \& Atkins, 1990; Keenan, 1995; Kiger, 1994; McQuay, 1995; Thayre, 1995). It is therefore imperative that nurses and other health professionals undertake thanatological research to help inform their practice.

The sudden and unexpected death of a partner is an area that is often difficult to study due to the affected population being hidden in the overall population of bereaved people. If a person dies following a protracted illness then the relatives and friends are more easily accessible due to the ongoing contact that they have had with health professionals, hospitals or hospices. It is therefore much easier to access bereaved people following a protracted illness than a relative of a person who has died outside of a hospital or been brought in dead to an Emergency Department (Davies, 1991; Harte-Barry, 1997; McQuay, 1995; Tye, 1993).

A literature search revealed that there is very little published research on the experiences of the surviving person after the unanticipated sudden death of a partner. The studies that do describe the impact that death has upon the surviving partner are generally concerned with a death that has been related to suicide, homicide, chronic disease or Acquired Immunodeficiency Syndrome (AIDS) (Brabant, Forsyth, \& Melancon, 1992; Bucholz, 2002; Levy, 1991; Parkes, 1987; Quigley \& Schatz, 1999; Range \& Niss, 1990; Richmond \& Ross, 1994; Smith, Mitchell, Bruno, \& Constatino, 1995; Speck, 1985; Zisook, Chentsova-Dutton, \& Shuchter, 1998).

The majority of thanatological studies which involve the surviving partner are retrospective surveys utilising quantitative methodologies following an anticipated death (Anderson, 2000; Bowling \& Windsor, 1995; Caserta \& Lund, 1996; Chen et al., 1999; Coolican et al., 1989; Davis \& Nolen-Hoeksema, 2001a; Gilliland \& Fleming, 1997; Hogan et al., 2001; Hyrkas, Kaunonen, \& Paunonen, 1997; Jagger \& 
Sutton, 1991; Kirschling \& McBride, 1989; Levy, 1991; Middleton, Burnett, Raphael, \& Martinek, 1996; Prigerson, Bierhals et al., 1997; Prigerson, Maciejewski, \& Rosenheck, 2000; Quigley \& Schatz, 1999; Schneider, Sledge, Shuchter, \& Zisook, 1996; W. Stroebe, Stroebe, Abakoumkin, \& Schut, 1996; Sweeting \& Gilhooly, 1990; Zisook \& Shuchter, 1991; Zisook, Shuchter, Irwin et al., 1994). These studies are often based upon hospice and palliative care experiences whereby the surviving partner's bereavement is recognized and supported by family and friends who may have had time to adjust to the impending death (Sanguesa, 1995). In addition to this support, the surviving partner may have had access to institutionally based bereavement counsellors, social workers or trained volunteers, with whom they may have developed some level of rapport.

The surviving partner of a sudden death does not have time to prepare for this unanticipated death, nor the time to develop a prepared support network (Sanguesa, 1995). It has been demonstrated that surviving partners of a person who has died suddenly are often neglected by family and friends who are also inadequately prepared to help (Anderson, 2000; Detmer \& Lamberti, 1991; Rosenblatt, 1994; Sanguesa, 1995; Shuchter \& Zisook, 1993). Confounding this lack of personal support is that the institutional support that is available (e.g. the Coronial Enquiries Section bereavement support services) may not be familiar to the surviving partner, and may be under-utilised or not accessed at all.

It is only over the past few years that qualitative methodologies have been used to describe grief and bereavement (Chethik, 2000; J. Costello \& Kendrick, 2000; Daggett, 1999; Duke, 1998; Elliott, 1999; Harte-Barry, 1997; Horacek, 1995). Phenomenology has been a popular choice for qualitative research due to the use of face-to-face interviews and the intimate nature of the data analysis resulting in a rich and deep description of the phenomena (Clark, 1993; Daggett, 1999; Harte-Barry, 1997; Neimeyer, Prigerson, \& Davies, 2002; Margaret Stroebe, 2001; M Stroebe \& Schut, 1999; Zisook, Shuchter, Sledge, Paulus, \& Judd, 1994).

The other significant component of this study is that it included both men and women. Studies in this field of sudden death have mainly concentrated on the effect of bereavement upon the widow (Davies, 1991; Remondet \& Hansson, 1987; Robinson, 1995; Sable, 1991). This is not surprising considering that it is statistically less common for a male to outlive his female partner. The demographics of conjugal bereavement are heavily weighted towards the female due to two reasons, the first being that the majority of women are partnered with men who are older, and the second is due to the biological fact that women 
generally outlive men by an average of five years (Australian Bureau of Statistics, 2002b). In Australia, at every age men are more likely to die than women, with the largest differences in the 15-34 years age group where male death rates are three times higher than female death rates (Australian Bureau of Statistics, 1997). In the 2001 Australian census the distribution of widowed people was 738,397 (80\%) women and 181,507 (20\%) men (Australian Bureau of Statistics, 2002b).

Kirschling \& McBride (1989) who studied age and gender differences in widowhood found that women reported greater somatization, loss of control, and rumination than did the men. The men displayed greater levels of denial by internalising their pain, which may be due to the socialisation of the machismo role (1989). This research is supported by Stroebe (1998) who reported that women are more likely to seek social support following the death of their partner, whereas men are more likely to rely upon their own resources and not acknowledge the depth of feeling that they experience following their partner's death. Failure to acknowledge the nature and extent of their emotional responses, for example: hurt, anger and confusion, may mean that men do not talk to family and friends and do not access formal or informal counselling sessions (M Stroebe, 1998).

Stroebe (1998) also found that following the death of their partner, men have higher mortality rates, take longer to 'recover' in terms of feeling 'normal again', have higher rates of mental illness, and suffer higher rates of physical illness than do women. Stroebe concluded that men were more vulnerable to health problems than women were, following the death of their partners. These findings have implications to all health and caring professionals, in that men may need to be more actively targeted for follow up bereavement support, than is currently acknowledged.

The gender imbalance has started to be rectified in the past few years with more researchers concentrating on widowers as well as researching gender differences (Chen et al., 1999; Daggett, 1999; Hyrkas et al., 1997; Kaunonen, Tarkka, Paunonen, \& Laippala, 1999; Kirschling \& McBride, 1989; Klein, 2000; Schneider et al., 1996; Tudiver et al., 1995; Zisook, Paulus, Shuchter, \& Judd, 1997).

Throughout the thesis previous studies are included to assist the reader to place the findings of this study into context. Given that most of the studies that have been cited are large quantitative research projects, a direct comparison with the findings of this thesis cannot be made. However, it is useful to place the findings of this thesis into the larger arena of thanatological research. 


\section{Purpose of the study}

The purpose of the study was to explore the phenomenon of grief and its impact upon men and women who had experienced the sudden unanticipated death of their partner. It included the meaning of grief, and how it is manifested in their everyday lives. The study will lead to a greater understanding of grief from the survivor's perspective in this previously under described group.

\section{The research question and objectives}

The objectives of this study are:

1. To explore the meaning of grief for men and women who experience the sudden unanticipated death of his or her partner;

2. To describe how grief is manifested for them in their everyday life;

3. To identify if there are common themes in the survivor's experiences;

4. To compare their experiences with other research and literature related to this area;

5. To formulate recommendations for the appropriate support and counselling for men and women who have experienced the sudden death of a partner.

It is hoped that nurses and other health professionals who deal with the newly bereaved, may gain a greater insight and understanding into the way people live with this type of loss in order to provide appropriate health care and empathetic counselling, support and education.

\section{Definition of terms}

Sudden death: an unexpected death that occurs with either a brief warning or no warning, is not anticipated, and results in either the person dying immediately following the cause or within a short time frame without regaining consciousness. Death informing: the process of informing a surviving partner (and family and close friends) of the death of their partner.

\section{Structure of the thesis}

Chapter Two is dedicated to introducing Husserlian phenomenological research from a conceptual and philosophical view with Chapter Three describing 
how a methodological process was used to achieve a Husserlian phenomenological outcome. Chapter Four gives a brief outline of the individual participants' story. The six interpretive themes that were developed are detailed in separate dedicated chapters, which are:

\section{Relationship to one's self}

- The surviving partner's relationship with self whilst experiencing a shattered life

- The surviving partner's relationship with self whilst experiencing the reclamation of his or her life

\section{Relationship to others}

- The surviving partner's relationship with others whilst experiencing temporary dependence on and receiving support from others

- The surviving partner's relationship with others while regaining independence

\section{Relationship to world}

- The surviving partner's relationship with the world whilst experiencing the maze of officialdom

- The surviving partner's relationship with the world whilst experiencing the emergence of a new life order

At the end of each sub theme section, the findings of this research project are placed into context with the existing thanatological research and literature. However not all sub themes elicited equivalent research, which resulted in the previous research and literature being included at the end of a theme.

Chapter Eleven is devoted to an overview of the study and the development of a summation of patterns that have emerged from the participants' experiences. Chapter Twelve is dedicated to creating recommendations for those professionals who are involved in the care of the bereaved person and opportunities for future research. 


\title{
CHAPTER TWO
}

\section{HUSSERLIAN PHENOMENOLOGY - PHILOSPHICAL}

\section{FOUNDATIONS}

\author{
Small is the number of them that see with their own eyes, \\ and feel with their own hearty.
}

Albert Einstein (Miller \& Hrycyniak, 1996, p.207)

\section{Introduction}

The aim of this research was to describe and attempt to understand the experience of people whose partners had died suddenly and unexpectedly. In order to achieve this aim, Husserlian phenomenology was considered to be the most appropriate methodology. This chapter will describe the philosophical foundations of this phenomenological approach to research in general and nursing and thanatological research in particular, and why Husserlian phenomenology was chosen as methodology. A description of the phenomenological research process will be detailed in Chapter Three.

\section{Qualitative research methodology}

Nursing researchers have increasingly utilised qualitative research methodologies over the past quarter century (Anthony, 1996, p.69; Barkway, 2001; Corben, 1999; Paley, 1998; Ratcliffe, 1998; Salsberry, 1989; Tatano-Beck, 1994; Taylor, 1995). Munhill \& Boyd (1993) suggest that a paradigm shift has occurred in nursing, whereby the nursing profession has moved from the: “...medical, atomistic causal model, to a distinct, holistic, interactive model" (p.12).

During the latter stages of the twentieth century nursing scholars began a quest to define nursing as a distinct profession within health care with its own unique philosophy and models of care (Van-der-Zalm, 2000). In order to capture what it is that makes nursing practice different to other health professions, qualitative research methodologies were often chosen over quantitative methodologies, which had hitherto dominated health research (Van-der-Zalm, 2000). Omery (1983) encapsulates the reasoning behind this choice: 
What was deleted in the objective scientific experiment, the subjective experience, was beginning to be perceived as more basic, and real in the understanding of human knowledge and behaviour than the codifications that the experimental researchers called data (p.54).

Nursing researchers have increasingly used phenomenology as a methodology of choice when attempting to discover what the people nurses care for really experience from their own perspectives and context (Annells, 1996; Schoenhofer, 2002; Valente \& Saunders, 1997; Yegdich, 1999). Van-der-Zalm (2000) asserted that phenomenology can provide living knowledge for nursing practice:

The phenomenological approach has gained popularity among nurse researchers as an alternative investigative method to those used in the natural sciences. As more nurse scholars and nurse researchers utilize phenomenology as a research approach, it becomes critical to examine the implications this may have for nursing knowledge development and for the utilization of that knowledge in practice... It is clear that phenomenology contributes to empirical, moral, aesthetic, personal, and socio-political knowledge development. Its contribution is not in developing predictive and prescriptive theory, but in revealing the nature of human experience. Although interpretive inquiry, such as hermeneutic phenomenology, does not prescribe action for use in clinical practice, it does influence a thoughtful reflective attentive practice by its revealing of the meanings of human experience (p.211).

The research topics that nursing researchers have chosen to use phenomenological methodologies to study have often been the foundation stones of the profession. For example LeVasseur (2002), studied the art of nursing by interviewing nurses and using the opening question: "Tell me of your experience in helping a patient turn a corner in his or her illness and come to see his or her situation in a new way" (p. 14). The aim of the study was to gain understanding into the object of nursing art, which is conceptualised: “... as a transition that the nurse helps facilitate with a patient who has become: “...stuck in some way" (p.14).

Kralik, Koch, \& Wotton (1997) used a combination of Heideggarian and Husserlian phenomenology to gain understanding as to what they felt was important about the nursing care that nine post surgery patients experienced. Two major themes emerged from the interviews with the women, who described nurses as being either engaged or detached with their nursing care.

Valente \& Saunders (1997) believed that nurses should consider the full range of research methodologies in order to find the appropriate fit: 
Often a quantitative paradigm fits well with laboratory sciences and economic analysis. However, clinical or behavioral science settings often do not allow strict control over patients' differences and external influences. If a nurse wants to examine phenomena that are embedded in the context and a person's experience and perceptions, then other methods are needed. Students, researchers, and clinicians should understand, evaluate, and respect a wide array of methodologies. For example, understanding a mother's grief at her son's death is no more or less important than understanding cost analysis or program evaluation (p. 9).

\section{Phenomenology as a philosophy}

The Macquarie Dictionary defines a phenomenon as: “...an appearance or immediate object of awareness in experience," (Delbridge, 1982, p.1297) and phenomenology as: “...the school of German philosopher Edmund Husserl 18591938, which stresses the careful description of phenomena in all domains of experience without regard to traditional epistemological questions" (p.1297). Husserl believed that the relation between a person's perception and objects and experiences was not passive, and that human consciousness actively constitutes the objects of experience (Holstein \& Gubrium, 1994). Holstein and Gubrium (1994) claim that: "...this (phenomenology) has become foundational for the qualitative study of reality-constituting practices..." (p.263).

Alfred Schutz (1964) argued that ordinary people reconstitute the everyday world continuously and therefore: "The safeguarding of the subjective point of view is the only but sufficient guarantee that the world of social reality will not be replaced by a fictional non-existing world constructed by the scientific observer" (cited in Holstein \& Gubrium, 1994, p.263). In order to truly value an individual's worldview or paradigm, the researcher must suspend his or her ontological belief system. Schutz (1964) refers to this concept as bracketing, which may reduce any bias that the researcher could introduce due to his/her previous experience (cited in Holstein \& Gubrium, 1994, p.263).

Schutz (cited in Holstein \& Gubrium, 1994) also refers to individuals having a stock of knowledge, which the individual uses to allow them to make sense of their experiences, derived from previous experience. Images, theories, ideas, values, and attitudes are applied to aspects (or categories) of experience making them meaningful, thus forming the basis of what Schutz calls typifications. Typifications allow the individual to function within society without having to greet every experience as a completely new experience; typifications are incomplete, open ended, and modifiable. 
Language is the medium in which typifications are transmitted and given meaning (Schutz cited in Holstein \& Gubrium, 1994, p.263). Language provides a methodological framework in which an individual's worldview is stored and can be conveyed to another. Social interaction, therefore constructs as much as it conveys meaning. The use of language from a phenomenological perspective is regarded as being unique to the individual and an important part of that individual's experience.

The last tenet of Schutz's theories is that the majority of individuals react to the stimulus of everyday life in similar fashions, and despite the individual giving a unique account of their experience; commonalities will emerge (cited in Holstein \& Gubrium 1994). A phenomenological study will therefore have the underlying assumption that there will be commonalities, with themes and categories emerging, enabling the results to be related to and integrated with those of other phenomenological studies that have examined the same phenomenon, according to Eichelberger (cited in Patton, 1990).

\section{Husserlian phenomenology}

The German philosopher Edmund Husserl (1859-1938) is credited with developing a philosophy that searched for the truth by studying: "...how people describe things and experience them through their senses" (Patton, 1990, p.69). Husserl believed that people only understand what they experience by: "attending to perceptions and meanings that awaken our conscious awareness...(and that) experience must be described, explicated, and interpreted" (Patton, 1990, p.69).

A logical-positivist research study emphasises the need for the researcher to search for purely objective results, whilst separating the observer from the participant. When a Husserlian phenomenological approach is used, the observer becomes the device that is used to uncover the true meaning behind the participants experience, which becomes an inter-subjective experience for the researcher (Tatano-Beck, 1994). Husserlian phenomenology requires the researcher to suspend all judgements of the extemal world which is described as the 'epoche' (Paley, 1997). The epoche is not a research methodology but an attitude that must be adopted prior to attempting the research project (Paley, 1997). Therefore the researcher's 'natural attitude' or everyday assumptions are bracketed to allow the person's experience to be revealed without bias or influence (Paley, 1997).

Husserl believed that the relation between a person's perception and objects and experiences is not passive, and that human consciousness actively constitutes 
the objects of experience (Holstein \& Gubrium, 1994). In the search for reality constituting practices, phenomenology is a fundamental research methodology that stays true to the participant's reality as he or she perceive it (Holstein \& Gubrium, 1994).

Husserl's 'eidetic reduction' is a philosophical device, the purpose of which is to render concepts clear, explicit and complete (Paley, 1997). Husserl claimed that: "empirical or individual intuition can be transformed into essential intuition ... which gives the essence" (Paley, 1997, p.6). In using what Husserl refers to as 'free variation' the phenomenologist strips away any extraneous material to reveal the true object or the 'thing itself' (Paley, 1997, p.6).

The role of the phenomenological researcher is to discover and unveil the 'core meaning' of the experience for each individual. If we think of phenomenology as taking a backward looking approach, in other words an a posteriori approach, then the phenomenon in this study, being the sudden and the unexpected death of a partner is the 'cause' from which there is a multiplicity of 'effects'. In order to reveal as many 'effects' as possible, the phenomenologist needs to explore the experience from three domains: the relationship the person has with him or herself, with others and the world, which includes the ethereal (heavenly) world.

Husserl's way of finding the phenomenon does not involve descriptions of anything in the person's own words (Paley, 1997). The researcher is the person who is responsible for entering the person's experience and uncovering the meaning of the experience. Participant quotations are used to provide evidence of the thoughts, moods, and feelings and to provoke a response from the reader (Sandelowski, 1994).

The use of intuition in order to create extended descriptions of the experiences encountered by people who have experienced a particular phenomenon, is a sense that many nurses use in the practice of nursing (Giguere, 2002; McCutcheon \& Pincombe, 2001). Intuition is an intangible phenomenon that is not easily defined or articulated that can give valuable insight into the experiences of people.

\section{Phenomenology in the practice of qualitative research}

Phenomenology asks the question: "What is the structure and essence of experience for these people?" (Patton, 1990, p.69). Phenomenological research focuses upon the descriptions of what people experience and how they experience 
what they experience (p.71). Husserl regarded himself as an explorer who developed a philosophy that needed to be developed further by future phenomenological researchers (Sawicki, 2001). Several methodological approaches have been developed in line with phenomenological philosophical thought in order to achieve a truly phenomenological research result. The various methodological process' that have been developed may differ but not the fundamental principles of phenomenology (Tatano-Beck, 1994). Phenomenological methodologies have been devised by researchers such as: Colaizzi, Giorgi, Van Kaam, and van Manen, over the past thirty years.

Husserlian phenomenological research underpins, but is different from two other qualitative research frameworks, Heuristic and Hermeneutic inquiry. Heuristic researchers have an intense emotional and intellectual involvement with the phenomena being studied (Patton, 1990). Hermeneutic research involves the researcher searching for historical or environmental condition/s that places the person's experiences into context (Patton, 1990). The researcher has a world-view and has their own unique interpretation of their own experiences. However when a Husserlian phenomenological approach is used for research purposes, these experiences are not included in the research process. Husserlian phenomenological research methodologies therefore encourage detachment in analysing the experience, whilst emphasising definitive descriptions of the structure of the experience, and presenting a distillation of the structures of experience. The participant is subsumed in the process of the descriptive analysis, resulting with the researcher discovering the essence of experience (Patton, 1990).

The ability of a researcher to remove him or herself totally from the research findings has been criticised as being unrealistic (LeVasseur, 2003). However, Ahern (1999) proposed that the researcher can use reflexive bracketing whereby the process becomes: "an iterative, reflexive journey that entails preparation, action, evaluation, and systematic feedback about the effectiveness of the process" (Ahern, 1999, p.408).

\section{Phenomenological research and nursing}

The underlying philosophy of nursing is that people have a right to be treated as individuals who have their own world-view, whilst being free to determine their own destiny and develop their own potential (Munhill \& Boyd, 1993). If individuals are free to experience their own reality and describe it, then phenomenology as a 
philosophical approach and as a research methodology can be useful in informing nursing practice.

Annells claims that phenomenology is useful in helping nurses to explore 'pathic understanding' which she refers to as: "concerning human life, inclusive of aspects like feelings/emotions, interactions, meanings, and responses; (which is) useful for empathetic nursing action" (1999, p.6). Nurse researchers have used phenomenology in an attempt to understand core phenomena such as empathy (Baillie, 1996), caring (Schoenhofer, 2002), and ordinariness in nursing (Taylor, 1995).

Phenomenology and nursing philosophy have several similarities, both rely upon interviewing, observation and the interaction with people to allow a deeper understanding of the person's experience (Tatano-Beck, 1994). Nurses and phenomenologists both use the 'self' as an instrument of data collection, and both philosophies require that the observer/researcher/clinician form a close relationship with the participant/client (Tatano-Beck, 1994).

A feature of nursing research in recent times is for phenomenologists to challenge previous research that asserts that a Husserlian phenomenological approach has been utilised (Paley, 1997; Yegdich, 1999). Yegdich (1999) challenged a study undertaken by Baillie (1996) titled "A phenomenological study of the nature of empathy" claiming that Baillie had not used a truly Husserlian phenomenological approach. Yegdich asserted that a significant number of nursing researchers claimed to have used a Husserlian approach, but had not taken a truly eidetic approach in the search for 'the things themselves' to reveal the essence of the experience (p. 84).

Yegdich asserted that the difficulties nurses experience with empathizing with their patients is influenced by:

Nurses' own attributes and previous personal and professional experience impact on their ability to empathize, while knowledge about people and how they are feeling is important for developing empathy. Empathic feelings are difficult to generate when nurses have no similar experience or when the patient is difficult to know or communicate with, while further barriers include a stressful working environment and lack of time (p. 85).

Yegdich (1999) reviewed several studies that had attempted to define empathy as it related to nursing, and claimed that the definitions of empathy too closely mirror that of sympathy, and that the notion of different types of empathy for different caring professions (such as counselling and nursing) are fundamentally 
flawed given that empathy is a universal human condition unrelated to professional ownership or definition.

Yegdich (1999) claimed that nursing researchers who have studied empathy are confused as to whether they are studying empathy as a phenomenon or people's experience of empathy. She claimed that in Baille's (1996) study it was unclear as to whether the phenomenological research was concerned with empathy, or empathic people:

The material elicited is based on assumptions underlying the question 'What is it like for you?' in contrast to critically inquiring, 'What is it like and how is it manifested?' The former questions are apt for defining humanistic elements that focus on individuals' uniqueness, rather than a phenomenological attitude, which attempts to apprehend phenomena for all. We, as readers, are thus excluded from objectively sharing the findings on the essential structure of empathy, as they can only apply to the nurses studied (p. 90).

Yegdich (1999) reminds her readers that nursing researchers who use phenomenology commonly use it as a research method, rather than a method of intuition (p. 97). This results in a subjective description of the experiences that are clouded by the researchers own experiences and assumptions. Yegdich, therefore asserted that Bailie's research into empathy did not reveal the hidden qualities of empathy, instead reflected the participants' subjective experiences, which is inconsistent with phenomenological philosophy.

\section{Phenomenological research and thanatology}

From a philosophical point of view Husserlian phenomenology is sympathetic to the notion of loss. People often transcend the present and through remembrances can recall that which is absent. Husserl felt that people could differentiate between what is temporarily not present in their life and that which is permanently missing (Sokololowski, 2000). Husserl was comfortable with the notion of 'absence' and the ability of people to imagine a concept of things that are absent (Sokololowski, 2000).

Thanatological research involves researching a potentially vulnerable population of people (Murray-Parkes, 1995; Rosenblatt, 1995; Skinner-Cook, 1995). People who have a terminal illness, or are involved with a terminally ill person or have had a significant person in their life die are considered to be a group who are at risk of exploitation (Rosenblatt, 1995; Skinner-Cook, 1995). The researcher has to be cognizant of the newly bereaved person's vulnerability. Ethical considerations 
are important in determining the most appropriate research design in order to minimise harm when researching this group of people. What is ethical includes what a person considers to be good, right, moral, just, proper, virtuous, and lawful (Murray-Parkes, 1995).

Rosenblatt (1995) argues that researchers who use a phenomenological approach and undertake intensive interviews are in a good position to be aware of the ethical considerations when involved in thanatological research. The interviewer can judge as to how the person is reacting to the discussion, thus allowing the person to stop or pause the interview, or to redirect the nature or style of the questioning. These occurrences would be documented in the researcher's notes and could be incorporated into the results of the study (Rosenblatt, 1995). When quantitative methodologies are used, the researcher is not exposed to the negative reactions to the investigative process (e.g. mailed questionnaires), the respondent has to deal with the feelings evoked by the questionnaire alone, without the support of the researcher.

The process of a phenomenological style interview is investigative by nature and not actively therapeutic, however, participants in studies using this approach often state that the interview had a positive and therapeutic effect (Skinner-Cook \& Bosley, 1995). Skinner-Cook and Bosley (1995) used a Likert style questionnaire in order to ascertain whether previous research, which utilised a phenomenological, open-ended interview style approach, had been stressful or therapeutic to the participant. The results were very positive, the majority of participants stated that the research had been useful in that the following benefits to society would be gained by: “...educating others; promoting more open discussion about death; preparing others for loss experiences; helping other bereaved individuals understand their own grief; giving hope to other bereaved individuals; helping professionals better understand grief issues" (pp. 163-164).

None of the participants who took part in the Skinner-Cook and Bosley (1995) research project regretted having been involved in the original project, or felt that they had been exploited. The participants mentioned personal qualities and listening skills of the interviewer as being an important component of the interview. The participants rated personal attributes such as empathy, warmth, caring, kindness, gentleness, humanness, understanding, sincerity, and being nonjudgmental and interested as important qualities of an interviewer. One participant was quoted as saying: "The researcher was open, understanding and supportive, and not embarrassed by emotion" (p.166). Another participant stated that: "The 
empathic, open ended style was very hopeful, including the researcher's ability to follow feelings and ideas which emerged through the interview process" (p. 166). These findings follow on from Patton's (1990) point earlier, that the maturity and personal attributes and skills of the interviewer are very important components of a phenomenological interview style study.

Thanatological research needs to be undertaken showing sensitivity and respect to the individuals involved. Using a phenomenological approach means that the researcher has an open inquisitive mind, which should not contaminate the research process. By using open-ended in-depth interviews, the researcher is claiming a willingness to expose him or her self to the potential of vicarious psychological trauma associated with the participants' experiences related to death. I believe that participants of this style of research usually value this approach because it is seen to be a humanistic and personal approach.

\section{Conclusion}

Husserlian phenomenology was the methodology chosen for this research study because the underlying philosophy and process are considered to be very effective at disclosing the real experience of people who have lived through the phenomenon such as a partner dying sudden and unexpectedly, with the experiences grouped under the overarching experiences of grief and loss. The experiences that are revealed form: "...the world about us that is there for us all, and to which we ourselves none the less belong" (Husserl cited in Yegdich 1999).

In closing, it is important for the reader to understand that no theories or models are being established as a result of this research. However, as a result of creating the interpretive themes, experience patterns may emerge that can form the basis of an experiential model related to the phenomenon being studied.

The participants' experiences form the basis for increased understanding amongst those who work with people who have experienced the loss of someone who had formed a significant relationship with him or her. Phenomenology is one way of helping broaden this approach in the quest to increase the knowledge base in thanatological research. 


\section{CHAPTER THREE}

\section{PHENOMENOLOGY AS A RESEARCH METHODOLOGY}

We shall not cease from exploration... and the end of all our exploration will be to arrive where we started and know the place for the first time.

T. S. Elliot (Miller \& Hrycyniak, 1996, p.61)

\section{Introduction}

This chapter describes the methodological process used to achieve a Husserlian phenomenological outcome. As was discussed in Chapter Two, Husserlian phenomenology is one of many different philosophical approaches used in phenomenological research. Omery (1983) stated that phenomenology has developed: "out of a philosophical movement that is still in the process of being clarified. As a result, one can find multiple interpretations and modifications of phenomenology philosophy" (p.50). Likewise the methodological approach that can be used to achieve a Husserlian phenomenological outcome can be varied, with the methodological approach that was used in this research project being adapted from a number of previous phenomenological researchers. Regardless of the variation that may exist in phenomenological methodology, the fundamental philosophy underpinning the methodology remains the discovery, explication and preservation of the person's experience of a particular phenomenon.

\section{The phenomenological methodological process}

Analysis of the data followed Amedeo Giorgi's style of phenomenological methodological process $(2001 ; 1985)$. Giorgi used a stepwise process, which starts with the researcher listening to the audiotape of the interview and reading the entire transcript to gain a sense of the 'whole'. The researcher then uses intuition to reflect upon each transcript in order to discriminate 'meaning units' from each participant's description of the phenomenon being studied. The researcher then uses his or her 
intuition to focus and interpret the phenomena. The final step in Giorgi's method is that of synthesising the information in order to identify any common themes (Giorgi, 2001).

Sandelowski (1995) makes suggestions for beginning the explication process by including getting a sense of the whole, extracting the facts, identifying key topics or major storylines and dimensionalizing the informational content, and using frameworks to reduce experiences (Sandelowski, 1995a). Explication of qualitative material then involves the breaking apart of the material into 'meaning units' in order to produce knowledge that evolves from the researcher 'seeing' the data in new ways, from new angles or new perspectives (Sandelowski, 1995a). All of the transformed meaning units are synthesised into a consistent statement regarding the participant's experiences. Intuition is used to reflect across all of the 'meaning units' to uncover themes. An exemplary narrative is written to illustrate each variant theme, which is then validated by participants and supervisors.

The methodological approach has been adapted from several phenomenological researchers (Devenish, 2002; Holroyd, 2001; Sherwood, 2001). In summary, the methodological process used in this study was:

1. Interview the participant - tape recording the conversation,

2. Transcribe the recording,

3. Listen to the recording and correct the transcription and make annotated notes,

4. Return the corrected transcription to the participant,

5. Incorporate the participant's corrections and responses into the new transcript and remove any identifying information and insert pseudonyms,

6. Create participant profiles to gain a snapshot of his or her experiences, return to the participant for authentication

7. Create a case study based on one participant's experience, to gain a sense of a person's entire experience, returning it to the participant for authentication,

8. Divide the individual (idiographic) transcript into natural meaning units (NMUs),

9. Create central themes, which reduce the NMUs to recognisable sentences,

10. The central themes are then clustered into a constituent profile, which is a non repetitive list of descriptive meaning statements which are sorted under the headings of the participants' relationship with self, others and the world, (this was applied to two male and two female participants' transcripts, to expedite the process),

11. Merge all of the participants' transcripts, and intuit referents (key words), used to (using a qualitative computer software), search for the referents across all of the participants' transcripts,

12. Cluster and merge all of the referents and create a nomothetic (all participants) thematic index,

13. Develop interpretive themes and sub themes divided into the participant's relationship with self, others and the world, and then

14. Create phenomenological explication of the participants' experiences. 
Each of these steps in the methodological process will be explained in detail throughout the remainder of the chapter.

\section{Participant selection}

The number of participants selected for this study was not predetermined. As time went by and the phenomenological process was progressing, the decision to stop recruiting new participants was made in consultation with the supervisors. The number of participants was both congruent with accepted phenomenological research criteria (Woods \& Catanzaro, 1988) as it is a relatively homogenous group in that participants have all experienced the same type of loss. When defending the number of participants that have been involved in a study, qualitative researchers will often claim that they have achieved informational redundancy or theoretical saturation (Sandelowski, 1995b). To achieve this, it is not necessarily the number of participants which is important, but the nature of the study and the selection of suitable participants (Sandelowski, 1995b). Purposeful sampling refers to a group of people who have in common events, incidents and experiences, which are needed to justify the appropriateness of their inclusion (Sandelowski, 1995b).

Purposeful sampling is in contrast to probability sampling which quantitative researchers rely upon to provide enough variety within a research population to allow generalisability (Sandelowski, 1994b). Therefore the number of participants in a qualitative research study is individualized to suit the purpose of the study and the depth that the researcher wishes to achieve, because the more participants involved in a study increases the risk of a more shallow approach to the interpretation of the data (Sandelowski, 1994b).

The study involved interviewing ten women and five men whose partner had suddenly and unexpectedly died. The inclusion criteria was designed to create a relatively homogenous group of people who had experienced a similar phenomenon, and included the following:

- The partnership must have been that of a significant commitment (demonstrated by either length of time together or cohabitation),

- The deceased partner should have died up to five years prior to the interview,

- The deceased partner should have been aged between 18 and 65 years at time of death, 
- The deceased partner should not have been involved in high risk activities such as parachuting, motor car or motor cycle racing or be employed in a high risk occupation such as the armed forces,

- The deceased partner should have died of natural causes which were not related to any known pre-existing illness,

- The deceased partner may have died from traumatic causes, which were not caused with criminal intent,

- The deceased partner should not have contributed knowingly to his or her death such as suicide.

The inclusion criteria were created to include a group of people who were relatively fit and well and who were living a life, which included the ordinary amount of risk that most of us experience, with the associated life expectancy that is age appropriate to each gender. Suicide and homicide were excluded due to the increased risk of the surviving partner experiencing a complicated bereavement (Cutcliffe, 1998; Rando, 1993).

\section{Recruitment of participants}

This research project was promoted using several means. The first approach that was used was to contact the state and local newspapers in order to have an article written describing the aims and objectives of the project to hopefully stimulate interest in the project and recruit members of the public who had experienced the phenomenon under study. The local community newspapers were very supportive and ran two articles that resulted in several participants responding. The daily state-wide newspaper also ran a small article that unfortunately included several mistakes, the most obvious one being that it read as though the study had already been completed. The state-wide Sunday newspaper agreed to interview a participant, and myself including photos of him and his children. This all took place at his home, and the resultant article looked very impressive when proof read, however it did not get published due to the newspaper undergoing an 'editorial makeover' the following week, resulting in the article not fitting in with the new style of the newspaper.

I was also interviewed on the national radio broadcaster, for the regional programme in Western Australia, which created interest from several potential participants, all of whom unfortunately fell way outside the inclusion criteria. The other source of recruitment was by word of mouth, which also provided several participants. 


\section{Ethical considerations}

As with all research projects undertaken at Edith Cowan University involving human participants the project must be considered and approved by the Ethics Committee prior to commencement.

All potential participants made contact with me by telephone. During the initial telephone conversation I described the aims and objectives of the research project and what I required of them. They all agreed to be interviewed, so I then made an appointment to proceed with an interview. Prior to the interview I sent them a letter introducing the research project (Appendix $A$ ) and myself in more detail and included a consent form (Appendix $B$ ). When I met with them I gave them the option of not proceeding with the interview, all agreed to proceed. The participant was then asked to sign a consent form. I also completed two other forms that included personal details (Appendix $\mathrm{C}$ ), as well as demographic details and family profile (Appendix D).

In order to allow the participants the right to reconsider their involvement in this research project, they were informed that they cọuld withdraw their consent and participation at any time. I was able to provide a contact list of counselling services to the participant, had they wish to become involved in bereavement counselling, following the interviews.

The right to privacy and confidentiality is fundamental to any research involving human participants. This is particularly important when the nature of the research involves intimate and personal information. In order to preserve the participants' privacy I incorporated several safeguards. No identifying data was made on the tapes, or notes, or transcripts. The data was coded, with the name of the participants known only to myself. The audiotapes were erased following the dissertation being examined. The data has been kept in a locked filing cabinet and will be destroyed five years after the dissertation has been examined.

\section{The interview procedure}

Each participant was interviewed once, at a time and place of their choice. No time limit for the interview was imposed upon the participants. An audio tape recorder was used to record the interview. The audio tape recorder was used as discretely as possible so as not to distract or intrude upon the interview. Interviews are often used in qualitative research, which require the interviewee to recall past 
experiences and emotions. According to Crowe (1998) the interviewee's memory is subject to enculturation, and is reconstructed rather than recalled. Therefore the process of the interview is that of reconstructing past events and emotions according to the interviewee's current situation. Van der Kolk (cited in Crowe, 1998) claims that memories, particularly those involving traumatic events, are often stored in the memory in non-verbal modes and sensations and visual images, which may make it difficult to retrieve the memories in linguistic forms. The challenge for qualitative researchers who employ methodologies such as phenomenology is that participants may need to augment dialogue with other forms of communication such as art, music or poetry. This occurred in one case with a participant who utilised a poem, which helped her articulate some of her feelings.

Once the audiotape recorder was activated I invited the participant to discuss the relationship between him or herself and their partner, the circumstances surrounding their partner's death, and their experiences following the death of their partner. The conversation was then allowed to flow naturally, but if needed the use of a number of prompts could have been used (Appendix E). These prompts were used to enable me to keep the conversation alive and on track as well as maintaining some level of consistency across the interviews.

The participants were interviewed in a mutually acceptable place and time. Every participant chose to be interviewed in his or her own home except for three. Of these three participants two chose to be interviewed at my home with the other choosing to be interviewed in my work office. Interviewing a participant in their own home is preferred because it is a place of comfort and security, and due to the house usually being the original family domain it would naturally have remnants of the relationship with the deceased partner which would allow the researcher access a third dimension of the participants experience.

\section{Transcription}

As soon as possible after the interview the audiotapes were listened to, in order to allow the researcher to gain a sense of perspective from the outside, "The main aim of evocative inquiry is to listen to the things that are before us, that have a hold on us through the mediating function of the evocative text" (van-Manen, 2002). The tape recordings were then sent to an expert transcriber, who transcribed the recording verbatim. The transcriber included any emotional responses such as crying, sighing, coughing and laughter. The use of transcripts is the easiest manner 
in which to preserve the recorded interview. However, the transcript must accurately reflect both the words that are uttered as well as the silences. The aspects of the conversation that have occurred which may be missing from transcripts are certain features of speech, such as changes in pitch, volume, stress, and rate (Sandelowski, 1995). The nature of this study inevitably led to emotional responses that are just as important to take note of, as are the verbal utterances, which add descriptive detail to the analysis. Field notes were written immediately following the interview to record these responses. These notes included any contextual details such as the way the participants presented him or herself for interview, whether they seemed to be overly anxious, distressed, or crying during the interview, and any personal reaction by the researcher to the interview (Sandelowski, 1994a).

The transcripts were then returned to the participants who were encouraged to edit or comment upon the transcripts (no men returned the transcripts, four women returned edited transcripts). I then listened to the audiotape and corrected the transcript according to the participants editing whilst annotating the transcript with pertinent notations; all identifying data was then changed or obscured, all names were changed to pseudonyms.

\section{Idiographic analysis}

The next step was to create individual participant profiles to create a snapshot style picture of the surviving partner, their family and their experiences following his or her partner's death. These profiles were then sent to the participants for authentication and approval for inclusion in the thesis (Appendix F). Following the creation of the participant profiles, a case study was written which gave a more complete picture of a participant's experiences (Appendix $G$ ). The next step in the phenomenological process was to choose two male and two female interviews to manually analyse at an idiographic or individual level, an example of one of the idiographically analysed interviews is included as Appendix $\mathrm{H}$. All of the dialogue was stripped of extraneous words such as 'um' and 'er' and any repetitive dialogue, and then a natural meaning unit was extracted by highlighting the single theme of each piece of dialogue. For every natural meaning unit a central theme was created:

- Experiences immediately following the death

- Adaptation strategies to deal with transitional change

- Maintaining previous shared experiences

- Experience of aloneness in relation to social isolation versus social contact 
- Experience of the funeral

- Relationship with deceased partner

- Relationship to the health and caring professions

- Relationship to children, family and friends

- Relationship to the community

- Relationship with deceased partner's personal items

- Experiencing a new social status-identity

- Relationship to religion or faith

- Experiencing significant dates-events

- Relationship with officialdom

- Memorialisation of the deceased partner

- Relationship with the future

- Experiencing new relationships

The central themes were converted into a constituent profile which were then clustered in various subcategories under the three main categories of relationship to self, others and world.

\section{Nomothetic analysis}

From the insight gained from the idiographic level of analysis, 335 referents (key words) were created to code all of the transcripts en-mass (or nomothetically). With the assistance of the Qualitative Solutions and Research's N6 qualitative data analysis programme, 350 pages of sorted data were created.

The results were then organised under the categories of relationship to self, others and the world, as a thematic index which is a non-repetitive sequential list of meaning statements and referents used to create interpretive themes (Holroyd, 2001). Through this 'eidetic reduction', patterns of meaning or themes belonging to this particular phenomenon emerged, which became the working material for phenomenological writing (Devenish, 2002; Holroyd, 2001; Sherwood, 2001; vanManen, 2002).

At this stage, six interpretive themes were intuited and arranged under the categories of relationship to self, others and the world. These interpretive themes form the basis of what is often referred to as the findings or results chapters in nonphenomenological dissertations. A chapter has been dedicated to each interpretive theme. All of the sorted chunks of transcript were then absorbed into a descriptive analysis of the material with usually only one chunk of transcript being retained to allow a participant to describe the experience in his or her own words. The writing of the participant's experiences should reflect a: "Lived-throughness, through anecdote and imagery, bring experience vividly into presence, making it immediately or unreflectively recognizable" (van-Manen, 2002). 
The final stage of the explication process involved transforming the interpretive themes into an extended description (explication) of the phenomenon. It is at this stage that the researcher introduces the literature in order to compare the findings with previous research. If the literature is introduced earlier in the process then the researcher's ability to bracket his or her presuppositions may be compromised, which may lead to the data being contaminated (van-Manen, 2002).

\section{Participants' responses to the interview experience}

One of the major concerns of thanatological researchers is that of the ethical conundrum of researching bereaved people (Murray-Parkes, 1995; Robertson \& Welch, 1997; Skinner-Cook, 1995). Previous research has supported the findings of this research project in that the participants often found the experience of participating in thanatological research to be beneficial (Skinner-Cook \& Bosley, 1995). All of the participants when asked how did they feel about talking about the experiences said that they valued the opportunity to tell their story. The participants also stated that they wanted the world to know what they had experienced. Dana felt that the experience of talking to me was cathartic. Several participants cried during the interview, however laughter was a prominent emotion during all of the interviews, especially when reflecting upon the deceased partner's life, or amusing events that have happened since.

Sally felt that the experience of talking about her experiences to an independent person was beneficial, and that she was pleased Peter's death could help other people revaluate their own lives and relationships:

Yeah, I, I actually need to do it, I think but I can't do it with the people that are close to me because it's too hard for them, and I, I understand that now, I probably didn't early on, um and a lot of conversations get back to it with them, so, I'm really trying hard not to do that with them. Because it is, it's hard, and I think that's one thing that I sensed a lot of was that basically everybody else's lives are essentially the same, jobs to do, work to go to. Life is going on for them, in a relatively normal way, when they don't think about this twenty-four hours a day, seven days a week like I do. Which is where people I think need to um, and I've said, I've said to a few people you know, go and talk to someone about it...

You know, that you have to deal with it on your own to, you know, there's a lot of issues there, I mean I think it questioned everyone's relationship when it happened where they were at in it, how they felt about each other, did they tell each other I mean Peter and I, I kissed him goodbye every day, he never left without that kiss or, and I 
remember saying that to someone, and they were like, I don't do that, it could be your last kiss, It was for me, and somebody said to me when they knew you know how are you, really how are you, and I said you know I had my last kiss on Thursday 5th July, that's how I am, and they were like oh, you know shouldn't have asked that question really, but um, what do you tell people, you know I think it really may have been, have a look at their own, a few people have said to me you know, it's changed us, so much, what we're doing, so it's gotta be for something hasn't it, can't be for nothing, so I'm glad for those things, I'm glad it has made people re-evaluate their lives.

Lyn was concerned about confidentiality, and was given the opportunity to edit her transcript so that it could not to be traced back to her:

Um, not too bad I mean I get concerned you know about the, confidentiality of it all and that respect I mean, I wouldn't like to see myself in like, the front page of, National Enquirer or anything (laughs) I have had a bizarre life, you know my life has been really strange, and, I keep telling myself this is like I'm, I'm paying off, a ghastly war crime from a former life.

Carol described she felt sad during the interview. Rosalie felt relaxed about volunteering for the research, knowing that she could cancel, whenever she wanted to.

Dean decided to take part in the research because he felt that it was time for him to start getting on with life, as his family were becoming more independent:

Oh yeah, well time sort of um it's three and a half years down the track now. Oh yeah time always heals, heals everything. Oh I still sort of do feel you know, I still feel there's a void there and um I don't sort of feel like jumping over the moon or anything. I know you've got to give yourself a push and a shove and I'm most probably not prepared to do that or haven't been prepared to do that up til now. I think I've been too involved with the family and looking after their welfare but I think they're all sort of on the road to better things now. And I should look outward I think rather than inward.

David was able to articulate his feelings very well when asked how the interview had been for him:

Oh obviously it brings back, you know, in ways as you've seen, tears, but, um, yeah oh it's easier as time goes on much easier as time goes on, um, I thing the thing that, that has hit me more today than anything is the fact that even though I'm now in another relationship were I feel quite strong about that relationship, that I can still have tears you know but as I thought would, it would go away, it obviously doesn't It's um, yeah, obviously it never will I suppose, it's strange cause I always thought that, that, though time will heal it would actually close in the entire void and there wouldn't be that feeling 
there, so I can see how women, you know fifty years after the death of their babies, still have some sort of emotional attachment to, to, to, to that child even though they may have known them for a short period that they, you get that emotional attachment it doesn't seem to disappear, and yet, I certainly don't have the same feeling towards old girlfriends, you know what I mean, you don't, well it's not there, but it is for Lorna, you know and I suppose it's, obviously twenty two years of your life just suddenly, gets, nipped off and, and, you know, so yeah I, I suppose the whole area of motor car accidents and, you know all those sorts of deaths are um, you know must be quite, quite, traumatic, but also, that healing process means that it never does really fully heal..

\section{Rigour and phenomenological research}

According to Tatano Beck (1993) when qualitative research is undertaken, internal validity is referred to as credibility, external validity is referred to as fittingness, and reliability is referred to as auditability. Credibility is attained in a phenomenological study by the researcher reducing the description of the phenomena being experienced by the participants as vividly and as accurately and consistently as possible. Fittingness in a phenomenological study is achieved when the results are considered to be representative of the whole, and 'fits' the data from which it was generated. Auditability refers to the ability of another researcher being able to follow the decision or audit trail of this researcher easily and logically, which allows intersubjective verifiability (Tatano-Beck, 1993).

In order to ascertain the authenticity of the my presentation and interpretation of the participants' experiences, a draft copy of the interpretive themes chapters and the conclusions, recommendations and future research chapters were sent to two female participants and one male participant for review (Appendix I \& J). Several participants had volunteered to review the thesis, with three being chosen randomly for expediency. The feedback was supportive with the participant reviewers stating that overall the aims of the research project had been achieved, and that the descriptions were evocative and thorough. The participant reviewers were also asked if he or she had any other recommendations or further research, the male participant responded with several suggestions, which have been included in the final chapter.

An example of one of the participant reviewers responses is included below: 
The aim of this research project was to describe as closely as possible what life was like for people whose partner had died suddenly and unexpectedly. Do you believe that this aim has been achieved?

Yes, I believe this aim was achieved. Your descriptions in the draft research project exactly describe what life was like following the sudden and unexpected death of Alf.

I related completely with the other participant's transcripts of what life was like following the sudden and unexpected death of their partner.

Each participant's insightful journey through grief touched my heart with their honesty and candour and gave me a renewed sense of self and hope. Having shared our stories was in itself a powerful healing experience.

Do you believe that the descriptions portray as completely as possible, the experiences that you encountered and felt since your partner died?

Yes, it was such a revelation! The descriptions portray exactly the experiences I encountered and felt since Alf died.

What would you add or detract from the descriptions?

I would just add that it was heartening to know that what I experienced and felt they did too and that we all travelled that road less travelled.

Did the descriptive chapters evoke strong emotions and/or images?

At first when I began to read the chapters it felt rather weird reading my transcripts. I felt a sense of detachment as though I was reading about another person, not me. That was because the person I am now is so different to the person then. The personal growth and self-development has been significant. My faith has sustained me in ways that have astounded me. I never gave up hope and believed that I would okay.

I felt a sense of achievement. I learnt to redefine myself and rebuild my life, resulting in a stronger and independent person.

Further into the readings I broke down and sobbed. I momentarily relived the tragic event that devastated my life and the overwhelming pain and despair that ensued. I cried for a love lost, and a family life shattered in the blink of an eye.

I also welled up inside and sobbed when Sally talked about how she had her last kiss from her husband on Thursday $5^{\text {th }}$. She said how she kissed him goodbye 
every day without fail. She reminded us the importance of the daily kiss, as it could be the last. I was very much affected by that.

For days I found myself reflecting on the other participant's transcripts and their experiences following the death of their partner.. It evoked strong feelings of sadness, empathy as well as compassion and understanding. Their stories did inspire hope and optimism for the future.

Do you think that I have captured the nature and intensity of the experiences, feelings and emotions that affiect the mind, body and soul and your relationship with yourself, others and the world, following the death of your partner?

You touched the very essence of my pain and despair following the death of Alf with such sensitivity and compassion. I believe you accurately and truthfully presented our experiences, feelings and emotions following the death of our partners in your thesis as well as capturing its nature and intensity.

What do you think of the experience pattern that I have proposed? Do you have anything to add or detract?

I thought the proposed experience pattern to be very pertinent. The clearly set out guidelines hopefully will be implemented and used when dealing with the surviving partner.

From my experience you are correct in saying that the surviving partner whose partner has died suddenly and unexpectedly will never truly reconcile the death and will in some way manage to encapsulate the death in order to progress with his or her own lives. I also believe the surviving partner encapsulates the grief in order to control the grief. It is a very valid point you make! Well done on your proposed grief model!

What do you think of the recommendations that were made? Do you have anything to add?

I found the recommendations made very thorough, detailed and clear. Again hopefully it will be implemented and used as a guideline for health professionals to better understand and help the surviving partner.

What do you think of the recommendations for future research into grief and bereavement? Are there any other recommendations that you would have made?

Again I found the recommendations you propose for future research into grief and bereavement to be valid and important. Hopefully it will result in a better 
understanding of the phenomenon and a better way in dealing with the surviving partner.

\section{Do you have any further comments?}

I wish to take this opportunity to thank you, Martin for allowing me to share my journey through grief. It has been such a powerful healing experience.

To read about my fellow participant's journey through grief has been a humbling and inspiring insight into their own journey through grief and that we all travelled that road less travelled.

I wish them and you abundant blessings and I hope you all continue to travel well in life. Congratulations on a well-done thesis...wishing you every success!

David, who reviewed the draft thesis, summed up his experience of the process:

I'm amazed how therapeutic I have found this undertaking. To consciously think about bereavement in an objective way, rather than drift in and out in of my own comfort zone, has helped me question and resolve numerous issues. What has been helpful is to read the experiences of other participants. Therefore one good outcome from this thesis would be to condense the experiences into a small book so that the newly bereaved know what they might expect in the short term. Another good outcome would be to summarize the thesis's relationship topics as these would also be invaluable. Another good outcome would be for you, Martin to follow up the participants on an annual basis over the next few years and eventually document it in the form of a book (as mentioned above, I think re-partnered people actually go through and back the transition process, or part thereof). Again the literature would benefit to more then the suddenly bereaved.

\section{Conclusion}

Phenomenological research is a complex methodology, which is founded upon a philosophy whereby researchers attempt to understand phenomena through the meanings that people assign to them. The analysis requires the researcher to reflect upon the participants' experiences whilst suspending his or her everyday natural attitude. This reflection should take the researcher on a journey where themes emerge, which emulates the phenomenon being addressed. This means that the researcher must listen to the participants with every part of their being so that the participants' true experiences are exposed (van-Manen, 2002). 
The phenomenological results that emerge should allow the reader to follow the experiences of the surviving partner easily and as Koch (1998) asserts: "that if the research product is well sign posted, the readers will be able to travel easily through the worlds of the participants and makers of the story and decide for themselves whether the story is a legitimate research endeavour" (Koch, 1998).

Phenomenological research is an exhaustive and exhausting methodology. When a researcher immerses him or herself in the experiences of people who have been transformed by a tragic event in their life, the researcher will often find him or herself feeling saturated to the point of drowning. It is when the researcher comes through the other side of living with the participants' experiences that the researcher can take the vocative turn whereby he or she addresses living meaning with the act of writing (van-Manen, 2002).

Chapter Four is dedicated to creating a snapshot of the participants' experiences. This was done to give myself and the reader a more complete picture of the people involved and the circumstances surrounding the death of the person. 


\section{CHAPTER FOUR}

\section{THE PARTICIPANTS}

The capacity to be alone thus becomes linked with selfdiscovery, and self-realization; with becoming aware of one's deepest needs, feelings and impulses.

Anthony Storr, (Zonnebelt-Smeenge \& Vries, 1998, p. 91)

\section{Introduction}

One way of getting close to each participant's story is to create a short profile that summarizes the gist of the participants' experiences. Each profile was sent to the participant with an explanatory letter (Appendix F) seeking their approval for inclusion and the right to edit the profile if they wished. Only one participant refused to have a participant profile included, one participant could not be located to gain permission.

\section{The participants}

\section{Sally and Peter}

Sally is an administration officer for the organising body of an annual international sporting event. Sally was 34 when Peter a 36-year-old accountant and information technology developer, died from multi-trauma having been struck by a car whilst riding his bicycle on a dedicated cycleway. They had been together for six years and married for three and a half years. It had been nine months since Peter died when Sally was interviewed. Sally has two children, Eliah, 5 and lan, 3.

Sally was at home when the Police informed her that her husband had been seriously injured. The police took Sally to the hospital, whilst a friend cared for the children. Sally described herself as feeling numb. Peter was admitted to the Intensive Care Unit and died from complications associated with multi trauma seven days later. Sally stated that the Police and the hospital staff were very supportive 
and compassionate except for the neurosurgeon who was treating Peter's head injury. Sally described him as being arrogant and inappropriate.

Sally described Peter as a fun loving man who was always keeping active and fit who loved cycling. Sally felt that Peter was someone who would always be her husband and the father of her children, and could not contemplate the thought of 'replacing' him. She described how difficult it was to eat, as cooking and drinking wine was a central part of their shared experiences.

Sally has had support from her parents and family (which is sometimes limited due to their own family responsibilities), as well as friends but had been disappointed by some people who had promised support but failed to follow through.

Sally felt the loss of a shared future together very keenly. She described the responsibilities of being a sole parent as being a million times greater than when Peter was alive. Sally lamented the loss of a father to her two boys: “...they (had) a wonderful father, that (sic) was going to bring them up to be such balanced men, you know he could cook, he would shop and he was physical...it was great balance".

Sally held mixed feelings regarding the driver of the car, hoping that she could eventually find peace in her life, but on the other hand hoping that she would not forget what she had done, and the impact this had had on Peter's family.

\section{Julie and Bill}

Julie worked with her husband running a farm, and is now retired. Julie was 62 when Bill a 67-year-old died following thoracic surgery, which was to remove a tumour. They had been together for 40 years. It had been 5 years since Bill died when Julie was interviewed. Julie has four children; Patricia, 40; Ben, 44; Mark, 42 and Kelvin, 35.

Bill died three days following his surgery, with his family around him, which allowed for some chance to say goodbye. Julie described the hospital staff as being supportive with the surgeon being particularly involved and compassionate.

However, the General Practitioner was not informed of Bill's death, with Julie having to tell him herself.

Julie's friends and family gave her support, but of her two sisters, only one who was able to give support with the other not having much contact at all. Julie has enjoyed a close relationship with her children. The first Easter following Bill's death Julie went for a bush holiday with her daughter. Julie has since been on an 
international holiday (she visited China), which she believes that she would not have done if Bill had still been alive.

The general community have been supportive of Julie, especially the clubs that she and Bill were members. Only one man has said something insensitive when he heard that Bill had died, telling her that there were many more fish in the sea.

Julie moved out of the family home which had become too cumbersome to manage two years following Bill's death. She chose a smaller house in a nearby suburb to her daughter, who had to face her own personal tragedy when her baby died. This other grief experience tested the family, with Julie, struggling to reconcile the death of someone so young. The hospital compounded their bereavement when they sent a letter reminding the parents that their dead baby was due for her sixmonth check up.

Julie remembers Bill as bright and happy, enjoying his retirement by playing golf and camping; she feels that he was lucky to have died when he was still able to do everything that he wanted to do. Julie is not concerned about her own death, stating: "Well of course being the age I am, I think as you get older each year you sort of think oh well that's another year, l've done what I want to do, lets hope I don't carry on until I'm in my Nineties, I don't want to live until I'm too old because I just don't want to..."

\section{Jane and Graham}

Jane is a university administration assistant who was 49 when Graham a 48year-old physiotherapist died from a myocardial infarction. They had been together for 21 years. It had been 3 years since Graham died when Jane was interviewed. Jane has three children, Carol 21, Ann 18, and Kylie 16.

Graham had been visiting the north of Western Australia when he became unwell, soon after seeking medical assistance he had a cardiac arrest and died. Jane described Graham as being very fit and healthy. Jane described receiving the news as like a "bolt out of the blue...unbelievable...total shock". It was six days before she could be with his body.

Jane described herself as needing to keep busy over the first 18 months as a way of distracting herself from the reality of Graham's death. She realised around this time that she hadn't given herself any space to feel her way through her grief. 
She hadn't told anyone how lonely and sad she was. It was then that she sought the assistance of a counsellor who proved to be very helpful for her.

Jane described her relationship with Graham as being very close and special. Six months after Graham died when Julie was attending a function at the amateur football club of which Graham was a member, she was asked by several men if there was a new person in her life.

Jane remembers being distressed attempting to unravel the bureaucratic red tape following Graham's death. She describes one bank as being atrocious, with the staff being incompetent. Having to get multiple copies of death certificates and Justices of the Peace signatures caused her significant anguish.

Jane's view of life is to not get too tied up in the minutiae of life and to take everyday as it comes, and enjoying whatever eventuates. When Graham was alive they always planned for the future (including a property in the South West of Western Australia). These days, she lives a life based upon the enjoyment of whatever eventuates.

\section{Dana and Carl}

Dana was a schoolteacher and an author who was 63 when Carl a 62-yearold consultant engineer died suddenly following a short illness. They had been together for 42 years. It had been three years since Carl died when Dana was interviewed. Dana has three children, Elle 42, Stuart 35, and Bob 33.

Dana feels that the medical team caring for her husband didn't take the illness Carl was suffering seriously enough, which contributed to his death. This led to anger and confusion, which was eventually reconciled to a point. Dana described the loss of a partner, with whom you have been so close to for so long, as being a physical pain.

Dana has received a lot of love and support from her children and friends. She has also found solace in reading (especially poetry), writing and listening to music. Dana feels that for the first two years following a partner's death that you are slightly mad. Dana also describes how she feels that she is part of the "legion of lost women", and misses the companionship and having someone feel that you are special.

Dana and Carl shared a very active life, playing tennis, hockey, swimming and walking together. Since Carl's death, Dana has discovered what it is like to be vulnerable, having been part of a couple for so long, with all of the protection and 
comfort that it provides: "I think oh God ....what an awful person I must have been, so complacent and content. But you learn from losing the most important person in your life. I hope I am more aware of how vulnerable people are, and how lonely people can be". Being alone has forced her to confront loneliness and isolation, reaching out to friends for support.

Dana is open to the concept of forming another relationship but believes that it is unlikely at her age due to the overabundance of women who are alone, and because in so many ways you still feel married.

\section{Rachael and Kevin}

Rachael was a business proprietor who was 49 when Kevin a 49-year-old business proprietor died following a shark attack at a suburban beach. They had been together for 30 years. It had been two years since Kevin died when Rachael was interviewed. Rachael has three children, Ruby 24, Arnold 18, and Annie 16.

Rachael described Kevin as a vibrant man who had a great zest for life. They had been together since leaving school. They shared a love of the beach with a morning ritual of walking and swimming at the beach everyday. On the day Kevin was attacked by a shark, Rachael was walking with friends on the beach when she was told that Kevin had been attacked, she was at the scene when his body was brought ashore.

Due to the rare nature of Kevin's death the media exposed the family to the world, even broadcasting the funeral on TV around the world. The media intrusion was something that took Rachael and her family by surprise. The other side of the public nature of Kevin's death was that Rachael and her family received a lot of community support.

Rachael managed to employ someone on the afternoon of Kevin's death to run the business. She soon decided to sell Kevin's business, as it would have been too difficult to manage on her own. Fortunately she had close friends who were able to assist her in winding up all of the administrative loose ends, which were considerable.

Rachael tries to remain positive about life but has found it difficult working her way through her own grief, whilst supporting her children. The traumatic nature of Kevin's death has meant that two of the children have not been able to swim at the beach since. She still asks herself about the fairness of why Kevin was killed, when he was such a good man, and there are so many who aren't. Rachael also 
doesn't relish the thought of remaining a 'statistic' for the rest of her life, but maintains that life is for living.

\section{Mary and Alf}

Mary was a business proprietor and who was 48 when Alf a 51-year-old public servant died from being struck by a car when he was a pedestrian. They had been together for 33 years, having been married for 28 years. It had been two years since Alf died when Mary was interviewed. Mary has two children, Sam 21, Stephanie 19.

Mary was with Alf when the car struck him. Mary described how shocking and brutal Alf's injuries were which she remembered in graphic detail. Mary described herself as being numb and in shock for some time following Alf's death, with the police and hospital staff being very kind and supportive.

Mary was well supported by her friends and family, following Alf's death. She also had a strong sense of Alf trying to reach out and support her. Mary described feeling unbearably empty, remaining strong in the presence of others, but breaking down, when alone.

Mary: “...he was always so good to me, I mean nothing, nothing was ever a problem you know... he would always do, do everything, I was unfortunately very dependant on Alf, I always have been and I didn't think that I would survive when I lost him... immediately I went into total shock, when it happened". Mary described feeling as though she and Alf had become one entity. Since his death she has found strength and independence that she was not aware of possessing while Alf was alive. Mary has joined the public speaking group "Rostrum" and is doing things she never thought she was capable of doing.

Throughout this experience Mary has been able to maintain her faith in God, which has been comforting to her. Mary's Chriștian ethics have allowed her to forgive the driver of the car, having publicly advocated that she should not be jailed for the driving offence.

\section{Lyn and Geoff}

Lyn is a lawyer who was 45 when Geoff, a 44-year-old building trade supervisor, died from a myocardial infarction. They had been together for a few months and married for a few weeks. It had been 2 years since Geoff died when 
Lyn was interviewed. They had two children each from previous relationships with none living with them.

Lyn described her relationship with Geoff as being ideal. They had both had bad experiences with previous relationships, and considered themselves to be very lucky that they had met each and were both looking forward to enjoying their life as newly weds when he died.

Lyn described being informed of Geoff's death as being very surreal, with her being in a daze. The trauma that Lyn experienced was exacerbated by the involvement of Geoff's ex wife and his children being present wheri he died and attending the funeral. Lyn had to leave Geoff's home, because his ex-wife was still the sole beneficiary of his will.

In the ensuing months, Lyn had difficulty maintaining her professional and personal life: “...I just didn't care, didn't care what happened to me, at all, I was obviously, not good enough, you know, everything had gone wrong, and l've been rejected by all these men, I mean this man said he'd never leave me, and he drops dead (laughs)". Lyn sought professional counselling, which she found inadequate, due to the counsellor's youth and lack of direct experience.

Lyn was emotionally labile for two years following Geoff's death, breaking down with little prompting. She felt Geoff's presence constantly and often sought solace by talking to him. After two years Lyn felt that she had to redirect her life, knowing that Geoff was not going to return. Lyn started to socialise again, going to her local hotel, and drinking without needing to get drunk.

Geoff's eldest son has maintained contact with Lyn, which has enabled her to be around someone who shared a close affinity with Geoff. At the time of the interview Lyn stated that she didn't plan much for the future, tending to take each day as it comes. However, Lyn has found an inner strength that she didn't realise she possessed, asserting herself in times of conflict and developing an independence, where she can be alone but not lonely.

\section{Tina and Barry}

Tina was a student support officer who was 57 when Barry a 64-year-old accountant died from a myocardial infarction. They had been together for 32 years. It had been 18 months since Barry died when Tina was interviewed. Tina has one child, David 22. 
Tina described a relationship that was difficult at times, placed under pressure following the birth of their only child when she suffered from post natal depression, had spinal problems requiring traction when David was 9 months old. Tina didn't feel fully satisfied with full time parenting and needed to return to the workforce. She also decided independently to terminate her second pregnancy when she was 40 , which further strained the marriage.

Tina described Barry as being a very difficult man to live with, having depressive episodes, needing to be in control, and undermining her self-confidence with his patronising attitude. Not long before Barry's death Tina had started discussing separation. Barry did not want to separate and was in the process of rebuilding their relationship when he died.

Tina found Barry collapsed and pulseless, at home, after she'd been out of the house for $\mathbf{4 5}$ minutes. In the process of performing cardio-pulmonary resuscitation, she suffered a myocardial infarction requiring hospitalisation. She described the hospital staff being very sensitive and supportive to her.

Despite the mixed feelings that Tina has experienced about her relationship with Barry, she put a lot of effort into arranging the funeral, to give him the recognition that he deserved.

Since Barry's death Tina has required low dose anti depressant's as well as spending time with a Clinical Psychologist to help her reconcile her mixed feelings about Barry. Tina has had many dreams, which she described as bizarre causing her distress. Despite the negative side of their relationship Tina was deeply saddened by Barry's death and misses him.

Tina has achieved a lot since Barry's death, continuing on with her job, maintaining the house, prudently managing her financial affairs, and finding selfconfidence that had always taken a battering from Barry.

\section{Carol and Richard}

Carol was a specialist medical practice Registered Nurse who was 58 when Richard a 61-year-old specialist surgeon died of a myocardial infarction. They had been together for 33 years. It had been two years since Richard died when Carol was interviewed. Carol has three children, Ariel 34, Jules 33, and Nessy 29.

Carol described their relationship as a combination of two strong willed people who complimented each other. Carol described Robert as a person who was dedicated to his family and his patients. Since 1975 they worked together in 
Richard's specialist surgical practice. Carol and Richard had bought a small property in the South West of Western Australia, which they visited as often as possible, they built a house on the property which was finished a year before Richard's death. It was on one of their weekend visits that Richard died following a myocardial infarction. Visiting friends who were both doctors of medicine tried in vain to resuscitate him.

Since Richard's death Carol has hardly spent 24 hours alone, describing her family and friends as being very caring and supportive. Robert's younger sister has been the only relative who has not been able to offer much support and has isolated herself from Carol. This relationship has since been reconciled with frequent contact between them both.

When Robert died they had bridging finance for a smaller house, which caused considerable financial strain upon Carol until she could sell the family home. Robert's practice also had to be wound up which was relatively straightforward but still very taxing.

Carol misses Robert terribly, feeling cheated by life, and feeling sad when she thinks about the missed opportunities that they would have shared in retirement. Carol has felt Robert's presence once when she was sitting alone she felt something brushing against her lips. She talks to him frequently; telling him what is going on in the family, and how she is travelling in life.

Carol has been on an outing with a man since Robert's death, the man was divorced, which is something that Carol feels is fundamentally challenging to any future relationships, due to divorcees having a negative view of their previous relationship, as opposed to her positive memories. Carol hasn't worked since Robert died.

\section{Rosalie and Charlie}

Rosalie was a secretary who was 49 when Charlie a 58-year-old Geology Professor died from no known cause. They had been together for 31 years. It had been two years since Charlie died when Rosalie was interviewed. Rosalie has three children, Mary 27, Linda 22, and Frank 20.

Rosalie and Charlie had a very close relationship, and were working together in the same university department, when he died. Charlie was on a field trip flying from Johannesburg to Siberia when he died during the flight. Rosalie was with friends at home following a night out, when two police officers came to the house to 
inform her of Charlie's death. Rosalie could not believe that they had the right person; she had talked with Charlie the day before.who was fit and well. The department of Foreign Affairs confirmed the details of his death to her on the phone, later that night

The family arranged a memorial service because Rosalie decided to have Charlie's body cremated. Rosalie, would have preferred to have only family and close friends present at the memorial service, to prevent any colleagues of Charlie's attending due to an acrimonious relationship that he had with them. However this would have prevented students of Charlie's attending which would not have been fair. Over 200 people attended the memorial service, including the colleagues who made Charlie's professional life difficult.

Rosalie regretted not being able see Charlie's body, but couldn't bring herself to have his body flown half way around the world. His ashes didn't arrive until months later, and were left by a courier outside the house, because she wasn't home. The bureaucratic problems associated with not having a final death certificate caused Rosalie problems with banks, and insurance companies, and stockbrokers. Despite being informed of his death one bank allowed periodical payments to continued to be debited from his credit card.

Rosalie's family and friends were extremely supportive to her. Rosalie misses the social life that she shared with Charlie, such as attending plays and movies, however she does continue to socialise with friends regularly. Rosalie also misses the physical contact, but at the time of the interview, wasn't contemplating a new relationship.

\section{Adam and Maria}

Adam was a university lecturer in nursing who was 41 when Maria a 38 year old university administration assistant, died intra-operatively whilst having a hysterectomy due to a Pulmonary Embolus. They had been together for seven years. It had been two years since Maria died when Adam was interviewed. Adam has three children Ben 15 (Adam's son from a previous relationship, who has died of a drug overdose, a year or so after this interview took place), Jeremy 13 (Maria's son from a previous relationship), and Dannie 7 (their daughter).

Adam described Maria as a very beautiful woman whom he greatly admired. He described their relationship as a great love affair. Maria was a very fit and healthy person who had been advised that a hysterectomy was the best treatment 
for her intra-uterine fibroids. Adam was contacted by phone by the surgical registrar informing him that there had been complications during surgery, and that he needed to come to the hospital, where they informed him of her death. The staff found it difficult talking with him because he was well known to them.

Adam described how complicated things were arranging relatives to travel from Maria's home country of The Philippines, but the closeness of the family was comforting and supporting. During the ensuing months Adam, became increasingly depressed, drinking up to a bottle of Whiskey a day. He decided that he had better seek help, approaching his general practitioner who was also Maria's general practitioner. Adam was shocked to discover that the doctor had not been informed of Maria's death, which meant that the session was mainly spent with Adam supporting the distraught doctor. Adam was prescribed anti-depressants.

Adam has sought support from a bereavement support group (with limited success) and individual counselling for himself and the boys. Adam described the loneliness: "...it seems like its me doing it all ... you know, you probably have days like that, its not that unusual, but at the end of the day... I've got no-one to love me in my bed, you know..."

Adam is beginning to see a future where he will lose weight, get fit, play guitar again and contemplate another relationship, but in the meantime caring for three children, continuing to work and deal with the ongoing sadness of the loss of Maria occupies all of his life.

\section{Brian and Jenny}

Brian was an Emergency Department Registered Nurse who was 38 when Jenny, a 35-year-old full time mother, died from a pulmonary embolus which she developed four weeks after fracturing a patella which had been surgically repaired (she was 16 weeks pregnant when she died). They had been together for nine years. It had been two years since Jenny had died when Brian was interviewed. Brian has two children, James 5, and Ricky 3. A more complete case study featuring Brian's story is included as Appendix F.

Brian and Jenny were happily married and enjoying raising a young family with the future bringing another child. Unfortunately due to a simple accident their future plans didn't materialise. Brian was present when Jenny complained of chest pain, and died within a few minutes. He did not try to resuscitate realising that she 
was probably suffering a catastrophic medical condition, making any attempts at home based resuscitation futile.

The hospital staff were supportive, and family and friends offered comfort and support. Brian described how he took a pragmatic approach to life after Jenny's death. His need to care for his children meant that he had to "get on with life". With the help of his sister he returned to work, because staying at home was driving him crazy. Brian needed the support and friendship that colleagues offered as well as the need to be doing something "useful". Being at work allowed him the distraction from the loss he had suffered.

Brian was well aware of the unusual circumstances he had found himself in being a young widower. When applying for supporting parent payments from the department of social security he discovered that he was the only male receiving the payment in the region, and that the form did not have a provision for the status of widower.

Brian firmly believed that life was for living, and without diminishing his relationship with Jenny, decided to start a new relationship nine months following Jenny's death, which lasted several months.

\section{Don and Jane}

Don was a university lecturer (PhD) was 43 when Jane a 40 - year-old academic died from no known cause. They had been together for one year. It had been six years since Jane had died when Don was interviewed. Don had no children. Jane (herself a widow) had two children Julia 18, and Garry 12.

This participant refused permission to include a full profile in the thesis.

\section{Dean and Janine}

Dean was a retired business proprietor (no post secondary qualifications) was 69 when Janine a 54-year-old medical secretary died from a cerebral haemorrhage when an intracerebral Berry aneurysm ruptured. They had been together for 22 years. It had been three years since Janine died when Dean was interviewed. Dean has three children, Mike 25, Sarah 18, and Jimmy 18.

This participant did not respond to two attempts to gain permission to use a participant profile. 


\section{David and Lorna}

David was a research scientist who was $\mathbf{5 0}$ when Lorna a $\mathbf{4 5}$-year-old accountant and full time mother died of aspiration pneumonia following a cerebral haemorrhage. They had been together for 23 years. It had been two and a half years since Lorna had died when David was interviewed. David has two children, Jimmy 10 , and Kelly 8.

Lorna had survived breast cancer for several years prior to her death, which resulted after she inhaled her own vomitus following a seizure. David felt that the hospital was negligent in their care of Lorna who was left alone in her hospital bed having had an intracerebral haemorrhage. David had great difficulty accessing information regarding Lorna's treatment in the hospital, and felt that the hospital was reluctant to communicate fully and openly with him because they were protecting their staff. It wasn't until he had an article published in a newspaper that he was given the information that he requested.

David was left with two young children to care for, with minimal domestic skills. He decided to give up work and care full time for the children, which he has not regretted. David has had patchy support from Lorna's parents and sister; all of David's relatives live on the east coast. Friends and neighbours (especially his children's school community) have been supportive to him and the children. David has found that Lorna's friends have drifted away, telling him initially that they wanted to continue the friendship, but the reality was that they were connected to Lorna, not to him: "But the reality is, that, you're so consumed doing your own thing and you don't have a lot of time to just suddenly ring up and say look l'm really lonely can you...you know."

David feels that there will always be a void within him created by Lorna's death. David lives in the here and now, and is creating things such as sundial's and pottery. He does not miss his previous job.

David has become involved with another woman, Katherine recently. Both sets of children get on well together, with his children enjoying the company of Katherine. David wasn't looking for someone to get involved with but is grateful for the company, support and the physical side of the relationship. 


\section{Overview of participants}

The sample was limited to heterosexual men and women only in this study. The length of the relationship between participants and their partners was recorded, but was not a variable considered in this research due to the small number of the participants.

The people who volunteered to participate in this research project were a remarkably homogenous group. Five men and ten women were included in this study. The age span of the men was 38 to 69 years, and the women 34 to 63 years. Every participant except one was born in Australia and all were from an AngloSaxon or Anglo-Celtic origins. All participants acknowledged that their faith systems had been derived from experience with the Judeo-Christian religion. One participant regularly attended church, with another participant describing herself as having a strong spiritual belief system, which did not include regular attendance of church.

All of the participants owned (or were buying) their own homes, and lived in middle to upper class socio-geographical areas. All were part of the broad socioeconomic group referred to as 'middle class'. All of the people lived in the greater Perth metropolitan area except one who lived in Sydney.

Most of the participants (11) held post secondary educational qualifications. All participants except one worked in professional occupations. All participants professed to be in a loving and satisfying relationship, except one participant having considered divorce, but who was attempting to reconcile the relationship when her husband died.

The next chapter introduces the first of the major interpretive themes and the sub themes. Each interpretive them chapter is introduced, and then the sub themes are explored. Each interpretive theme chapter is closed with a phenomenological explication of the participants' experiences. 


\section{CHAPTER FIVE}

\section{THE SURVIVING PARTNER'S RELATIONSHIP WITH SELF,}

\section{WHILST EXPERIENCING A SHATTERED LIFE}

He that outlives a wife whom he has longloved, sees himself disjoined from the only mind that has the same hopes, and fears, and interests, from the only companion with whom he has shared much good and evil; and with whom he could set his mind at liberty, to retrace the past or anticipate the future. The continuity of being is lacerated; the settled course of sentiment and action is stopped; and life stands suspended and motionless.

Samuel Johnson, (Hill \& Powell, 1934, p. 419)

\section{INTRODUCTION}

The sudden unanticipated death of a partner resulted.in the surviving partner experiencing shock, confusion, denial, anger and chaos, resulting in the life that he or she had hitherto experienced being shattered and subsequently fragmented.

This calamitous event creates disequilibria and disharmony, leading the surviving partner to attempt to protect him or herself from further insult. The surviving partner often described being in a surreal world where they are not fully aware of what is happening around them.

This chapter explores the experiences of the surviving partner in relation to their sense of self, as a newly bereaved person. The surviving partner's life has been shattered, leaving him or her to wonder whether they will ever be able to pick up the pieces and find some semblance of normality again.

The surviving partner's experience of shock in relationship to discovering that his or her partner has died

The participants' emotional responses to the news or the first hand witnessing of a partner's death resulted in he or she being able to recall the event in 
vivid detail, as was the case with all of the participants in this study. One of the most graphic descriptions of a partner's death was given by Mary, who having gone out for a morning motorcycle ride as a pillion passenger with her husband, Alf, witnessed him being struck by a car that had entered the emergency lane on a freeway when he had stopped the motorcycle to retrieve a pair of sunglasses:

...so he had to duck, duck and he tried to duck, and she just, got him, ah with such, the bang, I mean I still had my helmet on, and I was you know a bit of a distance, and I just, you just don't believe what your seeing, you know, I mean. It's just, I just how you scream but nothing comes out, and I'm screaming and I'm running and running and trying to get my helmet off you know, it's like it's not coming off, and um and I don't really know what she, she, she pulled over, eventually, um, and I, and I raced to him and before I you know by the time I got down there seemed like there were you know a few other people there already had, not long been behind, and stopped, and I raced, and there he was, just all twisted, on the, on the Freeway and, the blood, I just couldn't believe all this blood that was coming out of his mouth, and he was gasping, and I just leaned over and I just sort of you know was trying to not do anything to try to move him, but just was there leaning over to him, right to his ear, and just you know calling out to him, and asking him, you know, please don't go, I mean don't, don't leave me, don't leave me, don't leave the kids, hang in there, please don't leave us. He was on his back and was trying to, to gasp, and then all of a sudden, he went all quiet he just, like he settled right back, and I think, I believe that he heard, he heard something, he heard, cause I said I love you Alfie, please don't leave, please don't leave, hang in there, I don't want you to go, and um, he then went all quiet, after l'd said all that, and then um, our doctor appeared, um there was someone coming from (the major city) hospital, um they'd been working in emergency, and, so that all the right people were there, you know, and then there were um, some other people and they, anyway they had to take me away, they, they removed me because um the doctor could see, something was happening, that, they didn't want, why I think they, needed to do things to Alf to try to stabilize him, and I was taken um into the Police car.

The life of the participants was thrown into turmoil following the sudden and unexpected death of his or her partner. Participants used expressions such as: "It was like a bolt out of the blue" (Jane), and "God that was a shock, total, I mean you're numb" (David). The words that were used most often by participants to describe their initial reactions to their partner's death were "shock" and "numbness". Rachel stated: “You just really can't think clearly and you just think you're whole life is going to change but can't sort of function really because of the shock that you're in." 
Mary was struggling to cope with the enormity of what had just happened to Alf:

I wrapped myself around a, traffic pole and everything, and I went into total, total shock and there, right there you know I just really wanted to die, you know I said you know I can't take any more, I can't, just can't take anymore...

Physical reactions such as uncontrollable shaking despite not being cold and becoming hyper-emotive resulting in screaming was described by some of the participants as a reaction to this overwhelming event. Tina was under such great duress that she had a myocardial infarction whilst she was trying to resuscitate her husband: "I'm trying to do all of this and I'm trying to get breath down him when I couldn't even get his teeth apart, I was in a terrible state, but I didn't know l'd had a heart attack at that stage due to shock because I couldn't bring him round. I'm expecting him to breathe and he never did."

The subsequent feeling of numbness was a response to the overwhelming stimuli surrounding the sudden and unexpected death of their partner leading to a reduction in the capacity to cope with any further insult. Mary encapsulated these feelings well: "I was absolutely numb, I just went through the motion of everything, just doing what you have to, not because I wanted to, just because it's the defence mechanisms."

The ordinariness of life has been altered forever in the blink of an eye. Dana described the intense emotional response: “...when you're as close as that, it really is physical pain."

\section{Relationship of findings to existing literature}

The responses that the participants in this research project described are congruent with the existing qualitative and quantitative research and literature. The sudden and unexpected death of a partner can be described as catastrophic for the surviving partner. The initial reaction to the sudden and unexpected death of a partner is a profound and often overwhelming experience, with the surviving partner usually having no prior experience to guide him or her. The accompanying shock and confusion leaves the surviving partner with the feeling that their lives have been torn apart (Cooke, Cooke, \& Glucksman, 1992; Davies, 1991; Doyle, 1980;

Kellehear, 2000; Leming \& Dickinson, 1998; Rando, 1993; Sanguesa, 1995;

Skinner-Cook \& Oltjenbruns, 1998; Straub, 2001; Wright, 1991). 
The somatic response to such a traumatic event is well documented in the literature and may be ongoing (Bowling \& Windsor, 1995; Jagger \& Sutton, 1991; Prigerson, Bierhals et al., 1997). Physical manifestations of a grief experience may include insomnia, exacerbation of existing cardiovascular conditions, precipitation of depression, and depressed immune system resulting in increased infections (Rando, 1993). The equilibrium of their normal everyday lives has been disrupted to such an extent the protective responses of numbness and denial take over to allow the surviving partner time to process what has occurred to them.

The ability to describe in minute detail such an event is attributed to the effects of norepinephrine and cortisol, hormones that are released during stress reactions and which improve memory (Claes, 2004; Monk, 2004). It would be understandable, that the levels of norepinephrine and cortisol in Mary's body would have been raised significantly given the circumstances of Alf's death. The ability to maintain such detailed memories of such an event is known as 'weapon focus phenomenon' the phrase being derived from witnesses of armed robberies who have been able to give precise details of the event for long periods of time afterwards (Claes, 2004).

\section{The surviving partner's experience of confusion and chaos in relationship to the sudden death of his or her partner}

The ordinariness of the surviving partner's life was disturbed suddenly, violently throwing the surviving partner into a state of disharmony leading to a state of confusion and chaos.

Adam described how he reacted when he left the hospital following his wife's sudden death:

Ben and Jeremy and I walked out and I could hardly remember where I parked my bloody car. I was thinking, I don't know if there's going to be a funeral, I need to... we went to the supermarket and I bought a whole lot of loaves of bread, about eight or ten loaves of bread because of sandwiches and all these big bottles of Coke. The boys needed to drink something. l'd no idea really.

What Adam described was how he entered into a survival mode, relying upon his prior experience to give him direction and allow him to function at a basic level, in order to fulfil social and family roles, i.e. prepare for a funeral and wake and feed his children. 
The loss of control that participants felt when they were overwhelmed by a catastrophic event is that they are being swept along by the enormity of the aftermath. Participants described him or herself losing his or her identity and becoming confused and conflicted with his or her role, feelings which are distressing for people who are used to being in control of what was hitherto a reasonably predictable life.

Mary described her hyper-emotive state having witnessed her husband's death, she also described being aware of her husband's presence in the police car, and how his presence allowed her to calm her self:

...and I just started screaming and throwing myself all over the back and he (a police officer) saw, he came running and then he, called out for someone to get assistance to bring the ambulance maybe (for a) sedative to calm me down cause l'd just gone totally hysterical, and so they had to sort of, hold me down and eventually um, oh that's, that, that is when I went into survival mode then, then I just went very quiet, and, and again just ah, I think that's when, I really knew, that he had gone, I think I must have sensed, that he, his, his soul had left his body, and ah he may even have been around, I don't, I don't know because um, you know I was just praying so hard in the police car, and then all of a sudden he was there when I went out of control and, then everything just went really quiet...

\section{Relationship of findings to existing literature}

The sudden unanticipated death of a partner results in the surviving partner experiencing feelings that he or she have lost control of their life, confusion, and chaos, resulting in the life that he or she was hitherto experiencing being shattered and subsequently fragmented. The responses that the participants in this research project described are congruent with the existing qualitative and quantitative research and literature (Cooke et al., 1992; Davies, 1991; Doyle, 1980; Kellehear, 2000; Leming \& Dickinson, 1998; Rando, 1993; Sanguesa, 1995; Skinner-Cook \& Oltjenbruns, 1998; Straub, 2001; Wright, 1991).

When the deceased partner dies accidentally, research indicates that the death can seem more unreal than a natural death (Range \& Niss, 1990). Several participants described experiencing the presence of their deceased partier, a phenomenon explored in greater detail in Chapter Six. 


\section{The surviving partner's experience of denial in relationship to the sudden death of their partner}

A few participants experienced a sense of denial following the death of their partner as well as a sense on unreality, Rosalie summed this feeling up well: "I said it's not true, it's not happened, you know total denial, it's not that it hasn't happened you know it's not true, I'll sort it out when we go back to the house." Other participants describe feeling like zombies wandering around, with part of them knowing their partner is dead, but another part still thinking (wishing) that he or she would be home soon. Having a fit active partner makes the death seem even more unreal. Despite having witnessed Alf's death, Mary described how she felt that Alf was still alive for several weeks following his death:

...and for weeks, it felt like Alf was just away, I just kept saying oh he's just away, he's just away, he'll be back, he'll be back (laughs) and, and I was really deluding myself in, in, in a lot of ways, I sort of knew, l'd say then on one hand l'd say, he's not, but he is, cause it just feels like he is, and it did, you know doesn't feel like he's not here, you know and even at night time um it was okay, as well l'd be thinking like that as well he's just working late, or he's you know he's been away and his not going to be home till later, you know, it was ah, and I think again it was just, it was just the way I had to cope.

\section{Relationship of findings to existing literature}

The responses that the participants in this research project described are congruent with the existing qualitative and quantitative research and literature. The experience of denial following the death of a person with whom a person has a significant relationship with is a well-documented phenomenon (Hockey, Katz, \& Small, 2001; Kirschling \& McBride, 1989). By denying that the death has taken place the surviving partner is self-regulating the impact of the reality upon him or herself. Stroebe \& Schut (1999) refer to this as: "the need for dosage of grieving" (p.198), meaning that the surviving partner takes respite from dealing with the stress of the bereavement and is part of an adaptive grieving process.

\section{The surviving partner's experience of being with the dead partner's body}

Participants found that being with his or her partner who has died in their presence, or seeing their dead body for the first time following their death was a confronting experience. This may have been the first time that the surviving partner has been in the presence of a dead body. Adam described his situation as such: 
l'd managed my nursing very well, in general. I'd never had anyone who'd died on me, you know, and l'd only ever laid-out two people in my career (when I) couldn't avoid it, you know. Probably, in retrospect, I had quite an anxiety about death, you know.

Four participants were present when their partner died. Brian responded to his wife's call for help when she was showering:

Then she yelled out my name and I ran upstairs; it sounded pretty, you know, she yelled out my name twice and she was just lying on the floor in the shower. I got in the shower with her, you know, the tiled area outside the shower and I thought she'd fallen over and hurt her leg, she was quite pale. And I said "have you've hurt your leg again?" She said, "no, chest pain" and then she died, that was it. Just slumped down. Couldn't stand her up, couldn't get her to a bed; just then her breathing went, abnormal breathing and that was it. I called the ambulance. They came out pretty quickly, within seven minutes, but she was dead before they got there; she'd stopped breathing before they got there. That was it. I just knew straightaway it was either a heart attack or a PE. I didn't try anything cause I knew it wouldn't work.

When Carol completed her pre bedtime routine, she discovered Richard slumped in bed with no pulse: "I just went to him and I, cause no pulse no nothing, and $\mathrm{I}$ just screamed, and Jim and Jane were (there) in a second, and they just had him on the floor and worked on him for...but... Jim and Jane they tried everything." Carol was able to reconcile herself that Richard was being cared for by two very experienced medical doctors, and that there was nothing that could have been done in the circumstances to save Richard.

When Rachel arrived at the scene of the shark attack that resulted in Kevin's death and the maiming of one of his best friends she immediately realised that there was no way that Kevin could survive his extensive injuries. Mary knew that if her partner Alf had survived his injuries, that his quality of life would never return to the pre-injury level: "I knew when I saw him on that freeway, Martin he was twisted, I knew that his whole body was broken, his legs were going a different way to the rest of his body, it's the most awful thing to see, to know that if he'd survived he would have not been living."

Seeing the body for the first time left an indelible imprint upon the surviving partner's memory, all being able to describe the experience in detail, as Lyn remembered: 
...then when I saw his body, this is about ten o'clock in the hospital morgue I saw the blueness around his lips, and the, head trauma but he was really peaceful....

Participants described the experience of being with their partner's body as something that although harrowing was a special time that allowed the surviving partner to have some quiet time with the deceased partner. This time gave the surviving partner the opportunity to say goodbye to their deceased partner and reflect upon their life together.

Funeral parlours are sometimes criticised for presenting a body for viewing that does not resemble their appearance when living, which is referred to as "cosmetizing" (Leming \& Dickinson, 1998). The liberal use of make-up and hair dye can sometimes create a caricature that does not project the image of the dead person, as they were when they were living. Dana described the experience as: "I mean it didn't look like Carl for a start. I mean he was sort of all made up but it didn't feel like him. When I touched him it didn't feel as though there was anything was there." Fortunately this was not the case for most of the people involved in this study.

Other participants describe their deceased partner as looking realistic and presented appropriately. Mary described the experience as such: "I'm so pleased I did it, so pleased I said goodbye to Alf. He was so cold, he'd had been there for like days and I suppose (that's) the difference that you know having seen Alf to be still warm." Other participants described the deceased partner looking peaceful, handsome and young. Despite the unpleasantness of this experience, when the surviving partner is aware of the coldness of her deceased partner's body it becomes part of the reality building process. Don described the sense of finality as: "Yeah I had some time alone. Yeah. It was yeah and that um yeah gave a strong sense of the reality or the completion of it."

Despite the confronting nature of being in the presence of their dead partner, people often described the experience as worthwhile, with those who refused to see their dead partner sometimes regretting their decision.

\section{Relationship of findings to existing literature}

The responses that the participants in this research project described are congruent with the existing qualitative and quantitative research and literature.

Being present when a partner dies is an extremely confronting and sometimes-brutal exposure to the reality of death, especially when the partner dies through trauma 
(Neria \& Litz, 2004; Prigerson, Bierhals et al., 1997; Prigerson, Shear et al., 1997). One advantage of being present when his or her partner dies is the surviving partner can support them in their final hour of need. Another advantage is that there is some opportunity of saying goodbye (Haas, 2003) as Mary portrayed so clearly in her quote at the beginning of this chapter. A common complaint made by a person whose partner has died suddenly and unexpectedly is not having the opportunity to say goodbye to their partner (Hockey et al., 2001). Having the opportunity to say goodbye and talk with the body of the deceased partner could ameliorate this lost opportunity but is a subject that is not well documented in the literature.

\section{The surviving partner's experience of his or her dead partner's funeral and wake}

All of the participants attended the funeral or memorial service held for the deceased partner. It is a formal ceremony that most participants believed to be an event that they are expected to attend, as Tina described: "I didn't break down, I didn't cry, I was next to Trish and when they bought the coffin in, I started to cry and she said it's okay, and she just held my hand then I pulled myself together, and I was okay cause you know you have to go in..."

The funeral was an opportunity to celebrate the deceased partner's life as well as to say goodbye, which was aptly described by Mary:

As part of ah, the ceremony is like, when the service is done then um the family are on, sort of like there's the grieving, wife and my children we're sort of ah next to the coffin and I go first and give my farewell, to him, so I just kissed him and you know and have a little talk to him, and a lot of people actually found that really nice.

Participants described spending a great deal of time and effort to plan the funeral so that the deceased partner's life was captured as vibrantly as possible. Tina's experience was an example of this:

We had it in the Norfolk Chapel, and it was very nice cause we had Pamey's Angilicas by, Bob used to call him the Boy Treble everyone calls him the Boy Treble, and we love classical music, we loved Alan Jones and all of that type of music so, we had the beginning of the ceremony as Pamey's Angelicas, and then, the coffin was brought in, then a few words were said, and then, we had, Vilvadi's Four Seasons which we liked, and then we went out to the Spirit of Australia, you know because Bob was very, he loved being Australian, he loved being of Irish Heritage, he was very proud of who he was, he was a Fly Fisherman, and there was a beautiful picture 
that I have of him, cause now you can have a funeral service (as you wish) is... brilliant.

The participants described the funeral as a significant event in the partner's life following the death of their partner, which they valued the memories of.

Most participants had a 'wake' following the funeral. As Mary said: "that (the funeral) was very, very emotional, and I was just so drained, absolutely drained and we came back here and I hadn't planned anything, you know just, friends just took over and they, you know got all this stuff together."

The wake may be more therapeutic for the family and friends than the surviving partner, as Jane described: "the day of the funeral um, yeah there were quite a few people who um, came to the house bringing food but I didn't see them, I spent quite a bit, just time sitting in my room, and then yeah just when we went, oh I was completely, shut down not at all, not present."

David described how he arranged a combined funeral and wake when he held a memorial for Lorna in the parkland at the bottom of his street:

ah it was, not, it was really just, it wasn't a funeral in that, traditional sense it was more of a funeral in, people being able to say goodbye, so it wasn't a, a formal process of, you know the parents sitting there and lots of prayers and, you know wailing it was more people coming down and just having, hmm, sort of like a bit more of a formal wake than it was a funeral, and so that, the kids from school and everything were all running around doing their thing in the trees and running up and down the hill, um, so and I said to the kids that, that you know the funeral wasn't really, they've already said goodbye to Lorna, that ah the funeral was really for people that knew Lorna to have their opportunity to say goodbye so the kids never really saw it as a, as a funeral as such.

All of the participants' children attended the funerals regardless of age. None of the participants described their children experiencing any obvious ongoing negative effects from having attended the funeral.

The funeral and wake are socially ingrained ceremonies that have evolved to allow family and friends to remember the deceased partner and to help them come to terms with the death. All participants were gratified that so many people attended the funeral as validation of the love, affection and respect that people held for the dead partner.

Relationships have become far more complicated over the past two generations with increased levels of divorce rates, resulting in people having more 
than one significant intimate relationship in their lifetime and often having children from more than one relationship (Australian Bureau of Statistics, 2002a). This may result in ex-partners of the deceased partner feeling that they have a right to attend the funeral (Doka, 2002). This occurred with Lyn when Geoff's ex-wife attended the funeral:

Um and this was the woman who, like, you know... had taken money off him and I'm thinking what are you doing at his funeral? I was ready to fight her, in the street (laughs). It got me angry because I thought, don't be there for all the wrong reasons, and at a funeral, pretending that you lost him, and you haven't, you just lost, what he stood for, I hate that (laugh).

Regardless of the feelings of antipathy that Lyn had for Geoff's ex-wife, the ex-wife had her own reality and despite having been separated from Geoff for quite some time prior to his death, she felt the need to attended the funeral to commemorate the relationship.

In Brian's situation Jenny died along with their 16 week unborn baby. Brian's philosophy regarding this situation was that a baby is not truly a human being until it is born. This belief doesn't diminish the grief related to another lost life, however as Brian described his feelings below, it means that a separate funeral was not held:

...she (the undertaker) said some people have a separate funeral and she said would you like that so I can prepare ... And I said no, no, not at all. In my mind the baby was still inside Jenny when she died, so that, to me, that's the way ... I can imagine some people would, but to me ... The rest of Jenny's family were in complete agreement. You know, we were talking about things like this. The baby hadn't come out of Jenny so they were quite happy about it

Brian's unborn baby was given a name, and her life was validated at the funeral.

Having a relationship with a prominent person allows the partner to become familiar with media intrusion, which usually follows their death. When an 'ordinary' person dies in unusual circumstances, then the media intrusion can be overwhelming. Rachel experienced this phenomenon, following the shark attack that resulted in Ken's death while he was swimming at a popular metropolitan beach. This event captured not only the attention of the local and national media, but the international media:

So um, you know l'd never experienced anything like that before it's just, it was just amazing, anyway the, the children said to me a few 
days after Kevin died that they would like to be involved with the funeral and I said oh, well you know that's absolutely not necessary, we've got so much on our plate that were trying to get ourselves, you know, ready for a funeral in a week, and cope with what's happened, and every time we turned the television on. So, and then the, they had the picture of Annie and, the kids in, at the funeral and, guys were ringing up Annie then they had the children, the, you know Don in the wheelchair at the funeral. They had the, the funeral on TV. All over Australia, in England they had the funeral, they had, it was just awful, we had no privacy really.

The media intrusion continued until a friend who worked in the media called a truce by acting as intermediary between the family and the media. This didn't stop other people who were involved in the incident having to be constantly dealing with national and international media searching for first hand stories of a shark attack.

\section{Relationship of findings to existing literature}

The responses that the participants in this research project described are congruent with the existing qualitative and quantitative research and literature. The funeral is an important part of the reconciliation process and is entrenched in sociocultural and historical significance (Leming \& Dickinson, 1998). The 'wake' is a tradition that has evolved from Celtic origins (Leming \& Dickinson, 1998) and is considered to be an important adjunct to the funeral, where family and friends gather to remember the deceased partner in more informal surroundings than the funeral.

The participants described his or her children participating in the service and appreciating the opportunity to say good bye to the parent and memorialise him or her, which is supported by thanatological researchers who have found that children's experiences of funerals are usually regarded positively (Currer, 2001; Leming \& Dickinson, 1998; Skinner-Cook \& Oltjenbruns, 1998).

Lyn's need to publicly acknowledge her relationship with Geoff and her subsequent grief experience has become recognised and is referred to as disenfranchised grief, a phenomenon related to people who regard him or herself as having a significant relationship with the deceased person, which may not be acknowledged by others, especially if the relationship has supposed to have ended through divorce (Doka, 2002; M. Williams, 2001). 


\section{The surviving partner's experience of emotional lability in relationship to the sudden death of their partner}

The sudden and unexpected death of a partner resulted in a level of emotional lability that the participants had hitherto not experienced. The resultant distress was often overwhelming, and as Rachael discovered can be compounded by distraught friends and family, not being capable of helping:

I came upstairs and saw everyone there and I just burst out crying and I said Kevin, I've got to do these papers, so I saw the guy in the lounge room and I just said somebody help me, somebody help me and they all just looked at me, and they were all sobbing and I said well can somebody, and they, somebody.went and did it, my dad came and sat with me, but it was just all too much, and I thought, I couldn't, isn't that amazing I, I thought somebody, my close family will, my brothers, one's a lawyer and the other two are doctors, they can help me, and no they couldn't, but my dad came and sat with me and someone signed the papers and I said, what, what am I paying here and what am I doing here, and they said this is what you have to sign, so you know.

The distressed state that the participants described, involved an emotional lability that they felt that they had no control over, this was often manifested by uncontrollable crying as Brian recalled:

Amazing feeling, you know, I completely lost it when Jenny had died and the nursing staff came in from the hospital. And I was grief struck for the first week. And crying, sort of, little things would make me cry, like James wouldn't put his shoes on, you know, he'd put his shoes on but he'd move his feet so I couldn't do it up. And I got these tears rolling down my eyes and I said, come on let me do your shoes; why are you crying daddy and I said, oh, I'm missing mummy very much. And he said, yes, I'm missing mummy too.

All of the participants described periods when they were overcome by grief and cried like they had never cried before, with one participant stating that she cried intermittently for two years.

\section{Relationship of findings to existing literature}

The responses that the participants in this research project described are congruent with the existing qualitative and quantitative research and literature.

Crying is a natural physical expression of sadness and is considered to be an important physical release of tension (Rando, 1993). If the surviving partner cannot cry, it is not necessarily a sign of a lack of bereavement response, however can be part of the constellation of manifestations of complicated mourning (Rando, 1993). 
Gender stereotypes such as the tough stoic macho bloke, that have been enculturated into the Anglo-Saxon male (Martin \& Doka, 2000), could have inhibited the surviving male participants' ability to express their 'emotions through crying, but this wasn't reported as being a problem for the male participants in this study.

\section{The surviving partner's experience of anger and frustration in relationship to the sudden death of his or her partner}

The experience of losing someone you love can result in a level of frustration and despair that manifests in an anger that can surprise the surviving partner at it's level of intensity. Participants described venting their anger at the doctors involved in caring for their deceased partners; banks; insurance companies, or being forced to sell businesses or property, which occurred to Carol:

$\ldots$ and I, I, I, I, guess was I angry, was I angry about debt, but he had chosen to do it that way and I wasn't really angry... and we'd eventually sell the XXXXX Street house it wasn't a major problem but um, (I was) angry, cheated (sighs) ...I miss him terribly...

David was furious with the staff that was caring for Loma: "Like I just thought fucking hospitals are a waste of space. They are just a waste of space, she, she would have been better off lying on my bed and dying, from brain pressure, from the haemorrhage, and, and not being able to do anything about it than sending her of to a institution where you thought that she was ... safe." David felt that the staff had breached their duty of care, and that the staff had betrayed his trust.

Dana and her sons felt that Carl's treating doctors weren't taking the severity of Carl's illness seriously enough; she described the emotional responses that were evoked:

Anyway they kept telling me it's not life threatening, well it was, wasn't it? And that's what happened and I reckon that probably he had inflammation of the lining around the heart, something like that happened, I mean I don't know they kept saying oh it came out of left field, I felt very angry about that I suppose, and the boys got quite angry too because both the heart specialist and the GP had given us the same nonsense. Over and over again but neither of them came to see him, it was all on the phone. No that's not fair, Graham did come, he came up and looked at the drip thing that had been put in, but after that, that was just the one time. But the boys were also very angry and felt that he hadn't properly been looked after because particularly the surgeon was a close friend and hadn't. That was difficult and I thought well it wasn't going to help anything if they went all bitter, and I thought well it's over and done with. Elle felt like I did, that it wasn't going to achieve anything but make the boys very angry, 
so anyway we decided not to have one (an autopsy) and I suppose I do regret that now. Except that they feel that, it was just something that happened out of left field and nothing could have been done...

At Geoff's funeral Lyn, had to face Geoff's ex-wife and family on the night of his death, whom she knew had caused Geoff many problems since his divorce:

When I arrived there, the ex-wife was there... all the family of the exwife, a brother-in-law that he hadn't spoken to for five or six years, and hated, (who carried his coffin), I mean it was all bizarre but for the sake of not rocking the boat cause these people were grieving too, I just said very little, but I was, just so angry inside!

Adam recalled how he and his sons felt when faced with Maria's death:

... she actually died in theatre. Erm, they said, was there anyone I wanted to talk to and I just said, and I thought of my sister, in fact there was no family here, she's in New Zealand (or New South Wales). I had a good friend over in the Blue Mountains, and I asked them. Well, they actually got a social worker and female and er, I guess, sensed her discomfort or something, although I think she did her best, you know, I feel, you decompensate I didn't know how to behave, well, you know, I didn't want to ... burst into tears. I probably, ... it might have been Pam who might have come down thought at first she said she couldn't believe how angry I was, you know. And I probably was angry; I couldn't quite put that together, and they called the boys from school, you know, and Jeremy was in school and they said (indistinct phrase) and Jeremy has always said how he hated that fucking social worker, you know, she was patronising. But you know, your in a sort of disassociated state, you can't put it all together, I guess. I remember them arriving and Ben came first, because he was closest and Ben is my son so Maria's step-son and I was really dreading Jeremy coming, because Jeremy is worse, he's quite an introspective boy, his mother and he were very close, then when I arrived ... Ben was pretty full on ... I felt this great sense of trepidation for poor Jeremy. Then, you know, then you've got the technicalities, you've got to go and identify her body.

Adam described how he initially felt anger towards Maria:

But she was, you know, in the blue theatre gown, er, you know, I was angry with her, but I think I blocked a lot of that image, she was surgibathed, and they'd obviously done a fair aggressive CPR.... petechia...

Adam described his concern about his feelings of anger, and that it was not a sensation that was either well defined or directed but an intense sense of sadness: 
It's a real shit, I can tell you, I mean, I... just wish that I could scream, wail, vomit my sadness but its not, I mean, it creeps up on me and what you seem to fear more is, what I do anyway, is ... I suppose its anger, its not particularly well defined or well directed, its just that, you know, not at anybody, who could be angry at God or the surgeon, you know,

Mary described how she never felt hatred towards the driver who entered the lane accidentally killing Alf whilst walking in the emergency lane of a freeway, despite her negligent driving being responsible for Alf's death:

Well, no, I wasn't angry, at her, at all, and this is the interesting (thing) I ah, I never hated, her Um, I was just ah, always just confused, and always um, just, what happened, why, you know, what happened? What was she doing? That was all I ever (wanted to know). I knew it was an accident, or (caused) by a drunk, you know, like he, like immediately I was in shock, and I was numb, and I, all those sort of things um, when I saw her on the side of the road, um, my focus wasn't on her, it was just on, on Alf because of his condition and I, and, and you know I had, I had you know for me, I, all my energy, everything was just to, to think of him not to think of any think, like, you bastard, what have you done you know, if I, I didn't, didn't have the capacity in me But she was actually at that XXXXX convention, she'd been partying all weekend and hadn't slept, Yeah she'd been to a, she'd been partying and no, and, and you ask me about, my, my like in terms of was I angry, was I No ah, I, I wasn't, um not like that I mean later I did go through those emotions, of um, sort of, yeah but then, but there not anger and hate that I told people I never, you can ask anyone and they'll, they'll tell you that ah I never said that you know um I hated, I hate her, for what she's done and I'II never forgive her, or I'll never I don't know, I don't know why, I, just because I, I, I, I think I just turned to God straight away and, and asked him to give me strength, you know um, so I asked for all the right things, what I thought was important, not to go on to the negatives, of things, cause you know how, how destroying, hate is and anger. You know and I thought I don't want this, I don't want this, you know, to um, to stifle me. You know I, just I, I just, I just want to, um heal myself, I just, I want to somehow get better, you know I don't want, I don't want to stay, I don't want to go backwards. I didn't, I don't, I didn't want to go and, hide, in a corner you know and, and not come out um, it, you know there was ah, I had to face so many challenges

Most of the participants described how their feelings of anger had reduced over time, however it was anger that sometimes resurfaced when reflecting upon the loss of his or her partner and the shared future they were hoping to experience. 


\title{
Relationship of findings to existing literature
}

The responses that the participants in this research project described are congruent with the existing qualitative and quantitative research and literature. Thanatological literature describe anger and frustration as emotions that grip the surviving partner frequently in the first few months following the death of their partner (Gilliland \& Fleming, 1997; Harte-Barry, 1997; Hogan et al., 2001; Hyrkas et al., 1997; Straub, 2001). Elisabeth Kubler-Ross described the grief process in terms of stages (Redwood, 1997), this grief model has largely been superseded by models that are more fluid and less didactic (Corr, 1994; Moos, 1995; Murray-Parkes, 1987; Neimeyer et al., 2002). Some bereaved people still tend to think in terms of differentiated stages though, as Lyn explained: “... and then the sort of grief cycle thing, and I thought, yes I've come to this cycle, but then l'd go back here, and l'd think well I'm there I thought l'd finished anger, but I'm really angry at the ex-wife again."

\section{The surviving partner's experience of sleeping disturbances related to the sudden death of his or her partner}

Following the death of their partner, participants described feeling mentally exhausted but at the end of the day not being able to sleep. Several participants were prescribed medication to help them sleep with mixed results, as Mary described:

\begin{abstract}
.... you know as there's, there's people around everywhere and ah, they're, they're asking things they're doing things and you're, you're just on automatic, um so that day I don't really remember much, I was given sedatives so I could sleep um, I think I did that first night, I think I did, I just know that um there was one night there so maybe it would have been the first night that I did, and I just didn't, didn't sleep, just you know laying there just about all night, and then I be just totally exhausted.
\end{abstract}

One participant's thirteen-year-old daughter shared her bed with her for the first year following the death of her partner. Both found this comforting, with neither placing a time limit on the bed sharing, with the daughter, deciding one night that she wanted to go back to her own bed.

Adam described his experiences thus:

...I found that I was driving home and I was just feeling absolutely buggered, you know, I think it was five o'clock in the afternoon, and I could hardly keep awake, I felt, you know, I was having trouble with 
concentration, I felt sad all the time, and er, I was speaking to ... and a good old friend of mine, called Beth, knew her quite well too, you know, and she said "how're going?" and she invited me along. And I said I feel pretty shithouse, you know, I'm not sleeping properly, I can't stay awake, I think l've got some sort of depressive prodromal... She said, prodromal. Get real! Then, I think, I was (depressed) now, ... but funnily enough, you know, I think since I've read, you know, it seems to be quite classic, what bloody men do, you know, they go back to work, you know, they keep soldiering on and then suddenly bloody, come down in a bit of heap, you know. ...when she said that, I knew that the university should have an employee assistance programme (I spoke) to my head of department...(and said) I think, I'd like to go and see the employee assistance programme... and they were great. They just said you need time off and I went off and saw my GP...

One participant didn't realise how the stress he was experiencing was manifesting itself at night whilst he was asleep. David explained:

You know, and um, ah yeah so my sleeping patterns were disrupted, um, I didn't realise it at the time but I, I was cracking teeth and I had to go to the dentist, ah Lorna died in the August, and I was still going to the dentist in the February, because I busted about three or four teeth. Apparently...I was grinding my teeth at night um, ah, so there was this subconscious stress obviously.

Some participants described experiencing dreams and nightmares for extended periods following their partner's death. One participant described her dreams that involved her being trapped in a maze, which she interpreted as blocking dreams. Some of the participants have been confused by the themes of their dreams, but all described the dreams as being intense and often frightening. Jane recounted her experience:

And the night of Ann's Ball um we all went to a friends for pre-Ball drinks and I walked down the driveway um when she got into the Limo and I turned around and I could have sworn that Graham was there um yeah at first, when he first, he ah always behind me, always standing behind me and um apart from the time when I left Jan's and he was standing next to me um, and it's, it doesn't, it just, it's not even when I've really been thinking about him, it's just all of a sudden I think oh, hold on, what's going on here and then I have, yeah I have the, dreams I have are fairly constant to, of it's all a mistake um, he's only been up North working and he comes back and it's always, in all the dreams it's always trying, helping me.

Participants usually described dreams as being comforting with nightmares being disturbing as Sally described: 
I had a panic attack, one night a had a nightmare, I, I dreamed Peter's accident, and it was a terrible nightmare and l'd woken up and I thought someone was in the house, and (my), just, heart pounding, I just, definite panic attack, it was terrible I didn't think to ring anybody, you know I think when your in that, the next morning I thought I should have rung Dad, he would have come, and I told him and he said why didn't you ring me, I don't know, I was so, it was two o'clock in the morning I couldn't breath let alone make a phone call.

The surviving partner can find having to sleep alone for the first time in possibly years, difficult. Brian portrayed the loneliness of an empty bed:

...but there is, you know voids that people can't fill and that's those lonely nights and when I open my eyes in the morning and I look over in the bed and its empty, well sometimes lan is there or Eliah there you know they have snuck in and that's all right too, I don't mind that but yeah, it hits me the minute I open my eyes and it's my last thought when I go to sleep so it is, it is something that's with you forever, every day.

Several participants told of having moved the conjugal bed to a different position in the bedroom, buying new bed linen, or actually buying a new bed, because it was too disturbing to sleep in the bed in the way it was prior to their partner's death, as Sally described:

And she said um, have you thought about buying a new bed, I know it's out there, and I said Nina, I haven't, it's not a bad idea, I'll think about it, just think about it, don't do it straight away, don't get rid of the bed, put it in the other room or, you know but just maybe that will help, and I went home and I thought about it, and I thought well I can't really afford a new bed, really, realistically, I went and had a look, found one I really liked. So the bed wasn't in the same position it was in, it was in a different position and that was better, much better. And I thought, said to her, told her what l'd done and she said that was better idea really, Well a new bed was a nice idea but if l'd really needed one, sure I could have done it.

\section{Relationship of findings to existing literature}

The responses that the participants in this research project described are congruent with the existing qualitative and quantitative research and literature. Sleep disturbances were widely reported by participants in this study with all of the participants reporting that their sleeping patterns returned to normal over varying periods of time. Somnolence disturbances following a traumatic event such as the sudden and unexpected death of a partner are well documented (Prigerson, Shear et al., 1997; Rando, 1993). 
The prescription of anti-anxiety medication and sedatives for the newly bereaved person has been controversial, as Rando (1993) declared: "In the past physicians too readily prescribed too much medication for too many mourners with too little justification" (p.379). According to Rando many mourners who were over medicated, complained that they could hardly recollect any thing related to the post death rituals, and ended up have a delayed grief reactions when the medication was ceased (p.379). Current treatment modalities allow for the prescription of short-term medication to assist with sleeping difficulties (Rando, 1993).

Dreams and nightmares featuring the deceased partner are a common feature of the newly bereaved person (Hockey et al., 2001). The participants' descriptions of dreams and nightmares were congruent with previous research findings, in that the majority of newly bereaved people experience dreams with most of them being comforting (Hockey et al., 2001) and with nightmares are also a feature of the reaction to grief and are not considered to be abnormal unless part of a constellation of other ongoing psychologically distressing phenomenon (Rando, 1993).

\section{The surviving partner's experience of being bereft in relationship to the sudden death of his or her partner}

For the participants the sense of bereftness following his or her partner's death was very real and often profound. The feelings of bereftness manifest in an overwhelming sense of loss for the surviving partner. The sudden and unexpected death of his or her partner resulted in the loss of a companion, friend, lover, confident, co-parent, financial contributor, with the subsequent loss of a shared future. Mary described her sense of bereftness:

... he was my, my Soul mate, and so um, that was, that's was um, in itself, and um you know just a, a tormenting, tormenting me, so much and thinking that l've just, I've lost, l've lost so there was that, that, that immense sense of loss was just um, incomprehensible...

Adam described his loss in detail:

...after three years when I feel like something, when I sometimes get to crave intimacy not so much bloody sex, per se, but that's the relatively easy thing, you know...but to actually have that sense of connection, you know, that's what I really miss... and you don't get it from running or playing guitar! Its er, and that's the think, I think, its er, what I miss the most, what I found the greatest loss is not the, is that sort of, I don't want to sound (inaudible) ... the sexual ... a mental and intellectual stimulation, yeah. 
A sense of ongoing sadness pervaded the participants' every day life, with the surviving partner often not wanting to burden their family or friends by admitting how sad they actually feel years after the death of their partner. Jane articulated this phenomenon vividly:

Two years (after Graham died)...probably in about October or September last year, I um, talked to a girlfriend and we were having this conversation and I mean I knew that I hadn't dealt with it emotionally and I knew I never you know I would never let on to the girls (her daughters) how sad I felt or how lonely I felt because I didn't want you know, to worry them um, but I knew that that was wrong, you know I knew that.

Grief infuses every facet of the surviving partner's life, as Mary recounted:

... and I feel that it's probably because, you know but he, he, he's whole thing was because he was around, he was around, yeah, yeah so um, but um, but then sort of you know like the ah the weeks, then like the months um, it really, you know there were a lot of times where it really hit home, um it started to feel um, such emptiness, ah sometimes it was, it was unbearable you know um I, in the first you know, few weeks, l'd go into the walk-in-robe and you know I could smell, smell him, his clothes, um, and l'd just break down and I, I kept a lot of my um, a lot of people didn't see ah, um that sort of side of me a lot I kept that very private, and um so people saw this you know, someone who's really dignified and holding up, and being very strong, being strong for everyone, and that's what I was doing, on the face of it, but um in the privacy of my own self, um, I would break down, you know for hours just, couldn't do anything, couldn't leave the house, ah I had people asking me to come over to see them, suppose to go you, know to things and ah, I just wouldn't go and um, but they all understood, and I said you know whatever, whatever I'm doing is, you know you just have to understand.

\section{Relationship of findings to existing literature}

The responses that the participants in this research project described are congruent with the existing qualitative and quantitative research and literature. The experience of bereftness led participants to describe ongoing feelings of exhaustion, insomnia, poor concentration, poor memory, emotional lability, impatience, and an overwhelming feeling of sadness. These manifestations gradually diminish over time for most people (Chen et al., 1999; Daggett, 1999, 2002; Prigerson, Bierhals et al., 1997; Range, Kovac, \& Marion, 2000a), however can be overwhelmingly debilitating, for the surviving partner.

The feelings of loss that the surviving partner has, is a phenomenon that is common amongst bereaved people, and forms the basis for bereavement which is 
defined as the: "state of being that results from a significant loss" (Skinner-Cook \& Oltjenbruns, 1998). Bereavement leads to a sense of grief, which is defined as the: "process of experiencing the psychological, behavioural, social and physical reactions to the perception of loss" (Rando, 1993). Rando emphasised that grief is not a static entity, and is a naturally expected response which is dependent upon the individual's unique perception of loss (Rando, 1993).

When someone has died, people often describe their death as a loss, this notion of loss is widely described in the literature (Daggett, 1999; Davis \& NolenHoeksema, 2001a; Gamlin, 1998; Hofer, 1996; Mason, 1992; Murray-Parkes, 1998; Sable, 1991; W. Stroebe et al., 1996; M. Williams, 2001; Wortman \& Silver, 1989). Recent thanatological literature recognises that the experience of bereftness or loss associated with partner bereavement is ongoing and in reality never disappears, with the surviving partner integrating the loss into their lives and adapting to their lives to cope with the changes associated with the loss (J. Costello \& Kendrick, 2000; Daggett, 2002; Davis \& Nolen-Hoeksema, 2001a; Davis, Wortmann, \& Lehman, 2000; Gamino, Hogan, \& Sewell, 2002; Gamino, Sewell, \& Easterling, 2000; Hockey et al., 2001; Levinson \& Prigerson, 2000; Neimeyer, 2000b; Reisman, 2001; Margaret Stroebe, 2001; M Stroebe, 2002; Wayment \& Vierthaler, 2002; Wolfe \& Jordan, 2000).

\section{PHENOMENOLOGICAL EXPLICATION OF THE PARTICIPANTS' EXPERIENCES}

The participants involved in this research project where all in committed relationships that had usually developed over extended periods of time. The love and affection that was an integral part of the relationship shone through in the interviews, even in the one interview where the relationship was undergoing a period of ambivalence. The relationship that the participants had with his or her partner was torn asunder when his or her partner died suddenly and unexpectedly.

The surviving partner's response to the death of their partner is a multidimensional experience that included a host of emotional reactions. The surviving partner was so overwhelmed by discovering that their partner was dead, that they experience a level of shock that was profound. A few of the participants witnessed the death of their partner, which was an agonising experience that had been indelibly imprinted upon their memory. 
The surviving partner's sense of reality was distorted leading to the suspension of their life, as he or she knew it. The surviving partner vaguely recalled the immediate few hours following the death of their partner, describing how they felt numb and as if they were in a haze. The severity of the surviving partner's reaction was from profound shock that involved the feelings of being paralysed or "shutting down" to hysteria featuring screaming, shouting and shaking uncontrollably. The numbness that followed was gradually replaced with a cloud of despair, anguish and misery. The surviving partner described how the realization that his or her partner had actually died, slowly dawned upon them with the stark reality that their shared life with the deceased partner was now over. Despite the finitude of the death slowly taking hold, the surviving partner would often drift in and out of this reality into another more surreal state believing that their partner was still alive, and simply absent from home, to return soon.

The participants who were able to be with their partner's body took the opportunity to reiterate their love for their partner and to say goodbye. This was usually the only opportunity for the surviving partner had to give their farewells to the deceased partner.

The funeral was a time that was dominated by friends and family, with the surviving partner being involved with decision-making, but being aware that he or she were being guided by the funeral director, and family or friends. All of the participants described the funeral as being a celebration of the life of the deceased partner whilst being clouded by sadness and feelings of loss.

Following the funeral the surviving partner had to resume life in a state of disequilibria and disharmony, in other words his or her life had been thrown into chaos. Whilst attempting to come to grips with the reality of the death of his or her partner the surviving partner had to continue to parent dependant children, maintain domesticity, run the family business, whilst being confused, having difficulty concentrating, being emotionally labile, crying frequently, whilst battling with the anger and frustration of having this calamity thrust upon them with no warning.

The surviving partner would often experience bouts of anger and frustration bursting through. These emotions could be directed at him or herself, the deceased partner, family, friends, the medical profession, and hospitals or in the case where a motor vehicle accident caused the death of the partner, the driver of the car.

The overall emotion that was expressed by the surviving partner was that of profound sadness, and the overwhelming sense of loss, emptiness and yearning. 
The strength of these emotions would often be manifested as a pain or ache that permeated his or her entire being.

The surviving partner would often be plagued with anxiety and self-doubt, feeling that a part of his or her being was missing. He or she felt empty and no longer in control of their lives. Despite feeling exhausted, the surviving partner often had difficulty with sleeping and experienced dreams and nightmares.

The surviving partner soon discovered that the experience of grief was ultimately a phenomenon that had to be experienced alone. The void that was left by the sudden and unexpected death of a partner was an intangible entity that led to feelings of vulnerability and loss of a sense of self. This left the surviving partner in a state of flux that retarded him the ability to care for him or herself, especially if he or she had to care for dependent children. 


\section{CHAPTER SIX}

\section{THE SURVIVING PARTNER'S RELATIONSHIP WITH}

\section{SELF WHILST EXPERIENCING THE RECLAMATION}

\section{OF HIS OR HER LIFE}

Eyes must be opened to a new reality. Such an 'opening of one's eyes,' a revelation, can never be given directly in so many words. We see inner reality only through an 'aha' experience, a sudden insight into our own being. There is no way to describe inner reality directly.

John Sanford, (Miller \& Hrycyniak, 1996, p.115)

\section{Introduction}

Having experienced a life-changing event of such magnitude as the sudden and unanticipated death of a partner, the need for the surviving partner to participate in life continues. How each person deals with this experience is uniquely associated with their individual personality, the nature of their relationship with the deceased partner, their age and their previous life experiences.

The sudden and unexpected death of a partner leaves the surviving partner in the situation of needing to rebuild their life which often results in the development of insight and empathy building, the creation of hope and hopefulness which may enable the surviving partner to reconcile and integrate the death of their partner into their lives creating a renewed sense of self.

This chapter explores how the surviving partner used his or her internal and external resources to deal with the impact that the sudden and unexpected death of a partner has had thrust upon them, to enable them to continue to participate and function in life at whatever level they were capable of at the time. The concept of how time affects the impact that the death of a partner has on the surviving partner 
and the assumptions that society make about 'time related recovery' are also discussed.

\section{The surviving partner's previous experience with the death of someone close}

Participants' experiences of the death of someone close to them impacted on how they reacted to the death of their partner. Mary had experienced tragedy prior to her husband's death and described how the death of a child affected her sister:

Yeah, that's right when all these, had so much happen, in such a short period of time and then to you know to have, have this you know it's, cause, cause l'd, l'd had you know quite a bit a tragedy, like at first it was my, my Sister's um child, um Stephen he died of cot death, and um that's now about five years ago, you know I flew back, for um for the funeral and helped, helped her through it, cause ah, you know this was her child and ah she not functioning at all, um and that was you know devastating and that was the first time that l'd actually experienced a death.

Rachael reflected upon how her sister coped following the death of her partner and the contrasting adaptation style she had adopted:

So I think you know, my sister lost her husband I think about six years ago, very suddenly, he had ah, amoebic meningitis and she had two young children, and she had all the family around her, and all the support you could need, and she went to bed for five months, she just couldn't, couldn't even bathe the children, she couldn't get up, she couldn't do anything and I thought to myself I am not going to do that, l'm going to get up, l'm going to go to the (laughs) hairdressers, and I'm going to get out, and I'm going to just keep going, and I'm probably a different person...

Don's mother died 15 years prior to Jane's death, so he had had some exposure to the death of someone close; despite this experience it was Jane's death that prompted him to continue the exploration of the deeper levels of life:

Um I realized that this was, this was a big thing that had hit me. I sort of was aware of that, I not, the only other um death of anyone close that I have had has been my mother she died 10 or 15 years before. So l've not really had any involvement with death really other than that one. I think one instance. Um ah so this was the first time even a close friend had you know, I had any close friends die. Um so um I realized suddenly that I had been hit with something really big and that I needed um, I needed quite a lot of time and space to um deal with this...You know, never sort of um certain sorts of things I've 
never erh faced and all this was something, an area - it wasn't just death but a something more than that but l've just not faced.

Um I have a strong philosophical bent anyway so you know, spent a lot of time trying to grapple this and come to terms with it. And as I say I had no intellectual framework or framework from my upbringing to deal with it. So that in fact, has been an issue that had already arisen some years before. And you know that realm had sort of peaked over the horizon as it were or something. So in a sense I don't know that I got terribly far with that in the last ten years um but it's a sort of ongoing thing.

The death of a partner does not isolate or insulate the surviving partner from other tragedies. In Rachael's life she had to endure several tragic events that compounded her own and her childrens' grief following the death of Kevin. Two weeks following Kevin's death, the father of their son's best friend committed suicide, a couple of month's following Kevin's death his father died, a few months later a fellow student at their daughter's school was badly injured in a horse riding accident becoming a quadriplegic, this was followed by another student's mother dying of a brain haemorrhage. Six weeks prior to being interviewed, Rachael's father had died.

\section{Relationship of findings to existing literature}

The responses that the participants in this research project described are congruent with the existing qualitative and quantitative research and literature. Westernised people have a tendency to relegate thoughts of death to a level that does not interfere with their everyday life (Jones, 1997; Kellehear, 2000). The combination of low infant and child mortality rates and the dramatic increase in life expectancy for the non- indigenous Australian population means that individuals are generally not exposed to death until a grandparent dies (Kellehear, 2000).

The manner of coping that people adopt following tragedy may not be predicated entirely upon by previous experience, however exposure to death and tragedy prior to the death of someone close will often play a part in the surviving partner's ability to reconcile the death and integrate it into their lives (Hogan, Morse, \& Tason, 1996; Kirschling \& McBride, 1989). 


\title{
The surviving partner's experience of endurance whilst participating in everyday life
}

Participants described having to endure the participation of everyday life whether they felt they had the ability to cope or not. The participants in this study all described the need to continue functioning at some pre-death level. The men in this study all described taking a pragmatic approach to life. Brian described his experience:

\begin{abstract}
But after the funeral, after that one week, all of a sudden I felt, you know, like all the grieving was done, you've got to go on with life. Even the next day, about six o'clock, the kids are up, they want breakfast...and no one else is going to do it. I mean, you've got relatives staying there and that, but, you know, you've got to do it. And its like people saying, Brian, how on earth do you do it. Every day the kids'll want to eat breakfast, there's that daily routine you've got to keep with the kids and it keeps you going, you know its ... But after that...intense week... up until Jenny's funeral, then after that, like an amazing weight just sort of lifted off and I could actually feel, sort of, Jenny around for about a fortnight afterwards, you just feel her around, little things that would go right in the house, things that could go wrong go right. And then after that, sort of, that feeling, sort of, went away, of Jenny being around.
\end{abstract}

Having children to care for, directs the surviving partner's life as Sally recounted:

To get on, to get out of bed, l've got to get out of bed in the morning I don't have a choice, l've have to get up, get lan to school on time, to pick him up, to play with Eliah, to make sure their fine, you know, get there, go shopping, take them to the doctor when they're sick, you know I Eliah had a terrible experience in hospital, in December, and um, he's, he's just been my accident prone who got a leaf stuck in his eye causing a corneal ulcer.

The demands of everyday life give the surviving partner little choice but to participate to the best of his or her ability. Four of the women interviewed had partners who owned a business, with one woman owning her own business. They were all suddenly faced with the choice of continuing the business or disposing of it. Rachael thought that she could keep the business going:

Cause I thought oh well I'll try and run the business and I thought, no, it's alright if you don't have any stress, but then (at the time of Kevin's death) I couldn't handle any problem... And I, I had a joint signature on the bank, that was about as far as I knew, I sort of was all the, the how the company, the business was set up, I had absolutely no idea... And then you know I can remember the, the next day, um, I couldn't go down to the business, the poor apprentice was trying to 
sob and run the business and, and um a friend said that he was, um available and he would run the business for me. And cheques to sign, and I'm thinking what am I doing, he said I've got a really good mechanic do you want to employ him and I said oh, do I have to pay him very much and I, he said oh it's whatever and he, and so I employed someone, you know, I employed someone that afternoon actually, to help with the business.

The impact of the death of the business owner extended to customers, patients, suppliers and other business people, which increased the community support for the surviving partner, a factor, which is explored further in Chapter Eight.

All of these women decided to sell the family business. Mary, decided to sell her business because of the difficulties she faced in managing the accounting side following Alf's death:

...you know, the man just is there, and he's the nurturer, he's the ah, the caveman, you know he, he, he, he just does everything, and you just let them do everything, cause they want to do it as well, and I told you how he loved doing everything, I mean he, he paid all the bills, he did everything, I didn't, I mean he did my books, I mean, I can't do, I can't fill in a tax form, ah, you know my business he always did the bookwork, you know I did nothing, all I did was, I'm very good, with people...

The participants often found that they had to take on roles that hitherto had been the domain of the deceased partner. Dana explained her situation:

It's all the little things you have to do. You know you've got to pay all the bills. You've got to keep everything up to date. I never had to be a maintenance person before, because Carl was.

Other female participants described similar experiences, regarding home maintenance and having to hire people to perform home maintenance that their husbands would normally have attended to. The surviving men had to face role change challenges that included undertaking domestic chores as David explained:

$\mathrm{Hmm}$, and so you know you don't, you don't have the same, time to, to dwell on things cause it's, it takes you four times as long to cook dinner as it, you know I mean it used to take me forever to you peel potatoes and boil the water and get the co-ordination of getting the food on the plate at the same time for everybody you know so yeah it wasn't a disaster and it wasn't a success, it wasn't um, it wasn't excessively stressful it was just time consuming you know and um, yeah, so yeah these meals arrived every you know every couple of days from the people from school, um and the school was very ah supportive. 
Participants often described the business of everyday life as a useful distraction, allowing them to go into automatic mode, feeling as though they were useful, and still being able to contribute to family life, whilst keeping the surviving partner active and making them tired enough to sleep at night. Brian described his experience:

I can still remember the thoughts that were going through my mind, yes, two years ago, and as I said, on day one, the kids have got to be looked after, the kids have got to go off to day-care; you've got hundreds of, you've got to wash, you've got to wipe, you've got to do all the things that your wife would do around the house ... as well.

There was a perception amongst the male participants that it would be easier for a widow to maintain a semblance of normality following the death of her partner due to her pre-existing parenting and domestic skills as David explained:

I think that's where women probably are fortunate when they lose there partner that, your fundamentals, their fundamentals don't change, in other words their still looking after the house and keeping the house going whereas my fundamentals were, I go to work and come home.

David didn't mind participating in domestic duties when Loma was alive, it was having the burden of this responsibility full time, whilst still having energy and time to spend quality time with his children that concerned him. David decided not to return to work so that he could give his children his full attention.

Having to continue to provide nourishment for him or herself and their children can be both a burden and a task that provided the surviving partner with useful chores that filled in time and again provided a useful distraction, as Sally explained:

...yeah, just thinking about food, I mean I did all the shopping um, the main shopping, if I, if I didn't buy the right things I would go the Growers Market with the kids, and have a great time.

The men described shopping and cooking as tasks that caused anxiety, feeling that they were unprepared and probably unsuited to the task, David described his experiences:

...my cooking skills were zero, and so really that was a whole, learning curve for me, um you know, I mean I think it took me three hours to do the first shop, you know it was like go through and thinking wow, what do I need (laughs) is that worth that price, is this you know what are the specials and bargains and all that sort of shit 
you know, and so as I said in one of my Christmas letters you know I've got to the point now where I can go shopping and I don't even have lists you know, so yeah, and so it was really just...a learning curve, it occupies your time and it's, it's saturates everything that you do, and so, um, it's probably a mental out for you, whereas I suppose women, still doing what they're normally doing but they're got this void, this is created whereas I got the void but I have to do other things.

Overall the participants felt that having to deal with everyday life was important in that it motivated them to get out of bed in the morning and go through the rituals that are associated with providing for family and maintaining a home. Obviously there were times when participants felt the task of managing both family and home burdensome in their new solo role, but overall the need to be needed and the distraction that it provided was seen to be therapeutic.

\section{Relationship of findings to existing literature}

The responses that the participants in this research project described are congruent with the existing qualitative and quantitative research and literature. The men often described 'working' through their grief which is a well documented approach often taken by men (Caverhill, 1997; Chen et al., 1999; Martin \& Doka, 2000). The problems associated with role change following the death of a partner are well described anecdotally on Internet Web Sites such as Griefnet and Widownet. The male participants found that taking on domestic roles was challenging, with the female participants having to also adapt to a new role that included financial management and home maintenance, which is a well documented phenomenon (Brabant, Forsyth, \& Melancon, 1992; Caverhill, 1997; Hustins, 1993; Lund, 2001; Martin \& Doka, 2000; Quigley \& Schatz, 1999; Staudacher, 1991).

\section{The surviving partner's experience of his or her own health and well- being}

The participants in this study generally remained in good health, with three participants describing stress related health problems. Lyn described how it was a friend who advised her that she should seek counselling because she was frequently unwell:

So, when this guy said, go to the you know the psychologist friend of mine, might help you with your self esteem issues (laughs) I thought oh, can't harm and by then l'd been crying a lot too, I think when I walked into his surgery I was in tears as well, and fifteenth sore throat which I need antibiotics for and, um they wouldn't give me antibiotics 
anymore and I was just distressed, cause I wanted these antibiotics (laughs).

Following Geoff's death Lyn lost approximately $60 \%$ of the colour of her hair, and kept seesawing between gaining and losing weight. Lyn used up all of her paid sick leave from work, and was 'Doctor Shopping' with several doctors offering to prescribe anti-depressant medication, which she would start to take, then stop, feeling that she didn't need medication. The last doctor she consulted performed a variety of blood tests that revealed that she was suffering with iron deficiency anaemia. Lyn was relieved to find a physical cause for her somnolence and apathy.

Sally described losing all interest in food and losing six kilograms from her original 54 kilograms during the first few months following Peter's death, describing herself as appearing skeletal. Adam gained weight, with his fitness suffering, due to lack of exercise that he found difficult to find the time and inclination to perform. At the time of interview he was looking forward to taking up running again, not only to lose weight and increase his level of fitness, but also to increase his energy levels. Rachel described how hard it was to make the effort to perform physical exercise when feeling depressed, despite this she made herself swim three times a week and walk everyday. Rachael forced herself to go for her usual walk the day after Kevin died, and described the difficulties she encountered trying to avoid the media:

I forced myself to go the next day, and did a normal walk, tried to dodge the press and (laughs) went the other way and they came the other way but I did, I wait on, I for the first six months I used to sort of not walk on a Saturday and Sunday, even walked on a Saturday and Sunday only because I thought it was, oh I felt it was quite important for me to um face what had happened, and then fitness and keeping well, cause I was very conscious of (this).

\section{Relationship of findings to existing literature}

The responses that the participants in this research project described are congruent with the existing qualitative and quantitative research and literature.

Following the death of a partner the surviving partner has had to deal with pressures that he or she may have never faced before, which may result in increased levels of ill health, increased accidents and greater risk of morbidity (Bowling \& Windsor, 1995; Jagger \& Sutton, 1991; Prigerson, Maciejewski, \& Rosenheck, 2000). The majority of participants managed to maintain reasonable levels of health and wellbeing. For one participant the stress of the grief she was experiencing manifested itself with a decreased ability to ward off infection. Three participants 
complained of problems maintaining their weight following the death of their partner. Most participants described how important physical exercise was in enabling them to think clearly and not feel so stifled by the sadness that clouded them. When asked whether any of the participants had experienced an increase in accidents or injury amongst him or herself or their children, none believed that there had been any significant increase.

The risk of increased mortality and morbidity upon the surviving partner not only has a great impact upon the individual and their family and friends but also has an impact upon society in general. Prigerson and colleagues calculated the increased health costs associated for widows following a harmonious marriage compared to those widows who had experienced an inharmonious marriage (2000). The authors found that on average the annual health costs for those widows who had a harmonious marriage were $24 \%$ higher than those widows who had experienced an inharmonious marriage (Prigerson et al., 2000, p.349). This was the reverse for when the women were married; with the women who were in inharmonious marriages utilising health services $31 \%$ more than the women in harmonious marriages (Prigerson et al., 2000, p.349). These findings are interesting, given that all but one of the participants reported having a harmonious marriage.

\section{The surviving partner's experience with the use of alcohol and other drugs}

Three participants were prescribed sedation to help them with the insomnia that they experienced in the first few days following the death of their partner. No participants remained on sedation for more than a few days. These participants described how despite being mentally exhausted they could not sleep without medication for the first few days.

Three participants were prescribed anti-depressant medication by their family doctors. Adam described his experience:

Yeah, I take, a low therapeutic dose of Zoloft. I try and get off that every now and then...I don't fear the sadness overall because I think that I'm working through some of (with) therapy...I might have some anxiety about not taking an anti-depressant albeit a low dose, is that if a don't take it I feel overwhelming sadness, its just my own ability, you know, just er, thinking, l've got to be at work at 9 o'clock to do a tute, you know, 9 to 1,2 to 4,4 to 6 , you know, l've got to get my little girl dressed for school and dropped off at the Baptist at 8.20 and deal with the city traffic, she loves that so much ... and I'm worried, you 
know, about road rage! Things go wrong, you know, and l've lost it on a few occasions. You know, l've lost it on a couple of occasions and said fuck this, that could happen anyway, but its just that its me, it seems like its me doing it all and even if, you know, you probably have days like that, its not that unusual, but at the end of the day, there's, you know, l've got no-one to love me in my bed, you know, and that's, oh ... No-one to help do Dannie's hair, and you can only, you know, that's the sort of...

The lack of partner support revealed itself not only with the minutiae of everyday life but feelings of loss of companionship, love and affection and ongoing friendship. This resulted in an overwhelming feeling of sadness for all of the participants. A few participants sought professional help when the level of sadness encroached upon their ability to function effectively. Tina was advised by a friend to consult a clinical psychologist:

Lesley suggested that I go and see $X X X X X X X X$, who was a Clinical Psychologist with um research areas in bereavement, and that type of thing, and I was sort of like falling in a heap, so I went to the Doctors and ah I told her that, and that I was going to see $X X X$ $X X X X X$, and she put me on Serapax, so I started off on half a tablet, and I'm on only half a tablet now, but I was taking a whole tablet for about nine months, and my dreams I thought when I went down to the half tablet they would be, better.

Unfortunately for Tina, she was finding the dreams that were very disturbing, weren't helped by the medication.

Two participants reported a significant increase in alcohol consumption following the death of their partner. Adam went to see his family doctor because of the anxiety he was experiencing:

I...had, those sorts of anxieties for a couple of weeks, were I used to worry that I might die, you know, and all of the kids would sit there with me at some stage or other and particularly Danielle, ... I mean, he actually took blood and so forth, and then when I went back to see him he was talking about gamma GT, you know, the level was up a bit because, he said have you been drinking! Have I been drinking! Towards a bottle of whisky a day....No, what I had was a couple of big, bloody (benders).... ones, you know. In fact, my mate, Pat, my mate's a very big drinker and we drank two bottles of whisky in one night. You know, and some wine. I thought I might have really died and the ICU looked after me and ... don't want to talk about that.

Lyn's experience with her increased alcohol consumption was in the public domain. Lyn met Geoff at their local pub where they eventually had their engagement party and wedding reception, as well as Geoff's wake. They were a 
popular couple at the pub; following Geoff's death Lyn began drinking to the point of needing help to get home:

...it was a time I can't remember too much of, I started to drink...so after work I would go, from work and I would walk in, to the pub, and I would have, either a lemonade or l'd have a glass of red wine and then I would walk out because that was a routine, and when I establish something that I knew that, that would happen at five o'clock, you know when I could leave I could go there and then I could came back to a empty flat. Yeah, so it became a real habit. ...people, who knew what had happened became very supportive at the pub, and again, even as flaky as I was, and you know falling on the floor or whatever they just, looked after me and got me home and, yeah I went through some terrible times there, in the sense that, oh you know, I'm not, I'm, I'm not proud of, you know falling over in the street and, you know drunk, So and as I say my girlfriend, was really wonderful in those days, she just, pulled me out, put me to bed, you know, very lucky...

Lyn's drinking represented her feeling of reckless disregard for her own wellbeing which she described as being the result of an ongoing feeling of rejection from the men she had previously been involved with, and then experiencing what she felt was the ultimate rejection from Geoff:

So I had that sort of, I just didn't care, didn't care what happened to me, at all, I was obviously, not good enough, you know, everything had gone wrong, and l've been rejected by all these men, I mean this man said he'd never leave me, and he drops dead (laughs)... that's terrible, ultimate rejection, yeah, so, yeah I don't know how I really got, as I say I don't remember much about all that, but I did some very stupid things in that time, yeah.

Lyn gradually reduced the amount of alcohol she was drinking, due to the need to be more alert at work in order to deal with increasing work pressure. She discovered herself channelling her anger over Geoffs death by responding to aggressive clients with aggression herself.

The use of alcohol caused problems for Sally who described how guilty she felt by having a drink:

I didn't drink, for um, a couple of weeks really, I remember, I don't remember what day it was, it was before the funeral and we'd finalised all the arrangements, I think Sally and Ben were there and you know come and have a drink, good bottle of champagne... so I poured myself, we are, we all had a glass of champagne and um, somebody arrived to see me, and I couldn't go out there with a glass of champagne, I felt so guilty. 
Sally eventually, started drinking alcohol without the associated guilt, and enjoyed the experience because it so much reminded her of the shared love of good food and wine that she had enjoyed with Peter:

It took a while to open a bottle of wine in the evening, if I was by myself, because (of the memories). And funny things, um Macca loved the way wine sounds, that first glass you pour when it sort of goes, glug, glug out of the bottle makes that beautiful noise and um, I just like pouring that first glass, cause that's like his (love).

\section{Relationship of findings to existing literature}

The responses that the participants in this research project described are congruent with the existing qualitative and quantitative research and literature. Most of the participants did not increase alcohol consumption or admit to using recreational drugs. The two participants who had difficulty managing their alcohol consumption eventually reduced their consumption to manageable levels. Increased consumption of alcohol and pyschotrophic drugs (both prescribed and illicit drugs) occur in people who are recently bereaved (Rando, 1993). The need to alleviate pain and loneliness are the most common reasons that bereaved people increase his or her use of alcohol and pyschotrophic drugs (Rando, 1993). Alcohol is the most common mood altering substance used in the bereaved population, with the Parkes and Weiss study cited in Rando reporting that alcohol consumption increased in $28 \%$ of the bereaved population studied (Rando, 1993).

Three participants required sedation to assist with insomnia, and three participants required anti depressants to help them deal with ongoing depression, which in total represents $40 \%$ of the participants, despite the small sample, it is interesting to note that it compares to $26 \%$ found in the Parkes and Weiss study (Rando, 1993). The continued use of pyschotrophic substances is considered to increase the risk of complicated grief (Rando, 1993).

Symptomatic Major Depression (SMD) and Subsyndromal Symptomatic Depression (SSD) has been has been noted as a common problem associated with partner bereavement (Zisook, Shuchter, Sledge, Paulus, \& Judd, 1994). One study found that up to a third of surviving partners had SSD two months following the death, with $28 \%$ at 12 months and with $9 \%$ increasing in severity after 12 months (Zisook et al., 1994). These results need to be considered with caution, with clinical manifestations of depression and grief being very similar (Rando, 1993). Rando cites Jacobs and Lieberman (1987) who assert that clinicians should be concerned if the bereaved person is suffering the clinical manifestations of SMD six months or a 
year following the death, or have a delayed onset after several months, result in profound self esteem disturbances, psychomotor retardation, suicidal ideation, cause subjective distress or impair social or occupational functioning. If these problems are identified then the bereaved person may be considered to be progressing into an ongoing depressive illness (Rando, 1993).

The statistics quoted from the previous studies cited above have been used to place the participants of this study into context with a greater population. The results of this study cannot be generalised to the greater population due to the small number of participants.

\title{
The surviving partner's experience of creating diversions as a method for filling the void left by his or her deceased partner
}

\section{All of the participants described the need to keep him or herself 'busy'} following the death of their partner. The death of their partner created a void in the surviving partner's life that he or she recognised was not going to be filled quickly or easily, so by creating diversions the surviving partner created a method that could fill the real time and space that they now had whilst masking the emotional emptiness that they experienced.

Returning to work was one way of filling in time and creating a diversion. Jane described the trauma of returning to work soon after Graham had died:

\begin{abstract}
I remember driving back from Denmark on Australia Day and going to school the next day, and the Dean of Perth and I can't remember what his name is um, stood up and he always welcomes staff at the beginning of the year and tells a funny story, and the funny story he told us was about a funeral that went wrong, how the coffin fell off the car into the lake and, and I'm sitting there and then at the end they, what you know, they encourage um suggest to people, suggest is a better word I think that, come and light a candle at the beginning of the year and the music they played was the music they played at Graham's funeral, so I just sat there and I absolutely lost the...I just cried and cried and cried and I thought my God how on earth am I gonna do this and two days later there I am teaching um ten classes of boys, I have two hundred and fifty boys and that was it, and so it was all a bit of a, I mean it was probably the best thing for me to do was to actually go back to school and get into, back into some sort of routine.
\end{abstract}

Jane went onto describe how she tried to keep herself as busy as possible for the next 18 months, lunching with friends, going out with people in order to fill her days up as much as possible. Jane's insight into her need to keep herself diverted from her situation didn't occur until the second year, as she explained: 
And I think the first year is such a blur, was such a blur, was such a I don't know like a full on busy year and then, the second year you actually think "Oh hold on this is actually for real", cause the first year is just such a blur.

Other participants describe similar situations, occupying him or herself with sporting and recreational activities, immersing him or herself into their children's lives, finding things to do that deflected them from the fact that they no longer have a mate who had occupied a significant part of their life.

The void that is left following the death of a long time partner is a concept that the surviving partner often found difficult to deal with. The surviving partner found himself or herself in a situation of needing to find diversional activities that he or she enjoyed, however most of these activities were usually shared activities that reminded them of their deceased partner, which is supported in previous research (Costello, 1999; Gamino, Hogan, \& Sewell, 2002).

\section{The surviving partner 's attempts at maintaining previous shared experiences}

Several participants described pursuing experiences that they had shared with their partner prior to their death. These participants felt that they should be able to continue to enjoy a pastime or recreational endeavour, despite the death of their partner. They also believed that by doing so it would enable them to maintain some link with their deceased partner. Despite having the experience of your husband dying at his favourite beach in tragic circumstances, Rachael refused to stop visiting the beach that was so much a part of their lives, and returned the next day:

I decided I had the attitude that I would do it (go back to the beach for her early morning walk). And I think I decided that on the day that Kevin died, that I was gonna do it, and I'm only a small person who, that normally would be fairly quiet but, and we were, we did everything together, so I was never used to going out on my own, so I found that was huge. I go down (to the beach) every day as well, I went the next day. I forced myself to go the next day, and did a normal walk, tried to dodge the press and (laughs) went the other way and they came the other way but I did...I wait on, I for the first six months I used to sort of not walk on a Saturday and Sunday, but I even walked on a Saturday and Sunday only because I thought it was quite important for me to face what had happened, and then fitness and keeping well, cause I was very conscious of supporting the children and whatever problems they had in their lives, staying strong, to get them through. 
Returning to previously shared holiday destinations was done by several participants with mixed feelings, all of them returned with family or friends to support them, as Dana described:

Yeah so we had we did go and oh it was just so hard. But we had
adjoining cottages with very close friends and they helped me
through it all. You know girls I went through Uni with and school.
They came and stayed I mean he was all around me, in every bay.
You know we used to go diving in the bays together. Somehow
facing it, and doing it, worked for me. I sort of think about that, I feel
that connects me with Carl.

Continuing to attend previously shared sporting events is an important way of both maintaining the memories of the deceased partner as well as pursuing a past time that the surviving partner still enjoys. Rachael found it a comfort to maintain her membership of an Australian Rules Football team, and continued to attend games:

So I made sure, the kids couldn't come with me to the footy initially, because that was just happy memories and they felt too sad to come, but I renewed the membership there, the same, kept the same seats, and the people...

Several participants described how important it was for them to continuing to pursue experiences that they had shared with their deceased partner. Despite the initial pain that these experiences caused, all of these participants reported that they drew comfort from the memories that were evoked from these experiences.

Thanatological texts that are designed as 'self help books' often advise the surviving partner that maintaining shared experiences following the death of a partner is an important step in the rebuilding and reclamation of the surviving partner's life, whilst organising the memories and stories of the shared life in a way that is comforting to the surviving partner (Zonnebelt-Smeenge \& Vries, 1998).

\section{The surviving partner's experience of the use of music, and poetry as aesthetic therapy}

Most participants described using music as a means to ameliorate the pain that they were experiencing from the death of their partner. Don articulately described his use of music following the death of Jane:

Um I played music a lot. I played music a lot anyway just because I enjoy music and I like um, I enjoy music and I find it very um good for me. And I often find myself, I sort of just in the normal course of 
things sort of searching through my mind or search through my CDs for the piece of music that I'm needing for that what's happening you know sort of how I am sort of feeling. Um and I found two or three pieces of music that I, I played just constantly for virtually a year and certainly for six months. And um one curious thing was, like one of them was a, choral thing, Kings College Choir, Cambridge and a number of different pieces. And there was two or three of those sort of tracks together that I played a lot. And I um the curious thing was that one of them I, I you know after six months or so I went and looked - what are these tracks and one of them was um I think it was by Croft, the burial service for the dead. And I um sort of, it was primarily the music but there was also some and I was listening to the words, a bit matched but I almost sort of subliminally. I found I thought, "oh this is pretty interesting." This is interesting. Um but there was a few pieces like that and there was another piece I remember that $\mathrm{I}$, it was a piece by, the piano piece um it was Schubert and the particular recording I had was played by a very outstanding pianist who died when he was in his early 30's from leukaemia I think about fifty years ago or something like that. When there was no treatment and that sort of stuff. And, and the recording was actually I think probably the final concert he actually did so it was made you know like a few days before his death. And I played this many, many times over and over. It's a very um erh a very beautiful, extremely beautiful but with a kind of sadness in it to. And I think as much as anything um what it did like to me was like a sense of time. You know like I would often cry listening to this thing and I think it was something about the briefness of time and this young man and how he was going to die within a week. And you know the shortness of time and um there's like two currents, many currents in this music. There's one current which is sort of this left hand rolling sort of bass which is sort of like the in exorability of it, you know like in exorability of time. And then there is this upper hand stuff, which is just incredibly beautiful, surreal. And joy really joyous sort of stuff and this amazing sort of combination that somehow he could do this, at this point. Give people this.

The use of music was important in that it allowed the surviving partner to relive shared musical experiences that they had with their deceased partner, as well as having an aesthetically therapeutic effect upon them. Being able to play music was also important for two of the participants.

For Dana the reading and writing of poetry was something of which she derived comfort from following the death of Carl, as she described:

I got out all my old poetry books and I learnt poem after poem after poem after poem so that I didn't think (laughs). I didn't sit there and think or listen to music that would be terrible. I learnt so many verses of poetry you wouldn't believe, and then I got story tapes from the library and ran them all the time so. There are days when bit of music or something sends you off and you become as miserable as a you know a cold turkey... at the time I was writing a children's story and it was about a little Girl and her brother who lived with their 
mother up in a mining town, his and his Mother got killed in an accident and I, I was writing it at the time and it actually kept me sane. My business partner Val used to come and sit with me, l'd write it over and over again. I'd go over those chapters, but I did write a lot of those feelings in there. And I wrote poetry, yes I did and I wrote poems to Carl.

Dana recounted how a poem titled "High Flight" written by Jonathon Gillespie Magee in 1941 (Ames, 2004), a fighter pilot during World War Two who was killed in action, meant so much to her. Dana believed that if there was such a thing as a soul, then Carl would be: "...soaring in the clouds and the sun tipped clouds." The poem is included below:

Oh, I have slipped the surly bonds of Earth

And danced the skies on laughter-silvered wings.

Sunward I've climbed and joined the tumbling mirth

Of sun-split clouds - and done a hundred things

You have not dreamed of: wheeled and soared and swung

High in the sunlit silence, hov'ring there,

l've chased the shouting wind along and flung

My eager craft through footless halls of air.

Up, up the long, delirious, burning blue

l've topped the wind-swept heights with easy grace

Where never lark, nor even eagle flew;

And while, with silent, lifting mind, l've trod

The high untrespassed sanctity of space,

And put out my hand and touched the face of God.

Music and poetry have the power to evoke very strong images and reactions. When her favourite music was played on the radio, Sally described how she could become very depressed. Several participants described how when hearing the music that had been played at the funeral, transported them back to the day of the funeral which could cause distress at times.

\section{Relationship of findings to existing literature}

The responses that the participants in this research project described are congruent with another study by Range, Kovac and Marion (2000). Using art, music or the written word can allow the surviving partner to be emersed in a medium where his or her experiences can be explored, with the aim of developing insight and understanding. Writing is a therapeutic device that is often recommended by 
bereavement counsellors for people who are having difficulty expressing themselves to others, or would prefer to keep their thoughts private (Range, Kovac, \& Marion, 2000).

\section{The surviving partner's experience with the presence of the deceased partner}

Several participants described experiences where they felt that they were in the company of their deceased partner. All of the participants who described experiencing the presence of the deceased partner recalled that that the presence was comforting and reassuring, with the deceased partner being perceived as attempting to give support and reassurance to the surviving partner that they could cope and that they were not alone, such as was Brian's experience:

But after that, that week of intense week of, up until Jenny's funeral, then after that, like an amazing weight just sort of lifted off and I could actually feel, sort of, Jenny around for about a fortnight afterwards, you just feel her around little things that would go right in the house, things that could go wrong go right. And then after that, sort of, that feeling, sort of, went away, of Jenny being around.

Mary felt that her dog was aware of the deceased partner's presence:

Oh it's amazing, and the dog, the dog saw him, oh he must have, you should have seen, it was so eerie one night I woke up the early hours of the morning I just, just, just was woken and I'm just walking, and it's completely dark and I just put one of the lights on and the next minute I could see Joey's out there and he's just looking in, and he's like looking, over, at something, and there's nothing there that I could see.

Jane's experience of Graham's presence is strongly linked to her dreams, which frequently feature him in a supportive role:

And the night of Ann's Ball um we all went to a friends for pre-Ball drinks and I walked down the driveway um when she got into the Limo and I turned around and I could have sworn that Graham was there um yeah at first, when he first, he ah always behind me, always standing behind me and um apart from the time when I left Jan's and he was standing next to me um, and it's, it doesn't, it just, it's not even when I've really been thinking about him, it's just all of a sudden I think oh, hold on, what's going on here and then I have, yeah I have the, dreams I have are fairly constant to, of it's all a mistake um, he's only been up North working and he comes back and it's always, in all the dreams it's always trying, helping me. 
Jane also described how she felt that Graham was with her when she went

to see a counsellor for the first time:

...the first time I went to see Jan the counsellor, I um I walked out of her house and I was walking down her driveway and I had an, an incredible, incredibly strong sense that he was walking by my side with his arm around my shoulder and he said to me good on you.

Only one participant had the presence of the deceased partner confirmed by another person, which was Rachael who described how her mother witnessed the presence of Kevin at the same time:

...the first, week he died, I could hear him crying outside, I'm sure I could, my mum said she heard sobbing to, absolutely, it just sounded like him crying outside, you know, it was just, it was awful...

Other participants' children had also described to their parent how they were aware of the presence of their deceased parent.

The only episode of paranormal phenomenon that was described by the participants occurred to Mary:

But there was, you know, um a couple of unusual things that happened in his room, one was um with a little candle that (was) from his Graduation um it's one of those wide ones, and um ah it started to flicker, out of the blue, it was flickering and it wouldn't stop, until you know he called me in, and ah, I just, I just broke, and broke down and said it was your Dad, I said your Dad's trying to, connect somehow, somehow the energy you know, he found a energy field and ah, yeah that's, that's, that's well that's what we, you know...

Most of the participants described talking to their deceased partner as a way of maintaining a dialogue with the deceased partner, whom they sorely missed, as Don explained:

Um I spent a lot of time talking with her, like I was living alone by myself. So actually quite a lot of time talking with her. Just um sort of, I suppose a lot of it was conversations that we might have been having if she was still alive...just exchanges, conversations that ah I would like to have had. Or just sharing things I had done during the day or things that had come up or thoughts about her just um. So that um I guess most of that was just talking to her, talking out aloud but to myself. But I did that quite consciously know that I was doing that and feeling that it was a good thing to do.

The main reason the female participants found that they talked to their deceased partners was to ask their advice, or to seek help and support. Carol 
spoke of this: “... a few times l've said to him, get off your backside and give me a hand, I need your help, um, yeah his presence isn't, like I thought it would be, got to say that, but I don't feel alone, alone..."

Feeling the pressure of being a sole parent, some participants would ask for support from the deceased partner in caring for the children, as Sally described: "Yeah, I'm asking him a lot, at the moment I'm saying to him what am I doing with these bloody kids, please help me, work it out, help (laughs)."

Other participants often gave his or her deceased partner updates on what has been happening in their lives or asking their opinion about things that the surviving partner is doing, such as Rosalie:

...I might, you know talk to him something happens and I might say you know, what do you think of that kind of thing. (Something) would happen I'd make a mental note or even write it down you know I must tell Charlie about this when he comes back, um and I'm, just sort of slowly not doing that now...because I know, after you've been together for that long. You know l'd have a pretty fair idea of how he would react to something, if he'd think what's. Whether he would laugh about it or look concerned and that sort of thing.

\section{Relationship of findings to existing literature}

The responses that the participants in this research project described are congruent with the existing qualitative and quantitative research and literature. Several participants described being aware of the deceased partner's presence. Most of these encounters were described as being of a comforting nature. Having conversations with the deceased partner was also described. The awareness of the presence of a deceased partner has been well documented over the last two decades with many people reporting encounters with people who they have been close to, as well as experiencing paranormal behaviour (Bennett \& Bennett, 2000; LaGrand, 1999; Moody \& Perry, 1993; West, 1998).

\section{The surviving partner's experiences with the need to have time and space to grieve}

The participants all described the need for time and space to grieve for the loss of their partner. A significant number of participants described how they internalized his or her grieving in order to not appear to be taking longer than expected to deal with their grief, as Dana explained: 
You know, laugh and the world laughs with you, cry and you cry alone. And that's perfectly true. People don't want to hear two and a half years down the track (or whatever) that you're still (grieving).

The participants all reported how they gradually became aware of the incongruity between the societal time limits of the bereavement period, and the actual ongoing bereavement experience the participants were living through, as Rachael explained:

...um, you know you have your days where you absolutely don't want to cope but I can, I know I can and the kids can see that and they know they can too, but um you know people just have this concept that um, well that was six months ago, so you're right now, she' right, she's (laughs) doing it, yeah.

Some participants recognised that it would be inappropriate to get involved in another relationship until they had a reasonable amount of time to deal with the effects of the death of their partner, such as Don:

...I also made a very conscious decision that I wouldn't get involved in another relationship for at least a year or 18 months or so and I didn't. Um and that was very enormously valuable. That was a conscious decision, you know I needed time; I needed space that's all.

It also takes time for the surviving partner to adjust to the alteration in their status as a widow/er, which is discussed in more detail in Chapter Ten.

Sally described how Peter's mother was having difficulties dealing with the burden of caring for her dependent husband whilst attempting to incorporate the death of her son into her life at the same time:

And his poor mother, I mean you know, I speak to her on the phone and you know, she said to me, I still can't believe he's not here, I said I know, I'm the same, she said whenever I um, get Michael settled, and I stop thinking about him for a second, l'm just flooded with Peter thoughts, and she's still crying and you know, I think you poor woman, you've got no time to grieve, and you, your nursing your husband, it's horrible, horrible, horrible...

During the first few weeks following the death of their partner the participants described how inundated their lives were with family and friends. Despite the family and friends being well meaning, the surviving partner often needed to be alone to process what had happened to them. The bombardment of extra stimuli created by 
people taking over roles to assist the surviving partner can crowd them to the point where they have to isolate him or herself to cope, as Jane described:

Um, but the day of the funeral um, yeah there were quite a few people who um, came to the house bringing food but I, I didn't see them, I was sort of spend quite a bit, just time sitting in my room um, and then yeah just when we went, oh I was completely, shut down not at all, not present...

One method of creating space for Don, was to use meditation to help give his mind the room it needed to process the effects of his grief:

Um one thing I did was I decided that I would meditate regularly, um I had meditated on and off for 10 or 15 years you know. I had done meditation about 10 years before occasionally. So I had decided that I would you know regularly meditate and the way I did that was I went to an introductory class of 10 weeks or so and I did another 10 weeks. So you I sort of, I actually did meditate pretty much daily for that year, and also for quite some while after that. So like you know some two or three years after that. And I think that was tremendously valuable.

\section{Relationship of findings to existing literature}

The responses that the participants in this research project described are congruent with the existing qualitative and quantitative research and literature. The need for the surviving partner to have a balance between the need for solitude and contact with family and friends is a nebulous concept that was poorly articulated by participants, and will be explored further in Chapters Seven and Eight. For the surviving partner to be able to process the myriad of emotions that they are experiencing following the death of their partner, they need both active and passive support from family and friends, whilst having time alone (W. Stroebe, Stroebe, Abakoumkin, \& Schut, 1996).

The lengths of what society believes are acceptable bereavement periods and the behaviour of the bereaved person are culturally dependent and have altered over time (Jones, 1997). Jones (1997) claims that in Australia most people do not follow strict protocols on how and when they should present him or herself to society, unlike the Victorian period when guidelines were quite prescriptive:

Widows usually wear mourning for two years. Diamonds and pearls are frequently worn with deep mourning...but gold is not usually worn until a year has passed. A widow is not expected to go into Society until at least three months have elapsed. Even then her visiting is 
confined to relatives and intimate friends. Gradually she reappears, though she should avoid dances and balls for at least a year (p.22).

The lack of any identifying clothing (such as black) and the absence of any reintegration guidelines for the bereaved person to re-enter society, leaves the bereaved person with no formal recognition or protection for that matter, from people who assume that grief is a finite phenomenon that completely diminishes over a prescribed timeframe. All of the participants in this research project believe that the community is out of touch with the reality of what they have experienced, a view that is supported by current theories of grief and bereavement (Hyrkas, Kaunonen, \& Paunonen, 1997; Steen, 1998; M. Stroebe, 2002; M. Stroebe, Gergen, Gergen, \& Stroebe, 1992; Walter, 1996; Wayment \& Vierthaler, 2002; Zisook \& Shuchter, 1985; Zonnebelt-Smeenge \& Vries, 1998).

\section{The surviving partner's use of humour and laughter as a therapeutic device}

The interviews for this study were not maudlin events. The participants were engaging and often animated in their enthusiasm to recount their stories.

Participants often laughed during the interview when recalling humorous events or when reflecting upon their lives with fondness. There were times during the interview when participants were either close to tears or occasionally cried, but on the whole the participants delivered their stories in a manner which was respectful to their deceased partner but also in a manner, which was well articulated, and in a conversational way that flowed freely.

Participants also described the use of laughter as a therapeutic device that could alleviate sad times, and help the surviving partner transcend the sadness and finality of their partner's death. Jane described this process:

...what's really important and I think also what's helped me um and I was very good at it for the first year was just ah, taking a day at a time and making sure that sometime during that day I, I had a laugh with the girls (her daughters) you know just, just doing that, not trying to think about the future where as when Graham and I were together we always thought about the future.

Rachael referred to the healing properties of laughter:

....and I think that's absolutely the best medicine, you've got to laugh every day. ...we laugh, we laugh at everything, as soon as we get down there we laugh, we find something to laugh about (laughs), and we do, we laugh and we laugh and we save up jokes... 
It may come as a surprise that the interviews were often punctuated by laughter, with the participants' use of laughter a sign of the need to lighten the conversation. Humour and laughter when used appropriately and with sensitivity, can allow the surviving partner and those around him or her to feel a sense of normality.

\section{The surviving partner's experience of significant dates and anniversaries}

One of the most difficult experiences that the participants described was that of experiencing significant dates and anniversaries for the first time. Sally was the only participant not to have been bereaved for twelve months or more, and described her experiences:

...(I) suppose l've still got a few more firsts to do, haven't I? I feel very, I feel very flat leading up to them too, I feel very anxious, I get very snappy with people and you know, and I know why, I hope they do (understand) (laughs)

Other participants who have experienced significant dates and anniversaries all described how difficult it had been to negotiate their way through the day whilst attempting not to dwell too much on the same day last year when they were experiencing it with their partner.

Christmas is characterised by the close involvement of family and friends, coming together to give and receive presents. As Christmas is fundamentally about the celebration of birth and life thereafter, it is a poignant reminder to the surviving partner and their family that a significant member of the family is no longer with them.

Some participants described the Christmas celebrations as being a positive experience because where they were surrounded by family and friends as well as their children and were able to draw comfort from that, as Sally explained:

We had Christmas Eve there (at her parents house), which was lovely cause, Dad's such a big kid at, he always has been, Christmas, he just loves Christmas and when we were kids you know, it was just the best fun for him so, and he just loves doing it, so he writes them a letter from Father Christmas. Yeah he's very good, and yeah so, Christmas Day was really, was really nice I was just with the family...

Other participants described the experience as difficult, with him or herself and their loved one's going through the motions, celebrating an event that had lost 
it's previously held status as a special time of love and sharing, as Rachael described:

I mean I can remember um, in December I took the children um Christmas shopping, and I thought well you know l'll just, take some money out and we'll just, go Christmas shopping, and we sat at Karrinyup, just looking around, and there was absolutely nothing that we wanted. Yes, my Parents came back and we had Christmas together and then ah, yes they were (there), (it was) not, not a very happy time at all.

Having to organise Christmas gifts, cards and all of the other things that are required to prepare for an event such as Christmas, was difficult for the men, because they had relied so much upon their partner who normally fulfilled this role, as David explained:

Initiating the making of cards or the buying of presents and all that sort of stuff so yeah Christmas is a, Christmas and Father's Day and things like that I need to initiate, the presents and purchasing things all that sort of stuff which I wouldn't have done in the past. Um Christmas we've, we've always had with the grandparents and Rae um so we've sort of maintained that so, it hasn't been, too big a drama, but it's obviously lost, hmm a lot of it's flair, hmm probably not so much because of the loss of Lorna , but also the kids are getting older.

Other participants described New Year celebrations as more difficult to deal with than Christmas. New Year celebrations are usually a time when people look to the future and make resolutions to change aspects of their life so that they can become a better person, as well as wanting to have a better year than the year before. For some of the participants the thought of facing a New Year alone was daunting, and not a prospect to be relished, which made participating in New Year celebrations difficult. Jane described the second New Year she had experienced since Graham's death:

Graham died which was Christmas 2000, um my Sister came over from the Eastern States to spend Christmas with me and then she went, my brother has a house down South, and she went down South for a few days, and I found that really, it was between, it was just after New year, and I remember she went the morning of Carol's birthday, we went for breakfast on the second of January and then she went away, and at night I had some of Carol's friends around, and that was awful because I had nobody here, and I found that really, really difficult um, yeah but it's always that, always that first year you can at least think well this time last year Graham was here...somehow during that first year when you think oh, this time last year Graham was here sort of eases it a bit, ... 
A few participants found that experiencing special occasions and anniversaries could be harder the second and subsequent years following the death, as the immediate memories of shared experiences become more distant with time, as Jane described above.

The first anniversary of the partner's death is a time that all participants found difficult. The first anniversary gives the surviving partner the opportunity to remember and commemorate the life of the deceased partner whilst in the protective presence of family and friends. Dana decided that on the first anniversary of Carl's death that she and her children read all of the cards and letters that had been sent to them:

...on the anniversary of his, the first year that Carl died I had all the cards that people had sent me, and letters that people had written me, and the kids all came, and Richard was here from Canada. It was actually a cold night, so we lit the fire in the sitting room, just in there, and we read them again and then burned them, together.

The first anniversary is a time when family and friends want to help memorialise the deceased partner, which when done discretely can be a positive experience. When family and friends organise parties to celebrate other milestones, the surviving partner may be left feeling alone with painful memories and emotions as Jane described:

Friends of ours, and we went up um to a hill over looking that bay over looking Jurien bay and had champagne at sunset and um we you know one our friends just said a few words, and that was, yeah that was really lovely, I mean it was really sad, but it was um, but I was you know, I had really close friends with me, and then I, I went, I had my wedding anniversary and that was in um, on January the twenty six and that must have been the day I drove back from Denmark was our wedding anniversary um, and then Graham's birthday and then um, and then I had my fiftieth birthday in September and the girls really, cause Graham was one for, you know for you celebrate and have huge parties and have a good time and my girlfriends ah, you know they, they organised this party for me, it was, it was a beautiful spring day and we had um lots of people in the back garden and um, yeah, (but) that was difficult.

Jane also went onto explain how she felt the second year after Graham's death more difficult to deal with than the first due to the increasing distance between her new life and her old life with Graham that was inevitably developing over time, and also that gaps were occurring when family and friends were not around her in times when she was feeling vulnerable. The other issue that Jane raised is that despite ongoing memorialisation of the deceased partner being primarily designed 
to celebrate the life of the deceased partner, the events also continued to act as a reminder that they are indeed dead, which could serve to compound the grief experience:

\begin{abstract}
Graham died which was Christmas 2000, um my Sister came over from the Eastern States to spend Christmas with me and then she went, my brother has a house down South, and she went down South for a few days, and I found that really, it was between, it was just after New Year, and I remember she went the morning of Carol's birthday, we went for breakfast on the second of January and then she went away, and at night I had some of Carol's friends around, and that was awful because I had nobody here, and I found that really, really difficult um, yeah but it's always that, always that first year you can at least think well this time last year Graham was here. But the second year, it really starts to hit home, you can't think Oh, this time last year Graham was here. Cause this time last year Graham wasn't here, but somehow during that first year when you think Oh, this time last year Graham was here sort of eases it a bit, but Um, so um, and I found the first of the memorial lunches really, that was in the July of 2000 after Graham had, you know, died and then six months or something, that was really difficult cause you know they were all of his mates, and there were a few, I don't know, two hundred odd people and it's, at the luncheon, and lots of couples and just, and now I you know, they, that was an annual thing but l've said to the girls you know, don't be surprised if I don't go this year, um cause I said I'm, I'm sick of the constant reminder that Dad's not here.
\end{abstract}

Participants described how family and friends remembered the anniversary of the deceased partner's death but would often forget their wedding anniversary, leaving the surviving partner alone contemplating the memories of a happy occasion contrasted with the sadness of the death of their partner.

As time progressed, family and friends start to forget to commemorate the anniversary of the death, which is a reminder to the surviving partner that memories are beginning to fade for people; this contrasted with the surviving partner's own vivid memories which the surviving partner wants acknowledged, as Adam pointed out:

But it certainly gets you, you know, it's the time coming up, that brings it all back now and yea, I mean like, kids don't remember exactly when, you know, I mean, Dannie doesn't, every day's a new day for her and I'll always consider day to day affairs. Yeah, my sisters didn't ring me and I was a bit put out by that and I rang Olivia in New York she certainly knew immediately but because there's a time difference there, and she had a mass over there.

Other significant milestones such as birthdays would always be reminders that the deceased partner is no longer with the family, but as Tina described, time 
can allow the surviving partner to have the emotional wherewithal to approach sensitive items such as sympathy cards with a fresh perspective and use them to celebrate the life of their deceased partner, in contrast to the time that the cards were written which was basically to recognise the death of the partner:

...so I got through his birthday, his birthday's the twenty four of, of December so that's Christmas Eve, so by making myself busy, but it's getting easier, it's getting a lot easier, I can, I actually, went through some, photos yesterday whereas I haven't been able to do that first of all, and there were a lot of things that I couldn't, I, I couldn't go through the sympathy cards until it got to Christmas.

\section{Relationship of findings to existing literature}

The responses that the participants in this research project described are congruent with the existing qualitative and quantitative research and literature. The first anniversary of the partner's death was universally described as a difficult day where the surviving partner had not only to deal with his or her own remembrances and emotions, but those of their family and friends. Other significant dates and events all posed unique challenges that resulted in mixed responses.

During the first year of bereavement the surviving partner had no previous experience to help them cope with the event. At least with the second year the surviving partner was able to draw upon the previous year's experience. However as one participant pointed out the second year served as a reminder of the distance that was inevitably growing between them and the living relationship that they had experienced with their partner.

Rando (1993) describing anniversaries and other significant dates causing the bereaved person to experience a Subsequent Temporary Upsurge of Grief (STUG). According to Rando (1993), previous authors claimed that anniversary reactions resulting in STUG were symptomatic of complicated grief. Rando however believes that STUG that are triggered by significant dates are natural and should be expected (p.64). Zonnebelt-Smeenge \& Vries (1998) recommended that the bereaved person could attempt to modify their previous experiences and therefore ameliorate the impact of the experience, on each subsequent significant date by incorporating the pre-death celebrations with new post-death celebrations that signify new beginnings (p.76). 


\section{The surviving partner's relationship with the deceased partner's personal items}

Most of the participants discovered that determining what to do with the deceased partner's personal items and when to do anything such as disposal, caused concern. Jane described this dilemma succinctly: “And every time l've attempted to um, do something about the clothes they, we all stand there and look at it, and closed the wardrobe, it's too hard". Not only did the participants experience their own resistance to moving or changing things around the house or disposing of clothing but they would sometimes be stopped by their children who felt that the deceased partner's personal items should stay exactly as they were when he or she died.

The need to memorialise the deceased partner by not changing anything in the house has been a constant source of frustration to Dean, where the two children who have remained living in the family home have steadfastly refused to allow him to alter the house, or remove old furniture or any of their mother's belongings. As the children became adults, Dean has wanted to sell the house to live in a smaller dwelling with less upkeep, but has been thwarted by his children.

Often the surviving partner elicited help from family and friends to sort through the deceased partner's personal items. Brian described his experience:

...all we could save, like scarves, for cousins when they grow up and things like that. And so that's stored away and I'll go through it one day and trim things down to things I remember and perhaps send things on to nephews and nieces and things like that in case they want to keep them. But that's still there, that's still stored away in the garage at the moment. And I'll keep that for the kids later on, you know, this is mum's junk that she wore, that she brought back from India ... Especially James, yeah. That's all stored - yes, packing it was very sad. But really it affected her sisters' a lot, but I didn't cry then, her sisters' were very tearful, but I didn't cry that was sort of, at the hospital at the time then, and then at the funeral home, at the viewing, you know, at the open casket viewing, and that was it. Yeah, yep. So l've got all the things to remember her by. The kids' drawings they made at the time, all black crayon, by James, yeah. But that's something. I'll sit down over a week or so, and go through it, I'm in no hurry to do that, that's something that will come in time. Not in a hurry either way, it's stored in the garage with all the other things for the house, at the moment. One day.

All of the participants professed to be in no hurry to start disposing of unused personal items, generally preferring to wait for a time that felt less threatening and 
distressing. Rosalie contrasted her feelings with that of another woman's experience:

...and I had to take days off work to go into town to do those things and stuff um, then after that, I, I was in no hurry but I thought you know I should do something with his clothes and I thought about it and, I just waited until the time was right till I felt comfortable about it, because, Phillip's Mother told me that when her husband died, um, she, she couldn't wait, she immediately in a frenzy got rid of everything.

Receiving clothing and personal items from the police following a traumatic death could be very confronting, as Sally explained:

So, I, the police said to me look, we've got his bike and his helmet, they gave me his backpack which had been, you know, ripped apart and, and most of it was quite soiled, all the things inside, but they gave that to me at the hospital the night he was admitted, and um, they told me, they had his bike and they had the helmet, and they said to me, that look really we'd like to destroy the helmet, it should never be used again.

Memories of previously shared experiences when the deceased partner was alive may prompt the surviving partner to want to dispose of items quickly as did Julie:

Now I found I couldn't look at that caravan and I, um, I, I said to my friends I, l've just got to get rid of it first and people, and people said don't get rid of anything for a while and I said look I've just got to advertise this for sale, it's a lovely caravan and it's sitting there, and I don't, every time I walk out outside I see it.

Intimate personal belongings such as clothing were often difficult to dispose of, with various family members claiming items for their use. Clothing items that represented the deceased partner's personality or lifestyle were often kept as mementos such as fishing vests, or academic gowns.

All participants described disposing of personal items and clothing as sad, but a necessary part of taking control of their life and living space. Dana described how it was difficult for her to enter the bedroom with Carl's clothes still in the bedroom, requiring her to move them fairly soon after he died, with her hiding a few special items for posterity. In contrast to Dana's experience, Mary found it comforting to have Alf's clothes around her.

Most participants kept the wedding rings of the deceased partner, Mary wanted to pass Alf's wedding ring onto her nineteen-year-old daughter, Stephanie, 
who felt that she wasn't ready to take it yet. So Mary decided to have the ring remodelled to include her engagement ring, her deceased mother's wedding ring and Alf's wedding ring, Mary described this act as:

...part of my healing thing as well, so ah, and this is part of me accepting, the letting go, because, you know when we take our marriage vows, what do we say, till death do us part...

Most participants remained wearing their wedding rings up to the point of interview, with a couple having removed them (or had never worn a wedding ring), when they entered a new relationship.

Most of the participants were still living in the home that they were living in when their partner died, and hadn't made any major changes to the house. Of the two participants who have moved house one did to down size and move closer to her children, with the other having to relocate due to the deceased partner's family claiming the house as per the dictates of his Will. Lyn had little choice but to move house soon after Geoff's death because it had been left in his Will to his family.

Geoff had not yet changed his Will to reflect his new marital status, which was only a few weeks old, when he died. In order to preserve as many memories of her relationship as possible, Lyn collected as many photos of them together, and made copies for his family, before the family moved in and started cleaning the house out around her the day after he died.

Dealing with the deceased partner's clothing and personal items caused anxiety for all participants. Knowing when to start sorting out clothes, and other sundry items was difficult for most of the participants to decide upon, except for one. All of the participants needed the support of family and friends to assist them to distribute items. One participant had to vacate the deceased partner's house which had not been bequeathed to her due to the short time she had been married, this experience was very traumatic and unfortunately didn't seemed to be sensitively handled by the deceased partner's family.

\section{Relationship of findings to existing literature}

The responses that the participants in this research project described are congruent with the existing qualitative and quantitative research and literature (Clark, 1993; Daggett, 2002; Harte-Barry, 1997; Zonnebelt-Smeenge \& Vries, 1998), where the surviving partners all faced difficulties in storing or disposing of the deceased partner's personal effects. 
The surviving partner's experience with rituals and the memorialisation of the deceased partner

The memorialisation of the deceased partner was an important way for participants to maintain a living memory through creating memorials such as gravestones on the gravesites for those who were buried, burying the ashes with a plaque above the site, placing plaques at the site of death, planting trees above the buried ashes, or scattering the ashes at a significant place. Ongoing memorialisation involved formal and informal memorial services on the anniversary of the death of the partner.

Creating a memorial to the deceased partner was seen as an important tribute that allowed the surviving partner, family and friends to remember and celebrate the life in their own way. The participants in this study had experienced a variety of memorialisation strategies.

All but two of the deceased partner's were cremated. Jenny was one who had been buried, along with her sixteen-week-old unborn baby, Brian explained the rationale for this:

\begin{abstract}
Yeah, that's right, sixteen (weeks pregnant). And so to me, it hadn't come out and so it wasn't a separate baby; it died with Jenny, inside Jenny, so it seemed right to stay there with Jenny and we acknowledged that she was pregnant. On Jenny's gravestone, we had a brass plate (installed)... it's like a, a lawn cemetery, and I just had Jenny N... and our unborn baby, Shari; that's what Jenny wanted to call it. The funeral director said some people have a separate funeral and she said would you like that so I can prepare ... And I said no, no, not at all. In my mind the baby was still inside Jenny when she died, so that, to me, that's the way ... I can imagine some people would, but to me ... The rest of Jenny's family were in complete agreement. You know, we were talking about things like this. The baby hadn't come out of Jenny so they were quite happy about it...
\end{abstract}

The disposal of the deceased partner's ashes was a significant event that involved planning and consultation with family and friends. The participants chose one of two methods to dispose of the ashes, either to bury the ashes in a designated plot or in a place that was significant to the deceased partner or easily accessible to the deceased partner's family, or to scatter the ashes to become part of an outdoor area that was significant to the deceased partner and their family.

Tina decided to take Barry's ashes back to his home state of New South Wales to scatter them in the surf that he spent so much time in as a youth. Tina 
was accompanied by her son, David and in the process discovered a lighter side to travelling with her husband's ashes as she recalled:

Anyway Wendy and Sue (close friends) took me to the airport ....and, saw me off and everything and it was, just sort of like a bit sad that there he was (the ashes) in a carrier bag and, you know... because l'd taken him as hand luggage you know you have to put your mobile phone, and your bag and everything through that little thing (the $x$-ray machine), so Sue said to the guy at the checkout, she's got her husband in there would you be very careful, that you see that it goes through there alright (and) nothing happens to it, well the poor bugger, he was at the other end you know like he's got this bag here and he's going, (shuffle sound) like this with it you know trying to arrange all the paper creases in it and, like and I asked Sue why did you do that to him and she said well, I didn't want anything to happen to him while...while it's going through there .

The actual scattering of the ashes was characterised by mixed feelings as

Tina remembered:

...we made it to Sydney, my Sister-in-law picked us up, we had, a nice dinner, then it got to about three days up the track, and ah Trish said I, think we should go and do his ashes tonight, it was Saturday night we were all going out to dinner and she said, we'll wait until it's seven o'clock and it's dark, and she said we'll just the three of us, I didn't arrange a big service cause I didn't think I could hack that, so anyway I'm glad that I, you know like had a look at the package, you know so I open it all up, and they had it done up like I don't know what, and I'm glad that I opened it all before I got down the beach because I would have been saying friggin hell you know I can't get this package open, so I got all the cello tape off it or whatever and there it is, it's just, it was just white ash, and you just look at it and you think, you know like that's a life in there, you know and it's just sort of like, that's a bit sort of sad, anyway it was blowing a gale, and we walked down to the beach and we got right down the front and you know there wasn't a soul around, so it was absolutely magic, when we got down there I opened up the bag, and I gave a handful, well Trish put in and got a handful, I had a handful, and David actually took a handful, and he just waded in, the wind dropped, there was nothing, he waded right in to his waist and when I got back to Perth I felt a tremendous sense of, um, closure and feeling not good, but feeling a lot better than I did before I went.

The decision to bury the ashes is often made for practical reasons such as accessibility, as Dana explained:

But we have a family plot in the old part (of the cemetery) there and for a long time I didn't even go and get the ashes. I didn't know what I wanted to do with them. We used to go to Rottnest a lot together and I thought well maybe l'd take them to Rottnest. Then we got a cottage down South and I thought Carl loved that. But then the kids 
said well we want somewhere where we can go to see him, so in the end we about twelve months later we buried his ashes in with the family plot with a plaque. We arranged our own sort of little service just the family. By this time Richard had come back again a year later but he can't keep coming he's got a family of his own over there.

The participants described the disposal of the deceased partner's ashes as being a significant milestone that allowed the surviving partner, family and friends to create a symbolic gesture together, which can be customised to suit their own wishes and completed in their own time frame. It is not always a sad occasion and can be a time of celebration and recognition of the deceased partner's life and memory, as Sally illustrated:

And we drank lots of wine, and it was a good day, it wasn't terribly, terribly sad it was, it was, I think we all felt a sense of, of some purpose there that we had come to do something, and we did it and, um it was a good thing, and it was what he wanted and we knew that, and Andrew said that's where he wants to be as well Sarah told him if it was that cold she'd just throw him off the rocks, she wasn't getting wet for anybody (laughs).

For Rachael and her family the mourning of the death of Kevin was very public due to the nature of his death, this resulted in a public memorial ceremony taking place at the site of his death as well as the placement of a plaque at the site. This public support was well received by Rachael and her family.

The creation of a memorial need not be in the form of a commemorative plaque, it can be as simple as completing a project that the deceased partner was working on prior to his death. Friends of Carol offered to complete a barbeque that Richard was working on at the rural retreat where he died. Despite the goodwill involved in this project, one of the daughters found it upsetting because it was a reminder that her father could not complete it himself.

In Adam's house I noticed that the family had created a shrine to memorialise Maria. It was a glass-fronted cabinet that contained various mementos, with photos of Maria and family and friends on the top of the cabinet. Leaning up against the cabinet was Maria's guitar. When I pointed out what I regarded as a shrine to Adam he expressed surprise, not realising that is what it appeared to be to me. His daughter Dannie (who was seven years old at the time) took me aside following the interview and showed me a photo album which included pre marriage photos, wedding photos, family photos and photos of the funeral. Dannie walked me through the album in a matter of fact manner befitting a seven year-old child; I 
found this interaction to be very moving. Other homes I visited had many photos dedicated to the memory of the deceased partner.

\section{Relationship of findings to existing literature}

The responses that the participants in this research project described are congruent with the existing qualitative and quantitative research and literature. All participants described how the memorialisation of their deceased partner was an important experience. Whether this involved creating plaques, scattering ashes or holding memorial functions, the opportunity to ceremonially recognise the important place that the deceased partner held in their lives. The creation of memorials and the process of mourning is culturally specific which changes over time (Hockey, Katz, \& Small, 2001; Kellehear, 2000; Leming \& Dickinson, 1998; Walter, 1999), the experiences of the participants of this research project reflects that of a group of people who are from Anglo-Celtic backgrounds in a Western Society.

The creation of memorials and the performance of rituals has been found to be beneficial to mourners in: “... that appropriate rituals can facilitate adjustment to bereavement, and that performing rituals can have significant positive outcomes for participants" (Castle \& Phillips, 2003, p. 41).

The normalcy of everyday life is shattered when a partner dies suddenly and unexpectedly. According to Reisman (2001), most people's assumptions about everyday life are illusory and are tenuously linked to the person's disproportionate level of positivism, which impedes a person's ability to conceptualise the prospect of bad things happening to him or her (p.446). It is when the illusion is broken by the sudden and unexpected death of a partner that the surviving partner has to recreate his or her world and one way of doing that is to continue to have a bond with the deceased partner. Previous grief theories and models were reluctant to encourage continuing bonds with the deceased partner because of concerns that this could lead to a complicated grief experience (Costello \& Kendrick, 2000; Reisman, 2001; M. Stroebe, 2001; M. Stroebe et al., 1992; Walter, 1999).

The participants in this research project demonstrated the need to continue to respect the bond that they had with the deceased partner when they were living, by continuing to have a relationship with the deceased partner through memories, and memorialisation. There is no evidence to suggest that these continuing bonds with the deceased partner were hindering the psychosocial, physical wellbeing or growth potential of the surviving partner, an observation consistent with that reported in the literature (Costello \& Kendrick, 2000; Field, Gal-Oz, \& Bonanno, 
2003; Genevro, Marshall, \& Miller, 2003; Reisman, 2001; M. Stroebe, 2001; M.

Stroebe et al., 1992).

\section{The surviving partner's experience of holidaying following the sudden and unexpected death of his or her partner}

Several participants had taken significant holidays since the death of their partners. The thought of travelling without their partners caused concern for some, but this was outweighed by the need to have a break from everyday life. All of the participants who did take interstate or overseas holidays went with immediate family and/or friends, which gave the surviving partner the company and support that the surviving partner required. All of the participants described how much they enjoyed the holiday. Julie ventured to China, a place that she doesn't believe she would have visited if Bill were still alive:

I probably wouldn't have gone to China if l'd still had a husband, he wouldn't have gone (laughs) that's something you can do, you go wherever you want to go.

Mary decided to visit family in the United Kingdom and dispose of Alf's ashes at the same time:

I took, took Alf's ashes and I ah said to the kids um, that l'd like, you know you, both to release his ashes on the North Sea um we've got some dear friends that live North of Newcastle, and he was very close, to these friends of ours...she lives in this coastal town and there's a graveyard right on the, on the, on the, the ocean and that's where we released (the ashes), so I gave some to Stephanie, some to Sam and Marian got a bottle of champagne, the best champagne...

Several participants had taken interstate or overseas holidays following their partner's death. All travelled with family or friends and described the experience as enjoyable and worthwhile. By venturing on a holiday that was not the usual family vacation taken while the deceased partner was alive, allowed the surviving partner to explore their newfound independence; as well as providing them with a break from their everyday experience (Straub, 2001).

\section{The surviving partner's experience with the integration of the death of their partner, whilst reclaiming their life}

The participants described how they had used a vast quantity of time and energy following the partner's death focussed upon revising the past and reflecting 
upon the relationship in an attempt to make sense of what had happened. Other energy was expended dealing with the disruption that had impacted on the daily lives of the surviving partner and those around them, simply in order to survive on a day-to-day basis.

The sudden and unexpected death of a partner gave the surviving partner an opportunity to reprioritising his or her life and review their ambitions and overarching philosophical viewpoints. Brian admitted to having shied away from long-term commitments before he met Jenny, and since her death has used the opportunity to recognise this and revise his outlook on life:

Like a lot of what was going through me (was) a lot of gratitude for this relationship. I still feel gratitude just feel, even though it was brief all that sort of thing just, you know, yeah. But er the gratitude but also the march of time and the inevitability and all that you cant get away. ...Yeah in that case particularly this sort of clash between gratitude for the joy of it and the realization of the finality of it and of everything. Like so. Yeah. But I think one of the effects that her death had on me was that like getting a bit more real about my life, it was something that I realized that life is short. It could be tomorrow that I'm going to die and in a sense getting a bit more serious about things you know. But um because um in my life I have never, I've always had tremendous difficulty about making a commitment, you know like a lot of men. You know, like a lot of men not got married and um not had children and things like that. And um in some ways ah never really grown up. You know, never sort of um certain sorts of things l've never er faced and all this was something, an area - it wasn't just death but a something more than that but l've just not faced. You know so yeah. About the preciousness of things, I think, or something like that. Yeah. I became more, I think I became more aware of the preciousness of the present moment which sort of little daily things you know. Um because you know like most people I suppose you try to focus on the future you know look at that sort of thing.

Thirteen out of the fifteen participants had been in a long-term relationship with their partners prior to their death, the average length of relationship being 25 years.

Only one participant expressed any major regrets in the way that he had lived during his relationship with his partner, and that was centred on the encroachment of occupational life on his family life. Adam described the depth of sadness and anger that he experienced:

It's a real shit...I wish that I could scream, wail, vomit my sadness but its not, I mean, it creeps up on me and what you seem to fear more is, what I do anyway, is ... I suppose its anger, its not particularly well defined or well directed, its just that, you know, not at anybody, who 
could be angry at God or the surgeon, you know, ... And if I have any regrets it's we were both very busy. I mean, I felt lucky that we...that you know, er, understood each other, intellectually, and things like that, you know. You can really lose some of the comprising quality time care just with, turned to bloody shit, you know, the stuff, ... the quality time is being with your kids but then coming home and write up the minutes of some bloody committee, and you know, there'll be some bloody strategic plan, and then you write some fucking lecture then ... something else...Perhaps its what we wanted to do, is what we were doing, but er, work can be, take over your life ... I mean, then she's gone you just think well I just wish she was just (still here)...

Not one of the participants contemplated ever 'fully recovering' from the death of their partner. Most participants talked about still feeling married, or connected to their deceased partner in some way, and felt that even though this feeling may diminish over time, it would not completely disappear; David reflected upon this:

...and I suppose it's, obviously twenty two years of your life just suddenly, gets, nipped off and, and, you know, so yeah I, I suppose the whole area of motor car accidents and, you know all those sorts of deaths are um, you know must be quite, quite, traumatic, but also, that healing process means that it never does really, fully heal, hmm yeah...

When reconciling the relationship that the surviving partner had with the deceased partner and the nature of its ending, participants often reflected upon the fact that they were fortunate that they were able to enjoy the relationship for whatever amount of time that they were together. Only one couple had been experiencing difficulty with their relationship, which led to the surviving partner experiencing some ambivalence on reaction to his death. The remaining participants all described their relationships as being very satisfying. Don described how he used music to help him reconcile the gratitude that he felt for having had the relationship, and the sadness of having it end through Jane's death:

Like a lot of what was going through me (was) a lot of gratitude for this relationship. I still feel gratitude, just feel, even though it was brief all that sort of thing just, you know, yeah. But the gratitude, but also the march of time and the inevitability and all that you can't get away. So the music sort of enabled me to make some sense of what was going on to me, what particular sort of relevance. Yeah in that case particularly this sort of clash between gratitude for the joy of it and the realization of the finality of it and of everything. 
Dana referred to the transition as: "we becomes me". The need to rediscover the individual that was enmeshed in the relationship is necessary in order to gain some sense of self. Mary's description of her experiences with 'remodelling' herself echoes what several other participants described:

... and is sort of learnt by myself. Yeah and I've um, and in a lot of ways you know I was able to, to just come to terms with a lot of things myself, you know like you know I, just I, I just, I just want to, um heal myself, I just, I want to somehow get better, and um, and you know I kind of amazed myself, you know out, out of um, out of all of this yeah, l've just, got so much, it's given me so much strength, you know to ah, to be a better person, for it, and I know that everything will be okay, I have to believe. Because I have to believe in myself and I am believing myself, now that was before I thought of remodelling myself I am amazing myself and I really um, you know, putting myself out there and, and really putting myself out of my comfort zone. I didn't want to have to do, didn't want to do all those sort of things and, and then find myself in that position...

The surviving partner is often so caught up in surviving the demands of everyday life that it may take someone else to steer their reflections towards how well they have coped and how much they have achieved, which was something that Tina experienced. Tina was aware that she was managing to cope with everyday life effectively, but hadn't really taken stock of everything she had achieved following the death of Barry, until a colleague reminded her:

If I want to go and buy something, I go and buy it, and there's not an almighty argument and he always used to say if the financial devices were left to me you know like we'd be broke within weeks, but, it's fifteen months l've still got money in the bank, the house has not had to be sold, I've done beautiful things to it, I've paid for a funeral, l've paid off all the debt, not that there were many debts, and he'd, and I have to admit he's left me very well catered for, um I'm very lucky, but by the same token I've still got myself together and l've, I've got back to work and, I, I suppose I'm getting more confidence in myself when we did the personal development thing last year you know like, from the year before what have you accomplished this year or whatever, and um I said to one of the lecturers I said oh God you know like what with Bob dying and my heart attack and, you know I really don't feel that I've accomplished anything, and, she said to me, you have, you've gone back to work, you've done this and you've done that and she said just getting back to work is an achievement, and I just never even thought of that.

Taking on roles that Peter held prior to his death, has proved difficult for

Sally, such as cycling with her children, given that Peter was killed while riding his bicycle: 
(l've) got to learn how to ride a bike, and they love their bikes, so, they've got bikes, at home, but l've got lots of brick paving so, yeah, I took them to the park for the first time, two weeks ago, around Lake Monger, and they rode their bikes on the path, and that was a huge moment for myself, really, and nobody really realises I don't think how much it affects me.

Unfortunately family or friends often do not recognise issues such as the one Sally described above, which could hinder her ability to function in everyday life without experiencing anxiety associated with the reminder of her partner's death; the risks associated with cycling for her children and the guilt associated with not being able to fully participate in recreational activities, which her children enjoyed.

The surviving partner was thrust into a situation whereby unless they want to be dependent upon others to fulfil some of the roles that the deceased partner had responsibility for, then they are going to have to take the bold step of 'having a go' as did Carol, who was motivated by her independent streak:

...I get mad cause I don't know how something works and, you'd ask and then I think bugger it l'm going to try and do it myself you know, so I think I've learnt quite a few little tricks.

Carol also decided that she would enrol herself in a computing class, which is something she may not have bothered to do when Richard was alive.

Despite having the support of his sister who was living with Brian and helping with managing the home, Brian was aware that it was not the same as sharing the work with a partner, as he explained:

And I've just found now that I'm more restricted in the things that I can do, and the family can do. Because it's no longer the husband and wife team that are, husband and wife, I mean husband and wife in the one unit that can do things as opposed to my sister and myself. I've got to take my sister's job into account, and all that sort of thing, and yeah, so I'm much more restricted, not so much in the lifestyle but ... in the things that can be done.

In order to rebuild their lives the surviving partner believed that they have little choice but to integrate the experience of their partner's sudden and unexpected death into his or her lives. As David stated, "you actually end up with a new life".

The surviving partner's life has been infused with an experience which affects every aspect of their life, the way in which they are capable of responding to the experience will influence the way they feel about him or herself and others around them. Mary explained how she had used the experience of Alf's death: 
...you know I, just I, I just, I just want to, um heal myself, I just, I want to somehow get better, and um, and you know I kind of amazed myself, you know out, out of um, out of all of this yeah, l've just, got so much, it's given me so much strength, you know to ah, to be a better person, for it, and I know that everything will be okay, I have to believe...

Prior to, and immediately following Geoff's death, Lyn had talked about how she had been unhappy at work. At the time of the interview she reported that she had found a job that was causing her great satisfaction:

I stabilized a lot better than in the last year and everything, straight after that I got a promotion and things have gone really well since and (although) we're light on people, and I've got lots of work... it doesn't matter. Cause I'm happy. Yeah so and you've, I got people that, are kind of valuing what $\mathrm{I}$ do.

Several participants described how that it took about two years following the death of their partner, for them to start feeling 'better', enabling them to take control of their lives, as did Jane:

I, I felt much, much better than I had done for the last two years. Had a good couple of weeks away in January um, yeah so I felt much better and I had, I actually feel much, yeah much better I go to Yoga. Yeah, I mean I feel much better I and I can tell you know like starting the school year off again this year. I, I felt much, much better than I had done for the last two years.

The overall opinion expressed by the participants was that the process of integrating this experience into their lives could not be rushed and that people had to be allowed to process the experience and incorporate it into their lives at their own speed and level of integration. Dean articulated the way he felt about himself, three and a half years after Janine's death:

Oh yeah time always heals, heals everything. Oh I still sort of do feel you know, I still feel there's a void there and um I don't sort of feel like jumping over the moon or anything. I know you've got to give yourself a push and a shove and I'm most probably not prepared to do that or haven't been prepared to do that up til now. I think I've been too involved with the family and looking after their welfare but I think there all sort of on the road to better things now. And I should look outward I think rather than inward.

The void that is created by the death of a partner may in fact be more difficult to fill completely for the older surviving partner (Costello, 1999; Costello \& Kendrick, 2000), who may feel that they are unlikely to form a new relationship, or be able to 
discover new recreational pursuits, or holiday as easily as their younger counterparts. Having said that, at the age of 44, David doesn't believe that the void will ever completely close over:

I thought that it would be a process where, where the void would close in, and then just suddenly snap closed and, you would just move on in your life, but there was um, I think there will always be a, you know a bit of a void there that you can't, you can't fill, yeah.

All participants were aware that the death of their partner left them with a void to somehow fill. Most participants recognised that this void would never fully close, regardless of new relationships forming, or by them filling their lives with work, family or recreational pursuits.

The participants in this study all reported gaining insight and empathy in relation to other's suffering, surrounding the phenomenon of loss and the subsequent upheaval it had caused. Having experienced this phenomenon, the participants gained a sense of awareness of how others they have known have felt and how they would relate to them differently now, as Dana recognised:

I think "oh God what a dreadful, what an awful person I must have been". But you learn from life. I guess, (I'm) more aware of how vulnerable people are, and how lonely people can be... and one of my closest friends, whose husband had died very slowly and horribly, of cancer, she was a great support to me. I can remember saying when Ray died, Gosh Joan, you know he's watching over us and I think now what a stupid bloody facetious remark to make. I can remember saying equally facetious remarks, at times, you know to, to friends of mine who's husbands had died.

The male participants described how they now have far greater insight into the challenges of domestic life and being the primary parent, as David recalled:

I have a greater sensitivity to, to children and I'm more aware of their (need for) security, and their, failings and um, and the frustrations of, you know, domestic life and ah, you know the taxi service process that you go through, and you know all those sort of silly little things that just end up at the end of the day, being an irritation to a lot of housewives, you know, and um, and so yeah I'm more appreciative of that.

\section{Relationship of findings to existing literature}

The responses that the participants in this research project described are congruent with the existing qualitative and quantitative research and literature. All participants had spent considerable time and energy, trying to rationalise what had 
happened to them and how to make sense of this tragic event. The pursuit of meaning following the death of a loved one is a phenomenon that features prominently in thanatological research (Clark, 1993; Danforth \& Congrad-Glass, 2001; Davis \& Nolen-Hoeksema, 2001; Davis, Wortmann, \& Lehman, 2000; Neimeyer, 2000; Neimeyer, Prigerson, \& Davies, 2002). The need to find meaning in both the death of a partner and the surviving partner's drive to pursue life following that death for the surviving partner is something that was generally not articulated well by the participants of this research project. This finding is supported by Davis and colleagues (2000) who concluded that:

(a) a significant subset of individuals do not search for meaning and yet appear relatively well-adjusted to their loss;

(b) less than half of the respondents in each of these samples report finding any meaning in their loss, even more than a year after the event; and

(c) those who find meaning, although better adjusted than those who search but are unable to find meaning, do not put the issue of meaning aside and move on. Rather, they continue to pursue the issue of meaning as fervently as those who search but do not find meaning (p.497).

All participants described participating in everyday life as effectively as possible. The need to continue to care for family and home, kept the parents with dependent children focussed. The harsh reality of the participants' experiences was that life did not stop following the death of his or her partner.

The personal growth of individuals often occurs through him or her being challenged by adversity (Gamino, Sewell, \& Easterling, 2000; Hogan, Greenfield, \& Schmidt, 2001; Kessler, 1987; Neimeyer et al., 2002). The sudden and unexpected death of a partner is a challenge that the participants did not wish upon him or herself, however they have all discovered that the experience has led to personal growth, resulting in them discovering strengths and talents that they had not developed fully whilst living with their partners.

The sudden and unexpected death of a partner is a traumatic experience, that tests the surviving partner's ability to rebuild his or her life and reconcile the loss of arguably the most important person in their life (Daggett, 2002; Davis et al., 2000; Gilliland \& Fleming, 1997; Prigerson et al., 2000; Zisook \& Shuchter, 1991). The ability to incorporate this event into one's life is influenced by personality type; 
previous life experience; psychological wellbeing, and philosophical, cultural and religious paradigms (Rando, 1993; Walter, 1999).

\section{PHENOMENOLOGICAL EXPLICATION OF THE PARTICIPANTS' EXPERIENCES}

How a person reacts to the death of their partner is influenced by a myriad of factors including personality type, the nature of the relationship with the deceased partner and his or her previous experience with the death of someone close. The participants in this research project all demonstrated remarkable levels of resolve in their ability to build the death of their partner into their lives.

Regardless of how miserable or desolate the surviving partner felt that their lives were, he or she was thrust back into the living world. Everyday life continued on despite the surviving partner feeling dislocated from reality. The surviving partner needed to continue to function as a parent, family member and friend to those who were sharing the grief associated with the dead partner. The surviving partner often felt a barrenness that left them feeling that the core of their being had been hollowed out, leaving a shell of his or her former self.

People who had a passing relationship with the surviving partner only saw the surviving partner's outside shell that was a thin veneer that covered an inner emptiness that left the surviving partner despairing over the intense sense of sadness that travelled with them for every minute of each day.

This left the surviving partner in a state of flux that retarded their ability to care for him or herself, especially if they have to care for dependent children. The health and well being of the surviving partner was sometimes affected by this catastrophic event. The tedium associated with continuing to participate in everyday life, having lost of a soul mate, lover, companion, and co-parent, left the surviving partner with little energy or inclination to care for their own health, which sometimes led to sleep disruption, eating problems, increased number of infections, and the increased use of alcohol, or the need for prescription psychoactive medication.

Finding the drive to carry on would often leave the surviving partner little emotional energy level left for him or herself, to assist in dealing with the angst caused by the death.

The death of a partner left a void that left the surviving partner with feelings of desolation that needed to be ameliorated by creating diversions. The surviving partner often used the need to care for his or her children, or returning to work to 
allow him or herself the freedom and space to put their grief aside. The surviving partner would also immerse him or herself in music and the written word to help alleviate their sadness.

Some of the participants sometimes experienced the presence of the deceased partner. The presence of the deceased partner could manifest itself in dreams, or an aural or visual sense of the deceased partner communicating directly with the surviving partner. The participants who described this phenomenon reported that it was a positive experience and that they sometimes felt a warm auralike presence that was attempting to give comfort to the surviving partner.

The surviving partner needed to have time and space to grieve. The need to process what has happened to him or her, required the surviving partner to clear a space in their head in order to grapple with the conflicting thoughts and emotions that wax and wane, with the surviving partner often experiencing a whirlpool of distorted emotions. Given that the surviving partner cannot remove him or herself from everyday life, this process is slow and tortuous, with the surviving partner snatching time when they can to process the experience.

The surviving partner often used humour and laughter as a relief from the drabness associated with what can seem like relentless sadness and loneliness. Being able to share humorous memories with those who knew the deceased partner is an important part of creating a living memorial of the deceased partner that transcends the physical absence of him or her. This memorialisation continued every year when significant dates and anniversaries were celebrated. Experiencing these dates for the first year is universally distressing, with the surviving partner acutely aware of their missing partner. Most participants described how these feelings diminished in severity over time; however there were some who found that as time went by, they found it more distressing due to the increasing distance that was growing between them and their deceased partner.

In order to maintain the memory of the deceased partner rituals and the memorialisation of the deceased partner was important. Celebrating the deceased partner's birthday, wedding and death anniversary are annual events that allowed the surviving partner to gather with family and friends to share anecdotes and memories of the deceased partner. The memories evoked by these events would often lead the surviving partner through a journey mixed with happiness and sadness, often reinforcing the feeling of aloneness that the surviving partner experiences. 
The surviving partner found that one means of maintaining contact with the deceased partner was to continue to have the deceased partner's personal items surrounding him or her. Only one surviving partner disposed of the deceased partner's personal belongings soon after his death, with the remaining surviving partners' preferring to tackle this onerous task with the assistance of family and friends over a protracted period of time, when they felt that he or she had the strength to deal with the provocative memories that were evoked, and the guilt of the disposal of such items.

Having photos, and significant personal items of the deceased partner around the house, allowed the presence of the deceased partner to continue to be part of the family home and life. Having a memorial such as a gravestone or plaque at the site of death, also serve as a permanent testimony to the life of the deceased partner.

Eventually most participants decided that he or she needed a break from the humdrum of everyday life and decided to embark on a holiday. This decision sometimes caused angst and guilt with the surviving partner feeling that they may be betraying the memory of the deceased partner by enjoying a holiday, which is a time that is normally used as an important reviver of relationships. Travelling without the deceased partner, could cause anxiety, sadness and loneliness, however, most participants enjoyed the experience as it allowed them to take a break from their grief, by removing them from their everyday life that surrounded them with memories of the deceased partner.

The reconciliation and integration of the death of their partner into the life of the surviving partner is a slow and subtle experience. The surviving partner moves through life dealing with the minutiae of working, raising a family or dealing with everyday domesticity, with their pain and loneliness gradually receding into the background. Sadness and grief can rupture the fragile veneer of 'coping' that the surviving partner develops, but generally the frequency of these feelings is reduced. Slowly the surviving partner starts to take control of their life, regaining independence and strength, whilst realising that this does not have to reduce the love and respect of the deceased partner or stop them from wishing that they were still alive to share in his or her lives. In order to survive everyday life the surviving partner encapsulates or compartmentalises the memory of their deceased partner and as time goes by he or she is able to open that capsule when they want to, rather than having the capsule burst open randomly. 
The participants found that the death of a partner was a life crisis that could lead to the growth of insight and empathy. The participants often talked about how they had developed independence; gained new skills; had lost, but more importantly gained new relationships or strengthened existing relationships and that they had an increased awareness of the value of life and its fragility.

The participants had reprioritised their lives to reflect their experiences by reducing the time spent on trivial matters, and generally attempted to reduce or eliminating aspects of their lives which were burdensome. Although living without their partner was a prospect none of the participants would have wished for, they reconciled the fact that the deceased partner was not returning and that they would have to make the most of their own remaining lives. 
CHAPTER SEVEN

\section{THE SURVIVING PARTNER'S RELATIONSHIP WITH}

\section{OTHERS WHILST EXPERIENCING DEPENDENCE ON}

\section{AND REQUIRING SUPPORT}

A friend is one to whom you may pour out all the conents of your heart, chaff and grain together, knowing that the gentlest of hands will take it and sift it, keep what is worth keeping, and with a breath of kindness, blow the rest away.

Arabian proverb, (Miller \& Hrycyniak, 1996, p.123)

\section{Introduction}

The participants described how to varying degrees and within varying time frames, the sudden unanticipated death of a partner caused him or her to experience a loss of self-sufficiency, resulting in a need for support, comfort and guidance from others. This support was derived from the surviving partner's children, family, and friends. Other external support came from both the surviving partner's micro and macro communities, and their employment community.

The level of support the surviving partner received was dependant upon a number of factors such as how amenable the surviving partner was to receiving support, as well as the ability and willingness the supporting person had in helping people in crisis.

This chapter explores the type and level of support the surviving partner garnered from those around them, and the impact that this support had upon them. 


\section{The surviving partner's experience of his or her children giving support and comfort}

The closest and most intimate relationship the participants had following the death of their partner was usually that of their children. Most of the participants described a positive relationship with their children with two describing the relationship being strained at times. All of the participants had children except for one male participant. Seven participants had children under the age of 16 , with ten participants having children domiciled with them at the time of interview.

As discussed in Chapter Five, the week of the deceased partner's funeral was characterised by great upheaval, resulting in confusion and chaos. Despite the pressure that the family was experiencing, the participants' children generally displayed sensitivity, understanding and empathy towards their surviving parent. Rachel expressed surprise that her children were so eager to be involved with their father's funeral:

So um, you know l'd never experienced anything like that before it's just, it was just amazing, anyway the, the children said to me a, few days after Kevin died that they would like to be involved, with the funeral and I said oh, well you know that's absolutely not necessary, we've got so much on our plate that were trying to get ourselves, you know, ready for a funeral in a week, and cope with what's happened...

The close support at the time of the funeral that children gave to the surviving parent was highly regarded by all the participants, as well as the other attendees of the funeral, Mary recalled her experience:

...as part of...the ceremony is like, when the service is done there's the grieving wife um and my children we'll sort of ah (be) next to the coffin and I go first and give my farewell, to him, so I just kissed him and you know and have a little talk to him, and a lot of people actually found that really nice.

The ability to create a piece of music dedicated to a father in the days following his death is something most people would not possess. However Dana's 33 year old son Bob wrote a piece of music to be played at his father's funeral, which gave great comfort to his family. Dana had the funeral service audio taped, but had not listened to the recordings at the time of the interview and did not know when or if she would listen to them, due to the painful memories that may be evoked. 
Even the younger children were able to make contributions towards their dead parent's funeral, as in Brian's case:

We got the kids involved in the funeral, the cousins, Jenny's sister, Maria, who was probably the closest person to Jenny, they were over each other's place, you know, every second day. She'd suggested we get the kids involved in the funeral. We got little heart-shaped cardboard boxes and we each collected things in there that would remind us of Jenny and her kids would get some drawing, they'd draw something you know, then they'd collect some flowers and, James, my oldest, which was amazingly thoughtful, he remembered always walking along the beaches and picking up shells for Jenny as a three year old. So we went along there with Maria and her kids and some friends from down the road and we picked up shells, some nice little shells from the beach and then he's some grasses, remembered giving flowers, he remembered giving some yellow flowers to Jenny, and then he went up to get Aloe Vera 'cause Jenny was growing an Aloe Vera plant and he said to put it on sores...and I'll put them in the box and on the coffin, on the casket, and he said that's some Aloe Vera in case she gets sores in heaven she can put it on her sores. The amazing thought process!

Dana described all of her children as being demonstrative, which she really appreciated, as she was missing the physicality of her relationship with Carl. Dana also described how her other son, Stuart (35) was very supportive whilst maintaining an honest approach:

I was just thinking what, on the days just after Carl died. Stuart used to come and lie beside me while I went to sleep, and have you ever read the meditations of Marcus Arelious. Well ah, Stuart had it. He gave it to me, because he'd been working his way through it. There's some of it, it's really so, dense and thick I couldn't work out what it meant. Stuart read that to me and it sounded, just like Carl reading it. Stuart is the one that looks like him. I said to Stuart, "oh gosh you read that beautifully darling", and he said: "Oh Mum I don't understand any of this shit!"

\section{Relationship of findings to existing literature}

The responses that the participants in this research project described are congruent with the existing qualitative and quantitative research and literature. Having children attend the funeral of a parent has not always been accepted in every culture, and may not occur at some funerals in Australia as a matter of course due to strong resistance from within the family (Skinner-Cook \& Oltjenbruns, 1998). If childhood funeral attendance is culturally permissible, then the decision to attend, is usually left to the individual child, with either the parent or close family member or 
friend giving the child pertinent information so that they are aware of the process involved (Skinner-Cook \& Oltjenbruns, 1998).

\title{
The surviving partner's experience of creating an environment of mutual support between him or herself and his or her children
}

The participants often reported that the support that was given by his or her children resulted in the surviving parent reciprocating the support to their mutual benefit. Julie gave an example of adjusting one's life in order to benefit from family support when Julie decided to move house so that she could be closer to her daughter:

\begin{abstract}
Yeah, and ah, and ah, Patricia was down here and she um, she's the only one around really, Kelvin comes for weekends ah, and I thought well I spend more time in the car travelling down here, and I don't like asking them just to come for tea because they've got to come all the way up there, loved it up there, really did, but I thought it's time to get something smaller, so I found this place, with no back yard, just that out the front. And ah, I thought well I can at least get up and go, which I do. Patricia and Peter ah, found a place just here in um, Churchlands at the same time within walking distance of me. So we see each other all the time. And I think she loves that, and, and I, I love that. So it's making us closer together and of course I thought, I was going to be here to do the babysitting of course.
\end{abstract}

David gave up full time work to care for his children following the death of Lorna. David believed that the by placing his children's needs before his, has resulted in a lifestyle that is mutually beneficial, as he described:

I will continue trying to keep the children with their expectations and their hmm, desires going rather than me keeping mine going, so I suppose that's the sacrifice, as I say, but I, I don't see it as a sacrifice now, I think I initially did, but now I see, a lot of benefits have come out of it.

The relationship that the surviving partner had with their children was pivotal in assisting in regaining his or her sense of self and also selflessness following the death of a partner and parent. The relationship was generally characterised by mutual support between the older children and their parents, with a few of the teenage children causing anxiety to the new solo parent. The younger children provided unconditional love, and although far more demanding of the parent's time and energy compared to older children, they required a less complex level of care and support. 
A few participants noticed that their children sometimes took on the role of the deceased partner voluntarily, as Rachel described:

So, yeah, yeah, it's, it's tough, but you know as I said Martin I am, I am very positive and I think that's, the best way to be really, I mean especially when you've got children that, are still, dependant on you, and um, I said to Ruby I hope you don't want me to make (laughs) a speech at your engagement party, and Arnold said no, he said I'm going to make a speech he's taken on the role of his father.

Other children arranged birthday parties for their parents, and generally assumed a role that encompassed decision-making and leadership roles; Dana described her son Stuart becoming the paterfamilias. Having children assume roles previously held by the deceased parent is described by Skinner-Cook and Oltjenbruns (1998), as a way of showing empathy towards the surviving parent in an effort to reduce the burden that the surviving parent is experiencing.

\section{The surviving partner's experience of the relationship with his or her family}

The participants' immediate family usually provided the closest and most continuous support to the surviving partner, however there were individual close family members who did not provide as much support as expected for two of the participants.

The participants' mothers and fathers, as the senior members of the family are those who have had the longest relationship with the surviving partner, not all participants' parents were still living. It is was assumed by participants that their parents would be able to respond in a crisis with sensitivity, maturity and wisdom and be able to offer unconditional love and support in such times. A few participants found that his or her parents' ability to support them was hindered by age and infirmity. Not all parents, no matter how apparently able, were always capable of supporting their children in times of crisis, as Sally explained:

I don't know what you can do for me, um, I think people struggle with how do I support you, um my mother and I struggled for a while um, where she's my mum and all she wanted to do was make this go away, she couldn't and she couldn't deal with that, that was hard, really hard, and I, I've talked to her about it since, and I said to her you know, I know how you feel because I'm a mother too, and I want to make it better. 
The parents and parents-in- law of the surviving partner were experiencing their own responses to the death, and often had difficulty putting their own experiences aside to support the surviving partner. Sally described, this phenomenon in an earlier chapter with her mother-in-law who was nursing her ailing husband, whilst grieving over the death of her son. Dana's mother was 91 years old when her son-in-law died. As an elderly person, she found it difficult to be fully supportive to her daughter, and could not reconcile her long life compared to his.

Sometimes a participant's father had the added challenge of overcoming a socially ingrained macho persona in order to be empathetic to his child in a time of crisis such as this. When Peter died, Sally saw her father cry for the first time. Most of the participants described their parents as giving the best support that they were capable of, which mainly involved practical, domestic and childcare assistance when required.

David expressed his bewilderment over what he perceived as a lack of empathy towards himself and his children from his parents-in-law and his sister-inlaw following Lorna's death. It took some time before David developed some insight into why his in-laws behaved in this manner:

...there are things that you assume but then you find out later on that, that was just a wrong impression that you had...Loma was the, the glue that held a dysfunctional family together, she was the one that, that would take the kids up to see grandma and grandpa, she was the one that would get her sister around to our place and have dinner, in fact, again with the sister, her sister being single, um, l've been to Rae's place twice for dinner, in two and a half years, Rae's been here probably, a dozen or so times for dinner, um, her parents will, arrive, and, ah, you know for some reason you know they've always got to have a reason to be here they can't just drop in and say oh we've come down to see the kids, or we've come down to have a cup of tea, they've got to have a reason to come, and, that reason, once it's been initiated you know they might have come down and, and, and um, drop off something.

The participants reported how their siblings were part of the family support network that was generally very effective. The siblings were often better positioned to provide practical support with transport and active child-care, with the bereaved children often being in the company of their cousins, who were able to provide age related support to the children. However this is not always the case, with some siblings surprising the participants by not being able to offer effective support, as Julie discovered: 
...you know my sister that stayed away, she'll say even now oh, I think it's always better for people to have their friends not their family, it's too sad, and I think aw, I wonder is she's feeling guilty (laughs)?

This experience is in contrast to Brian's experience where his sister, Mardhie elected to move in with him so as to provide companionship, domestic support and child- care for his children. Brian found Mardhie's ongoing support to be enormously helpful, enabling him to return to work and have recreational time-out as well:

I wouldn't have anywhere near the life style I can now, being able to go to work, having a fulfilling life and being able to go to work and have income and all that, without my sister.

Adam described how both his sister (who travelled from New Zealand) and Maria's sisters (who travelled from New York, and the Philippines) were very supportive, staying with him for extended periods of time:

So her two sisters and her mother stayed here for, er, Olivia stayed for a month and her mother and her youngest sister, Cindy, stayed here for two months and that was great. It was a very viable support for me. My sister and my big sister, they're I both older than me, one runs her own business in New Zealand, she was here for ten days so she had to go back then and my other sister came over. And, I don't know, its over three years now. You get a lot of support initially, and a couple of wise people I know, have talked to me about that and its actually very true that you forget. There are a lot of people around you and then suddenly everyone's gone and you'll left alone. I was actually on sabbatical and doing my PhD, which I wasn't after that. I had about five months of it to go, you know, or something. After about three months I ended up doing quite a lot of work in this drug and alcohol unit, outpatient unit, methadone unit; giving out the "done" but then sorting out some of their staff problems, I don't know, why I got so involved, perhaps its just a focus or something, something to do.

With family staying with him Adam was able to attend work, and immerse himself in working with other vulnerable people in need, such as heroin addicts. As Adam described, family support was very much needed and appreciated by the surviving partner, but when it was withdrawn, as it inevitably was, the surviving partner was often left feeling very much alone.

Having a brother who has a background in the caring professions, proved to be helpful for Carol:

...we rang my brother, because...he's a social worker by trade and, so he then went and found the kids and told the kids and, I don't know, John must have rang because by the, by early the next 
morning all of Perth knew, you know I think he rang a few key people, I just left that all to John, we got up the next morning, packed up, John drove Richard's car back, and I came back with John and Janette and of course the kids were at home by that stage, friends were there that had heard, you know as you do...

Participants often stated that they felt vulnerable and uncomfortable when attending social occasions, especially formal occasions. Jane discovered that by having a sibling accompany the surviving partner helped reduce the associated anxiety and insecurity:

Um, we placed Graham's ashes on the Friday afternoon, I had the (memorial) luncheon on the Saturday that went through till six o'clock and then that evening there was a big Ball at oh, gosh would have been at the Yacht Club for a lot of us um, who had been friends, who were all born in nineteen fifty, it was our fiftieth and fortunately cause a few people said Oh, you know come along, we'll look after you, and I thought Oh, maybe I should go, and in the end my, my brother ended up being able to come with me, thank heavens, because it was, like nobody would have looked after me.

The surviving partner's family were usually able to give quality support, and were more likely to be willing to dedicate large periods of time to the surviving partner and continuing to support the surviving partner on an ongoing basis, than friends were. However the surviving partner sometimes found that support was not always forthcoming from close family, due to the individual family member's feelings of either inadequacy involving their own personal grief experience related to the death.

\section{Relationship of findings to existing literature}

The responses that the participants in this research project described are congruent with the existing qualitative and quantitative research and literature. The structure of the family system changes when a member dies, disrupting the existing status quo (Detmer \& Lamberti, 1991). Detmer and Lamberti describe the "Multigenerational Transmission Process" whereby the death of a family member will have an effect across the generations (p.366), resulting in the boundaries that normally delineate the subsystems within a family being permeated. The change in boundaries can result in relationship changes, with children taking a more adult role, and parents adopting new parenting styles, which will inevitably create confusion resulting in the need for adjustment for the family members (p.365).

The parents and grandparents of the surviving partner and the deceased partner will often feel guilty for surviving a child (Skinner-Cook \& Oltjenbruns, 1998), 
this may result in the parent or grandparent feeling lost and helpless when the need to comfort and assist the surviving partner arises. Other responses from parents may be due to them wanting to assume a more intimate level of parenting in order to protect the surviving partner from experiencing further harm, this can prove to be overwhelming for the normally independent surviving partner (Straub, 2001).

Siblings are an important support group for the surviving partner, but may suffer negative grief reactions that reduce their capacity for comfort and support (Detmer \& Lamberti, 1991), as some of the participants discovered. Gilbert (1996) believes that families often experience 'differential grief' which impedes mutual support. Each family member will grieve in their own unique way which has been influenced by their relationship with the deceased person, as well as their own personality type and previous grief experiences, resulting in different grieving styles and responses (Gilbert, 1996).

\section{The surviving partner's experiences with friends}

With most of the participants describing positive experiences with family following their partners' death, all participants reported having received a greater level of intimate support from friends. All of the participants described having great support from his or her friends, with only a few isolated instances where friends were unable to give the support expected from them.

Friends soon rallied around the surviving partner after being informed of the death of his or her partner. Apart from the emotional support friends were able to offer, they often provided practical support such as cooking meals, taxiing people around, caring for the surviving partner's children and performing a host of other everyday practicalities that lessened the load for the surviving partner. Mary remembered the time immediately following the funeral of Alf:

...but that was very, very emotional, and I was just so drained, absolutely drained and ah, we came back here and ah, you know I mean I hadn't planned anything, you know just, friends just took over and they um, you know got all this stuff together...

The participants valued having friends who took on roles for the surviving partner while the surviving partner was struggling to perform basic functions in the first week or two following the death of their partner, as Mary said: "Yeah, l'm very honoured, honestly, l'm very privileged to have these (people) as my friends." 
Most participants reported incidences where friends were sometimes

struggling to find the right words, or act in a suitable manner, as Sally described:

Or they come out with something ridiculous... which is terrible, or, or they're I really quite good at it, or they don't talk to you about it at all, they just talk to you about something else completely different and um, people are very sensitive around you, and that's hard they walk on egg shells... so you don't feel very relaxed around people, and I think immediately following and some months afterwards, I felt extremely vulnerable and exposed to the world...And that's okay, and, and I think that's what's really hard is that you don't want to stop people, speaking fluently with you and just freely, you don't want them to be on egg shells...

One of the biggest problems faced by friends who hadn't previously experienced the death of someone close is that the lack of experience reduced their ability to be empathically attuned to the surviving partner as Jane recounted one incident were this occurred:

...you know we'd have events and you know like the luncheon, and my fiftieth and you know and l'd say a few words and um people would cry, you know my sister-in-law would cry, and my close friends would cry and I wouldn't do anything l'd just keep going and keep talking and, and I think you know then people started to think Oh, well you know Jane's okay, she's really (OK)...Um I mean I could tell my friends how I felt but um and they would all say to me well, you know we've really, got no idea...

The experience of loss or trauma in their lives can create a bond between friends as Sally discovered:

I've got a few really good friends, and different circumstances to, a great girlfriend, she's actually my sister-in-law, and (she) had a little girl, um, with a (genetic) syndrome who is three now and she's lovely, and, and l've talked to her about some, some of the things, and we relate on such an amazing different level about things, but there are certain things about our situation that are permanent where we relate, and she said to me about this doctor coming in to tell her, that he'd figured out what was wrong with their baby, when she was days old, he (the doctor) was so excited, and it just made me remember this neurosurgeon coming in saying (excitedly), he's not going to die from his head injury any more.

The participants revealed that they didn't need his or her friends to engage in deep conversations where they may feel inadequately prepared or embarrassed, instead preferring that their friends listen, as Tina recalled: "I find I've got a good network of friends and I found basically what they do is listen." Lyn described how 
depressed she became following Geoff's death, and how a friend was instrumental in her survival:

Oh I just wanted to die (laughs) and ah, yeah a couple of times, um had a, had a, quite a bad time of it and, as I say I was lucky I had my girlfriend to talk to, she'd talk to me every night for one or two hours on the phone Or come over and sit with me and it was well beyond the, call of any friend let alone someone who, didn't know you that well but, she, she, I credited her with the fact that I'm still here, yeah. Brilliant woman. So (laughs)...

The participants all described feeling an overwhelming sense of lonesomeness following the death of their partner, most having been in long-term relationships. Friends performed an important function by increasing their contact with the surviving partner to reduce the time that they are alone, but as Sally explained her friends could never replace Peter:

Ah, a girlfriend gave me a book on the weekend which was nice, and, and you know I sort of relate to those people and they'll the people that are probably always going to be a little bit more in my life than maybe before, and, for some reason they want to do this, and I'm happy for them to, you know l'm not the type of person to run out and ask for help, so for they coming to me, and giving me, is wonderful and that, you know, l've got some lovely friends, which is good, but there is, you know voids that people can't fill and that's those lonely nights and when I open my eyes in the morning and I look over in the bed and its empty, well sometimes lan is there or Eliah there you know they have snuck in and that's all right too, I don't mind that but yeah, it hits me the minute I open my eyes and it's my last thought when I go to sleep so it is, it is something that's with you forever, every day yeah

Most participants described how their closest friends were of the same gender, but most had friends from the opposite gender who were able to be supportive. The female participants described their relationship with male friends mainly centred on them providing practical or professionally orientated help. Most of the male participants had female friends who they could confide in. The relationships that the male participants had with their male friends stayed relatively stable following their partner's death, with the male surviving partners using one or two close male friends as confidents.

A few of the male participants described being able to talk with male friends about how they were feeling, with most describing having more in-depth and intimate conversations with women, however Don had one male friend with whom he could discuss his feelings: 
I talked to a few friends, briefly, like my closest friends. Like I talked about this happening and um shared that with them um kind of shared my emotions. But I, I don't think I talked, I didn't continue to talk to people about it. Um I don't think I had any tremendously long conversations, you know I talked to one or two friends for an hour or two that sort of thing. But I certainly didn't keep returning to it and talking about it again and again or talking through it in some sense like that. I think I chose to do that by myself. Yes. Yes this friend is actually gay and so he has not a partner but he has had a number of close friends acquaintances die because of AIDS so he was very comfortable about it I think and he was very supportive. No, I didn't feel that there was anything I couldn't talk to him about.

Dean found that friendships tended to fade following the death of Janine.

Dean felt that his ability to maintain friendships was hampered by him feeling conscious of being alone, (which is discussed further in Chapter Eight). He

explained his situation:

(Friendships have) drifted off. I see, I see one friend in particular, Janine's girlfriend. We go down to the Ocean Beach Hotel about once a fortnight, and have a meal down there with the kids. Her kids and my kids and I see her husband quite a bit but he, he unfortunately had leukaemia for a while and ah he's been treated for that, and he's okay now but. You know, a lot of Janine's best friends, Maxine, Kay I see them occasionally. I went to a dinner there about a month or two ago. But they you know the situation is they've all got husbands, and they've got children now with families and you seem to - I suppose you retreat a bit. Ah you feel you'll a bit the odd man out. I really haven't really socialised very much apart from going to surf carnivals and going over East to surf championships and judging and a few things like that. I still do a little bit of stuff at Surf Life Saving to keep myself going. I really think I should...

David described Lorna as being a dynamic person who attracted people to her easily; hence most of their mutual friends were originally Lorna's friends.

Following Lorna's death the bond that held the friendships together was broken as David explained:

... and without her there stimulating, their interest in her and therefore our activities, um a lot of, Lorna's friends died away, even though at the time I made comment to them, it was like well you know what are we going do, it was almost like oh well you're our friend as well, you know I mean, you and Lorna were our friends, you know, you, you weren't, it wasn't just Loma, it was you and Lorna you know, and the reality is, it was, yes it was myself and Lorna not me, and, and so, yeah a lot of, a lot of people that I thought would be a lot closer and probably, be of more assistance, I mean a lot of people are out there saying you know if you need me, give me a ring, and yet they were, some of Lorna's best friends, and other people that weren't Lorna's 
best friends I think within their nature, have come to the surface of being, really nice people.

Other participants described how some friends surprised them by not maintaining the friendship or providing much more support. The participants who had experienced this felt that it was due to either the friend not being able to deal with their own associated grief or that the friendship was based upon poor foundations to start with and would never have been able to withstand a crisis such as a death, as Jane remembered:

I think it must be really, really difficult for some people to you know, lose your husband, or lose your partner and then, you do start to lose some of your social contacts, um, and then just yeah, just really having to um, have the, have the strength I guess to just sort of make a new start but, but it's, really it's quite, it's actually a very cruel society...

Rachel described how her children had difficulties dealing with Ken's best friend Dave, who was also savaged by the shark that killed Ken. The children had not been able to reconcile why he had survived the shark attack and not their father, as Rachel explained:

the children cannot have anything to do with Dave, they just don't
want to see him um, you know, because why did he get attacked by
the shark and why is he alive and Dad dead, you see...The children,
and um, he said, he said, he says to me all the time, don't you ever
worry l'll always look after you, and he, he, is helped Arnold with um
expenses trying to finish his car, and yeah, he is very good like that, I
think he's, he's in the background there.

Rachel continued to see Dave every day at the beach, with his scarred leg a constant reminder of the incident.

Most of the surviving partner's friends were willing and able to provide emotional and practical support for the surviving partner. The level of support changed over time as the perceived needs of the surviving partner changed. The main concern for the surviving partner was that their friends did not really appreciate the depth of sadness and loneliness that they were experiencing, and how these feelings didn't change much over extended periods of time.

Participants described the unconditional love and support they received from friends as what they needed most following the death of their partners. Practical support included helping with domestic chores, provision of food, transportation of them and their children, helping with the sorting and disposal of the deceased 
partner's property, helping with the disposal the family business, or large items such as cars and caravans, helping with family accounting and taxation needs were all highly valued by the surviving partner.

The surviving partner needed to have people give them empathetic and practical support, which allowed them the space and time to regain functionality. The surviving partner also needed the love and comfort from close relationships friends. The amount and depth of support needed varied depending upon the surviving partner's needs at the time. People who cared about the surviving partner needed to understand that the surviving partner's needs fluctuate sometimes predictably (around significant dates and events) but often unpredictably and are ongoing, and not necessarily reduced as a consequence of time. Mary summed up her experience of her friends' support:

\begin{abstract}
you...must never under estimate you know your, your friends you know like my, my female friends like, a lot are mothers and they're at home. But I tell you what, they're smart cookies. Like I mean they're educated people and some of the advice they gave me was brilliant. Absolutely, it was, I, you know, I was told things when I needed. So for me, they were my, like my counsellors. I tell you I can never, never thank them enough, there's no words, you know...
\end{abstract}

The participants often described how surprised they were with the quantity and quality of support they received from people. The participants also described their surprise at how support came from people that they would not have expected to receive support from, as well as the disappointment of not receiving support from some close friends.

\title{
Relationship of findings to existing literature
}

The responses that the participants in this research project described are congruent with the existing qualitative and quantitative research and literature. The social support that was provided by friends to the surviving partner formed a vital ongoing background of comfort and support (Anderson, 2000; Detmer \& Lamberti, 1991; Kaunonen et al., 1999; Martin-Baker, 1987; Moos, 1995; Rosenblatt, 1994; Sklar \& Hartley, 1990; W. Stroebe et al., 1996). As Kaunonen and colleagues (1999) concluded from their research: "Results suggest that those (widows) who had had social support were able to grieve by allowing themselves to disorganize and experience panic behavior" (p. 1304). Having a safety net of friends gave the participants a sense of security, when the grief that they are experiencing was overwhelming. 
The difficulties that some friends have in supporting the surviving partner are often due to their own grief related to the death of the partner. This has also been described in the literature with findings suggesting that the bereavement experiences can be profound and may severely reduce a friend or relatives capacity to support the surviving partner (Gamino et al., 2002; Sklar \& Hartley, 1990).

\section{The surviving partner's experience with community support}

Participants described how they discovered support from various parts of the community, such as neighbours, their children's schools, clubs and associations, which the deceased partner and or surviving partner were involved with, along with employers and work colleagues.

Participants often found him or herself being supported by people who were able to utilise their specialist skills to assist the surviving partner. These skills involved counselling, accountancy, and mechanical knowledge. Some participants described having people that they didn't know well or people who were not friends, being very supportive. Adam remembered how a local florist became very supportive by selling him the best orchids that she had every week. This was a flower that Maria loved because it reminded her of home, where her mother's frontgarden was full of colourful orchids. Adam would collect the flowers and found the experience to be aesthetically therapeutic.

Several women had to sell the family business following their partner's death. In Rachel's case, the man who bought the mechanical business offered to help her son complete the sports car that he had been working on with his father. At the time of interview the car was nearly ready for licensing.

David recognised that he would be lonely due to the lifestyle change of becoming a non-employed sole parent. Most of the people that were his established friends were working during the day, and at night they were home with their family, and on weekends they would be participating in recreational activities as a couple.

David explained how his childrens' school community had provided him with newfound friendships, activities and support:

....and what I felt, like, I think that the big, one of the, obvious things that has come out of it is because that my children go to a smallish school, and there's a lot of, parent - parent contact, that that has probably been my saviour, um the school, um, the school indirectly has provided me with, parent contact which is, provided me with you know, adult stimulation, ah it's, ah enabled my children, to, to, to participate in things, and I participate with them, that's like I was just 
bringing up then about, sailing. l'd go and do sports with the kids at school, and you know help out around the school with their bits, I'm in contact with, my children and also other peoples children, and that indirectly means that, you know, I have contact with other adults.

One of the most appreciated functions that family, friends and members of the community provided for the participants was the provision of cooked food. Sally's appetite for food was reduced for several months following Peter's death; however this did not deter people from attempting to feed her, as she explained:

...there wasn't food in the house, because there was a endless supply of food, arriving at the door. Um, and people were living with me, cooking for me, and trying to make me, you know, eat and which I couldn't do, I couldn't face food and I had nothing I had a cup of coffee, here and there and you know that sort of thing.

Sally eventually started cooking for herself, starting with fairly standard meals, and then began trying to replicate the Asian style dishes that Peter had cooked for her. She had never cooked these types of meals before, as she had only watched him cook. Most of the male participants didn't contribute to the family diet a great deal while their partners were alive, and relied heavily on food parcels to survive in the first few months following their partner's death.

One of the participants described how important it was for people such as neighbours not to treat the surviving partner like a pariah, by avoiding them. This often happened because the person was afraid of not knowing what to say or of saying something inappropriate. Rachel believed that the onus is on the surviving partner to reach out to people and discuss what has happened openly, leading the way to everyday conversation. As she explained, this helps to normalise life for the surviving partner:

If you tell, tell them and talk about it, they think oh you can, mention it, you don't have to cross the street and not speak to her and you can actually say hello to her and she's okay, so I think that, that is helpful to, you know people can stop and talk to you or wave to you or, it's really good, yeah.

Sometimes a person who was not close ended up providing valuable support, as Dana discovered:

I remember, not long after Carl died, I was walking the dogs over the park and, a girl came up to me from the tennis club years ago I hadn't seen her for a while, and her husband had died about eighteen months previously. She said to me all the conventional things and then that what you lose is somebody who loves you in that special 
way, she was much, much more desperate sort of case than I, but she said to me. I've had a book called "The Courage To Grieve". She said somebody gave it to her when her husband died, and she'd put it in my letterbox. Which she did, and it actually wasn't necessarily what was in the book, but the idea that she did it. I sort of, flipped through it and kept it by my chair I looked at it a bit, subsequently a close friend of ours, and he dropped dead to and I passed it on to Wendy, his wife and, and the funny thing is I don't know if any of us reads it, but it's the it's the symbolic gesture.

Not everyone is blessed in the art of tactful, empathetic conversational skills, as some of the participants discovered. Several participants described meeting people who had difficulty broaching the subject of their partners' death, as Mary described:

But a lot of people just didn't know how to, how to deal (with the situation), um a lot of people ah, found it difficult to ring, because they didn't know what to say you know um, and I'm sure everyone is different when they lose someone how, in how they ah, how they behave. I was ah, very good to everybody in that, that I didn't display any bizarre sort of things, telling people to piss off, or, or leave me alone, I, I, I didn't do any, any, any of that.

Rachel found that due to the unusual nature of Kevin's death she was bombarded with letters from people she didn't know offering their support and condolences but also wanting to tell her of their own personal tragedies, Rachel found this very difficult to deal with:

I think the hardest thing that I found, that people came to me and they wanted to tell me about some tragedy in their life, they all, they came to me and told me about, how their Father died or their Uncle died or their Sister or what had, some illness or tragedy. Yeah (laughs) but that, Martin people came to me all the time telling me their, problems and um, and l've always acknowledged, people that, have rung me or been around or, I couldn't write, I couldn't write to the people that wrote to me, I had, I had thousands of letters.

People frequently use death related colloquialisms in their everyday language that they are unaware of. As the participants described in this study, the surviving partner became acutely aware of the flippant use such colloquialisms, as Sally recalled:

I can't tell you how many of other people have said things like, oh you know, my husband would die if I bought that much Tupperware or blaa blaa blaa, it is so sensitive to you and you don't know whether to turn around and say, well my husband is dead, you know. And its not, its not even a thing, it's just a way, a way people use words to describe (things). I nearly knocked her lights out, and I, I think, I said 
that to her, I said to her, I said well at least he comes home again at the end of the you know the week or whatever, and I couldn't speak to her again, I haven't been able to, and I don't know whether she was just struggling to say something, to relate to me because she just, people want to just say something to you, they either, they don't know what to say, so say nothing.

The use of euphemisms to refer to the process of dying or death often irked the participants who would prefer people referring to the death directly, rather than using phrases such as 'passed away'. Some participants encountered people who gave them platitudes that didn't have the reassuring effect upon the surviving partner that the person had intended, as Brian remembered:

Yeah, she's gone to a better place and I said, oh, really, (chuckle); and I said quite outright that doesn't console me at all. This was during the week just after the funeral.

Some participants could not understand how people could automatically say how sorry they were upon discovering that they were recently bereaved, when the person did not know the deceased partner personally, whilst others came across people who made blatantly insensitive statements, as was the case with Julie:

...there was a dumb person at the Camping Club, he said oh sorry to hear about your husband, oh well never mind, there's plenty more out there, (laughing) I never spoke to him again.

Jane had members of the football club that Graham was involved with asking all the details of Graham's autopsy report, as well as asking her if she was seeing anybody new, both of which she found distasteful and inappropriate. Jane also discovered the incongruity between one person's actions and the way in which she articulated her thoughts when she came to visit her with her condolences:

And that's what one woman said to me (laughs) got to laugh, she came around you know and brought flowers when Graham died and said Jane how inconvenient Graham dying before the New Millennium.

Other people tried to draw inappropriate parallels from their own experience in an attempt to find empathy with the surviving partner, as was the case with Sally: "...one of the women from the kindy said to me, one of the mums, oh I know how you feel, my husband goes away all the time." Julie found that younger people tended to avoid the subject of the partner's death completely, whereas more mature 
people would at least tackle the subject, even if they didn't always succeed in creating quality discourse.

Jane was required to attend the beginning of term address by the Dean of the Christian private college she taught at. The Dean (who is a reverend) is fond of using jokes to enliven his speeches. Unfortunately during this speech he retold a story about a funeral that went wrong, when the coffin fell out of the hearse, ending up in a lake. At the end of the speech Jane remembers losing control and sobbing in despair.

Several participants described the pressure that they experienced by maintaining a public façade in order to avoid public sentiment, as Dana explained:

I knew those people well, but I don't see a lot of them now. But every now and then they ask me around to one of their dos. I really don't want to go because it's very traumatic for me because they all ask how are you going Dana? Are you coping well? And you think oh you know shit, am I only going to have to keep sort of saying I'm fine because they really don't want to hear anything else.

A piece of advice that was offered by Sally to people who were concerned about the most appropriate way in which they could can offer support to a bereaved person was to ask the person what it is that they wanted. Sally believed that there was little point in taking a hit or miss approach to supporting someone, when the surviving partner could have often prioritised their needs and allocated their support needs to the people that he or she feels has the best ability to provide the support.

The quantity and quality of support that was to be proffered by people cannot be measured by the number who attend the funeral, as Jane discovered:

There was you know about twelve hundred people at the funeral and now when I look at my support group um, I probably have still forty people, which I think is still quite a lot...

\section{Relationship of findings to existing literature}

The responses that the participants in this research project described are congruent with the existing qualitative and quantitative research and literature. Social support is integral to reducing the upheaval and social isolation experienced by the surviving partner (Kaunonen et al., 1999; W. Stroebe et al., 1996). The local community as a collective group has the resources and capability to lessen the burden of coping that the surviving partner feels, by providing practical support as well as providing friendship and diversional activities. 
Unfortunately not all people possess the ability to relate to people who are sensitive and vulnerable such as the newly bereaved partner. Exposure to the insensitivity of some people is something that the surviving partner cannot avoid and is a part of the reintegration into society as a widow or widower, which is often described as painful (Straub, 2001).

\section{The surviving partner's experience with loneliness, aloneness and social isolation}

All the participants described feeling lonely, alone and socially isolated to varying degrees, with these feelings waxing and waning at varying points in time following the death of their partner. Most of the participants were committed to longterm relationships with the death of their partner resulting in the surviving partner experiencing a sense of social isolation.

Most participants described periods of loneliness following their partner's death. The times when the surviving partner felt most lonely was when all of their children where out of the house, night-time when children and the surviving partner was alone in bed, and on the weekend when children and friends were occupied, leaving the surviving partner alone. Unless people were very perceptive and actively sought out the company of the surviving partner, people were not generally aware how lonely the surviving partner was feeling, as Jane described:

\footnotetext{
Two years (after Graham's death) probably in about October or September last year, I um, talked to a girlfriend and we were having this conversation and I mean I knew that I hadn't dealt with it emotionally and I knew I never you know I would never let on to the girls (her daughters) how sad I felt or how lonely I felt, because I didn't want you know, to worry them um, but I knew that that was wrong, you know I knew that (I should tell them).
}

One participant hadn't spent 24 hours alone since her husband died, which was two years at the time of interview. Other participants had spent some time alone, with those with no children living with them being more used to having periods of time where they had been alone, when their partner had been away. This previous experience probably didn't reduce the feeling of loneliness though.

David felt that the surviving partner becomes so consumed with surviving everyday life that they neglect to contact their friends, which can erode friendships over the long term. 
Apart from losing a long-term companion, lover and friend, the surviving partner is faced with life as a single person, a concept that was alien to most of the participants, and unwanted, as Mary pointed out:

I don't want to be single, l've always you know been down on people who are, who are single because you know they say how awful it is out there, and I don't want to have to go to clubs, and, you know have guys just, (ugh) you know, you know eyeing you off.

Several participants described not being able to go out alone to places such as movie cinemas or restaurants. The thought of going out alone was something alien to the majority of the participants, having been part of a couple for so long, as David described:

Um, I mean even though they (the kids) had sleepovers before, I was, (laughs) I was, ah I suppose I was of the old school where I wouldn't even go to a movie by myself, it was just a really weird concept. I mean I still haven't been to dinner by myself.

Apart from the social stigmatisation that participants were aware of as newly solo people, they were also keenly aware of socialising without a companion that was closely attuned to you, as Dana described:

I think, it's interesting that when, when you are a couple, a complete couple, you don't need other people, not in the same way. You are complete in yourselves. You can think I really don't want to stay at this dinner party any longer, and you catch his eye and you go. You share so many memories and things where you don't actually have to explain the background. And in a way there's a sort of arrogance that doesn't need anybody else.

Most of the participants' friends, who were married, were still coupled.

Several participants described the difficulty in going out as a solo person with another couple, as Jane explained:

(I was at a) wedding where you're the odd one out, and because I'm probably, like I don't have any other friends, female friends, who are in my situation I have one close male friend um who lost his wife six years ago and she was a close friend of ours, um but apart from that, um yeah I don't, I don't know anyone else and um so consequently you know a lot of social occasions I am the odd one out.

When a person is no longer part of a couple the dynamic of the existing friendships become out of kilter, as David illustrated: 
I premised it by saying this, when you lose a partner, you, you lose, a lifestyle which incorporates doing things together, and ah fitting in together and, hmm, you through your friends initiate things and they through their friends initiate things and through mutual friends you initiate things, when your partner dies, the void that they leave is also the initiation of friends, and Lorna was a very, you know out there sort of person.

Some participants felt that people asked them out to social occasions because they felt sorry for them. Dana was invited to attend a social function which included dancing, which was a pastime that she and Carl enjoyed as a couple:

People have asked me to dance, it's dreadful, I can't go. I've tried a couple of times l've thought what am I bloody well doing here? People feel they've got to suddenly look after you and I hate that, I don't want anyone to feel like that. So all those things that you've done in your life, you have to pare away, because it doesn't work any more.

Several participants were aware of some people having difficulty with their own partners being alone with the surviving partner, fearing that the surviving partner is now in a position where he or she may be looking for a new relationship. Sally described the tension developing in one of her friendships:

...that's something else that was really interesting, early on um, there's a couple who are friends, and I'm having a lot of trouble with her we were good friends, hadn't know each other for a long time, but we were good friends, and we always got on well, and she's not coping with him coming to see me, at all.

The participants who talked about this phenomenon stated that if they hadn't contemplated a relationship with their friends' partners prior to their partner's death then they would not consider it now that they are single. Despite this some participants said that they had to be careful that their behaviour was not misconstrued when they were socialising with friends.

The younger participants felt the isolation of widowhood more keenly than their older counterparts. When Sally heard that a woman who was involved in her daughter's school had become a widow, she felt less isolated, as she explained:

Um, and then, this girl at school, Julie who lost her husband on the last day of the holidays (that) Peter died, it's like you know you don't feel like you're so singled out any more you know, I thought I was the only person in the world that at thirty four that had, had lost her husband completely not true at all, but you do feel that way. 
Brian not only discovered that he was the only male drawing a single parent pension in a large region in Queensland, he discovered that there was no provision for the status of 'widower' on the form he had to fill in, reinforcing the unusualness of his situation.

David discovered what it was like being a male in the predominately female world of primary parenting.

Yeah, they tend to have that balance so that the boys talk with the boys and the girls talk with the girls sort of crap, you know, and so yeah, I have actually found, probably faults in the, in the system more that l've found faults in ah. Yeah, yeah, so, and again because not many men get involved in, in school environment ah it's, you know ninety nine percent women. Ah your level of conversation, can only go to a certain point, and then um, they go back to Venus and, and you can't, sort of a, a no go, it's not a no go, it's, you just don't get on to conversations that, that, may be confrontational, you don't get on to conversations that are problem solving, you don't get on to conversations that are, are family, don't get on to any um, any conversations which are associated with their other partner, just sort of things that you start to learn, that you don't do because otherwise. They will have conversations um, with regards to some of their marital problems when they become problems but in the general normal of things they won't, they won't go there. But you will, but I do get used as a sounding board, as a male, but, yeah ah it's a lot of, I mean, that there's a lot of non-equal opportunities out there for males for single males, when it comes to female, the female environment, so I find that, that's been quite difficult.

Dana felt that due to the number of widows, the surviving partner becomes merged into a group that is lost, as she explained:

...because suddenly you join the legion of lost women. You become invisible, you do. But it's, it's not so much a problem for me cause I have a wide range of friends and, and close friends, so we can laugh about it to each other. But you become invisible.

\section{Relationship of findings to existing literature}

The responses that the participants in this research project described are congruent with the existing qualitative and quantitative research and literature.

Loneliness and feelings of social isolation following partner bereavement have been well documented in the literature (J. Costello, 1999; Sable, 1991; W. Stroebe et al., 1996; Vanderwerker \& Prigerson, 2004). The experience of loneliness affected all of the participants regardless of their age or gender. Feelings of social isolation or exclusion are very real experiences for the surviving partner, leading them to feel that their journey through bereavement is one that they are sometimes travelling 
alone, due to their perceived lack of understanding from those around them (Straub, 2001). Stroebe and her colleagues, studied 60 recently widowed men and 60 recently widowed women, to determine whether social support influenced the level of loneliness experienced by these people (1996). The researchers discovered that due to the strong attachment that the newly bereaved widows and widowers had with the deceased partner, that social support did not reduce the sense of loneliness felt by the person (W. Stroebe et al., 1996).

\section{The surviving partner's experiences with pets as support and comfort}

Six of the participants had dogs as pets, and three had cats. Participants felt that having a pet was therapeutic, that dogs can provide unconditional love and company, as well as providing a distraction and comic relief during times of stress. Dogs also encourage the surviving partner get outdoors and exercise. The female participants felt more secure in their home with a dog as a pet. Dean explained how his dog was company during lonely times:

And ah I must admit that life does get lonely and the dog sort of helps a lot. As a matter of fact I had this little dog, a little white terrier, (she used to) bark like mad but she was a great little dog and ah she died last June twelve months and ah Mike went straight to the dogs home the next day and came back with this creature. Which wouldn't have been my choice but he just saw I needed a dog and ah it's been great company. You're great company, a great housedog. But it does restrict you ... you can't go away and ah I said Oh I'll put the dog in a dogs home and they say "No you can't, you're not allowed to do that". I said well we've got to work a plan out. Look if you're here or Jimmy's here or if I go away next time and Jimmy's up in Broome, well Mike is going to have to come here everyday to look after dog or go to a dog home.

When I interviewed participants at their home, I was constantly aware of the close relationship that the participants had with their pets. During every interview of a participant who owned a pet included the interaction with the pet, involving both the participant and myself. The comfort and companionship that was derived from the relationship between the surviving partner and his or her pet was highly regarded by the participants.

\section{Relationship of findings to existing literature}

The responses that the participants in this research project described are congruent with the existing qualitative and quantitative research and literature. The relationship the bereaved person has with his or her pets (especially dogs) is not 
that well documented in the literature, with the emphasis usually being placed upon the bereavement experiences following pet death (Straub, 2001). A study by Yuko Tanaka that supported previous research in Europe and the United States of America, found that companion animals helped alleviate the distress following partner bereavement in the elderly, in particular the respondents who had companion animals, when compared to those who didn't, had: "a greater sense of being loved, a sense of being protected, enthusiasm, self-esteem, a sense of usefulness, and a sense of purposefulness in life" $(2004$, p.8).

\section{PHENOMENOLOGICAL EXPLICATION OF THE PARTICIPANTS' EXPERIENCES}

During the calamitous time following the death of a partner the surviving partner needed the support of others not only for love and comfort but in order to take over some of the tasks that were burdensome. Family and friends helped the surviving partner attend to domestic matters, and other organisational matters such as arranging the funeral and the wake. Other functions that needed to be fulfilled were that of transportation needs, bureaucratic and financial matters, which could often be attended to by others.

The surviving partners' most intimate relationship following that of a partner was that of his or her children. The participants who had older children gained immense support from them. The older children were able to perform family functions that were hitherto the responsibility of either parent, thus allowing the surviving partner to have some time and space to deal with their loss.

The participants were able to experience mutual support between him or herself and his or her children. The participants who had younger children, experienced the extra demands that young children require from parents, however, the unconditional love and the exuberance that young children radiate could give comfort to the surviving partner who was feeling bereft. Younger children provided a distraction to the surviving partner, through the ongoing need of close parenting, as well as providing opportunities for play and sport and other recreational activities that were distractions, which could relieve the ongoing feelings of sadness and loss that the surviving partner was experiencing. Younger children also forced the surviving partner to articulate what death means and how permanent it is, which served to reinforce the reality of the situation, despite the painful reminder. 
The surviving partner's family often provided enormous support in a myriad of ways. The surviving partner's family (which included the deceased partner's family) also experience grief and loss in relation to the partner's death, and in most of the surviving partners' experiences were able to compartmentalise this when necessary, so that they could give effective support. Not all of the surviving partners' family members were capable of giving support to the surviving partner, which surprised and disappointed some of the surviving partners. Since the time of the interview, one of the participants has become completely estranged from her family.

The surviving partner's friends were often able to provide love and comfort as well as continuous support of a practical nature. The surviving partner was often able to have more revealing or emotional conversations with close friends than with their family. Friends were also able to provide distractions such as social outings and serve as a conduit to meeting new people. Some friendships became strained following the death of the partner, resulting in a few friendships dissolving. This was balanced with other friendships strengthening and new friendships forming.

The amount and diversity of community support often surprised the surviving partner. Those surviving partners who had dependent children had a microcommunity that rallied around the surviving partner providing them with food, transport, and quasi-parenting duties when appropriate. School also provided pastoral care for the children. Social and sporting clubs provided support along with help providing memorials commemorating the life of the deceased partner.

Pets were able to provide unconditional love and comfort to the surviving partner. Pets were also able to provide a distraction, and in the case of dogs, required the surviving partner to take them walking which forced the surviving partner outdoors, which could invigorate the surviving partner when they were feeling jaded.

Despite the best efforts of family, friends and the community the surviving partners' experienced loneliness, feelings of aloneness and social isolation. The surviving partner discovered that there was no instant or satisfying replacement for the deceased partner. The surviving partners' sense of loss and abandonment infused every part of their being, regardless of the goodwill, love and support that was provided by those around them. 


\section{CHAPTER EIGHT}

\section{THE SURVIVING PARTNER'S RELATIONSHIP WITH OTHERS}

\section{WHILE REGAINING INDEPENDENCE}

Grief is like sex. It can be done on your own, is best done with one other, and is disapproved of if done in public.

Colin Murray Parkes, (Walter, 1999, p.138)

\section{Introduction}

The sudden unanticipated death of a partner causes the surviving partner to experience social dislocation; resulting in losing, whilst strengthening and gaining relationships. The need to reposition oneself socially, often led the surviving partner to regain independence.

The surviving partner discovered that he or she was not grieving alone, with family, friends, and associates sharing in the grief experience. The need for the surviving partner to lend support to others was found to be unavoidable. The majority of the employed participants remained in the workforce following the death of their partner. This chapter explores how the surviving partner dealt with the needs of others, while dealing with their own needs.

The surviving partner's experience with children needing his or her support and comfort

As mentioned in previous chapters, participants described having dependent children as a major influence in how they adapted to life following the death of their partner. Despite suffering a tragic event such as the loss of a partner, the participants in this study managed to continue in their parental role as effectively as they could. As Sally explained: "I'm a mother for crying out loud, I want to fix it for my children, ...having had the children there...sometimes it's very, very hard but in other times it's helped me." 
All of the participants described how distressing it was to inform their children of their parent's death. As Mary stated: "it's the most terrible thing to have to tell your children."

It was especially challenging for parents with very young children, as Sally so eloquently explained:

And then I thought, you know, these poor kids, they're asking where is Daddy. and I'm saying he's in hospital, there were doctors and nurses looking after him and somehow I needed to prove that to them so I did, I told them we were going, and I said to them you know daddy, and I told them that well, he, they knew enough, that the police had come, and daddy had, had an accident so I had told them a little bit about it, in those days and I basically said to them you know Daddy's um, very hurt he got hit by a car, and he's very hurt and his chest is sore, and he's head is sore and we had a book, a little medical book for children so I was showing them, the chest with all your ribs. And, um, basically said to them that he needed things to help him breathe and there'll be some tubes in Daddy's chest, helping his lungs and in his mouth, and lots of equipment because he is in hospital, and all those machines are letting the doctors know what's happening, so um, not to be scared about it, and you know as best you can explain to an then, four and a half and two and a half year old so I did that, and we took them and you know, the hospital staff were like freaking out I think, a little bit, like, oh, my god these young children um, and I said well, no, look they need to see him, they need to see him.

Sally found it useful to use a popular animated film the "Lion King" (Allers \& Minkoff, 1994) as a medium to help her children verbalise their own grief whilst empathising with Simba, when his father died. Sally tried to encourage her children to relate to the concept that their father will always continue to live in them, as the Lion King tells Simba. The other animated film that Sally found useful was "Toy Story" (Lasseter, 1995) where the main character, Woody, doesn't have a father. These films gave Sally the opportunity to discuss and explore the concept of being fatherless with her children.

Young children have an abstract view of death as being a semi permanent state (Skinner-Cook \& Oltjenbruns, 1998) as Sally discovered when Eliah, who was five years old when he accompanied her to pick up his father's suits from the dry cleaner. When Sally asked Eliah why he appeared to be so happy, he replied that he was happy because he was going to see daddy. lan, Sally's youngest son who was three years old at the time of Peter's death could not understand why his father had died, as he believed that he was the strongest man in the world who could have kicked the car out of the way. On another occasion, when walking through a 
hospital recovery ward, Eliah thought that all of the patients were dead like his father.

The constant need to reinforce what has happened to young children is an added burden for the surviving partner, but also acts as a constant grounding mechanism, rooting them in the reality of the situation. As Brian discovered, the need to continue to care for your children gave him the incentive to continue to function:

I can still remember the thoughts that were going through my mind, yes, two years ago, and as I said, on day one, the kids have got to be looked after, the kids have got to go off to day-care; you've got hundreds of (things to do), you've got to wash, you've got to wipe, you've got to do all the things that your wife would do around the house ... as well.

The need to support children who are attending school is especially challenging. Rachel did her best in attempting to prepare her youngest child for her return to school:

One of the first things I said to Annie, I said now it's all well and good now, and people are bringing you flowers and the girls are writing you cards and you've got teddy bears, and I said but when you go back to school next year, people have, will have forgotten. They won't be worrying, you'll just be another girl there, and then you'll have to, just handle that you have, had this loss and cope on your own, and just get on with it, and people will say, you know um, go and asked your Dad to help you and things like that, and you'll have to handle that so I tried to prepare her for that be, and, but I, I just, I do feel that um, I do feel a lot of people haven't got over it.

Annie attempted to cope with the rigours of attending school while she was grieving, however this took a toll on her health, resulting in frequent bouts of illness. Eventually Rachel persuaded her to take up a sport, and she chose rowing, which improved her health and wellbeing, but also required a large amount of commitment from Rachel, to get her to and from training in the early hours of each morning:

Annie could barely go to school ah first term and second term I said you have to go to school but you can go to the sick bay, if you can't stay awake and she was barely doing any work at all and then at the end of the year she got the English prize for the year, top of the year...

Rachel also had her 18-year-old son Arnold to support. Arnold was supposed to sit his first Tertiary Admission Examination on the day his father died. Her 24 year old daughter, Ruby, was sitting the final year exams for her university 
degree on the following Monday. Rachel explained how concerned she was for

Arnold's mental health:

He found it tough last year, and I'm, I was so worried about him I mean, sometimes I would not, want to leave him alone because I thought he might have been suicidal or something like that, I, I got um, he was seeing a psychiatrist and counselling and everything I could do, for him, I could, I did you know. He's had special consideration (because) he was absolutely, you know messed up um because the college um, submitted marks that he's done from mocks and they weren't high enough, Scotch in the scheme of things didn't do as well that year in the TEE so, he's, what he thought his marks were going to be to get into what he wanted to, were not good enough to get into any of his preferences.

Mary found that her son Sam, who was in his third year of university studies, threw himself into his studies following Alf's death; however, Stephanie who had just finished school and was in her first year at university struggled. She ended up deferring her studies and taking part-time work. Mary described the university as being very helpful to both children, providing counselling and other support:

in the mean time um, um, my Son who's been going to Uni, he's doing $X X X X X$ and ah um he was in his third year of, of Uni, and Stephanie had just finished year twelve and had just started University at UWA, she'd only been two months and it had just come to Easter and, she'd really got behind, she found it a real struggle, and she thought oh yeah Easter, great I'm gonna have a bit of a break I'm gonna be able to catch up, catch up on assignments, and do all this and of course when all this happened it just, um, Sam was, I don't know, just, don't know whether, what it is with Sam he, he just went, how he coped his mechanisms was just get straight into, continue with his studies, he was counselled, um, at Uni, so were both of them, and they were very, very sympathetic at Uni, I mean, they said take as much time as you like, the counsellors were there to, to talk with them, um Stephanie found she couldn't go back, um it mucked her up to much, she couldn't cope, so she deferred, and just took on some casual work.

When a parent dies, the surviving child may be overly anxious that the remaining parent will die soon after (Skinner-Cook \& Oltjenbruns, 1998), which may result in children becoming hyper vigilant, over protective, or needing to be intimately close with the surviving partner as was case with Jane:

Kylie...spent the first year in my bed with me, she slept with me for a year, she was only thirteen and um, but she writes things down, she sort of expresses herself that way... 
Sarah and Jimmy, both 18 year olds, discovered their dead mother in their home's bathroom, after she collapsed and died from a cerebral brain haemorrhage. This experience proved so traumatic for Jimmy that he has yet to step foot in that bathroom since her death (which was at time of interview, three years). Both children have made it difficult for Dean to make any changes to the house, or to dispose of any of their mother's property, which he has found frustrating.

But you know Sarah made it quite clear that she didn't want anything disturbed and ah I would say that there would be a maximum of about $5 \%$ alteration in the place, which I mean... see like this chair. I mean Janine loved this chair and I said look they mucked around and were very, very careless and they broke it - the bloody chair. And I said where are the bits of it so I can put it together. And they said no look that's Mums chair it must stay there, So I said to Jimmy why what's this doing out of the back of it? He said it's hiding the back of the chair and I said let's get rid of the chair you know. And he said no, no, it's got to stay there. And boy, that chair it really makes it hard to do any moves. So um I'm going to really, really start cleaning things up. I started yesterday to tell you the truth that day after Sarah headed off for XXXXX. I thought l'd get stuck into Mike's room and oh I think there were bits of paper and things that had been there for years. I did say to her look when you go I want you to clean your room up completely and make it quite easy so that if I did sell the house and I had to get out of your room it would be easier. But that was too hard, she tidied it up a bit but. I mean if I sold this house people might want to live in it for a while but the value of this house is in knocking it over and putting a few units up. So if I sold it I would have to get out and all the junk so therefore l've got to start disposing of a lot of it. You've got no idea what my garage is like. There's 30 odd years accumulated. I bought this place in 1954. Ah the accumulation of bloody junk galore.

Following Ken's death at the beach Rachel's two eldest children have not swum in the ocean however the youngest child Annie has continued to swim at the beach and train for her "Bronze Medallion Life Saving Certificate."

The participants recall expending a large amount of their emotional resources on supporting their children, as Rachel recounted:

Yeah they're all getting their lives back together, they had a tough time, and then, see that was, I found that was difficult to, to try and support them.

The participants who were parents felt that they had little choice in continuing to participate in the care and support of their children, especially those whose children were under the age of eighteen. For those participants whose children 
were adults, the support was reciprocated, with the adult children being able to lend comfort and support to the parent.

\section{Relationship of findings to existing literature}

The responses that the participants in this research project described are congruent with the existing qualitative and quantitative research and literature. The impact of parental bereavement upon children may be underestimated, with children often being not acknowledged as grieving (Griffith, 2003). Young children may become anxious and fearful, and sometimes withdraw, the grief experience of young children is often compounded by underdeveloped language skills, which hinder communication (Griffith, 2003).

The participants' younger children's responses to the death of his or her parent being a temporary phenomenon, is well documented in the literature (Griffith, 2003; Leming \& Dickinson, 1998; J. Worden, 1996). The older children were able to grasp the finality of the death more quickly with some being able to comfort and support the surviving partner with others acting out or becoming belligerent $(\mathrm{J}$. Worden, 1996).

\section{The surviving partner's experience with his or her children in distress}

A few participants who had teenage children described them as displaying some degree of anti social or risk taking behaviour. The behaviours ranged from under age drinking which resulted in maudlin behaviour, or violent outbursts, car theft, and recreational substance use.

Jane described how Ann who was 18 at the time of Graham's death didn't talk about her father's death to any great extent with her, and became distressed when drinking alcohol, as she explained:

(Carol had her) ...twenty first birthday party in February and cause a lot of her friends were born in January and um it was huge, had a hundred and fifty people here um I mean obviously when I spoke, I acknowledged Graham, but her friends did too when they spoke, um I think because he was very much a part of their secondary school years she, she feels, she felt it more and I hope she would, I don't know, she was closer that the other two but she, it impacted more on her, as far as I can tell, the middle one (Ann) who's very much like her father, um, has not you know doesn't really um, tell you anything um, and the only times that she's really got very really distressed has been when she's had too much to drink. At her school ball, she fell in a real hole but um and I spoke to Jan the counsellor about it and she said well you know whether it's alcohol that brings it out, it's better 
that it comes out, rather than stays locked away in there cause she obviously, yeah, she feels it really you know very deeply but finds it hard.

Adam took his children to family therapy, because he was concerned about them both acting out their grief in harmful ways.

(We) had some family therapy anyway, and we all went along and er, with the one exception, this guy, not so much tripped up that's perhaps the wrong word, but, opened Jeremy up and Jeremy just burst into tears, you know, and was really very cathartic in the true sense of the word, very moving, I was in tears myself and it was just the grief, you know, for his mother he hadn't really got to that yet, he was out stealing cars, he wanted to kill people and you know, that was what he needed...Confused, he was fucking furious! And he's just sitting there for like an hour. And after a while the therapist said to him, you don't like being here Jeremy, he just didn't say anything; what's wrong with being here, he said, its fucking boring. He said, what's so boring about it, he said, you! And then, you know, they went on from there, and the next thing Jeremy got in touch with his anger and sadness...

The younger children would spontaneously erupt into tears because of events, or photos that evoked painful memories of their missing parent, or display the need to have more attention than another child. These reactions would keep the surviving parent constantly alert to their evolving needs.

The participants' children, who were behaving in ways that indicated a level of distress that could cause ongoing behavioural problems, sought counselling with varying degrees of success. The younger children appeared to be regaining the behavioural patterns that they had prior to their parent's death without professional intervention.

As was mentioned in the previous section, some children had difficulty revisiting the sites of their parents' death, or had other issues such as not wanting to get a driver's licence as in Jimmy's case, which may be related to not wanting to gain independence.

\section{Relationship of findings to existing literature}

The responses that the participants in this research project described are congruent with the existing qualitative and quantitative research and literature. The support needs for bereaved children can be profound and need to be recognised and given the acknowledgement that is required. The difficulties experienced by the children in this research project are reflected in the literature (Black, 1998; Elliott, 
1999). The ongoing effects of parental loss during childhood, into adulthood are of concern to health professionals with a significant increased risk of mental health problems in adulthood that have been related to the parental death during childhood being noted (Black, 1998; Elliott, 1999).

The experiences of the participants in this research project support previous thanatological studies in that the bereaved person is not usually able or willing to remove him or herself entirely from their everyday life, thus necessitating the ongoing commitment to those who are important to them such as their children (Rando, 1993; Straub, 2001; Zonnebelt-Smeenge \& Vries, 1998). Children who experience parental bereavement need quality support, not only from the surviving parent, but family and friends (Elliott, 1999; Griffith, 2003).

The need to acknowledge that young children are able to grieve is being recognized by society and researchers such as Griffith (2003) who quoted Alan Wolfelt's advice: "If they are old enough to love then they are old enough to mourn and to grieve," (p.217). The teenage years can prove to be challenging enough, without the added stress of a parental bereavement, Elliott (1999) cited Raphael (1984) as identifying adolescence as an age group that is particularly vulnerability to the loss of a parent. Raphael asserts that the stress of bereavement is superimposed upon the changes already taking place in adolescence; these changes may create their own psychological disturbances.

The participants in this research project discovered that their children needed a supportive and connected parent. The suddenness of becoming a sole parent and the burden of grief associated with the surviving partner's own sense of loss added to the stress experience by the surviving partner. The positive side of this experience is that the surviving partner who is still actively parenting is forced to maintain a sense of purpose and structure in their lives, which can assist them to integrate the death of their partner into their lives in a constructive and worthwhile manner (Zonnebelt-Smeenge \& Vries, 1998).

The importance of maintaining good quality communication between the parent and child, and being available to listen was reinforced by a study by Morin \& Welsh (1996) who interviewed 32 adolescents who had experienced death and loss. The group included 19 young people attending high school without a criminal record and 13 who had been through the judicial system. The authors discovered that regardless of background, $66.7 \%$ of the young people regarded talking and listening to parents, family and friends, as the most important comforting strategy (p.585). 


\section{The surviving partner's experience with allowing his or her children to develop their independence}

Another challenge that the participants had to face was allowing their children increased independence as they matured. Having lost the security of a partner, the surviving partner may feel apprehension at allowing their children increased freedom, as well as the potential to leave home. Mary decided to travel to Europe with Stephanie who was 18 years old:

...we travelled around Europe everywhere we had some friends to visit over as well, and it, it, it was, it was just so good, you know and I really saw the change in her, just in that time, she amazed me how, how she'd, how she'd grown up, how sort of like street wise, how, how she could, from knowing just as an eighteen year old to leave, and I knew the sort of person she was, she was so, home, sort of a body, to go to another part of the world not know anyone and to, to be able to do what she did is just, you know I'm very proud, very proud of her, and so when I came back I was so much happier, and at ease knowing that, she's going to be okay because in that six months I just fretted so much for her.

Rachel has remained very focussed on her children's well-being following Ken's death and has attempted to rebuild their confidence and independence. She explained:

...my concern is that they all, get, themselves fairly, you know, established and independent in their, and give them as much encouragement as I can, without draining myself too much, but you know, I just you know, try and remain positive really.

Rachel soon discovered that the other side of having independent children was that she was often left alone:

So, and you know I make sure that, I'm not sitting alone you know if the kids go out on Saturday night, Arnold goes out with his mates or, if Annie's got friends here I'll be home, but if she's going out I make sure I'm going out too, I don't, I don't sit alone, I just worked out, I hate being on my own, and I just think well it's my own fault if I am, I just get up and I'll organize something, or um, meet somebody or even go to the movies anything, so that I'm not sitting alone, you know so, but the kids always check, are you doing something tonight Mum (laughs)?

The teenage years are characterised by the need for the children to separate him or herself from the family in order to create a sense of autonomy (Elliott, 1999). From my own experience and that of friends and family, this increased level of independence that is sought by teenage children is normally dealt with some level of 
trepidation by parents who haven't experienced a loss. For the participants in this study, the increasing levels of independence that their children are requesting may represent another loss. The participants in this research project were mindful of this and the needs of their children and encouraged their increasing need for independence.

\section{The surviving partner's experience with his or her children's desire for a replacement father or mother}

The participants who had young children talked about the challenge that suddenly becoming a sole parent created for them. Some participants were acutely aware that their children would be comfortable with having another person in their lives. Sally observed with her children:

...the other night Dennis came, and um, with a present for Eliah for his birthday, and they don't have kids, and I know he desperately wants kids, and he is so good with my boys, and they love him, you know Dennis kicks the footy or throws them around, he's a big guy you know, he gets them on their bike and they fly in the air, he's just great fun and you know I see them laughing with him and it's lovely.

What Sally's children experienced is considered a normal reaction to losing a parent and should not be regarded as him or her forgetting or diminishing the importance of the deceased parent (Skinner-Cook \& Oltjenbruns, 1998). By allowing male friends to have a closer relationship with her children, Sally was also reducing the burden of sole parenting, and exposing her children to a range of role models.

\section{Relationship of findings to existing literature}

The responses that the participants in this research project described are congruent with the existing qualitative and quantitative research and literature. Younger children are more likely to yearn for a replacement for the deceased partner than teenage children due to them needing more intimate and constant attention from a parent than older children (Griffith, 2003; Skinner-Cook \& Oltjenbruns, 1998). The difficulties of managing children as a sole parent occur overnight for the surviving partner when their partner dies suddenly and unexpectedly, resulting in a parent who is burdened not only by the loss of a partner, but the loss of a co-parent. The surviving partner may need to rationalize the activities that he or she had previously shared with their partner and their children in order to create quality time with his or her children whilst adjusting to the new role 
(Straub, 2001). By attempting to provide the equivalent input of two parents, the surviving partner is likely to create a situation that causes more problems than they anticipated. The adjustment of children to a new partner is discussed later in this chapter.

\section{The surviving partner's experience of relating to the deceased partner's children}

Three participants described how they interacted with their deceased partner's children following their death. Lyn initially had a strained relationship with all of Geoff's family but eventually developed a friendly relationship with one of Geoff's sons. Don, did not have children of his own but attempted to maintain contact after Jane's death. He described this below:

I had a better relationship with, her not a strong relationship but some
relationship. And I spent, um because her husband had died some
years earlier the children of course were now orphans and um I felt
um that well obviously there was a lot um you know needed to be
done - could be done there. And I felt that was an important thing to
do um and so I had a fair bit of contact with them. But um within a few
months I sort of got the feeling that there were plenty of people
looking after them and also in particular I think it was fairly painful for
the daughter to see me. Because it reminded her very much of her
mother until the last few months of her mother's life and that sort of
thing. And so I just sort of gradually dropped out, I mean I sort of
occasionally made contact Oh every three months or something like
that. But it just became clear that there was nothing in particular that I
could do that wasn't already being done, so.

Both of these participants did not have a well-established relationship with the deceased partner's children, leading to the contact between them fading over time. Adam continued to care for Maria's son Jeremy following her death. The relationship was strained at times, as has been already described; however, the relationship between Jeremy and his stepfather has remained sound. As Adam discovered, maintaining a quality relationship with a partner's child is difficult enough without the trauma of his parent dying.

For the participants who did not have biological children from their relationship with the deceased partner, the deceased partner's children were a link to the deceased partner. By having some sort of relationship with them enabled the surviving partner to share memories of the deceased partner with the children.

With the increased number of marriages and partnerships ending in divorce and or separation the number of 'blended families' have increased in Australia (ABS, 
2002a). This increase in families where children have been sired from individual parents will inevitably increase the number of non-biological children living with surviving partners following the death of the child's parent. This is an area for researchers and health care and support services to be aware of.

\section{The surviving partner's experiences with bereavement counselling}

Seven female and one male participant sought professional help or support. The general feeling amongst the participants was that it was sometimes too difficult to talk to family and friends about the way they were feeling, especially if some time had passed since the death of the partner. Jane recounted how she was referred to a counsellor:

I was having a, um a massage every three weeks or so with a gorgeous lady who um, was actually a Buddhist and I found her very helpful just, she's just a lovely lady to talk to and, um you know and I said to her one day I thought It was really time to find someone else to talk to and she gave me the name of this lady and I been going to see her since October and she's, she's been fantastic. Yeah, she's been really helpful, and she's actually, she's a counsellor she's ...she's yeah, she's been really good and she just said to me you know my own, her major concern with me is that I just don't let people know, you know how I'm feeling and just dealing with it on a emotional level.

Jane's experience was not unique, with other participants describing how it was often difficult for them to talk to family and friends who were dealing with their own grief.

Having an independent person to talk with who is non-judgmental is the main reason professional counseling was sought. Rosalie and Rachel had a few sessions with counsellors, both finding the experience worthwhile. It allowed them both to express their sadness without feeling that they were encroaching upon someone or feeling guilty for having such feelings in the first place.

Unfortunately not every participant who sought help had the same positive experience, as Jane recalled her experience with a counsellor provided by the funeral company:

...it was the follow up that I was really, that, part of the, the package deal was that you had two sessions with a counsellor, well on reflection he was probably about the worst person I could have spoken to, he um, he never used Graham's name once, he said to me um, sort of briefly you know I told him what happened and then he said to me "okay what were your expectations, over the next thirty 
years" and I said, "oh, you know we were building in Denmark you know Graham had, we'd be Grand Parents and we'd travel and we'd do this and we'd do that and la di da di da" and he wrote it all down and then he got his pen and he crossed it all out, like this, and he said "Well Jane that doesn't exist anymore, that's shattered you know that don't you" and then he did this other little diagram and came up you know two years later and he said you know with this other shape um and you know and he said you'll take memories from, from, from Graham and this and you'll do this oh, and I thought, oh, anyhow, it, he was just shocking, absolutely shocking he couldn't, he was so impersonal and he came, he was their, their Psych, their Counsellor, and I can't remember his name, it was....

Sally gained some help at her eldest child's school, which she found supportive. Sally was offered counselling through the Coronial Enquiry Section, but decided that she didn't want to see a social worker, which they had offered. This was due to a poor previous experience with a social worker.

Adam had been attending psychotherapy for a few months at the time of the interview, with good results. However, the sessions were often painful and involved confronting the issues that have been troubling him, as he recalled:

Erm, I think that what I try and avoid actually is an evening with my bloody psychotherapy, if you like, you know, he wouldn't, he certainly pushes me a bit in terms of exploring my grief, if you like, and I would say I know you want me to cry, but l'm not going to fuck you! And, er. $I$ think the most graphic thing is seeing her in a bloody blue theatre gown you know, intubated, cannulated and dead... and, er, I think I try and not think about it and I certainly never er, you know, so I guess that brings it back I guess, and, the other unspeakable I have is the post-mortem, you know, when...

Of the seven women who sought professional counselling all but one reported that it was helpful to have an independent person to talk to who can give non-judgemental support and guidance. This was preferable to talking to friends and family who, as Carol pointed out, may have very little insight into what the surviving partner is experiencing through lack of experience and training.

Four of the men had not seriously considered seeking any form of counselling support, preferring either their own counsel or that of friends. David summed his feelings on the matter up:

Well to be honest, I got one pamphlet I think from um, the Funeral Directors on grief, and I read it, and, it seemed to be really just all common sense. So, I never really sought anything out, after that, I don't know whether they would but, no-one sort of tapped me on the shoulder and said, things are coming unstuck, so I felt that I was, probably, anticipating problems that might occur, and, you know 
assessing them reasonably well and that, I wasn't really having problems...

\section{Relationship of findings to existing literature}

The responses that the participants in this research project described are as mixed as is the existing qualitative and quantitative research and literature.

Bereavement counselling has become increasingly popular in Western societies, over the past quarter century (Schoenburg, 1980; Speck, 1985; William, 1991; W. Worden, 1991). The supporters of bereavement counselling advocate that the process, allows the grieving person to:

- Understand and express their feelings,

- Cope with the reaction of others,

- Adjust to life in the absence of the person who has died, and

- Utilise additional support available within the community. (Hennessy, 2004)

The counselling services provided in Australia vary in the approach that they use, level of training (and ongoing professional development), and the level of supervision that the individual counsellor has. The level of education ranges from post secondary college certificates to university Master level courses in counselling, psychology and psychotherapy. Not all authors are convinced of the efficacy of bereavement counselling with Jordan \& Neimeyer claiming that the empirical evidence to support bereavement counselling is weak (2003).

The Coronial Enquiries Section in each State offers specialist bereavement counselling services, with hospitals increasingly offering outreach programmes for the newly bereaved family member or friends of the deceased (Blake, 1995; Coolican \& Pearce, 1995; McQuay, 1995; Toomey, 1995), which will be discussed further in Chapter Ten. However the onus is usually placed upon the bereaved person to contact these services. This approach may need to be reconsidered, due to the need for active outreach programmes that tracks the bereaved person and his or her well being (Williams, O'Brien, Laughton, \& Jelinek, 2000).

\section{The surviving partner's experiences with support groups}

Only one male participant attended a support group. Adam described his experience very eloquently:

But they put on this grief workshop, the Catholic Church, close to here, and er, I was, I went there, I had to get Dannie looked after. I'd been running, a bloody, doing a lecture at six o'clock at night. Drove 
out there, got there, ... and I was appalled, I was absolutely appalled by the guy who was running it, patronising, and er, I was fucking furious with him. And, you know, people are well meaning going around and saying er, you know, what's grief. I mean its something you might do in some sort of preparatory workshop if you're working with professionals or something, you know. There was a woman sitting in that group who was just distraught, was sobbing, and you know, needed professional help then. And I left there feeling guilty that I just couldn't step in. The woman, the mother of eight, er, did it for me, God love her. Well, no, she was, there was some message given about er, you know, these things are a challenge also, you know, you grow through pain, and you know, the Lord puts these things in front of you and so forth. She stood up and said l've been a Catholic all my life, you know, and I have faith in the Lord Jesus and so forth, but if someone tells me once again that my husband died to give me a challenge, she said, you can stick it. And, yeah, I never went back to them either. And the Sister there, you know, who was a Catholic Sister, used to ring me and then give me various people's names who might, like, there was another guy who came along whose wife had died of cancer, erm, and socially we met a few times and had a lunch and then a dinner, you know, and they want to organise a social calendar and that sort of thing, I wasn't really interested, you know, in that sort of thing, you know, get my daughter a baby-sitter to go out somewhere, l'd rather go out to the bloody pub and get pissed, you know, with a few mates!

Adam did try another group called Solace, a bereavement support group that

he found more useful:

So in that first year, I rung up the bereavement centre, and I just went through, I went as a self-referral, you know, I rang up, dialled and heard someone said hi, and ... then I said my wife's died. I just rang them up and they treated me, you know, and I got very good service and, er, yeah, I found that a good weekly thing just to er, just to talk through some of the trauma... Solace, you know, and I rang them up and went out to a meeting they had further out west it was a group of women who were all bereaved, a long time bereaved, cause I think those sort of support groups, they've got the social camaraderie, bloody restaurants and all that sort of stuff, that's where the man said to me, you know, well I feel a bit shabby cause, he was actually quite amusing, said that his wife was a very forceful woman and she died of cancer and when they er, got the palliative care team, they had the cancer support group to support; it only took a couple of weeks and she was running it! And so he said he didn't really miss her but he felt very guilty, a bit guilty.

Despite using professional facilitators, Adam still found the attitude of one facilitator to be patronising:

I mean I had a good speech, and, you know, brought tears to their eyes and that sort of thing, and er, because I, you know, l've run groups and been in groups and I thought, and I felt quite, you know, I needed to say that, you know, I really felt that, you know, I loved this 
woman and she was what l'd waited my life for and then she died and I didn't understand. They had professional facilitators, you know, they train them. So this woman, who was running it..., said to me, "you poor pet, your heart must be broken" and I just wanted to say, well, fuck you, you know! But I didn't...

Adam felt, that although well meaning, the self help group he attended was more of a social support network which may not work that well for men who are usually in the minority.

\section{Relationship of findings to existing literature}

The responses that the participants in this research project described are congruent with the existing qualitative and quantitative research and literature. Bereavement support groups have become increasingly popular with bereaved people (Brabant, Forsyth, \& Melancon, 1992; Caverhill, 1997; Chen et al., 1999; Hustins, 1993; Levang, 1998; Lund, 2001; Martin \& Doka, 2000; Quigley \& Schatz, 1999; Staudacher, 1991), giving them the opportunity to be involved in a group that has in common the experience of grief and bereavement. These groups are mostly frequented by women, usually due to there being greater numbers of widows than widowers (ABS, 2002b).

One study found that support groups work better for women than men (Ogrodniczuk, Piper, \& Joyce, 2004). This may be due to the difficulty that men often have in expressing their emotions in a public forum, regardless of the size of the forum or the congruity of experiences that the participants have with each other (Joyce, 2004). Joyce found that: “... men were not as committed to their group therapy as women. In addition, women felt that men were less compatible than the women in the group" (p. 231).

It was interesting to discover that none of the participants had accessed the Internet for support. Widownet (Goshorn, 2000), Young-widows (Klein, 2000) and Griefnet (Lynn, 2000), are well established websites dedicated to offering online access to grief related information, research, poetry, images and bulletin boards, and are usually popular with men who find the anonymity that the Internet offers less confronting than personal contact in support groups or with individual counselling (Golden, 1999; Klein, 2000; Lynn, 2000). One study found that by having access to, and using the Internet, email and mobile phones, bereaved people had increased energy levels (Vanderwerker \& Prigerson, 2004). 


\section{The surviving partner's experience of returning to work}

Twelve of the participants were working prior to their partner's death, with eight returning to work within weeks of their partner's death. The main reason for returning to work was financial, with the next most cited reason being that the surviving partner found that work offered them security and support whilst allowing them to maintain a semblance of structure and continuity to their lives. Work was described as a welcome distraction from the surviving partner's grief experience. One participant described how he felt that work was so heavily engrained into his persona that he could not possibly be happy without working.

All but one of the participants described how their partner's employers or employees were supportive to them following their partner's death. This participant described how her deceased partner endured a working environment characterised by poor teamwork, egocentric personalities, and petty jealousies between coworkers, which all contributed to making the working environment very uncomfortable for him. This participant also worked in the same department, and experienced the same level of antipathy from her deceased partner's colleagues; she has since moved to another department where she is much happier.

A couple of participants described how returning to work was traumatic, with one recalling how she used to spend hours crying and not really achieving much. One participant returned to work, but left because she felt so "dumb", and wasn't able to concentrate on her work.

Carol worked with her partner, Richard in his surgery, which was eventually sold following his death. She felt that she didn't want to pursue any other paid employment since his death, but has contemplated voluntary work:

(If I went)...back to work now, probably kill me, and um, ah I always said look l'd like to do some work with hospice once the oldies (her parents) have gone, go do something in that area. I don't have time, at this stage, cause I fill a little bit of (my time with) the oldies at this stage, but oh l'd like to do something, voluntary work in something like that.

Adam continued to work but became increasingly overwhelmed by his commitments to work and family, resulting in him seeking help through his work's employee assistance service:

Then I went back to work I used to, I was teaching very well, people used to compliment me; I mean I was on auto pilot a lot of the time. I used to bloody go to work, do what I used to do; it was just more 
difficult in terms of managing the boys and Dannie and then, you know, I don't know where I was for more than a year. Then, I think, I was now, ... but funnily enough, you know, I think since I've read, you know, it seems to be quite classic, what bloody men do, you know, they go back to work, you know, they keep soldiering on and then suddenly bloody, come down in a bit of heap, you know. And, once again, I guess I was fortunate for, ... maybe, it appears there's some others, that maybe... when she said that I knew she was right and I also had been involved with setting up an employee assistance programmes from drug and alcohol point, I knew that the university should have an employee assistance programme it just wanted my head of department, and I said, I'm bloody doing very well, you know, I think, l'd like to go and see the employee assistance programme but they did have ... their own personnel so I thought and they were off campus; and they were great. They just said you need time off and I went off and saw my GP...

Brain described how he could not cope with being a full time house person, and that he needed the external stimulation that his work provided to keep him sane.

Brian described how he found housework repetitive and mundane:

After about three months everything was settled down, the kids were back into a routine, primary school care or day care or whatever. I was just going crazy. I was going home and you've got your ironing to do you've got the cleaning to do and you've still got to do the boy things, like mow the lawn and whatever, and I was going spare. And I could actually understand the housewife syndrome, where these people, you know, like housewives, women, people, lone people at home, male or female, get depressed, and they're on antidepressants, I could easily understand it. And boring! There's only so many times you can wash the dishes, once a day or at night after everything's done. There's only so many times you can vacuum the carpet once a week, thank you very much, l'll go crazy, don't want to wear it out. Clean the tiles and all that sort of stuff, what's the point, I fucking kick the ... Now look at this, this place, now look around here, this place was spotless last night. The kids come in and it's a fucking cyclone. And so the kids clean it up after work and all that sort of stuff. But you know, its pointless bloody vacuuming the carpet more than once a week because the place is a bloody mess again. Tiles are great, there's too much carpet in this world. I can't wait to convert this house, to tiles, when this carpet wears out. I want to get tiles!

Brian found that he craved the social stimulation that work provided:

I was going spare after three months; I was going spare. It lasted six months and then I was just getting toey to go back to work and I got, I went back, I said to my manager I wouldn't mind doing some parttime work, but I can only come 8 to 4 or 8 to 3 . And she said its no worries, we'll make allowances and in fact it ended by being quarter past eight because I had to get the kids to school, day care and then pre-school, whatever. I was just so happy to get back there, you know, casual, it was only once or twice but it was social contact. And 
I was really surprised that I just slipped back in. Whether it was the anticipation and the psychological build up to going back to work ... but I was just so social, so socially useful, I was contributing again. Not just staying at home, being locked at home. And I can understand, so easily now, how people who are housewives, say they're on anti-depressants. It's fucking depressing.

Brian described by working he was fulfilling his expected societal role, and that he felt useful when he was working, by contributing something to society. David, in contrast, elected to stop working following Lorna's death in order to care for his two young children.

\begin{abstract}
Oh no I just stopped work and just have really played house husband ever since, and tinkered around doing different things... You get a different focus on life I suppose, um, the role plays that you take on. I suppose it, you know a death, I mean there, there were people that at the time sort of went oh wow it's such a shock Lorna dying you know it's, it's, you know you suddenly realise that, you know the futility of things a lot of the things you do in life especially going to work and things of that nature and, and they change for about two or three months, and then the system caught them again and, they were, you know back to the old attitudes whereas, I suppose it was, it was such an impact on me that it, it's, it has actually changed the way that I see things, I mean I haven't sort of dropped out, but at the same time I don't see the importance of, you know um, pursuing my own interests, I see more, I see more importance in giving the kids a better, you know a good life.
\end{abstract}

David felt that he would return to work after about a year at home, but has discovered his new life to be satisfying. Apart from giving his time and energy to his children, David has taken up creative artwork, is managing a share portfolio, and maintaining the house and property, all of which has provided him with enough stimulus to keep him from being bored. David also believed that he would not been able to process the loss and grief associated with Lorna's death, if he had continued in full time employment.

\title{
Relationship of findings to existing literature
}

The responses that the participants in this research project described are congruent with the existing qualitative and quantitative research and literature.

Returning to work following a bereavement experience can be both stressful and rewarding (Fitzgerald, 2002). The bereaved employee will have to encounter fellow employees and well known customers who need to convey their commiserations for the bereaved person, which will test the surviving partner's resolve and patience (Fitzgerald, 2002). Exacerbating the levels of stress experienced by the surviving 
partner at work may be difficulty in working for extended periods, difficulties with concentration and fatigue (Fitzgerald, 2002). If the employer acknowledges these difficulties and the workload is adjusted to suit the bereaved employee then a comfortable work environment can be created (Fitzgerald, 2002). Once the surviving partner has settled into their work life again, the support and distraction offered by the working environment has been considered a positive influence (Fitzgerald, 2002; Zonnebelt-Smeenge \& Vries, 1998), an experience confirmed by participants in this study.

\section{The surviving partner's experience with the prospect of a new relationship}

Most of the participants discussed the prospect of forming a new relationship during the interview. Three of the participants (all men) had formed new relationships at the time of the interview. All of the participants described how difficult it was to contemplate the thought of 'replacing' their deceased partner with another person. As has been previously discussed all but one participant was living in what they described as a happy and satisfying relationship. None of the participants discussed any other relationships that either they had had, or the deceased partner had had during their relationship.

All of the participants described missing the companionship, the friendship, the shared memories, and the emotional and physical intimacy of their relationship. The participants who were parents missed the joint parenting, and the sharing of milestones and achievements with the deceased partner. For some participants the motivation for forming a new relationship was stronger than others, with some participants still feeling married to the deceased partner. Mary described the quality of her relationship with Alf:

...he used to do all little things, and he would just drop in, and you know and I'd sort of see him walking and l'd always you know, l'd always light up. He always had that sort of affect on me, even after all these years, you know how love changes, like you know, it's, it's much deeper, on a very deeper level and you, you really, you just appreciate them so much, you know, you appreciate them and, and he just loved me so much, I don't know if there ever, ever will be anyone that can do that, even a few days before he was killed, we would always go for walks, walk around and um we were walking and he just said, he just looked at me and he said darl he said I like being with you, and I said oh stop it, you know how you do, and pushed him you know, and you know that still rings in my ear. 
Having experienced a relationship such as Mary had with Alf, the prospect of discovering someone new who could generate the same type and depth of feelings was considered remote by several of the participants, as Mary explained:

...and I'm not quite sure how l'd ah, how, how I'm going to go but l'd like to think that, I'll just go with the flow and it will be like you know, starting all over again. Oh well, yeah, yeah so, if, if yeah it will be nice. No, no, no and I wonder whether l'll you know be doing a lot of comparisons um you know, I hope, but I probably will for a while. You'll be feeling much better and will be getting on with your life, but I mean you know how hard, but l've spoken to people who have ah, it's been twenty five years and it's still as, fresh as it was, you know, with your, with your own experience.

The desire for a new relationship can be sublimated in many forms as has been previously discussed. Dana openly discusses her desires with her friends who turn it into a humorous game:

So, my friends and I always laugh about it. We keep checking out all these sort of ah chaps on the telly (laughs) or someone you can have Robert Redford no I'm sick of him I'll have Paul Newman, this sort of thing.

\section{Relationship of findings to existing literature}

The responses that the participants in this research project described are congruent with the existing qualitative and quantitative research and literature. Considering or becoming involved in a new relationship was a confronting experience for all of the participants in this research project. The desire to continue in an ongoing intimate relationship was discussed by most of the participants, and is supported by the literature (Costello \& Kendrick, 2000; Cutcliffe, 1998; Doka, 1987; Gamino, Hogan, \& Sewell, 2002; Robinson, 1995; Schneider, Sledge, Shuchter, \& Zisook, 1996; Stroebe, 2002; Weiss, 1998; W. Worden, 1983).

The San Diego Widowhood Project was a prospective study in which 249 widows and 101 widowers who responded to detailed questionnaires at various points up to twenty-five months after their spouses' deaths. The main outcome measures for this study were marital and romance status, attitudes toward romance at several time points, demographic predictors of romance status, and self-reported measures of psychological well-being. Schneider and colleagues (1996) who were conducting the research discovered that:

By 25 months after the spouse's death $61 \%$ of men and $19 \%$ of women were either remarried or involved in a new romance. Women 
expressed more negative feelings about forming new romantic relationships. Younger age was a predictor of becoming involved in a new romance for women, and higher monthly income and level of education were predictors for men. Greater psychological well-being was highly correlated with being remarried or in a new romance 25 months after the spouse's death. It may be helpful for family, friends, and therapists to know that dating and remarriage are common and appear to be highly adaptive behaviors among the recently bereaved (p.56).

Age and gender differences were obvious in this research project in relation to the prospect or reality of a new relationship, with older women feeling that they were unlikely to be able to form a new relationship mainly due to the lack of available men in their age group, these findings are supported by the literature (Costello, 1999; Costello \& Kendrick, 2000)

\section{The surviving partner's experience of continuing to feel married to the deceased partner}

Several participants described having intense feelings of connectedness with the deceased partner. As Lyn described her relationship with Geoff: “...and that's the thing that you find, you think, I'll never, get that type of love again." Peter had been dead for nine months when Sally was interviewed, with her feeling very connected to Peter. Despite this connectedness she had the insight to be able to see her self becoming involved with somebody else several years hence, as she described:

So, you know I'm not going to be completely shut down to, you know something like that in the future, I sure that when I'm fifty I don't want to be living on my own, but then I can't, I just can't fathom it, you know I can't see anybody else here, you know the thought of getting married again, is just so foreign, you know I made my vows to a man that I still believe, to him. And no matter what happens in the future um, he'll always be my husband.

Tina was another participant who described how she had never contemplated a relationship whilst Bob was alive, and how it felt so alien to be thinking of it in real terms, now:

yeah well I just sort of feel that I'm too young to be on my own for the rest of my life, and I sort of think to myself, well then, l've never ever thought while I was married to Bob, I never looked at anybody else either. 
Despite the participants in the main describing having experienced good quality relationships, the surviving partner is now in a situation not of their making, leaving them uncoupled, and unsure of how to proceed from here, as Mary described:

I don't want to be single, l've always you know been down on people who are single because you know they say how awful it is out there, and I don't want to have to go to clubs, and, you know have guys just, ugh you know, you know eyeing you off and I didn't want to have to do all those sort of things and, and then I find myself in that position, and I'm thinking yeah but I don't have to go to those things anyway.

\section{Relationship of findings to existing literature}

The responses that the participants in this research project described are congruent with the existing qualitative and quantitative research and literature. As has been stated in Chapter Six, previous grief theories and models were reluctant to encourage continuing bonds with the deceased partner because of concerns that this could lead to a complicated grief experience (Costello \& Kendrick, 2000; Reisman, 2001; Stroebe, 2001; Stroebe, Gergen, Gergen, \& Stroebe, 1992; Walter, 1999). However there are grief researchers who believe that the surviving partner who has a high level of insight into their situation, will continue to have bonds with the deceased partner without any pathological outcome (Costello \& Kendrick, 2000; Field, Gal-Oz, \& Bonanno, 2003; Reisman, 2001).

\section{The surviving partner's experience with perceived barriers to forming a new relationship}

Several participants described his or perception of barriers hindering the development of a new relationship, which were both intrinsic and extrinsic. Adam described how the desire to become involved with somebody new was creating feelings of conflict. Adam described during the interview that he had become obsessed with the thought of only being involved with Asian women due to the wonderful relationship he had with Maria who was Philippino. Adam felt that his libido had been dampened by a combination of anti-depressants, grief and age, but he still keenly yearned for an intimate relationship. He also described how logistically difficult it would be to bring someone new into his life due to the dynamics of his family:

Yeah, anti-depressants take the edge off it, you know. I mean, bit of a, I mean, I don't know, it's a blessing and curse, you know, I think 
that certainly, you know, you've very untoward thoughts about young students, the Asian ones, I do, and you know, but, yeah, ah, whether it's a shift due to aging or grief or something, I don't feel as bloody sexually obsessed as I used to be, you know? And, yeah, so I don't, $\mathrm{er}$, and I think, certainly, er, l've got a different perspective on that, certainly, er, I've had opportunities and I've certainly had some sexual encounters, er, but I don't want, I'm wary of what I don't want, er, there's a group of women who are looking, well for a start, and three children, you know, a bit of er, put off, or one who might want to get close to you. Er, but women of around this age, who have their own loneliness and their own needs, you know, sexual, romantic, whatever, who make it a (inaudible) or something, if you were interested. I don't feel like getting myself into a position that, you know, entangle me, just because someone wants some sex, you know. I'd rather just do without or wait. I feel a bit tied up with that sometimes, I think, well, you know, how do you go courting, you know, with three and a half kids. Muriel, Ben's girlfriend, you know, she virtually lives here!

Another perceived barrier for some participants was age, with several participants being of an age where they felt that it was unlikely they would meet someone. This was especially true for the widows, who far out number widowers in Australia (Australian Bureau of Statistics, 2002).

A major concern that was expressed by the participants was that of becoming involved with a divorcee. Those participants who talked about the prospect of a new relationship all raised this issue, feeling that because they had experienced a relationship that was satisfying and full of love, that they may have difficulty relating to someone who had come from an unsatisfying or hate filled relationship. As Carol explained, when she accepted an invitation to go out:

I don't know but I, and it would be easier if it was someone who'd, lost a partner similarly. Because then you could respect when, I mean the night we went to the movies, I kept thinking God I hope he doesn't go on about his wife all the time had left him and so forth, but I must give him his due he didn't, but in course of conversation Richard's name came up an awful lot.

The reality of the situation is that the surviving partner is left with memories, which can feel real, while the divorcee is left with both memories and an ex-partner, as David explained:

The ex, I've met a couple of times, and yeah, that's, that's always a concern to me, um, because, I'm coming from a relationship where there was a loss rather than, rather than a hate. I don't see the ex as a, a threat or anything of that nature or I don't see the ex as, hmm I don't know I suppose you add, you add to their relationship with a different sort of maturity, but I suppose I, I feel, that, because she's 
come from a divorce situation, that she will have, um, ah some sort of protective attitude towards our relationship.

The other concern for the surviving partner is often how their children would react to them forming a new partnership. As Rachel explained:

I don't know whether I'll ever marry again, but I would like to have another relationship, yeah definitely, I, as long as, the kids are happy. Yeah absolutely, I was you know, I run that by them all the time. You know if I, you know go, get asked out for a meal or um, especially New Year's Eve. I said is it all right to go out with Brian, they said absolutely, absolutely, yeah cause he's a beautiful man, yeah, so um yeah that's, that's probably what I'll, you know l'll like to do, but you know when the, there's no rush. My concern is that they all, get, themselves fairly, you know, established and independent in their (lives), and give them as much encouragement as I can, without draining myself too much, but you know, I just you know, try and remain positive really.

The surviving partner has to balance their own need to form a new relationship with the possibility of their children's perceiving that the deceased parent was being 'replaced'. The participants described feeling the need to create an environment whereby the children were able to express their feelings, with the surviving parent reassuring the child/children that the deceased parent will never be replaced by a new parent.

David gently introduced his future partner slowly to his young children and was very aware that his new partner had been divorced for several years and that her children would have been able to reconcile the breakdown of their parents' relationship due to the animosity that usually precedes a separation and divorce, as he explained:

Bringing them in and, seeing how their relationship forms with the
other person, and bring them, ah bringing them to terms with a new
relationship, um because she's come from a divorced situation, she's
obviously, and for, you know for four or five years, she's had time to
talk to her kids about, you know new partner or whatever and her
children are at a age where there receptive of, of the need for a
partner.

\section{Relationship of findings to existing literature}

The responses that the participants in this research project described are congruent with a previous study. Introducing a new partner to the surviving partner's children is an experience, which is probably daunting for many surviving partners. Skinner-Cook \& Oltjenbruns (1998), found the research into the effects 
upon children of parental death were inconclusive and do not give a firm basis as to what effect new relationships have upon the children, in relationship to the new partner becoming a surrogate parent.

\section{The surviving partner's experience with gaining family permission to form a new relationship}

A few of the participants who had yet to commit to a new relationship, described how family and friends had talked with them, regarding future relationships. The surviving partner seemed to be in a more comfortable position to contemplate a new relationship when they have the support of family and friends.

Sally was surprised that her mother in law was conducive to her forming a new relationship in the near future. Despite Peter's close friend's tacit encouragement for her to pursue another relationship Peter was not really able to accept the reality of such an occurrence at the time, as Sally explained further:

Peter's Mum said to me very early, Sally I want you to know, a woman like you, you're so young, you shouldn't be alone, I know this is not what you want to hear but I just want you to know, from us, I know he was my son, I couldn't even hear her say it, but then I think it took her a lot of courage to, you know to tell me that. I wouldn't have, you know have to get their permission. You know, the funniest thing was that Andrew had said to me, Macca would want you to move on, be happy, you will find somebody else blaa blaa, and I remember saying Andrew you're not going to cope with it, if I go out with somebody else anyway, you are not going to cope with it, Macca you know blaa blaaa, because this and that, I said nah, just couldn't, I found out afterwards, that he drove up and down the street, like an old boy-friend would, he, he couldn't cope with me going out to dinner with somebody else, and he said to, he told me, and I said I knew that Andrew, and he said I know you did, you know me better than I do, I said no I just know what's real, it's nice for you to think there might be somebody else for me, at some point, yep, there maybe be, who knows, I don't know, we don't know what's in the future, if we knew what's in the future we wouldn't be sitting here now, doing what we're doing because we could change it.

Most parents would report that their children cannot imagine them as being sexual beings, and despite children taking a mature approach to the prospect of their parent forming a new relationship, the thought of the parent actually having sex can be confronting. Carol discovered this when she was talking to friends in the presence of her children:

I just said it jokingly, I did miss the physical side I said, and she said to me oh well I would too, and then I said not that I'm going to go and get laid and Nonie just fell off her seat, but Les looked at me, and I 
thought, I didn't till afterwards think oh well I wonder what, you know, whether she, I don't know anyway so um, I can't, I just, it's funny and you can't put, I don't know I mean the kids looked really funny. Oh well they're great about this.

The friends that Carol was talking with had since lost contact with her, leaving her to wonder whether Nonie felt that Carol was a threat to her relationship with Les.

Most participants did not relish the thought of living their remaining years alone. Although the immediate prospect of a new relationship was not an important component of their lives, it was something that did surface every now and again, as Jane described:

... and I mean I can see that, I mean I still think you know what if I live for another thirty or forty years I don't actually fancy being on my own, I wouldn't mind having someone to share my life with but, I mean I've got you know like my priorities are the girls and I um, and I think probably Carol would be very accepting of someone, she would, cause she would like me to be happy.

\section{The surviving partner's experience with missing the emotional and physical intimacy of the relationship}

Several participants described how they missed the physicality of the relationship they had with their deceased partner. Jane started attending a masseuse, in an attempt to maintain the physical contact with someone, without having to become involved in a relationship:

a girlfriend suggested it probably in um, in the April after Graham died so you know four months after he died um, she was going to this lady and so I starting going and um, I probably went every fortnight for a while um, yeah and it was just, well it was the touch and just but just talking also...

Mary described how she would enjoy having a companion to go on outings, but that she felt that it was inappropriate to take the relationship further despite her need for intimacy:

Um, to go to the movies, to go out to dinner, ah for a cuddle, a kiss you know I miss that passionate kiss, um and it's not like I can sort of just go hey do you want to give me a passionate kiss you know (laughs) you, you just don't do that. 
Dana was another participant who missed the passion that she experienced with Carl:

I miss all the passion and the love, I mean because we had a great partnership that way, that's hard to have suddenly, something that had been so, vital just stop. Hmm, hmm, that's it, so when you say to me, would I consider another, another companionship. Yes I, I think I would, but on a different sort of basis. Not that I would anyway but I reckon I had probably the best sort of partnership. ...I miss the companion, somebody close, and somebody that really thinks you are special.

Adam also craved intimacy, with him sublimating these feelings and channelling his physical needs through running and his more ethereal needs through playing guitar:

I mean I get to the point now, after three years when I feel like something, when I sometimes get to crave intimacy not so much bloody sex, per se, but that's the relatively easy thing, you know, (inaudible), bloody forty year old, er, but to actually have that sense of connection, you know, that's what I really miss. That's why I continue to have er, and you don't get it from running or playing guitar! Its er, and that's the think, I think, its er, what I miss the most, what I found the greatest loss is not the, is...sort of...the sexual ... a mental and intellectual stimulation.

David described that part of him could rationalise having a relationship to satisfy him sexually, in his heart, he couldn't really contemplate, not being emotionally attached to someone whilst having a physical relationship:

I suppose one of things that you do realise that we fit together, like gloves, because really I suppose you can fit together with anyone, like a glove, you, your satisfy your needs, and there's a lot of fish out there that would satisfy that need, and I think were both receptive to the fact that, that our need for it, our specific need for the, that actual other person, is only in time and, and familiarity with them and, and building a relationship with them, but the sexual need could have been with anybody but you wouldn't do it with anybody.

David also described how time plays a part in determining when someone who has gone through a traumatic event such as the death of a partner or divorce, is ready for a new relationship:

Um, someone had said to me earlier on, that when you, when you, if you, lose a partner through divorce, it takes you about two years before your ready to go back again, and if you lose a partner through death it's probably three or four years before your, sort of, you know come out of the wilderness so to speak, and so I suppose I just 
always had that in my mind that, that, that would be good to have a root every now and again, it wasn't, I wasn't after a partner.

The intimacy that was shared between the surviving partner and the deceased partner included sexual and non-sexual intimacy that may have be as subtle as a light touch when the partner was walking by, or the presence of the deceased partner in the conjugal bed. This intimacy is not easily replicated through other means or through people who the surviving partner is not in a sexual relationship, which left the surviving partner feeling the loss of intimacy as a chronic yearning for intimate contact with another human being.

\section{The surviving partner's experience with taking the tentative steps of having outings with members of the opposite sex}

A few participants had been out with members of the opposite sex, not necessarily with the view of developing an ongoing relationship. Sally described her experience as such:

I went for dinner with a friend last week, he was a boyfriend of mine, from fifteen years ago, he now lives in London, he's never been married his never had children um, and he was single, ah right, he's single right now he's been single for the last two months, he lives in London, and he wanted to see me and I thought, well I felt quite safe with about it, because we had a bit of a history, so there's more to talk about, then. The right now stuff, and there was a certain amount of comfort with that sort of thing, you know, so, and I thought it's a good test too, to see how I am, with a one on one situation, and I, I had a lovely time, and it was a great dinner and all that, but l'm not anywhere near thinking romantically with anyone. And I did feel a certain amount of betrayal to Peter, you know then I thought this is mad, you know, I can't, I shouldn't feel that way, but I did, and maybe it was too soon, to do it, I don't know, but you don't know until you do it, do you?

Other participants described their outings as being pleasant experiences, where they did not feel pressured to take the relationship any further than that of a simple outing. Not all participants had the same positive experience as Sally did. Lyn described her experiences as being self-destructive:

Um, I have been out, um with, with chaps, and I think I needed to know that I was still, able to get out, there and, meet people, but they were disasters, the, the couple I went out with were total disasters and, um, yeah I don't know I was, almost on a self destruct pattern anyway and, it was disastrous, and, yeah I'm still living it all down (laughs) yeah I'm very popular, but, um, I always get to the point where I think I can't, I can't do this, and I end up just, walking away 
from it (laughs) cause I just, get to the point where I think no, I don't know what I want, I sabotage everything, that starts, if it starts to go somewhere, I sabotage it, so I don't know, I, I don't see anything long term at all, or short term actually (Laughs).

The participants who had reported positive experiences were the one's that wanted companionship at the time, and not a complete intimate relationship.

\title{
The surviving partner's experience with a new relationship
}

Three of the participants had formed new relationships at the time of the interview. All of these participants were men and all had started relationships between 9 months, and two years following the death of their partners. All three of the men described how they were not actively engaged in pursuing another relationship, and that through a variety of circumstances a relationship developed. Don described how his friends decided that it was time for him to meet somebody new, so they set up a dinner party with three eligible women for Don to meet. Don described how he lacked the volition to form a new relationship, and appreciated the prompting and encouragement of his friends:

\begin{abstract}
After about 15 or 16 months, something like that. Actually what happened there was I wasn't particularly interested in starting another relationship. I would have been quite happy to just continue the way it be. Um and a couple of mutual friends, a couple of friends decided that it would be good for me...She was the better one of the three, the other two were terrible. So in a sense in was sort of pushed on me a bit but then it was at the point where I had to make a decision to pursue this or do something about it, and I did so. In some way I obviously felt um that I wanted to start another relationship. So maybe they did me what was a useful jolt.
\end{abstract}

Don hadn't talked about his relationship with Jane to his new partner very

often. When he told her that he was going to be part of this study, she commented to Don that he didn't speak about his relationship with Jane very much. It surprised Don that she had noticed that.

David also described not being actively engaged in seeking a new relationship. His new partner initiated the relationship, as he explained:

...it didn't really worry me, it didn't, it wasn't, I wasn't out looking for somebody, and I think it was only, through obviously her, hmm spying me so to speak, that, that she initiated the whole process, and um, otherwise l'd yeah, otherwise l'd still be, quite happy by myself. 
The new relationship developed very quickly, which David attributes to their maturity and previous experience. David expressed concern over the possibly disparity in their situations, with his new partner, having been divorced. This didn't seem to be causing any problems with the relationship at the time of interview, with David describing the relationship as feeling very comfortable:

\begin{abstract}
Um, it was almost like gloves, it was um, in fact it was, it was a bit scary for both of us in a sense that it seemed to be so natural, and um, yeah, I mean because there'd been, you know about two years since l'd been with anybody, um and even though the memories there are of Lorna, I mean Barb's got a totally different build, I mean she has a similar sort of personality but she's got a totally different build...and my getting into a relationship is, am I just going back to what, my expectations were, in other words am I really having a relationship with her or am I having a relationship to fill the void that Loma left.
\end{abstract}

Like David, Adam had expressed concern regarding the motivation that drives widowers to seek a new relationship:

...I think, you know, from observation, with little contact l've had with other men that are bereaved and because there are not so many of them, is that I think I see some of them quite desperate to get a replacement, you know, I don't think its so much to do with sex, I think its to do with, er, the other domestic stuff, you know. In a way I'm glad that I'm a nurse, you know. I can do some things that maybe other males can't do because they trip on their own bloody masculinity or because they have had no experience in doing it. Maria and I, I mean, I love to cook, I used to do most of the cooking... washing and bloody, and vacuum, you have to do it all but I don't expect, I don't want a woman ... to do that, you know, be a domestic maid.

David has taken a pragmatic view to his new relationship, realising that both he and his new partner are fulfilling a need within each other, and that due to family pressures, the relationship may not last, but while it is working well, both he and the new partner were enjoying it, as he explained:

...and hope it works, it's not, you know l'll take her out to dinner and buy some flowers and, she'll, you know she'll come and give me a home cooked meal and all that sort of gobble de gook you, we don't seem to be getting into that at all, it's, it's just we, we realise we have our needs and, lets just go for it and see if it works, and if it doesn't work then, we will say goodbye to each other without any animosity.

David felt that the new relationship gave him the impetus to 'move on' as he described: “...so I suppose in a new relationship um, just gives me another focus 
that different focus that, you know probably allows me to move on." David had also described him feeling as though he was in 'limbo' following Lorna's death, which required something to change, thus allowing him to break out from this 'limbo' to allow him to start filling the void that Lorna had left in his life.

Brian became involved with another person 9 months after Jenny died. He described the relationship as forming quickly and naturally:

Only because we were in the same class, we'd been undergraduate students together. No romance, no nothing, and not even acquaintance, and certainly no more than that, and l'd phoned up one guy and he'd said "oh, yeah, here's some phone numbers for other people that I haven't seen for a while, phone Angela." We just hit it off. Just amazing, just amazingly quick. And whether it was sort of distance makes the heart grow fonder or anything; whilst clearly I was over in Brisbane and she was over here. I 'phoned her up a couple of times and really clicked, and I actually flew her over to Brisbane; after about three weeks, it was getting a bit ridiculous, so we had to have a face to face meeting. And she'd just divorced her husband, and you know, flew over to Brisbane for a weekend. And we got on well. The kids liked her and actually, coincidentally, it was Ricky's birthday. My friends in Brisbane also met her. Jenny's family were quite a bit for it, you know, very much the attitude of life goes on and if you meet someone else that's great. That's good.

As has been previously stated, having family support to form a new relationship is something that is considered important by the surviving partner.

\section{The surviving partner's experience with his or her children relating to the new partner's children}

One of the major concerns that the participants with younger children expressed was how their children would react to a new partner. Both Brian and David described how their children were interacting well with their new partners and children. As David explains:

...our kids get along really well, her, her children are much older, um, but they all get along, and they get along on $a$, on $a$, on a very friendly basis and she (new girlfriend), sees a great degree of importance in the work that she's doing, um, over time Josh has moved away from her, and Kelly still, enjoys being with Rae cause female company. Adult hood, so she really likes it and um, yeah the partner is, ah she's very hmm motherly, so she, she likes giving lots of cuddles and all that sort of stuff so Kelly just, likes that, Josh is a little bit reserved, but he's reserved anyway um, um but he, he enjoys, Brooke who's the thirteen year old, um and they swim and play cause she's, cause she's two years, two or three years older, she's doing, hmm physical things that a boy likes doing. 
Brian described a positive relationship between his children and his new girlfriend:

I've got a girlfriend, and she's got two kids and her kids adore my kids and vice versa, and they get on with me very well and the boys just love Andrea, so that's, that's another thing as well. Oh, probably we'll eventually marry but that's away down the track.

It was a high priority for all of the participants who had young children that they were comfortable with a prospective partner. The two men who were in that situation, both considered themselves fortunate that their children were not only getting along well with the new partner, but their new partner's children as well.

\section{PHENOMENOLOGICAL EXPLICATION OF THE PARTICIPANTS' EXPERIENCES}

The surviving partner's children needed his or her support and comfort following the death of their parent. The loss experienced by the children could be profound, with younger children not being able to fully grasp the finality of death, nor able to articulate their emotions, and being more likely to act out their grief experiences. The teenage children were experiencing the challenges of puberty and the need to develop independence and exert their individuality upon the remaining parent. This can lead to confrontation, anger and frustration, which can be very distressing for the child and the parent. Older children experienced loss and grief in adult terms, which does not lesson the impact of the experience, but means that the older child had to act 'grown up' and possibly lacking the maturity to sustain any 'adult like' coping mechanisms or strategies to protect him or herself from harm.

A few of the teenage children displayed behaviour such as antisocial acts. This behaviour may have occurred regardless of the death of a parent or stepparent, however the stress associated with parental death possibly exacerbated any emotional difficulties the teenager was experiencing.

The surviving partner was suddenly a solo parent without the ongoing support and guidance of a fellow co-parent. This new role came at a time when the energy and resources of the surviving partner were particularly low. The extra workload and the weight of solo decision-making drained the surviving partner even further. For those surviving partners who had fit active parents, the grandparents could reduce the workload considerably.

The surviving partner had little choice but to continue to support and care for his or her dependent children and nurture them through their experience of loss and 
abandonment. Eventually the family routine settled, with the children adapting to their new lifestyle. Special events at school, having to study in the final years of high school and university and face examinations all created added pressure for the children. The children, who were at school, were able to garner support from friends and classmates, as well as become or stay involved in sporting and recreational pursuits that provided a diversion from their home life.

Bereavement counselling was utilised by some surviving partners with mainly positive responses. Only one male attended bereavement counselling with his son and stepson, which was a painful but useful experience. The other men stated that they did not consider counselling, preferring more didactic advice like guidance and the reliance of their family and friends for support. The women found the counselling experience cathartic and valued being able to unload their emotions that they sometimes withheld from family and friends through not wanting to burden them with their grief. The opportunity to talk to an independent person was seen as the most valuable aspect of bereavement counselling.

Only one participant attended bereavement support groups, with mixed results. This participant found the Catholic support group he attended was too focussed upon divine intervention as fundamental to the challenges (ergo the death of a partner) that have been presented to the surviving partner throughout life in order to enable growth and strengthen the surviving partner's spiritual connection. The participant found that two of the facilitators were patronising and unprofessional, citing one instance where the facilitator did not suggest to a distressed member of the support group that she seek professional help. Some of the frustrations that this participant experienced were compounded by his own experiences with facilitating support groups. He felt that he could do a better job than the facilitator and this hindered his ability to focus on being (non professional) a group member.

Returning to work was an important activity that provided most of the participants with an environment that was supportive whilst providing a distraction from his or her home life where they had difficult to escaping the reality of their partner's death. Returning to work wasn't easy for a few participants who felt dumb and lacking in concentration. One participant had worked with her husband in his surgical practice, which proved to be too confronting to continue to be involved with. Work provided a sense of identity for one male participant, who felt out of place being at home all of the time, work also provided a social element, which he was missing at home. In contrast another male participant gave up work to stay at home 
and has found the experience fulfilling. One surviving partner worked in a workplace that could be described as antagonistic, necessitating her eventual departure.

The surviving partners often described how they continued to feel married to the deceased partner and felt an emotional bond that remained very real for them. The participants who entered into new relationships were still aware of an ongoing relationship with their deceased partner, regardless of being involved with somebody new.

The emotional and physical intimacy of the relationship was something that was missed by the surviving partner, but generally did not rank higher than companionship, friendship, support and love. For those surviving partners who either contemplated or embarked upon a new relationship, there were concerns of compatibility, especially if the new partner had experienced a divorce. The participants were also concerned with betraying the relationship that they had with the deceased partner, as well as acceptance by family and friends. Anticipating an outing with a member of the opposite sex filled some participants with trepidation. Having been in a long-term relationship, the thought of 'dating' was intimidating.

Generally the participants discovered that their concerns about forming a new relationship were ill founded, with family and friends encouraging them to pursue a new relationship and with children accepting that his or her parent was lonely and didn't want to be single forever. Three participants had embarked upon a new relationship at the time of interview, all of them men. These men weren't actively seeking to engage in a new relationship, but found themselves in situations where a new relationship developed. Those participants that had entered into a relationship discovered that the women who had been divorced weren't overly encumbered with antipathy towards their previous partner. The surviving partner's children adapted to the new partner's children, which was a concern to the surviving partner prior to forming a new relationship. 


\title{
CHAPTER NINE
}

\section{THE SURVIVING PARTNER'S RELATIONSHIP WITH THE}

\author{
WORLD WHILST EXPERIENCING THE MAZE OF
}

\section{OFFICIALDOM}

Bureaucrats are the only people in the world who can say absolutely nothing and mean it.

James Boren, (The Merriam-Webster dictionary of quotations, 1992, p.46)

\section{INTRODUCTION}

The sudden unanticipated death of a partner necessitated the surviving partner to negotiate his or her way through a maze of officialdom that they may have hitherto had little or no involvement with. In this study, this involved: the police, ambulance crews, hospital and support staff, pastoral carers, the Coronial Enquiries Section, funeral companies, insurance companies, financial institutions and the Department of Social Security. The surviving partner also had to deal with institutions such as banks and insurance companies during a period of their life that was difficult and stressful. All of these encounters reinforced the reality of the death of their partner, resulting in the surviving partner experiencing feelings of social dislocation, vulnerability, inadequacy, anger and frustration.

This chapter explores the impact that the experiences with officialdom had upon the surviving partner, and how the surviving partner dealt with these encounters. The surviving partner had to negotiate a myriad of officialdom following the death of their partner. These experiences often sapped the surviving partner of energy and added to the emotional turmoil that the surviving partner was experiencing, however serving to reinforce the reality of the partner's death. 


\section{The surviving partner's experiences with being informed of the death or injury of his or her partner by the police}

Discovering that his or her partner had died was an extremely distressing experience for the participants. The surviving partner is often in such a state of shock that they are not capable of processing the information, as Mary recalled:

...(you go into) this survival mode, whatever it is that's in us that makes you just do it, and you just do it, um your not even hearing anything properly, um, you just you know people are talking, half the time you, you, don't even know what they've said.

The police informed several participants of their partner's death. Sally described how she was at home with her children when the police came to inform her of Peter's death. Sally was expecting the arrival home of Peter from his bike ride; instead two police officers were standing at her door:

So I was in the bathroom, and lan, who is the elder boy he was, um, he was on the toilet of all things (laughs) and Eliah's in the bath and we heard this knock at the door, and you know, lan jumped up, and said Daddy's home, and we ran to the door, and I opened the door, the door he wouldn't normally come in, because obviously it wasn't him and um, it was two police officers standing there and really you know, you know, you get this sense, that they're not going to tell you something good, so I sort of don't remember inviting them in, but I know they came in, and I disobeyed, I said, look I got the kids in the bathroom, I'm bathing the kids, and I, I went to bathroom, and the young guy followed me in, and he basically said look you know, we really have to tell you, my partner really needs to tell you something, I've got kids of my own, I'll watch them them, blaa blaa and I, I walked out of the bathroom and, and one of them said, oh have you got a gun? So I sort of knew that they'd be all right Sally gained the impression that, doing their police talk. And I went out and he, the police man basically told me that um, you know Peter had been in an accident, um he'd got hit by a car, he's condition was critical and I had to get to the hospital as soon as possible and um, you know did I have someone to come for the kids, or one of them would have stayed there and those things, and I rang my girlfriend, who was coming anyway and then they put me in the car with the lights on, and the sirens and we went to hospital...

Sally gained the impression that the police officer was genuinely upset by Peter's accident and was very impressed with how the police cared for her, saying that the officers, really wanted to 'connect' to the circumstances surrounding accident.

Mary described being well supported by the police at the scene of Alf's accident, with the police officers driving her home to inform and collect her son, and 
then drive them to hospital. The officers accompanied her to the mortuary, and stayed while she and Sam viewed Alf's body. The officers then took Mary and Sam home and settled them, while alerting neighbours to what had happened so that Mary and Sam were not alone when they left, as Mary recalled:

I mean the Police officers just stayed the whole time. Ah the female one did, Sharon, she was just brilliant, and we, you know she tried to do all the right things like you know to distract me, to talk about things, you know the kids, um, then l'd ask her about her, she had a little daughter and she talked about how she lost her Mum and you know oh she was, she was absolutely marvellous, absolutely and eventually was taken back home...I was, you know when I eventually did, did come home, um immediately um they said you know is there anyone, did you want, would like to come down, and all I could think is was my next door neighbours, and when I told them and ah they just immediately, you know they went over, the Police officer went over and got them and they came...

All of the participants described the police as being courteous and respectful towards them, however a few participants described how the police officers appeared to be uncomfortable with this role, with three participants commenting on how young the officers appeared to be to them. Adam remembers when he went to view Maria's body, meeting the police from the coronial inquiries unit:

And the police that were there, they seemed about twelve! $A$ female constable came in with me, she was absolutely, she found it very confronting, you know. I even felt sorry for her I guess ... what the fuck is going on? What's happening here? You know.

The participants who had to give statements to the police described the experience as daunting and harrowing. They had trouble trying to organise their thoughts to give coherent statements. When it became obvious that the surviving partner was too distressed to give a statement, the police made arrangements to gain the statements at a later date.

\section{Relationship of findings to existing literature}

The responses that the participants in this research project described are congruent with the existing qualitative and quantitative research and literature. Informing a person that someone close to them has died is an unpleasant task that can be very distressing for the informant. How this task is approached and the skills that the informant possesses can make a lasting impression on the surviving partner (Burgess, 1992; Davidhizar \& Kirk, 1993; Fraser \& Atkins, 1990; Kendrick, 1998; 
Leash, 1996; McQuay, Schwartz, Goldblatt, \& Giangrasso, 1995; Prigerson \& Jacobs, 2001; Stewart, Harris-Lord, \& Mercer, 2000).

Stewart and colleagues (2000) surveyed 240 people from a variety of professions who were involved in death notification to determine their training and education experiences, and discovered that nearly $40 \%$ of the respondents had not had classroom or experiential training in death notification. These authors discovered that the causes of death that caused most distress when notification was required were: “...violent crime, drunk driving crashes, suicide, and the death of a child" (p.612). The survivor reactions that caused the most distress for the notifiers: " included attempts to harm self or others, physical acting out, and intense anxiety" (p.612). The respondents in this study stated that by spending time with family, talking with colleagues and spending time alone, helped them cope with the stress associated with death notification (p.612).

\section{The surviving partner's experience with the nursing profession in relation to the care and/or death of his or her partner}

All of the participants in this study described the nursing staff that they encountered as being supportive and caring towards them. Mary remembers her encounter with the nursing and medical staff at the hospital where Alf was taken before he died:

I mean the hospital staff they were um, they were so good, Martin they really were you know they're so sensitive, the nurse um, and eventually the doctor came but just so, gentle, and just give you all the time that you need, and um, all, all of that, and, and eventually you know had to sort of leave, and ah, we just, we had to still stay there cause they still had to do paperwork or something and um, buts it's, it's like, I was numb, absolutely numb, I just went through the motion of everything, you know just doing, doing what you have to do, not, ah not because I wanted to, just because um, I um it's the, the defence mechanisms...

Sally described gaining support from her Child Health Nurse who was willing to give practical advice as well as being an empathetic listener, as Sally recalled:

I actually spoke to, um my wonderful, wonderful, child health nurse $X X X X X X X X$, bless that woman, and I went to see her, and she was there through it all too, in the background but, oh, she just the most amazing lady... I've known her now for five years, because with the premmy's I saw her every week 
Adam described how a nursing colleague was able to give him empathetic support on the day that Maria died:

...when I was at the hospital on the day she died, they said to me is their anyone here you'd like to contact at the hospital. I, funnily enough there is a woman that I used to work with at $X X X X$ hospital years ago who'd I run into, you know, at my faculty, the Nurse Unit Manager of the palliative care unit, and she came up, you know, and I don't know, I just gave her a big hug, and, you know, she felt there ... was nothing I can do, you know, but someone like her did something by being there, and you know, I couldn't hug the bloody surgeon, you know.

Brian described how he asked the ambulance officers not to take Jenny to the hospital where he worked, because he didn't want the added burden of being surrounded by his or her nursing colleagues, however when he arrived at the alternative hospital he realised that he knew a lot of the staff there as well, as he explained:

And I said don't take her to the hospital I worked at 'cause...so they took her to the Royal Brisbane where l'd worked the year previously, but, I knew, I just knew there was no way she was going to survive; it was terrible. I had to 'phone up one of her sisters and had to get Ricky and get him ready, I was about half an hour behind the ambulance. And I got in there, and you know, all the guys, of course, I knew all the nursing staff. That was terrible.

As has been previously stated all of the participants reported having had good quality relationships with the nursing staff that were involved with them and their partners. Some participants also described how they received practical and emotional support from neighbours and friends who were nurses, which was highly valued.

\section{Relationship of findings to existing literature}

The responses that the participants in this research project described are congruent with the existing qualitative and quantitative research and literature.

McQuay (1995) determined that the priorities for the care of the family member who is faced with the death or possible death of a loved one were as follows:

Arriving safely at the hospital, being met by someone on arrival, having a private area to wait, obtaining immediate information and condition report, having someone from the ED know that they were there, receiving constant updates and condition reports, a caring and 
compassionate manner by staff, learning that everything appropriate was done, being assured that pain was absent or minimized, knowing that their loved one didn't suffer, and seeing their loved one as soon as possible (p. 541).

None of the participants had received any follow up by the nursing staff that had cared for his or her deceased partner, however studies have shown that bereavement follow up can be useful. The support that the newly bereaved person needs from health professionals has been well documented in the literature (Campbell, 2000; Connors, 1996; Cooke, Cooke, \& Glucksman, 1992; Coolican \& Pearce, 1995; Coolican, Vassar, \& Grogan, 1989; Costello, 1995; Davidhizar \& Kirk, 1993; Fauri, Ettner, \& Kovac, 2000; McKissock \& McKissock, 1996; McQuay, 1995; Prigerson \& Jacobs, 2001; Toomey, 1995; Tye, 1993; Wright, 1991). Campbell (2000), having reviewed several studies related to bereavement support, stated that: “...providing bereavement support during the first year after a loss is a therapeutic response and a desired aspect of a total health care system because it constitutes both humane and preventive medicine" (p.1252).

Nurses can provide an important and cost effective support service for the newly bereaved (Costello, 1995; Jackson, 1995; Koodiaroff, 1999; McKissock \& McKissock, 1996). The providers of unit (for example, Intensive Care Unit or Emergency Department) based nurse bereavement follow up services report that the bereaved people who have had contact with the services describe how their coping abilities are improved by them benefiting from the ability to be able to talk to someone who had had some contact with the deceased person, express their feelings and receive practical advice (Jackson, 1995). The nurses who are part of the support programmes also report positive benefits with one nurse stating: "As much as these families needed me, I needed them. They helped me see that life, miraculously goes on, and it is good. They helped me to stay focused and look on the positive side" (Costello, 1995, p.529).

\section{The surviving partner's experience with the medical profession in relation to the care and/or death of his or her partner}

When the partner died in a hospital or was taken to a hospital following his or her death, the participants' experiences with the medical profession were mostly positive, however three participants described negative experiences. Participants who described positive experiences described how they felt supported and cared for by staff involved whilst being given information clearly and in an empathetic manner. 
The negative experiences that the participants experienced with medical staff involved not receiving appropriate information and a perceived insensitivity, during conversations with medical staff. Dana became angry at Carl's treating doctors' perceived lack of concern with the infection that he contracted prior to his death. On several occasions Dana had to insist that Carl receive more intensive medical treatment than he was offered.

We both played a lot of tennis and hockey and swam and walked. We were very active. We used to go to the beach together every morning and he had a lot of trouble with his knees and his joints. So I persuaded him to go and have some tests, heart tests, he had the tests and they said that his left ventricle was blocked to a certain degree but it wasn't a problem at all, it wasn't life threatening or anything, and he should have one of those Angiogram's and it would improve the circulation in his legs and quality of life, but when he had the Angiogram three days later he went into this, this most awful fever and shakes and the whole of his leg went blue right up to his knee, and one night I thought he was going to die. I thought his leg was going to explode almost, and it was huge, you know and so hot.

Dana took Carl to see his local doctor who was away at the time, the replacement locum doctor prescribed Carl oral antibiotics, which Dana didn't believe was appropriate treatment given the severity of the infection. After three days the local doctor returned, and initiated intravenous fluids and antibiotics at home.

I knew it wasn't right and I kept saying it's not the right stuff it's not working. And they kept telling me oh, it's all right, it's all right. Carl told me not to make a fuss. Anyway, gradually over about three weeks it looked as though it was getting right. We even had a party on the Saturday night, that was about three weeks later and then on Sunday we, we went to that demonstration for Leighton beach you know and on the Monday we went down the beach, he walked along the beach and just he dropped dead.

An autopsy wasn't performed on Carl, the treating doctors believing that it was not necessary. Dana acquiesced to their wishes, a decision which she now regretted, because she believed that the infection pre-empted Carl's death. Dana has been left with an embittered view of the health system and a belief that patients and their significant others are powerless in directing their health care needs.

Sally had a negative experience with the neurosurgeon who was treating Peter for his head injuries:

...I guess it's, we're all different, how we hear things but he, um, I'll never forget, and my dad, I think he just didn't know what to do with this man, he walked in and he said to us one day, you know, Peter is 
not going to die from his head injuries, and I didn't know whether to punch him, or I don't know, I, I, he seemed to walk in with this wonderful news, that wasn't wonderful it was just, and it's like, I did my job because I'm the head guy. He's not going to die from that, because I've fixed that! But I do feel a lot, that people in these positions fail dismally at public relations and they need someone else to come in and tell you that but, you know, you do want to see the doctor. He could have taken ten minutes, couldn't you to realise the news you were delivering me, you could have delivered it a lot better than that, because he'd figured it out, give the man a cigar you know...

The neurosurgeon had offered cold comfort to Sally and her family, considering that Peter's chest injuries were extreme with both scapulae, both claviculae, and all anterior and posterior ribs fractured, resulting in bilateral pneumothoraces. Peter was also facing the loss of his crushed leg due to compartment syndrome. The leg was eventually operated on when his chest had stabilised, Peter died a few hours postoperatively.

Sally described how the treating doctor was initially wary of allowing her to see Peter's $x$-rays and CT scans, which she wanted to view in order to gain an understanding of the extent of Peter's injuries. When he agreed to show her the various radiographic films it enabled her to put into perspective the nature and extent of his injuries.

Some participants described outstanding care that was given with compassion and dedication. This was Julie's experience when Bill died following cardiothoracic surgery. Julie received a letter from the surgeon, soon after Bill's death:

Dear Mrs G, Please accept my sincere condolence on the passing of your husband Bill, I was deeply upset by his deterioration and death so soon after his surgery, and after what appeared to be an early excellent recovery from the operative procedures. You and your family showed great courage in dealing with the very difficult decisions leading up to his death, and I greatly admired you for this. I know you are now in a very difficult time, grieving, and I extend my deepest sympathy to you and your family, as I said on the ward, should you or any member of your family wish to talk to me anytime, please do not hesitate to contact me.

Despite the concern that Bill's cardiothoracic surgeon had for Julie, the local doctor who had referred Bill for treatment was not informed of his death. It was Julie who told him three weeks later. David's local doctor was not informed either, with David having to inform him himself. This also occurred in Adam's case. His local 
doctor, who had referred Maria to the gynaecologist for treatment had not been informed of her death, as Adam recalled:

\begin{abstract}
... about a month after the funeral, I thought, I recognised myself, I thought my blood pressure was over the ..., you know, so I went to see him (the local doctor), and he was good then, I could talk to him about what's happening; and I said the BP's up, you know, and I want to talk to you, and I started to tell him what's been happening, and I said, you know, since Maria died, and he just about fell out of himself. He was shocked. He was very, he asked me what happened, he is a true GP, one of the few left, you know, he does home visits and things like that. And he was a bit er, querulous as to why they wanted to do the surgery and why they didn't treat it more conservatively. I didn't really, you know, he was upset and angry I think.
\end{abstract}

Adam found himself consoling the doctor during the consultation, instead of receiving the support he required himself. The treating doctor or hospital failed to inform three out of the five local doctors who had referred patients to them.

\title{
Relationship of findings to existing literature
}

The responses that the participants in this research project described are congruent with the existing qualitative and quantitative research and literature. The participants negative experiences in relation to the doctors who were involved in the care of the deceased partner all involved poor communication. According to Prigerson \& Jacobs (2001), medical practitioners are often under educated in grief and bereavement issues, a finding supported by others (Bedell, Cadenhead, \& Graboys, 2001). In my experience over many years involvement with the education of medical and nursing students, death education was kept to the absolute minimum in both undergraduate and postgraduate courses, however there is evidence to suggest that innovative programmes are being designed to address the educational needs of undergraduate nursing students (Birkholz, Clements, Cox, \& Gaume, 2004).

When a patient dies suddenly and unexpectedly a doctor may feel a degree of failure in the manner in which the patient was treated or in his or her not being able to forecast the death (Bedell et al., 2001). This sense of failure may result in the doctor deciding to disappear into the background in order let the family 'get on' with the grief process (Prigerson \& Jacobs, 2001). Several studies support more involvement by the treating doctor(s) following the death of a patient, especially when the death was sudden and unexpected (Burgess, 1992; Connors, 1996; Davidhizar \& Kirk, 1993; Fraser \& Atkins, 1990; Kendrick, 1998; Kiger, 1994; Leash, 
1996; Malacrida et al., 1998; Martin-Baker, 1987; McQuay et al., 1995; Prigerson \& Jacobs, 2001; Stewart et al., 2000).

An extensive study by Malacrida et al; (1998) surveyed 390 families who had a family member die in an Intensive Care Unit (ICU) in the previous eight year period. The survey was designed to determine the level of satisfaction the family members had in relation to the level of care the deceased patient had received in the ICU. The authors concluded:

...that the relatives of patients who died were most dissatisfied with the care received according to: a) the type of death (e.g., sudden death vs. death preceded by a gradual deterioration in the patient's condition); and b) the manner in which the relatives were notified of the death (in person vs. by telephone). The personal characteristics of the people interviewed, such as gender and the closeness of their relationship to the deceased, also seem to have some bearing on the opinions expressed. A high percentage of respondents were satisfied with the treatment received by their dying relative and the information conveyed by caregivers. Nevertheless, the dissatisfaction expressed by some respondents indicates a need for improvement, especially in communicating information to the relatives of these patients. ( $p$. 1187)

These findings were supported by some of the participants in this research project, with poor communication causing the surviving partner to experience frustration, anger and mistrust towards the medical team involved in the deceased partner's care.

By sending a letter of condolence, a doctor is acknowledging that the relationship between the doctor and the patient was significant, and that he or she recognises that the impact upon the surviving partner is profound and worthy of acknowledgement. Julie's experience is noteworthy, as the practice of writing letters of condolence is not commonly undertaken, but is a practice that is being encouraged as being beneficial for both the treating doctor and the family of the deceased partner, because according to Bedell (2001): “Unlike expressions of condolence made by telephone or in person, a letter of condolence is a concrete gift that the recipient can and will review over and over" (p.1161).

\section{The surviving partner's experience with pastoral and social care}

Chaplains were involved with a few of the participants soon after the partner's death. They helped to arrange and participated in the funeral service.

Rachael discovered how interdenominational relationships have improved between 
the churches to the point where priests from different religions are willing to co-host funeral services:

Um, yes, Father XXXXXXXX came around, I'm not Catholic and the, the chaplain that was running along the beach from $X X X X$ College came along, and the school chaplain from Annie's school came and I said well I just don't know what l'm doing and they said well why don't we all three get together and do something, and I said well can you do that? Because I thought there were all the children were involved then and um Father XXXX was a personal friend of Kevin's that they swam together.

Social workers were also involved in a few instances, mainly helping the participants at the hospital. There were also a couple of instances of the social worker contacting the surviving partner from the coroner's court, this support was appreciated but not commented upon in detail. Three of the participants described negative experiences with social workers. Adam described his family's experience:

Well, they actually got a social worker and female and er, I guess, sensed her discomfort or something, although I think she did her best, you know, I feel, you decompensate I didn't know how to behave, well, you know, I didn't want to ... burst into tears. I probably, ... it might have been Pam who might have come down thought at first she said she couldn't believe how angry I was, you know. And I probably was angry; I couldn't quite put that together, and they called the boys from school, you know, and Jeremy was in school and they said (indistinct phrase) and Jeremy has always said how he hated that fucking social worker, you know, she was patronising.

David also described a negative interaction with a social worker:

Although a social worker met me at the hospital at the time of my wife's death, I can honesty say she was a waste of space. She had no idea of my needs and requirements or of my future needs and requirements. At times like these, the body and mind are in such shock you literally go dumb and numb. You shut down for selfprotection. I remember asking her if it would be beneficial for my children to see their deceased mother in ICU, to say "good bye". She couldn't give me an answer. I thought that would be a common question (surely mothers die every day).

Brian described his encounter with a social worker in Chapter Eleven, describing him as inexperienced and appearing hesitant.

Social workers play an important role in the immediate and ongoing support of the bereaved person. Therefore, appropriate bereavement training and ongoing supervision is necessary to maintain quality care (Fauri et al., 2000; Wells, 1993). 


\section{The surviving partner's experience with the Coronial Enquiries Section and hospital administration}

Several of the deceased partners had autopsies performed on their bodies.

Two of the autopsies could not determine the cause of death. Most of the participants were satisfied with the Coronial Enquiries Section staff, who had responded to their enquiries regarding autopsy details appropriately. Most of the participants were satisfied with the results of the autopsy when the cause of death was unequivocal.

David was left with very bitter memories of the manner that he felt that Lorna was treated and the subsequent treatment he received from the hospital administration following her death. Following Lorna's death the hospital did not contact him to inform him that her body was ready to be picked up the funeral parlour. He rang them on the Monday and was informed that she could have been retrieved on the Friday:

I just felt, oh I must say, look I just found the hospital, um fucking useless to be honest (laughs), the Administration process... Like I just thought fucking hospitals are a waste of space.

David also requested the results of Lorna's autopsy, but the hospital refused to issue the results to him informing him that he would have to apply through the Freedom of Information Act. This infuriated David. David eventually contacted a newspaper that agreed to publish his story. The hospital sent the autopsy report to David within three hours of the article being published. The autopsy report concluded that Loma had died from an intracerebral haemorrhage, however David believed that she actually died from aspiration pneumonia, from inhaling her own vomitus following a fit, and that the hospital was negligent by having her lying flat on her back. When David contacted Lorna's treating doctor a year later, the doctor informed him that the MRI scans had been lost and that there was now no proof of the intracerebral haemorrhage.

...and also I was reasonably negative about the hospital, um, I um, I suppose l've always had an attitude that once you get somebody to hospital they're okay, you know they're in good hands and I, you know I mean I know that the medical profession don't go to work wandering how many people they can bump off each day, but um, I just, I just feel that um, hmm you know once you've got somebody to hospital, and they appeared to be okay, then, the process would be a matter of getting better, not a matter of progressively continuing to get worse and so I, I now have a reasonably negative attitude towards, the entire medical process, and I can understand now why 
people go to alternative medicine or, alternative therapies, um, yeah I, I suppose it's just that over the years people have, hmm placed, um God like status on, on the hospital environment and, you know we should be, you know if anything goes wrong go to hospital the doctors will look after you, and it doesn't really work so yeah, so during that whole, process you know you're wondering why you know this suddenly happened to you, oh well to Lorna...

The participants who had experienced difficulties with coronial inquiries, mainly described delays in receiving information, however for Jane it was the delay in receiving Graham's body after he died in the North-West of Western Australia that caused her the most stress:

Oh, it was just, it was just unbelievable, and then we didn't see Graham for... That was on the Thursday, and we couldn't see him until the Tuesday, because they had to fly him down, and do the autopsy and yeah, so it was Tuesday before we saw him, and then the funeral was on the Wednesday.

The coroner is legally obliged to investigate any death that is sudden and unexpected (Kellehear, 2000), the only exception to this is when a deceased person has been in the care of a medical practitioner within a short time period immediately preceding the death and the doctor is willing to issue a death certificate with the cause of death. The relationship between the participants of this research project and the Coronial Enquiries Section were generally sound, with the exception of

David who found them to be inefficient, as he explained:

Yeah and so I didn't really have a problem with them taking the brain,
in fact I, we had the funeral, um, four or five days later after she died
and, they'd released the body, again this was a real drama, she died
on the, well she was technically dead on the Friday, I'm sorry she
was physically dead on the Friday, um, and on the Monday I rang
them to find out, when they would be able to release the body for the
funeral which we'd organised for the Wednesday, and they said oh
well you could have picked her up on Friday, they'd done the Autopsy
on Friday afternoon but no-one had contacted me...

\section{The surviving partner's experience with funeral companies}

Most participants reported positive experiences with the funeral companies that were involved with their deceased partner's funeral. Arrangements were generally made with little intrusion into the family's lives, and proceedings went generally well on the day of the funeral. Two participants had problems with the 
same company; Jane remembered the conversation she had had with an undertaker's employee:

I mean there's, the um, when the woman came around here and you know I spoke to her and you know had to choose the coffin and all that sort of stuff, um she was fine, but then she rang me on the day of the viewing and said to me "oh Jane I'm really sorry but you wont be able to view Graham in a coffin because um, he's too tall and we would have to squash him into it", they were her exact words, we would have to squash him into it now, Graham had a, you know he had a great sense of humour and I actually thought, I thought I can just imagine him, he'd be killing himself laughing because you know, they would have to remake his coffin, but I thought you know, I could actually see the funny side of it but I thought imagine you know if you'd said to somebody we'll have to squash your husband into the coffin, I thought what a stupid thing to say.

One other complaint about the same funeral company from another participant was that despite being warned by the family that there would be many people at the funeral, the undertakers did not provide enough condolence cards, which upset the surviving partner.

Jane's experience with the counsellor provided by the funeral company has been discussed in Chapter Nine. She was not impressed at all with his direct and rather blunt approach:

...but he was just terrible, he just he didn't give me any strategies to you know to cope with anything, he just sort of said well all those expectations you had, none of them exist anymore, and all those you know some of those memories you'll carry forward but, so $X X X X$ XXXX weren't, weren't um, crash hot.

\section{Relationship of findings to existing literature}

The responses that the participants in this research project described are congruent with the existing qualitative and quantitative research and literature. Over the past century Western society has become less likely to have a death occur in the home, and therefore unlikely to be involved with the intimate care of the deceased person (Kellehear, 2000). Generally Australians are also less likely to have a funeral service in a church (Kellehear, 2000). These trends necessitate the need for funeral companies to manage the handling, care, storage, and disposal of the deceased partner's body, as well as stage manage the memorial service (Jones, 1997; Kellehear, 2000). Given that the average funeral costs several thousand dollars, funeral companies need to provide quality service or risk losing custom through reduced customer recommendation, which is an important method of 
referral for funeral companies. The generally positive experiences that the participants in this research project had with funeral companies is testimony to a customer-focussed industry.

\section{The surviving partner's experience with government departments}

Following the death of a partner, the participants of this research project found him or herself faced with myriad bureaucratic and financial details to attend to. As various government departments needed to be informed of the death of the partner, participants soon discovered that they needed multiple validated copies of the partner's death certificate to submit as proof of the death of their partner. As David stated, there was no practical information available to help him coordinate the process of informing both government and non-government departments of Lorna's death:

...you know had they presented me with some sort of literature that, you know outlined, you know what I might go through over the next two or three or five, six months, something like that, would have been better for sure, um, what opportunities are out there, what I would have to do? I mean, (laugh) I mean from a, from you know do you de-register your wife from the electoral roll or you know all of these things. The 'big brother syndrome', that we all are fearful of doesn't exist in Australia, I had to, individually go to each (department), I couldn't just go to one (central point).

Most participants described how they found the filling out of forms upsetting and unnecessarily complicated. The constant need to inform people officially of the death can also result in the surviving partner feeling dislocated from their previous reality, as Mary explained:

It was so confronting for me, to have to accept the fact, for a, for a good while there, that's right, for a good while, I felt like I, didn't know who I was, I felt I had no identity what's so ever, I was so confused and when I was filling out forms I found it so distressing.

Sally reported that her experience with winding up Peter's affairs went fairly smoothly

Well, I did the best I could to tell everyone about it, some people, XXXXXXXX (an international credit card company), wanted a death certificate, others were happy over the phone, which was great, and I, I've probably only missed a couple of things, but one funny thing that happened, he used to get XXX (a business magazine) delivered, and I rang, and I cancelled, and I got a refund, for what he had already paid and they were great... 
Unfortunately, as Charlie died in-flight and had his autopsy performed in London, Rosalie was issued with an interim death certificate for several months until the final tissue cell analysis was completed. This posed problems for her in a few instances but most organizations recognised the interim death certificate.

Most government agencies act independently of each other. When the surviving partner was dealing with both State and Commonwealth government agencies there is no direct communication between the two levels of government. The number of government agencies the surviving partner has to inform of the death of their partner is considerable and includes the Commonwealth government agencies such as: Medicare, Department of Births and Deaths, Department of Immigration (passport), Australian Taxation Office, Commonwealth Electoral Office, and the State government agencies such as: Department of Planning and Infrastructure (vehicle registrations and drivers licence), the State Titles Office (land title changes), electricity and gas providers, the Water Corporation, and then there is the Municipal agencies for land rates, and library services. There is no doubt that informing all of these agencies can be a burdensome task for the newly bereaved person, however the reality of the partner's death is reinforced during this process.

\section{The surviving partner's experience managing financial affairs following the death of their partner}

Most of the surviving partners had joint bank accounts and credit cards, which became frozen immediately the bank was notified of the death of their partner. Therefore, it was necessary for some participants to delay the notification until they had transferred money to an account solely in their name so they could have access to money. Several participants described financial difficulties following the death of their partner. Lyn had to move out of her home following the death of her partner, as has been discussed in a previous chapter, which meant that she had to find money for rent and a bond, which led her to change employment to increase her income:

What happened is because things were going really badly for me and, and I know that a lot of it was everything that was happening before, but also death had compounded, I was trying to sort out the estate, I had to shift flats, um I had to find bonds and stuff, I mean it was all a bit of a nightmare I um, I thought I need more money, and they obviously weren't going to, do anything about it, because they weren't going to beforehand and, and I thought no l've got to do this on my own, so I asked for a secondment elsewhere 
Two participants were in the process of building or acquiring a new property at the time of the partner's death, which resulted in financial hardship. Jane could not go ahead with the building of the house, and had to sell the land:

We had um, signed the contract to build, we had the loan from the bank um the builders wife rang me the morning Graham died, just to check up on the colour of the something or rather um, so what I had to do after Graham died was I had, had to put the um the land on, on the market cause I had you know didn't have any money.

Carol decided not to sell one property at a reduced price, and kept both properties until she was ready to sell:

...and um, yeah, but then I mean with the house I just didn't know I was at the end of my tether, couldn't sell it what was I going to do, all this money and, and I thought this, I mean these financial people said don't worry you can afford to carry it Carol, it was just a nightmare. And I wanted to do that, and I wasn't gonna be, you know, trampled over cause I was a woman in this situation, and taken advantage of. People offered me ridiculously low sums for it and it could have been easy to say look take it and get on, but I thought no, blow them I'm going to battle you know stick this out, well I didn't achieve what I, what we had intended to achieve but I got closer than if I'd given in originally. But as the kids said to me what do you reckon dad would be doing, and l'd say he would be saying Carol, they really don't know what they're doing, and they are incompetent, and but, if that's what they, what they want to do, we can just accept it and we just move on, so he would have moved on probably a lot better...

A friend informed Rachel that her health insurance fund would issue a one off payment of $\$ 20,000$ to a member when a spouse dies suddenly. The payment was made to her the day after Kevin's death. According to Rachel, this benefit is not widely advertised by the health insurance company; subsequently not many members claim it.

All participants reported that their financial situations eventually settled when properties were sold, insurance policies were paid out or business' were sold.

Participants also continued in employment or applied for sole parent payments.

Tina explained that she found that she could manage her family's finances remarkably well:

If I want to go and buy something, I go and buy it, and there's not an almighty argument and he always used to say if the financial devices were left to me you know like we'd be broke within weeks, but, it's fifteen months I've still got money in the bank, the house has not had to be sold, l've done beautiful things to it, l've paid for a funeral, l've paid off all the debt, not that there were many debts, and he'd, and I 
have to admit he's left me very well catered for, um I'm very lucky, but by the same token I've still got myself together and I've, l've got back to work and, I, I suppose I'm getting more confidence in myself when we did the personal development thing last year you know like, from the year before what have you accomplished this year or whatever, and um I said to one of the lecturers I said oh God you know like what with Bob dying and my heart attack and, you know I really don't feel that I've accomplished anything, and, she said to me, you have, you've got back to work, you've done this and you've done that and she said just getting back to work is an achievement, and I just never even thought of that.

The older participants described their financial situations as being less perilous than the younger participants who had dependant children and mortgages and other loans to negotiate. Obviously those with life insurance policies had significantly less financial difficulties than those who did not.

Suddenly having to manage the family finances alone, proved to be a worrisome experience for most participants. Having to sell businesses and properties added to the increased responsibilities of the surviving partner. Having a secure financial situation at the time of the death of a partner allowed the surviving partner time to reorganise their financial circumstances, unfortunately, when a partner dies suddenly and unexpectedly, this is not always the case (ZonnebeltSmeenge \& Vries, 1998).

Only one participant had problems with taxation following the death of her partner, because he hadn't submitted a taxation claim for three years. This obviously took some time to sort out with the help of an accountant.

Jenny didn't have a Will that included her children, resulting in Brian deciding to create a trust for each child to protect some inheritance. Brian found out what he had to do to conform to the taxation laws and proceeded to lodge the trust himself saving a considerable amount of money, as he explained:

I just went and did it myself. Estimates from a lawyer, you know, a thousand dollars plus to establish a formal trust thing. Two pages, typed it up myself. Incredible. Sent it along to the Tax Office and they said, yeah, that's good enough, you know, (the ATO) made a private ruling. They said, yeah, what you've done is OK and its in accordance, so long as you do this, that and that, then the kids have to have the money. You just can't take the money back from the kids, once you give it to them its irrevocable, that's what it says in the Trust. Yeah, that's good enough. Yeah, these family lawyers... 
Brian discovered that if a spouse leaves all of her inheritance to the husband, then the husband has three years to redistribute some of the inheritance to any child under 18 years old, with a tax-free limit of $\$ 6000$.

Most participants experienced some problems when informing financial institutions of the death of their partner. Two participants made positive comments regarding how well they were treated by their banks (one of the participant's mother worked at her bank which made it easier for her), with the remaining participants either reporting neutral experiences or negative experiences. Participants described banks making mistakes with their accounts and credit cards, as well as experiencing poor public relations and inadequate and insensitive communication skills by bank staff, Adam described his experience:

Credit cards...same accounts and so forth. And problems with the bank stuffing up the mortgage, kept fucking up the mortgage. So I spoke to their head office people and had they had the death certificate this and they still sent out these mortgage notices to $\mathrm{Mr} \&$ Mrs. And I rang and told them and they sent me a customer survey, you know, and I wrote all over it, and then they rang me up and then I got a letter from the regional director, I think they got the message. But now after I sent the death certificate and a friend had talked to them about the money business and so forth, the Visa card, MasterCard's, Bankcard were on the 'phone, you know, and they wanted, well some of the accounts where she had a few thousand dollars but she was also in debt for a few thousand you know on the MasterCard and they wanted some sort of caveat thing that they'd get the first whack, you know.

Uncoupling one's self from joint financial matters is complicated because the surviving partner still needs access to his or her accounts. Participants complained about being sent mail addressed to either the couple or to the deceased partner, even after informing the institution of the partner's death, which they found distressing. The opposite occurred with Jane who was not being sent mail by an over sensitive bank:

...there were you know there were people who were totally incompetent um I remember with Graham's MasterCard with the XXX Bank, I just didn't get a statement for months and I rang and I got...put onto a special number in Queensland and I thought well you know I haven't had my husband's um statement for months, oh, no we don't like to send them to um, to deceased estates, we don't like to upset the people and I said well how on earth am I supposed to know, you know what's going on, I said it's the $X X X$ Bank I mean they were just, they were atrocious and then of course I was with the Wembley bank, branch and they closed down. 
Dana had such a poor experience with her bank that she decided to change banks, which resulted in her having to inform the new bank manager about Carl's death:

In the end I got so fed up with XXXX Bank. Simon had told them, sent them copies of the death certificate, I don't know how many copies of the death certificate after so many letters l'd written them. l'd been in there so many times we decided to go to the XXX Bank but then I had to go and see the new bank manager. I thought I'm going to be fine when I went in there all of a sudden he asked why are you moving your account? Just having to say it to a stranger, your emotions well up.... Well I had a long thought, whether l'd do it, but I felt that business of the banks made me so angry. And ah every now and then I ring up to say to them, look please change it. Then you've got to explain to some girl on the phone and it's just as bad.

The centralisation that has occurred in the banking industry over the past ten years may be one cause of some of the poor experiences that participants had had with banks. Smaller bank branches have closed and customer services are being taken from bank branch staff and handled by a central pool of staff in a central office. The lack of personal interaction can leave the surviving partner feeling alienated and vulnerable.

\section{Relationship of findings to existing literature}

The responses that the participants in this research project described are congruent with the existing qualitative and quantitative research and literature.

Financial difficulties can cause considerable stress and anxiety for the surviving partner (Carr et al., 2000). When the death of a partner is forewarned such as in cases of long-term terminal malignant disease, financial considerations can be discussed allowing the surviving partner to make the appropriate arrangements for possible financial security, which according to O'Bryant (1991) lead to more positive post death experiences for the surviving partner compared to sudden and unexpected death.

\section{The surviving partner's experience with insurance companies}

Several of the deceased partners did not have life insurance policies. Those participants that were recipients of the deceased partner's life insurance described the process of claiming against the policy proceeding relatively smoothly, except in Sally's case which proved difficult from the outset. This was due to Peter being struck by a car with the possibility of charges being laid against the driver: 
And that was a real struggle, getting the money through from $X X X$ (a major insurance company), bunch of bastards, $X X X$, I really don't like dealing with them at all, just so uncaring. I got a letter one day, um, and it was addressed to me, and I don't remember the lady's name on there but it had Dear Mrs somebody else, you know Dear Mrs Jeffnies or Dear Mrs Robinson or Dear you know, oh, just appalling, and this woman's attitude when I rang her was so bad, and that's at the end of a very long story of terrible negotiation with $X X X$, where I had to get a Lawyer involved, because, because I didn't have a death certificate that was complete, because of the investigation, they wouldn't release the money, and it was because, what involvement did I have in Peter's death, did Peter commit suicide, um how did he die, what was the cause of death, well he got hit by a car, but that's not the Cause of death, the cause of death, is, it an act of God, Is it a accident, did somebody murder him, Blaa Blaa Blaa, so learnt that, and I said, okay, well it was obviously an accident wasn't it, but until the coroner says it's an accident, if that lady had been charged, I wouldn't have the money now, because it would have then gone to an inquiry.

The insurance company gave Sally several forms to fill in, including some which had to be signed by her children who were two and four years old at the time, to confirm that the children agreed that Sally was the sole beneficiary of the policy. Sally also had to get other people to fill in forms on her behalf confirming the details that she was providing. Sally found the whole situation confusing and distressing, and she made lengthy telephone calls to the insurance company. In the end, Sally involved a lawyer to help expedite the process. When the insurance company finally agreed to the payout of the policy it still took over two weeks for the money to arrive, despite assurances from the company that it would only take a week to process. As Sally stated, she felt that she was not considered to be a 'real person' who is grieving but just another number to be processed at the company's convenience.

Several participants did not have a Will or an up to date Will, which caused the surviving partner problems when administering the estate following their death. Sally discovered how difficult it was to reorganise her life when Peter died intestate:

That was the only thing, we didn't do... and is the only bit of advice I ever say to anyone, get a will, doesn't matter what's in it; just make sure you've got one!

Financial difficulties compound the stress experienced by the surviving partner and can appear insurmountable immediately after the partner's death. The surviving partner has to rearrange bank accounts, claim insurance policies, and manage the family debt by him or herself. Not having life insurance policies or a Will 
exacerbates the financial burden, which is recognised as a major stressor following the death of a partner (Zonnebelt-Smeenge \& Vries, 1998).

\section{PHENOMENOLOGICAL EXPLICATION OF THE PARTICIPANTS' EXPERIENCES}

Being informed that your partner has died a sudden and unexpected death is a harrowing experience that is often imprinted in graphic detail upon the surviving partner's memory. The participants were all able to remember clearly their dealings with officialdom at the time of and after his or her partner's death.

All of the participants described how the police were unambiguous and supportive whilst informing them of their partner's death. The police stayed with the surviving partner until appropriate support was found and were sensitive in the gathering of further information.

All of the participants' experiences of the nursing profession were positive, with the participants describing how the nurses were supportive and empathetic towards them. Those participants who knew how the health system worked, and how to communicate with health professionals, had the least communication problems. However, they had the difficulty of having to face colleagues in a very confronting situation. Those participants who had limited or no experience with the health system found the experience overwhelming and confusing at times, which led to feelings of anger and frustration.

The participants' experiences with the medical profession were mixed. Individual doctors were supportive and demonstrated a professional level of concern for the surviving partners, however, there were instances when some doctors displayed insensitivity or a resistance to being candid with the surviving partner. Some surviving partners described having difficulty when attempting to get the treating doctors to take their partner's pre-death condition seriously. This led two of the participants to proportion some of the blame for the death towards the treating doctor. Other participants describe how doctors' communication skills were poor, and that three of the participants' general practitioners, who had referred the deceased partner to the treating doctor, were not informed of the death.

Participants didn't describe a great deal of involvement by the clergy. Only one participant had significant contact and this was due to the Minister being a friend who was present when the deceased partner died. 
The Coronial Enquiries Section was described as being professional, albeit remote. The participants reported that the autopsies were handled with sensitivity. One participant had difficulty accessing information through the Coronial Enquiries Section and the hospital, which caused him anger and frustration and led him to believe that both institutions had something to hide.

Funeral companies played a prominent part in the first week or two following the death (apart from one, where the body was cremated overseas), with all of the participants commenting upon their performance favourably. Funeral companies administer most of the arrangements and 'stage-manage' the funeral with the surviving partner acting as a consultant. The funeral companies were criticised by two participants, with one complaining that they did not have enough condolence cards, and another participant describing the funeral company's counsellor's behaviour as being insensitive and inappropriate.

Having to inform various government and non-government agencies of the death of his or her partner caused several participants' frustration and resentment that the information couldn't be passed from one related agency to another. Having to have several certified copies of the death certificate and having to fill in many forms proved to be a tiresome and repetitive burden for the surviving partner.

Financial difficulties were experienced by a few of the participants. Difficulties were encountered with frozen joint bank accounts due to the death of the partner. Other problems encountered by participants included having to sell property or businesses. Some deceased partners did not have life insurance policies or Wills. The younger surviving partners experienced the most pressing financial difficulties, as the older participants were more financially established and secure.

The surviving partner's experience of managing financial affairs following the death of their partner involved closing joint bank accounts and initiating new accounts, and having to deal with people over the telephone who were in centralised locations, isolated from the surviving partner. The surviving partner found him or herself dealing with several people in one organization, which led to communication breakdowns and insensitivity, which caused the surviving partner aggravation and feelings of disillusionment towards the banks involved. Some participants had to sell the family business and/or properties, which was worrisome and stressful, and compounded the sadness and sense of loss that the surviving partner was experiencing. 
Participants found that insurance companies were not easy to deal with. Overly complicated paperwork, insensitive staff, too many intermediaries, and delays in insurance payouts all compounded the distress of the surviving partner.

The death of a partner results in the need for the surviving partner to encounter professional people in circumstances that they may have not experienced before. The surviving partner finds himself or herself in a position where they are vulnerable and extremely anxious. Communication with people who are in positions of power is often fraught with difficulty due to the surviving partner being extremely sensitive to inappropriate or unfeeling exchanges. 


\section{CHAPTER TEN}

\section{THE SURVIVING PARTNER'S RELATIONSHIP WITH THE WORLD WHILST EXPERIENCING THE EMERGENCE OF A NEW LIFE ORDER}

Do not stand by my grave and weep.

I am not there. I do not sleep.

I am a thousand winds that blow.

I am a diamond glint of snow.

I am the sunlight of ripened grain.

I am the gentle autumn rain.

When you awake in the morning hush,

I am the swift, uplifting rush

of quiet birds in circling flight.

I am the soft star-shine at night.

Do not stand by my grave and $c r y$.

I am not here... I did not die.

Makahindan Prayer, (Straub, 2001, p.95)

\section{INTRODUCTION}

Participants found that the sudden unanticipated death of a partner causes the surviving partner to experience the need to revise their understanding of their sense of position in the world. This creates the need to rebuild his or her life meaning, resulting in a new sense of social status, a revised relationship with his or her faith, and a willingness to invest in the future leading to a new life order.

This chapter explores how the surviving partner integrated the death of their partner into his or her life while adjusting to their new social status. The surviving 
partner's relationship with God and his or her own sense of mortality and the future is also discussed.

\section{The surviving partner's experience of reconciling his or her displaced position in the world following the death of his or her partner}

All of the participants described how the death of a partner left him or her in a place in the world that was suddenly changed with their partner having been permanently removed, leaving participants feeling as though an important part of them had been cut away. They were left feeling as if they had been cast adrift, moving through life without a sense of purpose and direction. Sally described the way she felt following Peter's death: "I felt so exposed and I have never felt that way in my life before, my protection was gone."

All of the participants felt that the void they experienced would never be completely filled, as David explained:

I mean obviously you get people saying you know oh, the time will heal, but the reality is that, that's really is what happens you know, and yeah you just, you just, have this void that's, stuck on the back of your being and you just drag it along with you through time, you know and eventually it gets smaller and, and the influences aren't there anymore and, and, and life just goes on.

David went on to talk about not having a sense of loss for previous relationships like he did for Lorna, who held a significant position in his life as the mother of his children, his lover and companion. Dana discovered what loneliness really meant, and that qualities that may have been not fully utilised come to the fore: "I think loneliness is something that has a much deeper meaning than it used to have. You also have an awareness that you can cope with a hell of a lot things you didn't think you could cope with..."

Mary described how she had lost her best friend and soul mate when Alf died. Mary described the sense of loss as immense and incomprehensible. Mary's relationship with Alf could be described as a co-dependency, which she readily admitted to:

Um in the earlier days, I always wrestled with, with those sort of things thinking you know I mean he would say I love you more to me, than I would to him you know he would just off the cuff say it and um, and he was always so good to me, I mean nothing, nothing was ever, a problem you know and I used to get really irritated, so often, you know he, you know he would, you know I forgot something Alf can you just go and get it for me, or can you do this, can you do that, he'd 
always, he would always do, do everything, I was unfortunately very dependant on Alf, I always have been and I didn't think that I would survive when I lost him, so, to talk about exactly what happened, immediately um, I went into total shock, when it happened...He was really from day one, that he took over you know it was like I almost lost my identity, we'd became one, and, and I'm not saying that as a negative at all, it just that reflecting back on my life.

Being totally absorbed in a relationship often excludes a couple's need for other people, as Shirley stated: "it was just this total trust between the two of us that there was just no one else." Participants described having to reassess what was important in their lives following the death of their partner. Sally discovered that she became more aware of the importance of the people around her:

It really, it really did make me um, understand what was happening a lot more and I really think that's something that, I guess not everyone can deal with but in the understanding of things, I think it's important...Um, some relationships, the most important people in my life are always going to be there, and I think they were always there before, it's just that you really work it out...

Jane felt that it was important not to get caught up in things that were not important, and that:

... what's really important and I think also what's helped me um and I was very good at it for the first year was just ah, taking a day at a time and making sure that sometime during that day I, I had a laugh with the girls you know just, just doing that not trying to think about the future where as when Graham and I were together we always thought about the future.

Mary felt that the most important thing for her was to find some semblance of normality, and how she found that her faith in God helped her:

I, I don't know, I don't know why, I, just because I, I, I, I think I just turned to God straight away and, and asked him to give me strength, you know um, so I asked for all the right things, what I thought was important, not to go on to the negatives, of things, cause you know how, how destroying, hate is...

The surviving partner has had his or her world shifted suddenly and permanently leaving them with a hole to fill and the need to redefine him or herself and their place in the world, Neimeyer and colleagues (2002) argue:

...that a common theme in these accounts is that of the meaning of loss as expressed in both individual and collective attempts at adaptation. At a societal level, communal rituals, discursive practices, 
and local cultures provide resources for integrating the significance of loss for survivors and regulating the emotional chaos of bereavement. At an individual and interpersonal level, survivors struggle to assimilate the loss into their existing self-narratives, which are sometimes profoundly challenged by traumatic bereavement (p.235).

\section{The surviving partner's experience with developing a new social status}

The surviving partner is faced with the prospect of adjusting to a new social identity following the death of their partner. Fourteen of the participants were married at the time of their partner's death. All but one of the participants had not considered the prospect of suddenly becoming 'unmarried' prior to the partner's death Tina had contemplated this prospect, which left her with feelings of ambivalence following Barry's death:

I sort of think to myself, well don't keep counting what you did for someone before and expect, um, something back for it, because it mightn't come back from that person but you've done a good deed and you'll get, and I'm finding that, everything goes round comes round, and I've been tremendously fortunate with the, the mob at work with my friends that l've had, and basically now, when I sit and reflect, what would be nice is to have Barry back, how I want him, but of course it's not possible. I always used to say to Barry, this needs doing around the place...oh no we're not doing anything, that doesn't need doing or whatever, and I mean I couldn't possibly do that there, well nothing ever got done around the house.

Tina hadn't wished death upon Barry as a solution to her marriage difficulties, and had recognised positive changes to his attitude towards her prior to his death, but was not sure how long he would have maintained his new approach. Tina has been able to adapt to her new life well, taking opportunities when they have arisen. She has also enjoyed her independence.

The participants all realised that they had a new social identity whether they wanted it or not. Jane felt that it was important that the individual retained his or her own unique sense of identity. Sally felt that instead of being recognised as a widow she was seen by society as a single mother, and was perceived as having been in a failed marriage, which she resented:

I was applying at Centrelink, I went down there, and applied there, and that was very hard, um I think the hardest things about that, is the stigma attached to being a single parent, people don't view you as a single parent because a tragedy has happened (causing you to 
be)...a single parent, they think you've just got yourself into trouble and you're a single parent because you couldn't be a good wife...

Both Brian and Adam considered themselves lucky to have had nursing backgrounds, which had allowed them to be able to break out of the stereotypical macho male role enabling them to adapt to a life that is centred around children and domesticity, as Brian explained:

The other thing is that it'll be interesting to see how guys cope as you said before, being a nurse, you're sort of more touch with your feelings, than someone who's a copper, or ... at least I can cook for myself, I knew how to ... nurse, you're touchy feely sort of stuff but someone that's not got that sort of background. It'd be very interesting to see someone Italian or something like that...

The surviving partner has to adjust to having a new label, that of 'widow' or 'widower'. Rachel found the title of widow empowering in that it alerted the public to the fact that she had lived through a tragic event, however having her father die had left her feeling as though she needed some privacy to regain her strength, as she explained:

I did find that I, would always say you know I'm, I'm a widow, my husband's died and if they ask me then I'll tell them, um, but till really, I suppose till dad died, I sort of, felt strong enough to do that, that was absolutely not a problem but at the moment I'm sort of thinking well you know, I don't know if I really can handle the sympathy now, where as before it was $a_{\text {, }}$ a real positive thing for me.

For Brian the experience of becoming a widower led to an interesting exchange with a young social worker at the Department of Social Security when he was applying for the single parent pension:

....and this really young male social worker, and he's quite proud of it, he'd never had to face a guy whose wife had died, before; he wasn't put out but you could see he was hesitant. You know, he didn't quite know how to go, this was probably the first time he'd done an interview for this type of, you know, for someone whose husband or wife had died. Anyway, he's filling up the questions and there'd be like, ok Mr yes, Brian, yes, address, and now we've got to find out for the single parent pension, are you married, no, well, not any more; de facto, no, divorced, no, oh, widow, "ah, you're a widow?" And I said no I'm not a widow, I'm a widower, widows are female and widowers are male, and he said "other"! And I said, well, OK, if it'll work, so you can get your stats right and all this, so they didn't have that so I was... OK. And there was a couple of other questions and the female alternative, the correct female term as in widow but no widower and he couldn't work out what the equivalent of what that question was. And I found out that in four or five boxes I was in 'other'. 
Brian wondered how the Commonwealth Government tracked widowers who were receiving single parent pensions when they became lost under the 'other' category on all of their forms. As has been previously stated in Chapter Six, this lack of recognition of Brian's status could easily lead to feelings of social isolation.

\section{Relationship of findings to existing literature}

The responses that the participants in this research project described are congruent with the existing qualitative and quantitative research and literature. Adapting to a new social status and identity are related to becoming a single person, sole parent, pensioner, and ultimately widow or widower. The surviving partner's new status is thrust upon them suddenly and without warning, which leads to a confused sense of identity and position in the world (Harte-Barry, 1997; Malacrida et al., 1998; Ott \& Lueger, 2002; Owen, 2000; Prigerson, Maciejewski, \& Rosenheck, 2000; Schneider, Sledge, Shuchter, \& Zisook, 1996; W. Stroebe, Stroebe, Abakoumkin, \& Schut, 1996). The younger surviving partners were aware of their unusual status and experienced feelings of isolation, which is a common finding in thanatological research (Harte-Barry, 1997). The older participants in this research project were more likely to feel that opportunity for socialisation and prospects of forming new friendships and relationships were diminished because of their age, which is also supported in the literature (Costello, 1999; Costello \& Kendrick, 2000).

The male participants in this study were aware of the need to adapt to domesticity and were aware that this was in conflict with the stereotypical male role (Brabant, Forsyth, \& Melancon, 1992; Daggett, 2002; Quigley \& Schatz, 1999; Zinner, 2000). The men who had nursing backgrounds felt that it was easier for them to adapt to a domestic and sole parent role, however, David seemed to have adapted very well, and found the new role satisfying.

\section{The surviving partner's experience with his or her spiritual belief system}

All of the participants were from a Judeo-Christian background with varying levels of religious belief from very strong to nonexistent. Several participants described how they had a strong sense of faith in God. Most of those participants spoke of retaining their faith following the death of their partner, such as Mary:

Yeah, yeah so l've always had a very strong faith. You know and so there was no need for me to change religions or anything I'm quite happy there, my faith has always, it's never, never lost sight, never 
lost sight even though at times I questioned it, it's been a challenge, absolutely. Many times, many times you know he's (God) put me through the mill a few times, and I believe you know, he does that for a reason and hopefully, you know it's there you know, to make you stronger, and your to learn, you are to stop and think about and, and, and, and see why, well hang on well what can I, what can I reevaluate your life. Big time! Big time!

When Alf was killed Mary turned to God straight away and asked Him to give her strength, she asked Him to let her focus on the good things in life and to help her not dwell on hate. Mary credits her faith with enabling her to forgive the driver, who was responsible for killing Alf, even to the extent that Mary pleaded successfully on the driver's behalf to not receive a jail sentence for the driving offences that she was found guilty of.

Sally described having had a sense of God but did not attend church and doesn't think of herself as being overly religious. Her children have been attending religious studies at school and believe that their father is in heaven. Her children have asked her what their father would be doing in heaven. Sally replied that he would be talking with God' Her son lan, who was three years old, thought that he might be playing golf with God.

Unlike Mary and Sally, Carl's death led to Dana reviewing her faith, negatively:

I had always been reasonably religious not that I went to Church a lot but I don't think that is particularly the measure of it all, but you know it's funny as soon as Carl died, I closed God off.

Tina has remained ambivalent about God and the Church and has not regularly attended church due to her negative memories of her church attendance as a child:

...so Church is not my way, um, I would say God might be my way, in my own home, I don't say, I never, look to God, but I think God might be, someone, the sunshine in everyone's psyche, not necessarily a superior being, I can't think that all this happened just by chance, so there had to be a superior being, but who said God is malevolent, or benevolent, you, we don't know.

A few participants in this study were committed to a religious faith and remained committed following the death of their partner. The death of a partner resulted in only one participant decrying her faith. The remainder were either ambivalent or had their own sense of spirituality, such was the case with Don: 
Ah um my up bringing as a child had no religious content what so ever. My mother suggested we go to Sunday school about 2 or 3 times and I think that happened and that was it. So there's that, yeah. When I mentioned that I had done a certain amount of training in psychotherapy type of stuff. Um part of that or a central part of that involved practice entering altered states of consciousness and through the course of that and I've done it for over 10 years or more. Workshops, training I done that sort of stuff, and er some time after I had been doing that, I don't know 3 or 4 or 5 years, I began having these spiritual experiences occurring in the altered state of consciousness and that sort of blew my mind. Um and these were quite specific Christian for example, or as they present Christian experience and it was an enormous shock to my whole sort of worldview if you like. Um and ah this is before I met Jane, um and so that had already arisen and I had already been grappling with that and I mean I, my world-view is that if there's some strong evidence or some strong data there. And ah Jane's death I suppose it sort of just added more grist to that you know. Um Ah she had I think because of this experience she had been through with the cancers some years previously and nearly dying had, had begun to develop some sort of spiritual life/dimension in her life. Um we didn't talk about that a great deal I think because I was only just beginning to sort of find some way of dealing with that myself and so it was not a, not a big thing in our relationship. But it was something that was in a sense, we would have been compatible about it all, certainly would have been able to talk about the sort of thing. We didn't talk about... we didn't talk explicitly about spiritual stuff. But I think for her also it was only just beginning to open as well.

\section{Relationship of findings to existing literature}

The responses that the participants in this research project described are congruent with the existing qualitative and quantitative research and literature. The death of a partner gives the surviving partner the opportunity to review their faith and spirituality. Balk (1999) believes that bereavement is a life crisis that evokes spiritual change, and that the bereaved person derives:

... a new understanding of the meaning of human existence and revising assumptions about one's place in the universe is a singular form that indicates spiritual change at work. Three aspects must be present for a life crisis to produce spiritual change: The situation must create a psychological imbalance or disequilibrium that resists readily being stabilized; there must be time for reflection; and the person's life must forever afterwards be coloured by the crisis (p.485).

Pearce and colleagues (2002) investigated whether the use of a religious belief system impacted upon the health and well being of a widow or widower in the first six months and subsequent four months following the death of their partner. 
health outcomes. The authors found that: "bereaved individuals who relied more heavily on religion to cope with their loss did not experience a significant increase in health problems. Instead, they demonstrated a trend toward fewer disabilities at follow-up, controlling for baseline health, health service use and health behaviors. Conversely, bereaved individuals who had lower religious coping scores demonstrated a trend toward more functional disabilities and chronic conditions from baseline to follow-up, suggesting a decline in health over time" (p. 179).

\section{The surviving partner's experience with facing his or her own mortality and the future}

The sudden and unexpected death of a partner may result in the surviving partner reflecting upon his or her own mortality. The sudden and unexpected death of his or her partner resulted in several participants re-evaluating their own life and future death. The older participants were more aware of their own mortality than the younger ones, as Julie who was 67 when interviewed, described:

Well of course being the age I am, I think as you get older each year you sort of think oh well that's another year and um, I've done what I want to do and um, lets hope I don't carry on until I'm in my nineties, I don't want to live until I'm too old because ah, I just don't want to.

Don was 45 when he was interviewed and is contemplating a long life due to his paternal family being elderly. He did not feel that his life expectancy was any more at risk because Jane died when she was 40 :

Um, I suppose it makes you that little more aware that you're mortal um but because of my father and uncle I fully expect to live another 40 years sort of thing. So I don't feel suppressed...

A turning point in the life of someone whose partner has died suddenly and unexpectedly is when he or she starts to look toward the future (Davis \& NolenHoeksema, 2001b; Kendrick, 1998), however several participants described how they were more focussed upon living for today, rather than contemplating achieving things in the future, . As has been discussed in previous a previous chapter, David gave up full time professional employment to stay at home and care for his children following Lorna's death:

...my attitude towards things changed, um, ah I, I don't, I don't live life for the moment but I, I do have a, hmm a better appreciation of just you know, living now and doing the things that l'd like to do, and that's why I don't really have a drama of not working, I mean a lot of 
people are sort of, of fearful of the fact that (they don't have an income).

Lyn had taken a more fatalistic view of life following the death of Geoff. Having had the opportunity of a wonderful future for herself and her husband taken away after only a few weeks of marriage, Lyn discussed her newfound approach to life:

I don't think... I don't make plans, I live very much for the today, and whatever is in my pocket, um I don't really, think, of having to, go on holidays or things cause I don't particularly want to go on my own. I don't know, we don't know what's in the future, if we knew what's in the future we wouldn't be sitting here now, doing what we're doing because we could change it. Um I don't really look at future things anymore.

The participants who had dependent children all felt that they had little choice but to take part in life as well as they could. Several participants described how they tried to live as positively as possible, as Carol stated: "you get on now, you know, you've got a life to still live, and we will fill that..."

Several participants described how they wanted to get on with their lives and renew their zest for life again. Rachel described how she was regaining her joie de vivre:

(laughs) and I said to him on New Year's Eve I just, it's just twelve months but I feel so positive about my life. I said I am going to make the absolute best of my life and I'm not going to say, I'm not going to say no to very much. I will just do absolutely everything, I just thought, life after something like that happening, life is to short, you just make the best of your life. And go for it and I, that's, absolutely what I do Martin, I just go for it, I mean I, if anything is going I'Il be there. It's tough sometimes because, with me people want to throw themselves at me and hug me and support me but I would rather, you know, just get out there and get on the table and dance!

\section{Relationship of findings to existing literature}

The responses that the participants in this research project described are congruent with the existing qualitative and quantitative research and literature. In the first year or two following the death the surviving partner's feels that external forces, which he or she has little control over, dictate his or her life. As the surviving partner begins to take control of his or her life, opportunities to plan for the future slowly emerge: such as changing jobs, taking a holiday, and undertaking educational courses. Thanatological researchers all regard the act of planning for 
the future as an important turning point in the life of the surviving partner, in that it represents the surviving partner developing a sense of optimism and hopefulness (Coolican, 1994; Daggett, 2002; Davies, 1991; Davis \& Nolen-Hoeksema, 2001a; Gamlin, 1998; Hyrkas, Kaunonen, \& Paunonen, 1997; McKissock \& McKissock, 1998; Moos, 1995; Murray-Parkes, 1998; Remondet \& Hansson, 1987; M. Stroebe, 2001; M. Stroebe, Stroebe, \& Hansson, 1993; Zonnebelt-Smeenge \& Vries, 1998).

Survivors often take the opportunity to reflect upon their own mortality following the death of someone close. Any concerns that the surviving partner may have regarding increased morbidity and mortality following the death of a partner are well founded especially for the older person. Several studies demonstrate morbidity and mortality are increased following the death of a partner, especially for the older person (Bowling \& Windsor, 1995; Campbell, 2000; Jagger \& Sutton, 1991).

\section{PHENOMENOLOGICAL EXPLICATION OF THE PARTICIPANTS' EXPERIENCES}

The death of a partner left a void in the life of the surviving partner, which manifested itself in a sense that something was missing from his or her life and leaving a feeling of emptiness. Regardless of the distractions that the surviving partner employed to mask this emptiness, participants were always aware that they would never be able to replace their deceased partner and never fully recover from the impact that the loss had had upon them.

Following the sudden and unanticipated death a partner, the surviving partner found a new position in the world, which shifted the way that he or she perceives the world. The surviving partner's world is altered irrevocably. The surviving partner has had to redefine what his or her assumptions in life are, in order for him or her to plan for the future. Suddenly life was unpredictable, with the surviving partner finding it difficult to trust him or her self or the world in general.

The surviving partner has to reappraise what he or she values in life. Invariably the surviving partner will include children, family and friends in what they value most. The surviving partner has to find purpose and meaning in life. Not every participant talked about searching for any meaning associated with the death of his or her partner, with all of the participants resentful that their partner's life had been ended prematurely. None of the participants could make sense of the loss, as it had not been perceived to be any fault of the deceased partner. When a partner dies suddenly, through no fault of his or her own, it is difficult to reconcile the loss. 
The surviving partner can only hope to revise his or her place in the world, and be comforted by the memories of the relationship.

These feelings were reinforced by the surviving partners' awareness of his or her new social status of widower or widow (one participant was unmarried). This new label came with its own connotations, which were easier to accept for the older surviving partner, however, the younger surviving partner felt uncomfortable with what may be construed as an age related label. The new status also meant that they were single and therefore potentially available for a new relationship, which brought it's own confrontations. These included potential new suitors, other married women feeling threatened by the widows, and people wanting to set them up with a new partner.

For those participants who had preexisting spiritual beliefs, most were comforted by their belief system, with the death of their partner strengthening their faith, in all but one participant's experience. One participant remained ambivalent about her faith system, with another discarding her religious belief system following the death of her partner.

Inevitably the death of someone close without any warning serves to remind the surviving partner of his or her own mortality. This event gave the surviving partner the opportunity to reflect upon his or her life priorities, relationships, working life, financial needs, and ultimately allow them to plan for the future as a solo person.

Several participants described how, in order to regain balance and harmony in his or her lives, he or she needed to redefine him or herself and review his or her life story. Participants also needed to reposition him or herself with others and the world in order to gain some sense of stability and order. Concerns about their own mortality did not seem to preoccupy the participants. They also described how they actively tried to think positively and grow from their experiences, whilst developing their self worth and optimism for the future. 


\section{CHAPTER ELEVEN}

\section{OVERVIEW OF EXPERIENCES: ADSPICE, RESPICE AND PROSPICE}

Death radically challenges all socially objectwated definitions of reality - of the world, of others, and of self... Death radically puts in question the taken-for granted, 'Vusiness-as-usual' attitude with which one exists in everyday life...

Peter Berger, (Leming \& Dickinson, 1998, p. 141)

\section{INTRODUCTION}

Respice, Adspice, and Prospice: "regard the past, examine the present, and look towards the future" (Feifel, 1992, p. 5). I believe that this is an appropriate title for this overview chapter, in that it reflects the essence of the experiences of the participants in this research project. People actively store information and experiences gathered from their past, reflect and learn from them, and use them to predict and plan for their future. Knowing that life is finite allows us to create a timetable for life that enables us to plan for the future. People form attachments to others and establish significant relationships, such as the partnerships that the participants had experienced in this research project.

This research project was not about death per se, but the experience of life, the life that the surviving partner experienced following the sudden and unexpected death of a person who had been in most cases an inextricable part of the surviving partner's life over an extended period of time. The life that the surviving partner experienced following the death is linked inexorably to the life that they had prior to the death.

Unfortunately, the reader of this thesis was not privileged to hear the surviving partners' descriptions of their lives prior to their partners' deaths, as I was. 
A considerable amount of time was spent at the beginning of each interview gaining some insight into the relationship that the surviving partner had had with their partner. Every time I came away from an interview I was in awe of the quality of the relationship that had been described (there was one person ambivalent about their relationship). So much so, that I gained the impression that it was one of the driving motivations for these people to tell their stories. They wanted to honour their special relationship and memories of their partner and to express the depth of pain and suffering they had experienced because of their partner's death.

\section{Phenomenological explication of the participants' experiences}

The participants' relationships were characterised by love, intimacy, friendship, companionship, shared experiences and memories. The amount of energy and effort that had gone into these relationships had been enormous, with the relationship coming to an abrupt end with little or no forewarning. The everyday assumptions these people incorporated into their lives had evaporated in an instant. Their plans for the future had become suddenly irrelevant. The shock experienced by the surviving partner and disruption to his or her life is unfathomable to someone who has not experienced such a phenomenon.

In nearly all of the deaths the deceased partner did not have any time to prepare for the death. The deceased partners had all been living healthy and productive lives, leading to the expectation that he or she would live through to their retirement years, and beyond. One of the most difficult aspects of sudden and unexpected death is its randomness. This raises the questions: Why did it happen to him or her? Why was there no warning? Were there any warning signs that were ignored? How could this have been avoided? Why was he or she in the wrong place at the wrong time? The surviving partner was left wondering what he or she and the deceased partner had done to deserve this fate.

The love that was fundamental to these relationships (even in times of ambivalence) lived on beyond the death of the partner. This left the surviving partner yearning for the relationship to continue. The reality that the partner was no longer physically a part of his or her life left the surviving partner with a pain that was often overwhelming.

The sudden finality of the relationship left the surviving partner with no opportunity to say goodbye to his or her partner, no opportunity to reiterate his or her love for the partner, no opportunity to review their life together, and no 
opportunity to plan for the surviving partner's, and his or her children's, future without the deceased partner. This is one of the most distressing aspects of sudden and unexpected death.

The months following the sudden and unexpected death of a partner left the surviving partner in the wilderness. The surviving partner was left with a maze-like array of formal tasks to attend to. For the surviving partner who had dependent children, he or she had to bear the load of parenting duties alone. These tasks often provided a distraction from the anguish that the surviving partner was experiencing, however the drudgery of having to inform bureaucrats and administrators of the partner's death often left the surviving partner despairing and desolate.

Life for the surviving partner became dysphoric. He or she struggled to find a purpose in life, experiencing a bareness and listlessness and the same time being engulfed in sadness and sorrow. Often the surviving partner would find him or herself working on autopilot, performing life in a perfunctory manner.

Family and friends played an important role in supporting the surviving partner through these harrowing times. The surviving partner needed unconditional love and support that ranged from being task orientated to providing empathetic listening. Friends were able to assist the surviving partner to regain a social life by reducing his or her anxiety associated with being partnerless. The surviving partner's family were as supportive as their own grief would allow, which sometimes meant that individual family members were unable to fulfil familial obligations due to their own grief related concerns.

Having had his or her life deconstructed, the surviving partner had to reconstruct his or her own life as well as creating a new meaning to life. Creating new meaning meant that the surviving partner had to make some sort of sense of the death of their partner, which is probably the most difficult component of integrating the death of his or her life, because the death seemed so senseless.

Part of the reconstruction process is adapting to life as a single person. For some surviving partners this was a phenomenon that they had not experienced for many years. The surviving partner felt as though a piece of them was missing, which put them out of kilter when approaching other people and the world. Having to deal with people as a single person unbalanced existing relationships, and placed the surviving partner in a position in which they felt alien. The process of social adjustment was often painful and protracted. The security blanket of a partner was no longer there to insulate the surviving partner from exposure to society. 
The surviving partner sometimes experienced a reluctance to recreate his or her identity and sense of self because of the risk of diminishing the significance of the relationship with the deceased partner. The surviving partner eventually created a balance that incorporated the relationship with the deceased partner into his or her new life, allowing them to honour and value the relationship they had with his or her deceased partner. The integration of the death allowed the surviving partner to evolve and in time take pleasure in life again, whilst experiencing periods of nostalgia and remorse.

Due to the surviving partner's experiences he or she generally developed a new regard for the temporality of life and the preciousness of relationships, which informed his or her relationship with him or herself and others in the future. The surviving partner's spiritual belief system generally remained intact and for some participants was strengthened.

The overall experience of loss associated with the sudden and unexpected death of a partner was a life defining experience. It was an experience that forced the surviving partner to revise his or her sense of self, relationship with others and his or her view of life. The emotional scars that were caused by this experience will never completely heal, however with the appropriate support from family and friends, the surviving partner demonstrated an ability to rebuild a sense of hope and optimism for the future, whilst continuing to be connected to the past.

\section{Limitations of the study}

The main concern with this study was whether the survivors would be comfortable in disclosing information of such a personal nature. Given the sheer volume (over 350,000 words of dialogue) and quality of the material it became evident that this concern did not eventuate. Another possible limitation was whether female participants would feel comfortable disclosing personal information to a male researcher. On average the female participants proffered $55 \%$ more dialogue than their male counterparts, with the interviews being open and candid.

I believe that I was able to fulfil the role of the naïve researcher who could be immersed in the data while acknowledging and setting aside presuppositions and assumptions. As well as recognising my own remembrances of loss and containing them. I have never experienced the phenomenon under study directly, however, I have certainly experienced the phenomenon of loss and similar feelings to those that my participants experienced when their partners died. Having reached my 
middle forties I have experienced the deaths of friends and relatives and, of course, pets. All of these experiences need to be acknowledged and placed into my own context without contaminating the experiences of my participants. I do not consider myself a grief and bereavement expert, but as someone who has a vast experience in working with people who have found him or herself in tragic circumstances. So much so, that I have developed a keen sense of wonder as to what people experience following the sudden unanticipated death of their partner. According to Patton (1995): "the validity and reliability of qualitative data depend to a great extent on the methodological skill, sensitivity and integrity of the researcher" (p.11).

The opportunity to retell the participants' stories has been a privilege and has given me the opportunity to reflect upon my own life and relationships. To be invited into someone's life and have them describe such an important life-event was an experience that I will always value and respect. The warmth and best wishes that I received at the time and since have been wonderful. Several participants have sent me notes, updating me on their lives since the interview. Despite having the support of an empathetic supervision team and family and friends, the creation of this research project was essentially a solo journey, taking me places where I haven't always wanted to be.

Researchers who are studying sensitive material need ongoing support, as Johnson \& Clarke (2004) revealed when they surveyed researchers who were undertaking such work and found that: "researchers experienced a number of difficulties that centered around issues of lack of training, confidentiality, role conflict, costs to the participants, the desire for reciprocity, and feelings of isolation" (p.421). Living with others' grief experiences has at times been burdensome, and isolating. The phenomenological process requires that the researcher immerses him or herself in the data that can be overwhelming at times, requiring regular breaks, and support from the supervision team.

It is important to note that the findings from this research project are not generalizable to the greater population. The limited number of participants, the participant's self-selection and the informal structure of the interviews, mean that the findings are limited to this group of participants.

\section{Participants' updates on their lives since being interviewed}

When responding to the seeking of permission to include participant profiles in the thesis, participants often took the opportunity to send me updates on his or 
her life. Lyn described the most amazing story of how she had met a man who had so many things in common with Geoff, that it was uncanny. Lyn not only described similar personality traits, but other historical similarities that he shared with Geoff that were so numerous that she described it as being "spooky". Lyn said that she did plan for the future now, but not too far and not too much! Lyn never thought that she'd be settled following Geoff's death, and said that time is the great healer.

Sally has become estranged from her family, only remaining involved with her sister who lives on the opposite side of Australia. As Sally said: "friends are the family you choose, and I'm just glad I chose well." Sally has remained close to Peter's family but, unfortunately, Peter's father has since died from cancer. Sally reiterated how the interview had helped her.

Tina described her life as being good. Tina met a widower and the relationship lasting quite a while, with many an interesting conversation. Tina felt that, following a marriage like she had with Barry, she did not want to marry again, describing herself as: "not a co-dependant", something that her new partner found difficult to cope with. As Tina says: "I seem to choose men who are control freaks...movin' on...I have great girlfriends, a good job, and am financially secure, so I find my independence very endearing!"

Carol described how she is: "well and getting on with life, a different stage, one I had not anticipated...but one I am trying to embrace. Richard is still never far from my thoughts, but I try to dwell on how lucky to have had 35 years with him."

David made these comments following his review of the thesis:

I have personally found there was a need for me to change... to become a widower (or what ever name you choose; un-partnered, a sole-partner, post-partnered, even a single person). It has taken some time for me to slowly adapt (modify) my personal and social skills from a partnered person to a post-partnered person (often unconsciously). Becoming a post-partnered person has changed my relationship with, my family, my extended family, my friends and my self. It is as though I have adapted to living a new life. The process has taken me time, not effort to achieve the transition. It would be interesting to know if the transition process relates more to a prescribed period of time, rather then the post-partner's effort to change. Some one mentioned to me 5 years...it's over 5 years since Lorna died and even though I've been in a relationship for 3 years, I am only just feeling a sense of "now I can move on". So 5 years seems about right for me. Perhaps the bereavement process can't be hurried; perhaps it's a time dependent metamorphosis. It would be interesting to learn if others have experience the same. If so, it has an impact on the transition process, because it means the transition 
process can't be rushed. More so, perhaps those who seem to have "adapted" quickly, may still not have felt the release.

Mary sent me a speech that she gave three years ago that was part of her first speech after joining Rostrum (a public speaking club):

Until recently, I did not have the confidence or the courage to stand up here in front of you all. So to be standing here today says something about me. I am changing. I am not the same person I was 18 months ago. I used to be a wife, a lover, a best friend and soul mate. 18 months has gone by since my husband, Allan was tragically killed. The months of searing pain and utter despair became familiar companions.

I was numbed with pain. I just couldn't function and the days left me lost and alone - so vulnerable and so fragile. I was so scared. How was I going to cope with looking after myself, my children, and my home. I had always been dependant on my husband. He always made me feel safe and secure. However, the very pain and despair that was ripping me apart, to my astonishment, brought out in me such qualities of strength and courage I had never dreamt I possessed.

My first year of widowhood taught me compassion, self-reliance and to believe in myself. I feel I am growing with my responsibilities and I have more confidence in myself to begin the journey of rebuilding my life. I am emerging from an ocean of grief and embracing life with open arms. I will continue to make the changes necessary for my personal growth and I am optimistic of the future and the changes taking place in my life."

Mary also gave a short review of her life since Alf had died:

Four and a half years on and $\mathrm{I}$ am continuing to make the changes necessary for my personal growth and I am still very optimistic of the future and the changes taking place in my life. Faith, hope and courage and a strong belief in my sense of self have been my constant companions. I have learnt to take time to go slowly, softly and gently. Time is a healer and a friend. I took time to go travelling this year. My travelling spirit and enthusiasm took me to the breathtaking Canadian Rockies, the USA including Alaska and Hawaii. While travelling in Canada I met a beautiful man (Kiwi) who has warmed my heart and soul and given me a second chance of feeling true love again....My life is blessed... 


\section{IN CONCLUSION}

Phenomenological research is not primarily concerned with creating conceptual models, however the themes that emerge often follow experience patterns that can be compared to pre-existing grief models. The participants in this research project have described the integration of the sudden and unexpected death of a partner into their lives as a slow and often tortuous experience. Two eminent thanatological researchers, Stroebe \& Schut (1999), proposed a revised bereavement model that recognised that in adapting to a profound life experience, such as the sudden and unexpected death of a partner, the surviving partner uses a dual process of adaptation:

This model identifies two types of stressors, loss - and restoration oriented, and a dynamic, regulatory coping process of oscillation, whereby the grieving individual at times confronts, at other times avoids the different tasks of grieving. This model proposes that adaptive coping is composed of confrontation, avoidance of loss and restoration stressors. It also argues the need for dosage of grieving, that is, the need to take respite from dealing with either of these stressors, as an integral part of adaptive coping (p.197).

The concept of the surviving partner controlling the 'dosage' of the grieving process due to other needs taking precedence, or simply because the surviving partner is feeling that they have been 'overdosed' by the experience, is useful and reflects the way most of the participants in this research project have approached their lives following the death of their partner.

In an attempt to conceptualise what life is like for the surviving partner following the sudden and unexpected death of a partner, I have adapted a model proposed by Nancy Hogan and her colleagues (1996) that summarised the experiences of those who have suffered the loss of a loved one. Hogan used two entry points to differentiate between a loved one's death associated with acute or chronic illness and a loved one's death due to a sudden death:

Acute/Chronic illness:

Getting the news

Getting the diagnosis

Shock

Calculating the odds

Dedicating resources

Being there for them

Accommodating care

Negotiating treatment

Fighting for life

Enduring stress 


\section{Shutting it out \\ Maintaining hope \\ Losing the battle \\ Seeing the obvious \\ Ending the suffering}

Sudden death:

Finding out

Facing realities

Responding to the news

Going through the motions

Becoming engulfed with suffering

Missing, longing, and yearning

Enduring hopelessness

Existing in the present

Reliving the past

Making sense

Aching with physical pain

Getting through the day

Emerging from the suffering

Embracing hope

Getting on with life

Experiencing personal growth

Becoming (pp. 52 -59).

I have adapted the Hogan and colleagues (1996) model and created a conceptual experience pattern, which emerged from the interpretive themes:

Learning of the death

Reacting to the death

Facing realities

Living life in a perfunctory manner

Being immersed in sorrow and loss

Suffering pain and anguish

Missing, longing, and yearning

\section{Revising the past}

Creating sense and understanding

Review spiritual belief systems

\section{Emerging from despondency}

Revising existing relationships and establishing new relationships

Integrating the death into his or her life

\section{Discovering a new sense of self}

Adjusting to a new social identity

Experiencing personal growth and development

Contributing to life in a fulfilling and meaningful way

\section{Creating hope and optimism for the future}

Adapting to a solitary life and/or forming a new partnership 
Hogan and her colleagues emphasised that the experience of grief was both experiential and cyclical, as well as pointing out that 'grief resolution' was a hypothetical construct and may never occur for many, if anyone (Hogan et al., 1996). The experience pattern that I have created is not didactic, linear, or complete, it is simply designed to give the reader an idea of the experience patterns that have emerged from this research project. It must be emphasised that these experience patterns are mobile, often merge with each other, and follow no prescriptive time frame.

I concur with Hogan and her colleagues' (1996) conclusions in that I feel that the partial or absolute reconciliation of the sudden death of a partner is a phenomenon that may be unattainable, and may actually be an unnecessary component of the reconstruction process. The reconciliation of the death of a partner who has suffered a protracted, painful and or debilitating illness may be more achievable, however the comparative research with sudden and unexpected death is limited. The sudden and unexpectedness of the death can result in psychological trauma that is different from the grief associated with a death that was related to old age or a terminal disease, especially if the death is due to trauma (Neria \& Litz, 2004), however the experience may not be necessarily any less painful or easier to reconcile (Duke, 1998; Gilliland \& Fleming, 1997). One of the major problems associated with sudden death is that there is no chance to say goodbye, which surviving partners often report as a significant regret for them (Davies, 1991; Doyle, 1980; Henschen \& McBride, 1992; Keenan, 1995; McQuay, 1995; Rubel, 1999; Sanguesa, 1995; Wells, 1993; Wright, 1991).

The participants' experiences were in concordance with existing literature, in that the physical and psychological and social manifestations of the phenomenon of the sudden and unexpected death of a partner where similar to those experienced by participants in other studies (Daggett, 2002; Davies, 1991; Doyle, 1980; HarteBarry, 1997).

I believe that the person, whose partner has died suddenly and unexpectedly will never truly 'reconcile' this death. Rather, in order to live a quality life, the surviving partner integrates his or her partner's death into their life story by compartmentalising, or encapsulating the death. By creating a 'memorialisation capsule' within the surviving partner's mind, which is dedicated to the memory of the deceased partner, the surviving partner becomes able to participate in life without the constant intrusion of the associated grief experience. The 'memorialisation 
capsule' can be revisited at will, or may 'breakout' at times of stress or when prompted by significant anniversaries, dates, shared memories, people or events.

David made the point in his thesis review that the main thrust of life following the sudden and unexpected death of a partner is how a person adapts to unsolicited change. The amount of change experienced by the surviving partner is enormous. David described the process as a metamorphosis, which results in the surviving partner becoming a different person. The post death version of the surviving partner may present challenges to his or her children, family and friends who need to recognise that these changes are inevitable and require the adaptation of family and friends.

Overall, the message received from the participants in this research project was that the effects of the sudden and unexpected death of a partner on the surviving partner are profound and long lasting. The surviving partner needs time and space to grieve whilst being offered support from family and friends, the community, the working environment as well as the health and caring professions. The most significant message for people to understand is that the effects do not diminish rapidly, taking at least two years to settle, and up to several years to plateau to a reasonable level. The grief experience is a personal response, which needs to be acknowledged and respected by all who encounter the surviving partner.

Living beyond the unanticipated sudden death of a partner involves living with the partner's death until the surviving partner's own death. As I have stated earlier, ultimately the burden of grief is one that is experienced alone. On this note, I will let Mary conclude:

You know I just want to heal myself, I just want to somehow get better, and you know l've kind of amazed myself, you know out of all of this I've just got so much, it's given me so much strength, you know to be a better person for it, and I know that everything will be okay. I have to believe. 


\section{CHAPTER TWELVE}

\section{RECOMMENDATIONS AND OPPORTUNITIES FOR FUTURE}

\section{RESEARCH}

If you do not think about the future, you cannot have one.

John Galsworthy, (The Merriam-Webster Dictionary of Quotations, 1992, p.160)

The thing is to get the true picture, whatever it is.

Winston Churchill, (Miller \& Hrycyniak, 1996, p.215)

\section{RECOMMENDATIONS}

The following recommendations follow the themes as they emerged throughout the development of the thesis:

Informing of the death and the immediate support of the newly bereaved

The police officers that the participants of this research project encountered were described as being professional, courteous and sensitive. However, on the basis of the participants' experience it became evident that the police service allows junior and/or young officers to inform people of a death, without the support of a senior officer. This is a practice that should be discouraged unless it is absolutely unavoidable. In order to provide best practice, one of the police officers informing the surviving partner of the death should be a senior officer. This practice affirms to the newly bereaved person that the death of their partner is regarded as being important enough to warrant a senior officer, and also allows for supervision and support of the junior and/or young officer.

Informing the surviving partner of the death of his or her partner and the immediate support for the newly bereaved person is often challenging and sometimes difficult for the professionals involved. However through education, ongoing training and staff support, the stress involved can be ameliorated, thus improving the services offered to the newly bereaved person. 
The participants in this study felt that being told of the death in clear unambiguous language was essential. The suddenly bereaved person requires simple, open, honest and unambiguous communication to help him or her process the information. Euphemistic terms such as 'passed away' or 'we've just lost your husband' should be avoided.

One participant of this research project described feeling "dumb and numb" following the news that his wife had died. Information packages that give contact details and practical information on 'what to do next' will provide the newly bereaved with a source of practical information that he or she can access at will.

On the basis of the participants' experience it became evident that when communicating with the newly bereaved person health professionals also need to be aware of the importance of being open, truthful and attuned to the individual person's needs and sensitivity. The findings of this research project indicate that the suddenly bereaved person generally has indistinct recollections of effective communication between him or herself and the professionals that were involved in the death of his or her partner. This is in direct contrast to the distinct memories he or she has of poor or inappropriate communication. The participants who described negative encounters could recall some conversations verbatim, often described these exchanges with bitterness and resentment, and some of the accounts contained significant levels of rancour and vitriol. The other salient finding was that when the surviving partner felt that he or she was not being listened to, or when information was not given immediately or freely, the surviving partner's perception that the health professionals were partly responsible for the death of his or her partner became profound and did not fade over time.

Health practitioners who do not communicate effectively with the newly bereaved person undermine both their own professional integrity and the health profession's reputation of truthfulness in general. One of the most obvious findings from this research project was that the surviving partner requires honesty and openness from the health team caring for his or her partner.

\section{Maintaining the health and well being of the surviving partner}

The surviving partner experiences enormous upheaval following the sudden and unexpected death of a partner. On the basis of the participants' experience it became evident that the health and caring professions need to be prepared to 
respond to the bereaved person by having bereavement-based knowledge and establishing clear protocols to follow in order to maintain continuity of care.

The health and caring professions need to be cognizant of the powerful impact that a partner's sudden and unexpected death has upon the surviving partner. The health implications can sometimes be profound, leading to physical problems and neuropsychological problems that can impair cognitive functioning, interfere with somnolence patterns, and impair memory. The consequences of such a profound event can lead to significant psychosocial impairment, resulting in the surviving partner needing day-to-day support from friends and family to fulfil their daily family and social obligations.

The health and caring professions need to be vigilant in their relationships with the newly bereaved person and family in order to offer the most appropriate support available. Health practitioners who are treating the bereaved person need to be aware that the psychosocial and physical effects of grief can be mild to severe and manifest in many different ways, and remain ongoing for many years following the death of the partner. Health practitioners need to be aware that the bereaved person may use prescription and non-prescription drugs and alcohol in an attempt to ameliorate his or her feelings of bereftness; treatment interventions should be tailored to suit the individual with care and sensitivity.

\section{Bereavement follow up for the newly bereaved person}

On the basis of the participants' experience it became evident that the acute care areas that the participants were exposed to, do not have an established bereavement follow up service. Initiating such a programme should be a priority. As has been stated in previous chapters, bereavement services help to reduce immediate physical and emotional distress and may reduce long-term morbidity associated with the surviving partner's grief experience. Health services need to create bereavement outreach services that actively track the newly bereaved person. The surviving partner may decide not to take up the offer of counselling services, however by doing so the hospital or the Coronial Enquiries Section is sending a message to the surviving partner that the life of the deceased partner was valued along with the feelings of the surviving partner.

Nurses can provide an important and cost effective support service for the newly bereaved. Participants in this research project reported having good experiences with nurses, and appreciated talking to nurses who had been involved 
in the care of his or her deceased partner. Building time into the nurses' work schedule to follow up the newly bereaved person would allow both the nurse and the surviving partner the opportunity to gain satisfaction from further contact.

A team approach is essential in order to maintain good quality care and thorough transfer of information. The most obvious breakdown in teamwork that was evident in this research project was that three referring general practitioners were not informed of the death of his patient. The use of modern medical records and communication pathways should not allow this breakdown in communication to occur. The chain of communication should be consistent and complete, with all participants kept in the information loop at all times.

The information loop should also extend to the reinstigation of the practice of writing letters of condolence followed by a card on the first anniversary of the death, by the practice manager, hospital administration or Coronial Enquiries Section. As has been stated previously in this thesis, there is good evidence to suggest that this practice is supportive and appreciated by all parties involved.

Social workers and pastoral carers often provide an important adjunct role to support both the newly bereaved person and the staff involved. The responses from this research were mixed regarding the effectiveness of social worker intervention, this does not, however, undermine the important role social workers undertake in this situation. The most important recommendation to make from this study is that any health or caring professional who works in relative solitude needs regular supervision and ongoing education.

\section{Grief and bereavement education an ongoing support for the health and caring professions}

As has been previously described in previous chapters, ongoing grief and bereavement education for the health and caring professions is an area that has been described in the literature as weak. The need for undergraduate, postgraduate and continuous education in grief and bereavement issues is fundamental in providing the health and caring professions with the knowledge to be able to assist bereaved people when necessary. Undergraduate courses need to introduce death related subject matter across the curricula so that it is integrated from a biological, psychological, philosophical, ethical, legal and life span perspective, as well as integrating the subject across all years of the course so that students approach death studies from both an academic and personal developmental perspective. 
Providing support to the health and caring professionals who are caring for bereaved people is essential in order to preserve their own health and well being and professional integrity. Without proper education, debriefing and general staff support, health professionals may not feel competent when confronted by the emotionally demanding role of caring for the newly bereaved person.

\section{Coronial Enquiries Section and hospital administration}

The coronial enquiries section and hospital administration seemed to perform their roles effectively in nearly all of the participants' experiences. Despite this, having one participant with a poor experience is enough to warrant concern that inadequate communication and reluctance to divulge autopsy details is an area of concern.

On the basis of the participants' experience it became evident that death certificates should be issued as soon as possible following the death. Issuing at least ten certified copies of the death certificate to the surviving partner, despite the expense, would reduce the burden of having to access a Justice of the Peace to sign copies for distribution to government and non-government agencies, banks and insurance companies.

\section{Bereavement support for children}

The family system is fractured when a parent dies. The need to support parentally bereaved children as well as the remaining parent is an area that needs further recognition. Protocols and support programmes for the social and psychological support of the bereaved family need to be incorporated into the education system, child health programmes, community based health organizations and employment systems.

\section{Funeral directors}

On the basis of the participants' experience it became evident that funeral directors play an important and integral role in the care of the deceased partner and the surviving partner following the death. The need for highly trained sensitive professional funeral directors is imperative, given that the funeral director undertakes such a major role in the immediate time following a death. Appropriate communication skills and ongoing education will help to maintain the levels of professionalism reported in this research project. 


\section{Government and non-government agencies, banks and insurance companies}

On the basis of the participants' experience it became evident that when the surviving partner informed banks and insurance companies of the death of his or her partner the process often involved convoluted pathways that were characterised by poor system management. The lack of bereaved customer protocols was often exacerbated by the perceived lack of empathy and willingness for employees to take responsibility by passing the information on to others in the organization. Once these organizations are informed of a death, a liaison person should be allocated to attend to any follow up communication, so that the surviving partner does not have to continually reiterate his or her story and ensuring that the system does not fail through inadequate information.

\section{LIST OF RECOMMENDATIONS}

The following is an itemised list of recommendations, which are not presented in any order of preference or level of perceived importance:

- One of the police officers informing the surviving partner of the death should be a senior officer;

- The suddenly bereaved person requires simple, open, honest and unambiguous communication to help him or her process the information, from all of those involved prior to and following the death;

- Information packages should be available that give contact details and practical information on 'what to do next' following a sudden and unexpected death;

- The health and caring professions need to have bereavement-based knowledge and clear protocols to activate following a sudden and unexpected death;

- The health and caring professions need to be vigilant in their relationships with the newly bereaved person and family in order to offer the most appropriate support available;

- For those acute care areas that do not have an established bereavement follow up service then initiating such a programme should be a priority, which could be a nurse based programme; 
- A team approach is essential in order to maintain good quality care and thorough transfer of information;

- A letter of condolence including another information pack (in case the first was not issued or was lost) followed by a card on the first anniversary of the death, should be standard practice;

- Health or caring professionals who work in relative solitude (such as social workers need regular supervision and ongoing education;

- Grief and bereavement education for the health and caring professions, needs to be improved at undergraduate, postgraduate, and at staff development levels;

- Debriefing and general staff support is required for health professionals involved in the care of people who die suddenly;

- The Coronial Enquiries Section and hospital administration need to have protocols which allow the surviving partner to access information regarding the cause of death and pre-death treatment freely and easily;

- At least ten copies of the death certificates should be issued as soon as possible following the death;

- Protocols and support programmes for the social and psychological support of the bereaved family needs to be incorporated into the education system, child health programmes, community based health organizations and employment systems;

- Funeral directors require appropriate communication skills and ongoing education in order to maintain high levels of professionalism;

- Banks and insurance companies need to develop or improve protocols, system management and staff training in order to make the informing of a death less stressful and time consuming, with one contact person being allocated to deal with the surviving partner.

\section{OPPORTUNITIES FOR FUTURE THANATOLOGICAL RESEARCH}

Research informs clinical practice and vice versa. There will probably always be some degree of tension when attempting to integrate research findings into practice. The key to success is to involve clinicians in the research process and 
to have researchers involved in the clinical arena as much as possible (Neimeyer, 2000; Silverman, 2000; Wolfe \& Jordan, 2000). The Centre for the Advancement of Health believes that: "Good science is the gold standard in health care. To provide care for grieving individuals that is appropriate and of consistently high quality, it is important to act from a solid base of evidence" (p. 6).

Given that the vast majority of people in the western world die in institutions such as hospitals, hospices and nursing homes (Genevro, Marshall, \& Miller, 2003), it is not surprising that the majority of thanatological research is committed to end of life issues, anticipatory grief, care giver issues and grief related to death following a protracted illness.

Thanatological research that does include sudden and unexpected death is often centred on homicide and suicide. Therefore, there continues to be a gap in thanatological research for investigating the effects of grief and bereavement following a sudden and unexpected death that is caused by natural causes hitherto unknown to the deceased person; motor vehicle accidents, industrial, sporting and recreational accidents.

The Centre for the Advancement of Health's "Report on Bereavement and Grief Research" (2003) provided a review of the published thanatological research from 1985 - 2003. The authors suggest the following areas for further research:

- The relationships and interactions between physiological, behavioral and support mechanisms in shaping bereavement experience, and in placing some bereaved persons at greater risk.

- The relevance of pre-loss experience, care-giving, marital quality, family conflict and other related factors to bereavement reactions and experiences.

- The ways in which circumstances of the death may shape bereavement experiences.

- The nature and structure of effective coping in adaptation and recovery (sorting out such components as meaning-making, appraisal mechanisms, and loss- vs. restoration-focused coping.

- Theoretical formulations of traumatic grief, complicated grief, stigmatized grief, and the implications of each for assessment, prevention and treatment.

- The need for more nuanced understanding of the implications of who it was that died (e.g., parent, child, spouse, sibling, partner, caregiver, friend) for bereavement.

- The need for further purposeful specification of developmental influences on the nature and implications of bereavement across the lifespan, isolating and relating critical developmental variables, processes and patterns.

- The need for more purposeful identification and consideration of potential resilience and protective factors.

- The need for a more structured understanding and empirical verification of the efficacy of prevention and intervention strategies (pp 43-44). 
In addition to this list, I propose that there is a need for further research into the following areas (these research topics have not been listed in order of priority or perceived importance):

- The surviving partner's bereavement experiences related to sudden and unexpected death compared to anticipated death;

- Vicarious bereavement experiences of people such as friends, ex-partners, clandestine lovers;

- The experiences of bereaved people who have experienced the presence of the deceased person;

- The exploration of the notion that following the sudden and unexpected death of a partner the surviving partner continues to carry the memories and love of the deceased partner into subsequent relationships and how this affects the new relationship;

- Longitudinal studies with annual follow-up of the surviving partner to ascertain the effects of time on the bereavement experience;

- Continued exploration into gender differences especially in relation to any gender differences in the formation of new partnerships;

- The efficacy of bereavement related literature that was given to the newly bereaved person soon after the death;

- The impact that follow up bereavement calls and letters of condolence have upon the surviving partner's bereavement experience;

- How a person's ability to handle change affects the bereavement experience; and

- The impact that a pet has upon the newly bereaved person's experiences.

I would also like to challenge thanatological researchers to increase the use of qualitative research methodologies to tell the stories of the survivors, so that through their experiences we can gain increased insight into the true nature of the phenomenon being studied. The use of Husserlian phenomenology in thanatological research allows the individual to express him or herself without interference from the researcher, giving a pure and thorough description of the experience.

Husserlian phenomenology is a vibrant method for capturing the richness and depth of the experiences of people. It is also a time consuming and painstaking methodology that can be very demanding of the solo researcher's energy and commitment. One way of reducing the workload associated with phenomenological research is for more phenomenological researchers to become expert in the use qualitative storage and sorting computer software systems and referencing software systems, both of which make the handling of large data and other research related material so much simpler. Another approach to phenomenological research is to take a team approach dividing and sharing the workload, allowing cross fertilisation to occur and adding to the richness and the veracity of the interpretation. 
To be invited into the lives of people who have experienced grief is an honour and a privilege. In order to disseminate their stories to the world appropriately, research needs to be undertaken with the respect and care that the experiences deserve. I hope that I have achieved these principles and that whoever reads this material is touched by the participants' experiences and takes the opportunity to incorporate their experiences into their professional and personal lives. 


\section{REFERENCES}

ABS. (2002a). Divorce rates in Australia. Retrieved 22nd August, 2004, from www.abs.gov.au/

ABS. (2002b). Life expectancies of Australian men and women. Retrieved 20th March 2004, 2004, from www.abs.gov.aul

Ahern, K. (1999). Pearls, pith and provocation - Ten tips for reflexive bracketing. Qualitative Health Research, 9(3), 407-411.

Allers, R., \& Minkoff, R. (Writer) (1994). The Lion King [Motion Picture]. In T. W. D. Company (Producer). U.S.A.: The Walt Disney Company.

Ames, W. (2004). Poetry and literature. Retrieved 9th November, 2004, from http://www.poetsforum.com/poetryandliterature.htm.

Anderson, M. (2000). Death in the family. Retrieved 12 September, 2000, from www.ncl.ac.uk/ncfs/ncfs/document55

Annells, M. (1996). Hermeneutic phenomenology: philosophical perspectives and current use in nursing research. Journal of Advanced Nursing, 26(4), 705-713.

Annells, M. (1999). Evaluating phenomenology: usefulness, quality and philosophical foundations. Nurse Researcher, 6(3), 5-19.

Anthony, D. (1996). A review of statistical methods in the Journal of Advanced Nursing. Journal of Advanced Nursing, 24, 1089-1094.

Australian Bureau of Statistics. (1997). Life expectancies of Australian men and women. Retrieved 8 August, 2000, from www.abs.gov.au/

Australian Bureau of Statistics. (2002a). Divorce rates in Australia. Retrieved 22nd August, 2004, from www.abs.gov.aul

Australian Bureau of Statistics. (2002b). Life expectancies of Australian men and women.

Retrieved 20th March, 2004, from www.abs.gov.au/

Baillie, L. (1996). A phenomenological study of the nature of empathy. Journal of Advanced Nursing, 24, 1300-1308.

Baker, $\mathrm{H}$. (1987). Some thoughts on helping grieving families. Journal of Emergency Nursing, 13(6), 359 - 362.

Balk, D. (1999). Bereavement and spiritual change. Death Studies, 23(6), 485-493.

Barkway, P. (2001). Michael Crotty and nursing phenomenology. criticism or critique? Nursing Inquiry, 8(3), 191-195.

Bedell, S., Cadenhead, K., \& Graboys, T. (2001). The doctor's letter of condolence. National Vital Statistics Reports Final Data. New England Journal of Medicine, 344, 1161-1162.

Bennett, G., \& Bennett, K. (2000). The presence of the dead: an empirical study. Mortality, 5(2), 139-157.

Birkholz, G., Clements, P., Cox, R., \& Gaume, A. (2004). Students' self-identified learning Needs: A case study of baccalaureate students designing their own death and dying course curriculum. Journal of Nursing Education, 43(1), 36-39.

Black, D. (1998). Coping with loss. Bereavement in childhood. British Medical Journal, 316, 931-933.

Blake, M. (1995). After care program II. Critical Care Clinics of North America, 7(3), 531 532.

Bowling, A., \& Windsor, J. (1995). Death after widow(er)hood: an analysis of mortality rates up to 13 years after bereavement. Omega: The Journal of Death and Dying, 31(1), 35-49.

Brabant, S., Forsyth, C., \& Melancon, C. (1992). Grieving men: Thoughts, feelings, and behaviours following the deaths of wives. The Hospice Journal, 8(4), 33-37.

Buchanan, H., Geubtner, M., \& Snyder, C. (1996). Trauma bereavement program: Review of development and implementation. Critical Care Nursing Quarterly, 19(1), 35-45. 
Bucholz, J. A. (2002). Homicide survivors - misunderstood grievers. New York: Baywood Publishing Company, Inc.

Burgess, K. (1992). Supporting bereaved relatives in A\&E. Nursing Standard, 6(19), 36-39. Campbell, M. (2000). Bereavement follow-up to families after death in the intensive care unit. Critical Care Medicine, 28(4), 1252-1253.

Carr, D., House, J., Kessler, R., Nesse, R., Sonnega, J., \& Wortman, C. (2000). Marital quality and psychological adjustment to widowhood among older adults: a longitudinal analysis. Journal of Gerontology, 55B(4), S197-S207.

Caserta, M., \& Lund, D. (1996). Beyond bereavement support group meetings: exploring outside social contacts among the members. Death Studies, 2066), 537-556.

Castle, J., \& Phillips, W. (2003). Grief rituals: Aspects that facilitate adjustment to bereavement. Journal of Loss \& Trauma, 8(1), 41-71.

Caverhill, P. (1997). Bereaved men: How therapists can help. Psychotherapy in Private Practice, 16(4), 1-16.

Chen, J., Bierhals, A., Prigerson, H., Kasl, S., Mazure, C., \& Jacobs, S. (1999). Gender differences in the effects of bereavement-related psychological distress in health outcomes. Psychological Medicine, 29(2), 367-380.

Chethik, N. (2000). Reaching bereaved men requires innovation. The Forum News/etter Association for Death Education and Counselling, 26(5), 4-5.

Claes, S. (2004). Corticotropin-releasing hormone (CRH) in psychiatry: from stress to psychopathology. Annals of Medicine, 36(1), 50-61.

Clark, G. (1993). Personal meanings of grief and bereavement. Unpublished Doctoral Thesis, University of Alberta, Edmonton.

Connors, P. (1996). Should relatives be allowed in the resuscitation room? Nursing Standard, 10(44), 42-44.

Cooke, M., Cooke, H., \& Glucksman, E. (1992). Management of sudden bereavement in the accident and emergency department. British Medical Journal, 304(9 May), 12071209.

Coolican, M. (1994). Facing the death of a loved one. Dying, Death, Donation, and Bereavement Care, 6(3), 607-611.

Coolican, M., \& Pearce, T. (1995). After care bereavement program. Critical Care Clinics of North America, 7(3), 519-527.

Coolican, M., Vassar, E., \& Grogan, J. (1989). Helping survivors survive. Nursing 89, August.

Corben, C. (1999). Misusing phenomenology in nursing research: identifying the issues. Nurse Researcher, 6(3), 52-66.

Corr, C. (1994). Current models of death, dying, and bereavement. Dying, Death, Donation, and Bereavement, 6(3), 545-552.

Costello, G. (1995). After care program volunteer. Critical Care Nursing Clinics of North America, 7(3), 529-530.

Costello, J. (1999). "Filling the void": Grief and loneliness in older adults. Illness, Crisis \& Loss, 232.

Costello, J., \& Kendrick, K. (2000). Grief and older people: the making or breaking of emotional bonds following partner loss in later life. Journal of Advanced Nursing, 32(6), 1374-1382.

Crowe, M. (1998). The power of the word: Some post-structural consideration of qualitative approaches in nursing research. Journal of Advanced Nursing, 28, 339-344.

Currer, C. (2001). Responding to grief: Dying, bereavement and social care. New York: Palgrave.

Cutcliffe, J. (1998). Hope, counselling and complicated bereavement reactions. Journal of Advanced Nursing, 28(4), 754-761.

Daggett, L. (1999). Living with loss: The lived experience of spousal bereavement in men aged 40 to 60 . Unpublished Dissertation, University Of Alabama, Birmingham.

Daggett, L. (2002). Living with loss: Middle-aged men face spousal bereavement. Qualitative Health Research, 12(5), 625-639. 
Danforth, M., \& Congrad-Glass, J. (2001). Listen to my words, give meaning to my sorrow: A study in cognitive constructs in middle-age bereaved widows. Death Studies, 25(6), 513-529.

Davidhizar, R., \& Kirk, B. (1993). Emergency room nurses: Helping families cope with sudden death. The Journal of Practical Nursing(16 June), 15-19.

Davies, J. (1991). A sudden bereavement. Nursing Times, 87(33), 34-36.

Davis, C., \& Nolen-Hoeksema, S. (2001a). Loss and meaning. How do people make sense of loss? American Behavioral Scientist, 44(5), 726-741.

Davis, C., \& Nolen-Hoeksema, S. (2001b). Loss and meaning: How do people make sense of loss? American Behavioral Scientist, 44(5), 726-741.

Davis, C., Wortmann, C., \& Lehman, D. (2000). Searching for meaning in loss: Are clinical assumptions correct? Death Studies, 24(6), 497-540.

Delbridge, A. (Ed.). (1982). The Macquarie Dictionary. Sydney, New South Wales, Australia: Macquarie Library Pty. Ltd.

Detmer, C., \& Lamberti, J. (1991). Family grief. Death Studies, 15(4), 363-374.

Devenish, S. (2002). An applied method for undertaking phenomenological explication of interview transcripts. The Indo-Pacific Journal of Phenomenology, 2(1), 1-20.

Doka, K. (1987). Silent sorrow: Grief and the loss of significant others. Death Studies, 11(6), 455-469.

Doka, K. (Ed.). (2002). Disenfranchised grief - new directions, challenges, and strategies for practice. Champaign, Illinois, U.S.: Research Press.

Doyle, P. (1980). Grief counselling and sudden death. A manual and guide. Springfield, Massachusetts: Charles C Thomas.

Duke, S. (1998). An exploration of anticipatory grief: The lived experience of people during their spouses' terminal illness and in bereavement. Journal of Advanced Nursing, 28(4), 829-839.

Elliott, J. L. (1999). The death of a parent in childhood: A family account. IIIness, Crisis \& Loss, 7(4), 360-375.

Fauri, D., Ettner, B., \& Kovac, P. (2000). Bereavement services in acute care settings. Death Studies, 24(1), 51-64.

Feifel, H. (1992). The thanatological movement: Respice, adspice, prospice. Loss, Grief and Care, 6(1), 5-15.

Feinstein, D., \& Ramatowski, C. (1995). Staff support. Critical Care Nursing Clinics of North America, 7(3), 535-540.

Field, N., Gal-Oz, E., \& Bonanno, G. (2003). Continuing bonds and adjustments at 5 years after the death of a spouse. Journal of Consulting and Clinical Psychology, 71(1), 110-117.

Fitzgerald, H. (2002). The bereaved employee returning to work. Retrieved 12th August, 2004, from http://uww.americanhospice.org/griefzone/articles/returning2work.htm

Fraser, S., \& Atkins, J. (1990). Survivors' recollections of helpful and unhelpful emergency nurse activities surrounding the death of a loved one. Journal of Emergency Nursing, 16(1), 13-16.

Gamino, L., Hogan, N., \& Sewell, K. (2002). Feeling the absence: A content analysis from the Scott and White Grief Study. Death Studies, 26(10), 793-813.

Gamino, L., Sewell, K., \& Easterling, L. (2000). Scott and White grief study - Phase 2:

Toward an adaptive model of grief. Death Studies, 24(7), 633-660.

Gamlin, R. (1998). Using hope to cope with loss and grief. Nursing Standard, 9(48), 33-35.

Genevro, J., Marshall, T., \& Miller, T. (2003). Report on Bereavement and Grief Research. Calgary: Centre for the Advancement of Health.

Giguere, B. (2002). Nursing as Caring: A Model for Transforming Practice. Nursing Education Perspectives, 23(3), 146.

Gilbert, K. (1996). We've had the same loss, why don't we have the same grief? Loss and differential grief in families. Death Studies, 20(3), 269-283.

Gilliland, G., \& Fleming, S. (1997). A comparison of spousal anticipatory grief and conventional grief. Death Studies, 22, 541-569. 
Giorgi, A. (2001). A phenomenological analysis of descriptions of conceptions of learning obtained from a phenomenographic perspective. Retrieved 18th September, 2002, from www.ped.gu.se/biorn/phgraph/misc/constr/giorgi

Giorgi, A. (Ed.). (1985). Phenomenology and psychological research. Pitsburgh, Pennsylvania: Duquesne University Press.

Golden, T. (1999). Healing and the internet. The Forum News/etter: Association for Death Education and Counselling, 25(5), 3-9.

Goshorn, M. (2000). WidowNet. Retrieved 12th September, 2000, from www.fortnet.org/WidowNet/index

Griffith, T. (2003). Assisting with the "big hurts, little tears" of the youngest grievers: Working with three-, four-, and five-year-olds who have experienced loss and grief because of death. IIIness, Crisis \& Loss, 11(3), 217-225.

Haas, F. (2003). Bereavement care: seeing the body. Nursing Standard, 17(28), 33-37.

Harte-Barry, M. (1997). "Widows aren't meant to be in their Thirties." Bereavement experiences of widows with dependent children. Unpublished Qualitative, The University of Waikato, Waikato, New Zealand.

Hennessy, E. (2004). Bereavement counselling service. Retrieved 10th August, 2004, from http://www.grief.org.au/couns.html

Henschen, K., \& McBride, A. (1992). A retrospective study of the effect of an athlete's sudden death on teammates. Omega: The Journal of Death and Dying, 25(3), 217 213.

Hill, G., \& Powell, L. (Eds.). (1934). Boswell's Life of Johnson (Vol. 3). Oxford, United Kingdom: Clarendon Press.

Hockey, J., Katz, J., \& Small, N. (2001). Grief, mourning and death ritual. Buckingham, United Kingdom: Open University Press.

Hofer, M. (1996). On the nature and consequences of early loss. Psychosomatic Medicine, 58(6), 570-581.

Hogan, N., Greenfield, D., \& Schmidt, L. (2001). Development and validation of the Hogan Grief Reaction Checklist. Death Studies, 25(1), 1-32.

Hogan, N., Morse, J., \& Tason, M. C. (1996). Toward an experiential theory of bereavement. Omega: The Journal of Death and Dying, 31(1), 43-65.

Holroyd, C. (2001). Phenomenological research method, design and procedure: A phenomenological investigation of the phenomenon of being-in-community as experienced by two individuals who have participated in a community building workshop. Indo-Pacific Journal of Phenomenology, 1.

Holstein, J., \& Gubrium, J. (Eds.). (1994). Phenomenology, ethnomethodology and interpretive practice. Thousand Oaks, California, U.S.: Sage Publishers.

Horacek, B. (1995). A heuristic model of grieving after high-grief deaths. Death Studies, 19. 21-31.

Hustins, K. (1993). Gender differences and bereavement. Canadian Nurse, 89(3), 48.

Hyrkas, K., Kaunonen, M., \& Paunonen, M. (1997). Recovering from the death of a spouse. Journal of Advanced Nursing, 25(4), 775-779.

Jackson, I. (1995). Critical care nurses' perception of a bereavement follow-up service. Intensive and Critical Care Nursing, 12, 2-11.

Jagger, C., \& Sutton, C. (1991). Death after marital bereavement - is the risk increased? Statistics in Medicine, 10, 395-404.

Johnson, B., \& Clarke, J. M. (2004). Collecting sensitive data: The impact on researchers. Qualitative Health Research, 13(3), 421-434.

Jones, C. (1997). R.I.P The complete book of death \& dying. New York: Harper Collins.

Jordan, J., \& Neimeyer, R. (2003). Does grief counselling work? Death Studies, 27(9), 765786.

Joyce, A. (2004). Men and women respond differently to the group therapy format. Psychotherapy Research.

Kaunonen, M., Tarkka, M., Paunonen, M., \& Laippala, P. (1999). Grief and social support after the death of a spouse. Journal of Advanced Nursing, 30(6), 1304-1311. 
Keenan, K. (1995). The role of nursing assessment of traumatic events in sudden injury, illness and death. Critical Care Nursing Clinics of North America, 7(3), 483-488.

Kellehear, A. (Ed.). (2000). Death \& Dying in Australia. Melbourne, Victoria, Australia: Oxford University Press.

Kendrick, K. (1998a). Bereavement part 1: Theories of bereavement. Professional Nurse, 14(1), $59-62$.

Kendrick, K. (1998b). Bereavement Part 2: Breaking bad news. Professional Nurse, 14(2), 135-138.

Kessler, B. (1987). Bereavement and personal growth. Journal of Humanistic Psychology, 27(2), 228-247.

Kiger, A. (1994). Student nurses involvement with death: The image and the experience. Journal of Advanced Nursing, 20, 679-686.

Kirschling, J., \& McBride, A. (1989). Effects of age and sex on the experience of widowhood. Western Journal of Nursing Research, 11(2), 207-218.

Klein, M. (2000). Young-widows@eGroups.com. Retrieved 12th September, 2000, from unw.egroups.com/list/young-widows/info

Koch, T. (1998). Story telling: is it really research? Journal of Advanced Nursing, 28(6), 1182-1190.

Koodiaroff, S. (1999). Bereavement care: A role for the community nurse. Collegian, 6(2), 911.

Kralik, D., Koch, T., \& Wotton, K. (1997). Engagement and detachment: understanding patients' experiences with nursing. Journal of Advanced Nursing, 26(2), 399-407.

LaGrand, L. E. (1999). Messages and miracles - extraordinary experiences of the bereaved. Minneapolis, Minnesota, U.S.: Llewellyn Publications.

Lasseter, J. (Writer) (1995). Toy Story [Motion Picture]. In T. W. D. Company (Producer). U.S.A: The Walt Disney Company.

Leash, R. M. (1996). Death notification: Practical guidelines for health care professionals. Critical Care Nursing Quarterly, 19(1), 21-34.

Leming, M., \& Dickinson, G. (1998). Understanding death, dying \& bereavement (4th ed.). Fort Worth, Texas, U.S.: Harcourt Brace College Publishers.

Levang, E. (1998). When men grieve - Why men grieve differently and how you can help. Minneapolis, Minnesota: Fairview Press.

LeVasseur, J. (2002). A Phenomenological Study of the Art of Nursing: Experiencing the Turn. Advances in Nursing Science, 24(4), 14-26.

LeVasseur, J. (2003). Pearls, Pith, and Provocation: The problem of bracketing in phenomenology. Qualitative Health Research, 13(3), 409-420.

Levinson, D., \& Prigerson, H. (2000). Traumatic grief model and the spousal loss model. IIIness, Crisis \& Loss, 8(1), 32-46.

Levy, L. (1991). Anticipatory grief: It's measurement and proposed reconceptualisation. Hospice Journal, 8(4), 1-28.

Lund, D. A. (Ed.). (2001). Men Coping with Grief. New York: Baywood Publishing Company.

Lynn, C. (2000). GriefNet. Retrieved 12th September, 2000, from www.griefnet.org/

Malacrida, R., Bettelini, C., Degrate, A., Martinez, M., Marina, P., Badia, F., et al. (1998). Reasons for dissatisfaction: a survey of relatives of intensive care patients who died. Critical Care Medicine, 26(7), 1187-1193.

Martin, T. L., \& Doka, K. J. (2000). Men don't cry... Women do. Transcending gender stereotypes of grief. Philadelphia, Pennsylvania, U.S.: Bruner/Mazel.

Martin-Baker, H. (1987). Some thoughts on helping grieving families. Journal of Emergency Nursing, 13(6), 359-362.

Mason, P. (1992). Allowing for loss. Nursing Times, 88(2), 14-15.

McCutcheon, H., \& Pincombe, J. (2001). Intuition: an important tool in the practice of nursing. Journal of Advanced Nursing, 35(3), 342-348.

McKissock, M., \& McKissock, D. (1996). The nurses role in caring for the newly bereaved. Lamp, 53(5), 30-32. 
McKissock, M., \& McKissock, D. (1998). Coping with grief. Sydney, New South Wales, Australia: ABC Books.

McQuay, J. (1995). Support of families who had a loved one suffer a sudden injury, illness or death. Critical Care Nursing Clinics of North America, 7(3), 541-547.

McQuay, J., Schwartz, R., Goldblatt, P., \& Giangrasso, V. (1995). Death-Telling research project. Critical Care Nursing Clinics of North America, 7(3), 549-553.

The Merriam-Webster dictionary of quotations (Ed.).^(Eds.). (1992). Springfield, Massachusetts: Merriam-Webster Inc.

Middleton, W., Burnett, P., Raphael, B., \& Martinek, N. (1996). The bereavement response: A cluster analysis. British Journal of Psychiatry, 169(2), 167-171.

Miller, R., \& Hrycyniak, S. (1996). Grief Quest - Reflections for men coping with loss. Indiana: Abbey Press.

Monk, C. (2004). The effects of cortisol and norepinephrine modulation on emotional and nonemotional processing, from http://uww.clinicaltrials.gov/ct/gui/show/NCT00032838

Moody, R., \& Perry, P. (1993). Reunions - Visionary encounters with departed loved ones. Rochester, Minnesota, U.S.: Villard Books.

Moos, N. (1995). An integrative model of grief. Death Studies, 19(4), 337-364.

Morin, S., \& Welsh, L. (1996). Adolescents' perceptions and experiences of death and grieving. Adolescence, 31(123), 585-595.

Munhill, P., \& Boyd, C. O. (1993). Nursing research: A qualitative perspective. Norwalk, California, U.S.: Appleton-Century-Crofts.

Murray-Parkes, C. (1987). Models of bereavement care. Death Studies, 11(4), 257-261.

Murray-Parkes, C. (1995). Guidelines for conducting ethical bereavement research. Death Studies, 19(2), 171-181.

Murray-Parkes, C. (1998). Coping with loss. Bereavement in adult life. British Medical Journal, 316(14 March), 856 - 859.

Neimeyer, R. (2000a). Grief therapy and research findings in bereavement programs. Death Studies, 24(7), 603-610.

Neimeyer, R. (2000b). Searching for the meaning of meaning: Grief therapy and the process of reconstruction. Death Studies, 24(6), 541-558.

Neimeyer, R., Prigerson, H., \& Davies, B. (2002). Mourning and meaning. American Behavioral Scientist, 46(2), 235-251.

Neria, Y., \& Litz, B. (2004). Bereavement by traumatic means: The complex synergy of trauma and grief. Journal of Loss \& Trauma, 9(1), 73-87.

O'Bryant, S. (1991). Forewarning of a husband's death: Does it make a difference for older widows? Omega: The Journal of Death and Dying, 22(3), 227-239.

Ogrodniczuk, J., Piper, W., \& Joyce, A. (2004). Differences in Men's and Women's Responses to Short-Term Group Psychotherapy. Psychotherapy Research, 14(2), 231-243.

Omery, A. (1983). Phenomenology: a method for nursing research. Advances in Nursing Science, 5, 49-63.

Omery, C. (1983). Phenomenology: A method for nursing research. Advances in Nursing Science, 5(2), 49-63.

Ott, C., \& Lueger, R. (2002). Patterns of change in mental health status during the first two years of spousal bereavement. Death Studies, 26(5), 387-411.

Owen, M. (2000). Empowering Widows in Development. Retrieved 12th September, 2000, from www.oneworld.org/empoweringwidows

Paley, J. (1997). Husserl, phenomenology and nursing. Journal of Advanced Nursing, 26(1), 187-193.

Paley, J. (1998). Misinterpretive phenomenology: Heidegger, ontology and nursing research. Journal of Advanced Nursing, 27(4), 817-824.

Parkes, C. (1987). Models of bereavement care. Death Studies, 11(4), 257-261.

Patton, M. (1990). Qualitative evaluation and research methods (2nd ed.). Newbury Park, California, U.S.: Sage. 
Pearce, M., Chen, J., Silverman, G., Kasl, S., Rosenheck, R., \& Prigerson, H. (2002). Religious coping, health service use, and health among bereaved adults. International Journal of Psychiatry in Medicine, 32(2), 179-199.

Prigerson, H., Bierhals, A., Kasl, S., Reynolds, C., Shear, K., Day, N., et al. (1997). Traumatic grief as a risk factor for mental health and physical morbidity. American Journal of Psychiatry, 154(5), 616-623.

Prigerson, H., \& Jacobs, S. (2001). Caring for bereaved patients: "All the doctors just suddenly go". The Journal of the American Medical Association, 286(11), 13691376.

Prigerson, H., Maciejewski, P., \& Rosenheck, R. (2000). Preliminary explorations of the harmful interactive effects of widowhood and marital harmony on health, health service use, and health care costs. Gerontologist, 40(3), 349-357.

Prigerson, H., Shear, K., Frank, E., Beery, L., Silberman, R., Prigerson, J., et al. (1997). Traumatic grief: A case of loss induced trauma. American Journal of Psychiatry, 154(7), 1003-1009.

Quigley, D., \& Schatz, M. (1999). Men and women and their responses in spousal bereavement. The Hospice Journal, 14(2), 65-78.

Rando, T. (1993). Treatment of complicated mourning. Champaign, Illinois, U.S.: Research Press.

Range, L., Kovac, S., \& Marion, M. (2000a). Does writing about the bereavement lessen grief following sudden unintentional death. Death Studies, 24(6), 115-134.

Range, L., Kovac, S., \& Marion, M. (2000b). Does writing about the bereavement lessen grief following sudden, unintentional death? Death Studies, 24(2), 115-134.

Range, L., \& Niss, N. (1990). Long-term bereavement from suicide, homicide, accidents and sudden death. Death Studies, 14, 423-433.

Ratcliffe, P. (1998). Using the "new" statistics in nursing research. Journal of Advanced Nursing, 27(1), 132-139.

Redwood, D. (1997). A Daniel Redwood interview with Elisabeth Kubler-Ross, M.D. On Death and Dying. Retrieved 12th September, 2000, from unw.doubleclickd.com/kubler

Reisman, A. (2001). Death of a spouse: Illusory basic assumptions and continuation of bonds. Death Studies, 25(5), 445-460.

Remondet, J., \& Hansson, R. (1987). Assessing a widows grief: A short index. Journal of Gerontological Nursing, 13(4), 31-34.

Richmond, B., \& Ross, M. (1994). Death of a partner: responses to AIDS-related bereavement. Journal of Psychosocial Oncology, 12, 143-163.

Robertson, J., \& Welch, W. (1997). Can data collection during the grieving process be justifiable? British Journal of Nursing, 6(13), 759-764.

Robinson, J. (1995). Grief responses, coping processes, and social support of widows: Research with Roy's model. Nursing Science Quarterly, 8(4), 158-164.

Rosenblatt, P. (1994). Family distancing following a fatal farm accident. Omega: The Journal of Death and Dying, 28(3), 183-200.

Rosenblatt, P. (1995). Ethics of qualitative interviewing with grieving families. Death Studies, 19, 139-155.

Rubel, B. (1999). Impact of a grief-crisis intervention immediately after a sudden violent death on the survivor's ability to cope. IIIness, Crisis \& Loss, 7(4), 376-389.

Sable, P. (1991). Attachment, loss of spouse, and grief in elderly adults. Omega: The Journal of Death and Dying, 23(2), 129-142.

Salsberry, P. (1989). Phenomenological research in nursing: Commentary and responses. Nursing Science Quarterly, 2(1), 9-19.

Sandelowski, M. (1994a). Notes on transcription. Research in Nursing \& Health, 17, 311 314.

Sandelowski, M. (1994b). The use of quotes in qualitative research. Research in Nursing and Health, 17, 479-482. 
Sandelowski, M. (1995a). Qualitative analysis: What it is and how it began. Research in Nursing \& Health, 18, 371-375.

Sandelowski, M. (1995b). Sample size in qualitative research. Research in Nursing \& Health, 18, 179-183.

Sanguesa, L. (1995). No time to say goodbye. Observation, 8(Summer), 15-17.

Sawicki, M. (2001). Edmund Husserl (1859 - 1938). Retrieved 29th August, 2001, from www.utm.edu/research/iep/h/husserl

Schneider, D., Sledge, P., Shuchter, S., \& Zisook, S. (1996). Dating and remarriage over the first two years of widowhood. Annals of Clinical Psychiatry, 8(2), 51-57.

Schoenburg, M. (1980). Bereavement counselling. A multidisciplinary handbook. Westport, Missouri, U.S.: Greenwood.

Schoenhofer, S. O. (2002). Philosophical Underpinnings of an Emergent Methodology for Nursing as Caring Inquiry. Nursing Science Quarterly, 15(4), 275-280.

Sherwood, P. (2001). Client experience in psychotherapy: What heals and what harms. Indo-Pacific Journal of Phenomenology, 2(1).

Shuchter, R., \& Zisook, S. (1993). The course of normal grief. In M. Stroebe, W. Stroebe \& R. Hansson (Eds.), Handbook of bereavement (pp. 23-43). Cambridge, United Kingdom: Cambridge University Press.

Silverman, P. (2000). Research, clinical practice, and the human experience: Putting the pieces together. Death Studies, 24(6), 469-478.

Skinner-Cook, A. (1995). Ethical issues in bereavement research: An overview. Death Studies, 19(2), 103-122.

Skinner-Cook, A., \& Bosley, G. (1995). The experience of participating in bereavement research: Stressful or therapeutic? Death Studies, 19, 157-170.

Skinner-Cook, A., \& Oltjenbruns, K. (1998). Dying and grieving - Life span and family perspectives. Fort Worth, Texas, U.S.: Harcourt Brace College Publishers.

Sklar, F., \& Hartley, S. (1990). Close friends as survivors: Bereavement patterns in a hidden population. Omega - The Journal of Death and Dying, 21(2), 103-112.

Smith, B., Mitchell, A., Bruno, A., \& Constatino, R. (1995). Exploring widow's experiences after the suicide of their spouse. Journal of Psychosocial Nursing, 33(5), 10-15.

Sokololowski, R. (2000). Introduction to phenomenology. Cambridge, United Kingdom: Cambridge University Press.

Speck, P. (1985). Counselling on death and dying. British Journal of Guidance and Counselling, 13(1), 89-97.

Staudacher, C. (1991). Men \& grief - A guide for men surviving the death of a loved one. Oakland, California, U.S.: New Harbinger Publications, Inc.

Steen, K. (1998). A comprehensive approach to bereavement. Nurse Practitioner, 23(3), 54,59-64,66-58.

Stewart, A., Harris-Lord, J., \& Mercer, D. (2000). A survey of professionals' training and experiences in delivering death notifications. Death Studies, 24(7), 611-632.

Straub, S. H. (2001). Death without notice. New York: Baywood Publishing Company.

Stroebe, M. (1998). New directions in bereavement research: Exploration of gender differences. Palliative Medicine, 12, 5-12.

Stroebe, M. (2001). Bereavement Research and Theory: Retrospective and Prospective. American Behavioral Scientist, 44(5), 854-865.

Stroebe, M. (2002). Paving the way: From early attachment theory to contemporary bereavement research. Mortality, 7(2), 127-138.

Stroebe, M., Gergen, M., Gergen, K., \& Stroebe, W. (1992). Broken hearts or broken bonds. Love and death in historical perspective. American Psychologist, 47(10), 1205-1212.

Stroebe, M., \& Schut, H. (1999). The dual process model of coping with bereavement: Rationale and description. Death Studies, 23(3), 197-224.

Stroebe, M., Stroebe, W., \& Hansson, R. (1993). Handbook of Bereavement. Theory, research, and intervention. Cambridge, United Kingdom: Cambridge University Press. 
Stroebe, W., Stroebe, M., Abakoumkin, G., \& Schut, H. (1996). The role of loneliness and social support in adjustment to loss: A test of attachment versus stress theory. Journal of Personality \& Social Psychology, 70(6), 1241-1249.

Sweeting, H., \& Gilhooly, M. (1990). Anticipatory grief: A review. Social Science and Medicine, 30(10), 1073-1080.

Tanaka, Y. (2004). The Effects of Companion Animals that Ease Grief of the Bereaved Elderly. Retrieved 3rd Novemeber, 2004, from http://www.cairc.org/e/newsletter/2004/0407 1e.html

Tatano-Beck, C. (1993). Qualitative research: The evaluation of its credibility, fittingness and auditabilty. Western Journal of Nursing Research, 15(2), 263-266.

Tatano-Beck, C. (1994). Phenomenology: Its use in nursing research. International Journal of Nursing Study, 31(6), 499-510.

Taylor, B. (1995). Interpreting phenomenology for nursing research. Nurse Researcher, $3(2), 66-79$.

Thayre, K. (1995). Never going to be easy: Giving bad news. Nursing Standard, 6(9), 3-8.

Toomey, B. (1995). After care program volunteer. Critical Care Clinics of North America, $7(3)$, 533-534.

Tudiver, F., Woods, J., Permaul, A., Hilditch, J., Harmina, J., \& Saini, S. (1995). Do widowers use the health care system differently? Does intervention make a difference? Canadian Family Physician, 41( Mar), 392-400.

Tye, C. (1993). Qualified nurses' perception of the needs of suddenly bereaved family members in the accident and emergency department. Journal of Advanced Nursing, 18, 948-956.

Valente, S., \& Saunders, J. (1997). Phenomenology and the human dimension. Image The Journal of Nursing Scholarship, 29(2), 9.

Vanderwerker, L., \& Prigerson, H. (2004). Social support and technological connectedness as protective factors in bereavement. Journal of Loss \& Trauma, 9(1), 45-57.

Van-der-Zalm, J. (2000). Hermeneutic-phenomenology: providing living knowledge for nursing practice. Journal of Advanced Nursing, 31(1), 211-218.

van-Manen, M. (2002). Phenomenological Methodology. Retrieved 20th March, 2004, from www.phenomenologyonline.com/inguiry/9

Walter, T. (1996). A new model of grief: Bereavement and biography. Mortality, 1(1), 7-25.

Walter, T. (1999). On bereavement - The culture of grief. Buckingham, Philadelphia, U.S.: Open University Press.

Wayment, H., \& Vierthaler, J. (2002). Attachment style and beravement reactions. Journal of Loss \& Trauma, 7(2), 129-149.

Weiss, R. (1998). Separation and other problems that threaten relationships. British Medical Journal, 316, 1011-1013.

Wells, P. (1993). Preparing for sudden death: Social work in the emergency room. Social Work, 38(3), 339-342.

West, T. (1998). On the encounter with a divine presence during a near death experience. A phenomenological inquiry. In R. Valle (Ed.), Phenomenological Inquiry in Psychology: Existential and Transpersonal Dimensions. New York: Plenium Press.

William, J. (1991). Grief counselling and grief therapy. A handbook for the mental health practitioner. London: Routledge.

Williams, A., O'Brien, D., Laughton, K., \& Jelinek, G. (2000). Improving services to bereaved relatives in the emergency department: making health care more human. Medical Journal of Australia, 173(9), 456.

Williams, M. (2001). The loss of a silent partner. The Forum Newsletter - Association for Death Education and Counselling, 27(2), 12.

Wolfe, B., \& Jordan, J. (2000). Ramblings from the trenches: A clinical perspective on thanatological research. Death Studies, 24(7), 569-584.

Worden, J. (1996). Children and grief: When a parent dies. New York: Guildford Publications Inc. 
Worden, W. (1983). Attachment, loss and the tasks of mourning. In W. Worden (Ed.), Grief Counselling and Grief Therapy (pp. 7-18). London: Tavistock.

Worden, W. (1991). Grief counselling and grief therapy (2nd ed.). London: Routledge.

Wortman, C., \& Silver, R. (1989). The myths of coping with loss. Journal of Corisulting and Clinical Psychology, 37(3), 349-357.

Wright, B. (1991). Sudden death: Intervention skills for caring professions. Edinburgh, United Kingdom: Churchill Livingston.

Yegdich, T. (1999). On the phenomenology of empathy in nursing: empathy or sympathy? Journal of Advanced Nursing, 30(1), 83-93.

Zinner, E. (2000). Being a man about it: The marginalization of men in grief. IIIness, Crisis \& Loss, 8(2), 181-188.

Zisook, S., Chentsova-Dutton, Y., \& Shuchter, S. (1998). PTSD following bereavement. Annals of Clinical Psychiatry, 10(4), 157-163.

Zisook, S., Paulus, M., Shuchter, S., \& Judd, L. (1997). The many faces of depression following spousal bereavement. Journal of Affective Disorders, 45(1-2), 85-94.

Zisook, S., \& Shuchter, S. (1985). Time course of spousal bereavement. General Hospital Psychiatry, 7(2), 95-100.

Zisook, S., \& Shuchter, S. (1991). Early psychological reaction to the stress of widowhood. Psychiatry, 54(4), 320-333.

Zisook, S., Shuchter, S., Irwin, M., Darko, D., Sledge, P., \& Resovsky, K. (1994).

Bereavement, depression, and immune function. Psychiatry Research, 52(1), 1-10.

Zisook, S., Shuchter, S., Sledge, P., Paulus, M., \& Judd, L. (1994). The spectrum of depressive phenomena after spousal bereavement. Journal of Clinical Psychiatry, 55(Suppl), 29-36.

Zonnebelt-Smeenge, S. J., \& Vries, R. C. D. (1998). Getting to the other side of grief. Grand Rapids, Michigan, U.S.: Baker Books. 


\section{APPENDIX A}

\section{Letter to participant}

\section{Edith Cowan University \\ Faculty of Communications, Health and Science School of Nursing and Public Health}

\section{Dear}

My name is Martin Rodger, and I am writing to invite you to participate in a research project that will be exploring the effects the sudden unanticipated death of a person has on the partner who survives. This project forms the basis of a Doctor of Philosophy (Nursing), which I am currently studying at Edith Cowan University. When this project is complete, as many people will read the themes surrounding participants' experiences as possible. The conclusions may help guide health professionals such as doctors and nurses to know how to help people more effectively.

I have worked as a Registered Nurse for 23 years, in a variety of settings, mainly working in emergency nursing and the nursing education. My interest in the survivors of sudden death began when I was caring for people whose partners had died unexpectedly in the Emergency Department. I have always been concerned as to what happened to these people when they left the Emergency Department and how they coped with this experience.

I understand that your story and feelings are very personal, so please be assured that your personal details will be known only to myself and not connected to any of the information that you give. Be assured that confidentiality will be maintained at all times. You will be able to withdraw your offer to participate or refuse to have some or all of your information used at any point in the project. Further details regarding the research project may be found in the consent form that I have included with this letter. If you wish to discuss this project with an independent person, you may contact my supervisor - Dr Moira O Connor on XXXX XXXX.

If you agree to participate after having read the consent form, would you please complete and return the personal details form and the consent form in the stamped self addressed envelope provided. I will then contact you to make arrangements to meet you at a convenient time and place. Please do not hesitate to contact me on any of the contact numbers below if you wish to discuss this project further. I appreciate you taking the time to consider this request.

Yours sincerely 


\section{APPENDIX B}

\section{Consent form}

\section{Project Title: "Living beyond the unanticipated sudden death of your partner - a phenomenological study."}

Researcher: Martin Rodger, Home ph: XXXXXXXX, Work ph: XXXXXXXX, Mobile ph: $X X X X X X X X X X$

The purpose of this research is to describe the every day experiences of people whose partner has died without any warning within the last few years. In essence, I would like to know what are the thoughts, feelings and stories associated with being in this situation. It is hoped that this study will assist the people involved in health care, bereavement counselling and Coronial Inquiries, by allowing for a greater understanding of what someone in your circumstances has experienced.

Interviews will be informal and conversational in style and will probably take between one and two hours. The number of interviews will be determined on an individual basis. All interviews will be conducted in private and audio-taped. All participants will be able to stop the recording at any time during the interview or request that certain comments be edited from the tape if they so wish. A copy of the interview will be available for you if you wish to clarify anything or add further comments.

No individual will be identified on tape. Each tape will be labelled with a code number, as will the corresponding transcripts. When the research is completed, all the tapes will be erased. In the meantime, all the tapes will be kept in a secure location where no-one, other than the researcher, will have access to them. In the final report, no participants will be named, but rather pseudo-names will be used, quotations will remain anonymous.

\section{THIS IS TO CERTIFY THAT}

I,

Hereby agree to participate as a volunteer in the above named project.

I hereby give permission to be interviewed and for these interviews to be recorded on audiotape. I understand that only the researcher will have access to the research material obtained, and that there will be no identifying evidence on disks, cassettes and transcripts. I also understand that the information may be published, but my name will not be associated with the research. I understand that I am free to decline to answer any questions. I also understand that $I$ am free to withdraw my consent and terminate my participation at any time. I have been given the opportunity to ask whatever questions I desire, and these questions have been answered to my satisfaction.

Participant

Researcher
Date

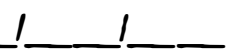

Date

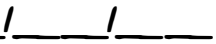




\section{APPENDIX C}

\section{Personal details}

\section{Edith Cowan University \\ Faculty of Communications, Health and Science \\ School of Nursing and Public Health}

$$
\text { Code - }
$$

Name

Address

Contact details:

Home:

Work:

Mobile:

Email:

These details will be kept in a locked filing cabinet, and only accessed by the researcher. Any other information given by you, will be kept separate. Interview material will be coded, thereby not having any of your personal details attached to the research material. 


\section{APPENDIX D}

Code -

Demographic details

Age:

Highest level of education:

Occupation:

Length of the relationship:

Cohabitation:

Name and ages of children, (including

relationship to participant and partner):

\section{Partner's name:}

Age at death:

Length of time since death:

Highest level of education:

Occupation:

Cause of death: 


\section{APPENDIX E}

\section{Questions which may have been used to guide the interview}

\section{Main question:}

(Participant's name) could you tell me about yourself and your partner (name of partner), the circumstances surrounding your partner's (name of partner) death, and your experiences following their death?

\section{Supplementary questions:}

1. How long were you and your partner (name of partner) living together?

2. What were the circumstances of your partner's (name of partner) death?

3. How did you feel immediately after the death of your partner (name of partner)?

4. How have those feelings changed since your partner's (name of partner) death?

5. Describe how you feel now?

6. When do you feel most affected by your partner's (name of partner) death?

7. When you feel upset about your partner's (name of partner) death, what do you do?

8. Have you had any counselling following your partner's (name of partner) death? If so from whom?

9. How has this counselling helped you?

10. Would you seek professional help again? (Why, why not?)

11. Have you attended any support groups, (was it helpful)?

12. Have you accessed any Websites that deal with bereavement (was it helpful)?

13. Who do you talk to about how you have felt? How has this helped you?

14. Have there been any people who have been a help or a hindrance to you since your partner's death? Can you tell me how they have helped or have been a hindrance?

15. People often report having dreams or visions in which they meet with or talk to their mates. Has anything like this ever happened to you?

16. How has your health been? Any accidents or injuries?

17. Some people turn to alcohol or drugs to help them cope with this experience. Has this been an issue for you?

18. If a friend of yours found him or herself in the same situation that you've experienced, what advice would you give?

19. Describe the most significant effect of your partner's death upon you? 
20. From my perspective as a health professional, is there anything that you can think of that would in anyway help you with what you're going through?

21. Is there anything else that you would like to say?

22. How has it been for you today - how have you felt discussing this? 


\title{
APPENDIX F
}

\section{Permission request for inclusion of a participant profile}

\author{
Martin Rodger \\ Nursing Researcher
}

\section{Dear}

I am writing to you to give you an update on my progress with the research project "Living beyond the unanticipated sudden death of a partner: a phenomenological study" research project that you participated in.

I am now in the sixth and final year of this $\mathrm{PhD}$ programme, which was upgraded from a Master of Nursing degree. As you will see from my new address, I have moved away from Perth, having left Edith Cowan University to purchase a very busy Seafood Takeaway in Kalbarri (The Jetty Seafood Shack). Yes, a real seachange. My wife and I decided at the end of 2002, that having each spent 27 years in the health industry, that we would have a break and earn a living feeding the masses. This decision was certainly made easier having interviewed you and others and being reminded of the shortness and preciousness of life.

I am now writing the thesis, which should provide an abundance of material about what life is like for people such as your self who have survived the sudden death of their partner. In the thesis I would like to include a brief profile of every participant, to allow the reader to have some insight into your particular circumstances. I have included a copy of your individual profile for your approval/editing. I have used pseudonyms to protect your anonymity, however I realise that due to the descriptions of your experience, you may feel that identification may be possible. If this is of concern to you then, you may choose to alter the profile or not to have a profile included. The profiles are a very brief overview of your situation. Your entire transcript will be merged together with the other participants throughout the thesis to create common themes. Individual quotes will be used throughout the thesis to reinforce the themes.

I need to remind you that the thesis will be available in the Edith Cowan University library for anyone to read. The thesis may also be made available for sale through the Internet.

Could you please fill in the attached permission slip and return it to me as soon as possible (A reply paid envelope is included). I would also like to know if you would be willing to review the six interpretive theme chapters that I am writing. Feedback from participants will help verify the results. I will only send these chapters to four participants for their feedback and this won't be for a few months yet.

As promised, I will send you a copy of the completed thesis, once it has been examined and edited. Thank you for taking the time to participate further in this study. I hope that you are travelling well in life. Please feel free to call me for a chat or email me anytime.

Yours sincerely 


\title{
“LIVING BEYOND THE UNANTICIPATED SUDDEN DEATH OF A PARTNER: A PHENOMENOLOGICAL STUDY"
}

\author{
A RESEARCH PROJECT FOR THE AWARD OF \\ DOCTOR OF PHILOSOPHY (NURSING) \\ BY MARTIN RODGER \\ EDITH COWAN UNIVERSITY
}

PARTICIPANT PROFILE PERMISSION

I have read the participant profile that you wish to include in your thesis "Living beyond the unanticipated sudden death of a partner: a phenomenological study".

I have decided to give you permission to use this participant profile (with no editing) in the thesis, understanding that it will not be used in any articles written for publication.

Name:

Signature: Date:

I / 2004

I have decided to give you permission to use this participant profile (with the editing that I have provided) in the thesis, understanding that it will not be used in any articles written for publication.

Name: Signature: Date: / / 2004

I have decided NOT to give you permission to use any participant profile.

Name: Signature: Date: / / 2004

I am interested in reading and commenting upon the interpretive theme chapters, realising that only four participants will be involved in this part of the study.

Name: Signature: Date: / / 2004 


\title{
Permission to include a case study
}

\author{
Martin Rodger \\ Personal contact detalls withheld for publication \\ $5^{\text {th }}$ May 2004 \\ Dear
}

In addition to using a participant profile in the "Living beyond the unanticipated sudden death of a partner: a phenomenological study" research project, I would also like your permission to include a case study featuring your story in the thesis. I have included a copy for you to read. The inclusion of a case study will allow the reader of the thesis to gain a more complete picture of a person's experience of life following the death of a partner.

Could you please sign the permission slip and return it along with the participant profile permission slip as soon as possible.

Thanks again for taking the time to participate in this project.

Yours truly,

\section{Martin Rodger}




\title{
"LIVING BEYOND THE UNANTICIPATED SUDDEN DEATH OF A PARTNER: A PHENOMENOLOGICAL STUDY"
}

\author{
A RESEARCH PROJECT FOR THE AWARD OF \\ DOCTOR OF PHILOSOPHY (NURSING) \\ BY MARTIN RODGER \\ EDITH COWAN UNIVERSITY
}

\section{CASE STUDY PERMISSION}

I have read the case study that you wish to include in your thesis "Living beyond the unanticipated sudden death of a partner: a phenomenological study".

I have decided to give you permission to use this case study (with no editing) in the thesis, understanding that it will not be used in any articles written for publication.

Name:

Signature:

Date: / / 2004

I have decided to give you permission to use this case study (with the editing that I have provided) in the thesis, understanding that it will not be used in any articles written for publication.

Name:

Signature: Date: / / 2004

I have decided NOT to give you permission to use any case study.

Name: Signature: Date: / / 2004 
Individual transcript analysis permission

Martin Rodger

Nursing Researcher

Personal contact details withheld for publication

$5^{\text {th }}$ May 2004

Dear XXXX

In addition to using a participant profile in the "Living beyond the unanticipated sudden death of a partner: a phenomenological study" research project, I would also like your permission to include an extensive analysis of your experiences in the thesis. I have included a copy for you to read.

I have used 15 participant transcripts in this thesis. All of the 15 transcripts were analysed together, using a software package that tracked over 250 key words. Four of the transcripts were analysed manually, such as yours. The inclusion of an example of a transcript that was individually analysed, in the completed thesis will allow the reader of the thesis to understand the depth of the phenomenological process that has been undertaken in order to validate the direction that the mass analytical process has taken.

Could you please sign the permission slip and return it along with the participant profile permission slip as soon as possible.

Thanks again for taking the time to participate in this project. 


\title{
“LIVING BEYOND THE UNANTICIPATED SUDDEN DEATH OF A PARTNER: A PHENOMENOLOGICAL STUDY"
}

\author{
A RESEARCH PROJECT FOR THE AWARD OF \\ DOCTOR OF PHILOSOPHY (NURSING) \\ BY MARTIN RODGER \\ EDITH COWAN UNIVERSITY
}

\section{INDIVIDUAL TRANSCRIPT ANALYSIS PERMISSION}

I have read the individual transcript analysis of my transcript that you wish to include in your thesis "Living beyond the unanticipated sudden death of a partner: a phenomenological study".

I have decided to give you permission to use this individual transcript analysis of my transcript (with no editing) in the thesis, understanding that it will not be used in any articles written for publication.

Name: Signature: Date: / / 2004

I have decided to give you permission to use this individual transcript analysis of my transcript (with the editing that I have provided) in the thesis, understanding that it will not be used in any articles written for publication.

Name: Signature: Date: / / 2004

I have decided NOT to give you permission to use any individual transcript analysis of my transcript.

Name: Signature: Date: / / 2004 


\section{APPENDIX G}

\section{Case study}

Brian was a 40-year-old Registered Nurse whose wife Jenny died when she was 30 years old, two years prior to Brian being interviewed. Brian and Jenny had been together for eleven years, and married for nine years. Brian and Jenny had two children when Jenny died James, who was three years old, and Ricky who was one year old. Four weeks prior to Jenny's death she had fallen over some uneven paving, whilst walking with her dog, fracturing a patella, which required surgical repair. When Jenny died she was 16 weeks pregnant with Sharon. The cause of Jenny's death was pulmonary embolism, most likely a complication of her fracture, surgical repair and possibly her pregnancy.

Brian described how he took a pragmatic approach to life after Jenny's death. His need to care for his children meant that he had to "get on with life". Brian described the need to return to work, which was an important part of his life prior to Jenny's death. Brian entered into a new relationship nine months following Jenny's death, which lasted several months.

Brian met Jenny in 1986 when they where both nursing at a major teaching hospital. Six months later they started dating. Jenny went back inter-state to be with her family, which disrupted the relationship for a year. Then a year later Brian went to a medical nursing conference in the city of Jenny's home state, when Brian made contact with Jenny on a Saturday, and they were engaged on the following Tuesday.

Jenny was planning to go on a six-month overseas trip through South East Asia, Turkey, India, Egypt, and Africa, which she had decided to cancel in order to be with Brian, but he insisted she still go on her trip. This turned about to be a pivotal experience of her life, especially Africa.

Upon Jenny's return she moved back to Brian's home state, and they were married, in 1989. In 1991 they left Perth, went on a trip around Australia, working slowly over to their home state. Then Brian took a job working as a nurse educator in the far north of the state. They both worked in an Aboriginal community there for 
a while. Brian described this period of time as a really good time of their marriage. They both wanted to have a baby. James was born in 1993. They then decided to move back the capital city to be near Jenny's parents who were both unwell. Then Ricky, was born in 96, and there's a bit of a story there. Brain described Ricky's birth:

"The week before he was due we went out camping, we hadn't been out camping for a while and Jenny really enjoyed camping. So we went down to the border of to a small caravan park there and just for the weekend and sort of woke up on the Sunday morning, we'd had a great night's sleep, both of us, and just as we were about to cook breakfast, and Jenny said, oh, l've got a bit of a tummy rumble. Oh, that's interesting it must have been the steak I cooked last night, or something before. Oh, no, no. And forty-five minutes later Ricky was born! At the back of an ambulance in the middle of nowhere."

Brian described this period of their lives as going really well, with him working full time He was working at the major inner city teaching hospital with Jenny looking after their children, and she was planning to start work part time now that Ricky was about to day care. Then in Brian's words: “...all that went wrong."

In July 1997, the family went on holiday to visit some friends. One afternoon Jenny took the dog out for a walk, two hours later she came back in the back of a ute. She'd been walking down the footpath, and the dog wasn't on the lead but she was following; she was twelve weeks pregnant and tripped over some uneven bricks on the footpath, landing on her knees fracturing a patella. She'd been lying on the footpath between half an hour, and forty-five minutes before someone came along and put her into the back of the ute and brought her home.

Having seen the local doctor in the hospital; the fractured patella was treated temporally with a Plaster of Paris "back-slab". Jenny was then flown to the capital city for a successful operation to wire the patella together. Jenny spent a week in hospital. Three to four weeks following her injury, Jenny had been recovering well. Brian was on leave looking after the kids and looking after Jenny. Jenny had been gaining independence, and was able to walk. On the morning of her death, Jenny had had a lovely morning in bed, talking and playing Ricky. James had gone to preschool and, it was the first day she'd been planning to go out to see a movie with her friends. Jenny got out of bed to have a shower, and Brian went down stairs to give Ricky his morning feed. Shortly after Jenny yelled out to Brian who ran upstairs; to find her lying on the floor in the shower. Brian thought that Jenny had fallen and reinjured herself. 
I called the ambulance. They came out pretty quickly, within seven minutes, but she was dead before they got there; she'd stopped breathing before they got there. That was it. I just knew straightaway it was either a heart attack or a PE. I didn't try anything 'cos I knew it wouldn't work. It wasn't going to work, I just let her go.

The ambos tried and that but it was a double story house they had to get her down and, of course, it was a twenty minute trip to hospital. And I said don't take her to the hospital I worked at. So they took her to the XXX hospital (the other major teaching hospital - author's insertion) where l'd worked the year previously, but, I knew, I just knew there was no way she was going to survive; it was terrible. I had to 'phone up one of her sisters and had to get Ricky and get him ready, I was about half an hour behind the ambulance. And I got in there, and you know, all the guys, of course, I knew all the nursing staff. That was terrible.

Brian spent the next two hours at the hospital, an experience he described as terrible. Jenny's death occurred about ten thirty in the morning. During that time a priest came, because Jenny was very religious. A social worker was also in attendance, along with the usual support from the nursing staff. Brian had also worked with the doctor who pronounced Jenny dead.

After about two or three hours they went back to Brian's place, then James had to be retrieved from daycare with the news of his mother's death being broken to him at home about half past four, five o'clock. Aagh, poor little kid; ..., he understood that mum wasn't coming back and he was very much mum's boy at that stage, and Ricky was dad's boy, very much dad's boy." Brian described the role of the Social Worker as being helpful with his youngest child, Ricky, and helping him relaying the news to the relatives.

Throughout the interview, Brian, often described how pragmatism guided his thoughts, and actions. The funeral had to organized, the children needed looking after, the household chores needed attending, and his work life had to be sorted out. Brian described the mixed feelings of having relatives stay to support him very aptly:

(The relatives)... are all well meaning and they're all talking about ... about Jenny which was really good, but at nine o'clock I was exhausted, I just wanted to go to bed, I can just remember it. And for the next few nights while they were all still there, helping us plan the funeral and talking about this and, of course, being a support but all I wanted to do was shut down and go to bed. The kids were in bed and, the kids were shot to pieces with their cousins coming up and that, and the kids were misbehaving. And the night, and so I remember, they stayed up till one, two three o'clock and all I wanted to do was go to bed. Yeah. But great support. Very very Catholic, very close family. A lot of support. Shows how you remember. All I 
remember is, the sisters that come down and wash up, Jenny's sisters would come and wash up, and they'd put all the things away but I can always remember saying its not where we put them, its not where Jenny puts them, or where I put, so you have to go the next day and put them back, you know, or you couldn't find something.

Jenny died on a Saturday, Brian's sister's birthday, Jenny was buried on his mum's birthday. Brian's mum wanted to come over for the funeral but she has emphysema so it took a week for her to get there. When asked how he dealt with the fact that his daughter had died along with Jenny, Brian stated that he felt that there was only one death...

...And so to me, it hadn't come out and so it wasn't a separate baby; it died with Jenny, inside Jenny, so it seemed right to stay there with Jenny and we acknowledged that she was pregnant. On Jenny's gravestone, we had a brass plate, ...., it's like a, a lawn cemetery, and I just had Jenny N..... and our unborn baby, Shari; that's what Jenny wanted to call it.

Brian's children were involved in the funeral. Brian bought little heart-shaped cardboard boxes and so they could each collected things in there that would remind them of Jenny and the kids would draw drawings, they'd collect some flowers and, James remembered always walking along the beaches and picking up shells for Jenny as a three year old. So we went along there with Mardhie (Brian's sister) and her kids and some friends from down the road and they picked up shells, and flowers. James remembered giving some yellow flowers to Jenny, and then he went up to get Aloe Vera because Jenny was growing an Aloe Vera plant and he wanted to put them in the box and on the coffin stating that: "...that's some Aloe Vera in case she gets sores in heaven she can put it on her sores"

Brian decided not to have the children see Jenny's body, saying that he preferred them to remember Jenny the way she was. The children were very much involved in the funeral, just before the casket went into the grave all the kids put their flowers or whatever ... James threw his flowers on after the coffin was covered in dirt that he helped to throw in.

Brian described his feelings in the immediately after Jenny's death and following the funeral:

Amazing feeling, you know, I completely lost it when Jenny had died and the nursing staff came in from the hospital. And I was grief struck for the first week. And crying, sort of, little things would make me cry, like James wouldn't put his shoes on, you know, he'd put his shoes on but he'd move his feet so I couldn't do it up. And I got these 
tears rolling down my eyes and I said, come on let me do your shoes; why are you crying daddy and I said, oh, I'm missing mummy very much. And he said, yes, I'm missing mummy too.

But after the funeral, after that one week, all of a sudden I felt, you know, like all the grieving was done, you've got to go on with life. Even the next day, about six o'clock, the kids are up, they want breakfast, they want, no-one else is going to do it. I mean, you've got relatives staying there and that, but, you know, you've got to do it. And its like people saying, Brian, how on earth do you do it. Every day the kids'll want to eat breakfast, there's that daily routine you've got to keep with the kids and it keeps you going, you know its ... But after that, that week of intense week of, up until Jenny's funeral, then after that, like an amazing weight just sort of lifted off and I could actually feel, sort of, Jenny around for about a fortnight afterwards, you just feel her around little things that would go right in the house, things that could go wrong go right. And then after that, sort of, that feeling, sort of, went away, of Jenny being around.

Despite taking a very pragmatic approach to life after Jenny, Brian admits to thinking of her everyday. About a month later Princess Diana died, Brian remembers attending to domestic chores whilst on leave from work and watching Princess Diana's funeral:

...and I sat down and watched it and I just, these tears rolling down my eyes, for no reason at all. I can just remember thinking, poor Di, poor $\mathrm{Di}$, and I thought, poor me. That's what I was thinking. Yeah, that was about a month after, yeah. I can still remember the thoughts that were going through my mind, yes, two years ago, and as I said, on day one, the kids have got to be looked after, the kids have got to go off to daycare; you've got hundreds of, you've got to wash, you've got to wipe, you've got to do all the things that your wife would do around the house ... as well.

Brian described the comfort zone that he occupied prior to Jenny's death, very well, not able to contemplate the tragic loss of your partner:

Oh, I, I couldn't even to begin, ... when you're married there's vague ideas just go through your mind, you know, like, what would happen if? But its not something, you think your young, your healthy, you've got your life ahead, you've got your kids, your paying off your house, you're almost done, you've got a good job, you're relaxed; great house, great surroundings, and I couldn't get a house like that in the nice bush surroundings, you know like, me with my job that I could cycle to and all that; over here.

The reality of Brian's situation was reinforced when he decided to apply for the Single Parent Pension. Brian described his first experience with the Department of Social Security Social Worker: 
Anyway, he's filling up the questions and there'd be like, ok Mr yes, Brian, yes, address, and now we've got to find out for the single parent pension, are you married, no, well, not any more; de facto, no, divorced, no, oh, widow, "ah, you're a widow?" and I said no I'm not a widow, I'm a widower, widow's female and widower's male, and he said other! And I said, well, ok, .... if it'll work, so you can get your stats right and all this, so they didn't have that so I was... ok. And there was a couple of other questions and the female alternative, the correct female term as in widow but no widower and he couldn't work out what the equivalent of what that question was. And I found out that in four or five boxes I was in other. And I thought this is interesting the form's not very well designed for Commonwealth statistics, you know. And you know, the poor old bereaved dads disappear in the system under other...(Brain's emphasis)...

Another interesting encounter with the DSS reinforced the unusual situation that Brian had found himself in. Upon approaching a clerk at the DSS to handover his loan details, the clerk already addressed him by his surname when he told her why he was there. This response obviously surprised Brian, who discovered that he was the only male receiving a single parent pension in the entire region that that particular DSS served. The last male that the clerk could remember was eighteen months prior to Brian's application.

Brian did not return to work for six months following Jenny's death. Then he started working on a casual part time basis, when Ricky started part time day care. It was during this period that Brian decided to move back to his state of origin, to have more support from his relatives. The main reason Brian made his decision to move was that his sister, Mardhie, agreed to move in with him and help with child care.

Two years following Jenny's death Brian is working four twelve our shifts per week in the busiest emergency department in his home state. Brian's sister Mardhie, is living with him and helps with child care. Being alone, Brian felt the constant strain of not having a partner to share with the family responsibilities:

...its very different, in that when you're married you've always got back-up, your wife's got back-up and you've got back-up if you have to duck out and do things, whatever. All of a sudden you can't go to your job, you've got the kids to look after, and of course, they're the priority. Erm, and if you do get a job, it's a daylight job, shared work's gone so the income drops down and all of that sort of thing, and the security's not there and all of a sudden you realise that, with marriage, it does take two to bring up the kids, presumably, you know, one to work and one to look after the kids, wherever that is, or you job share or whatever. And all of a sudden, there's not that reserve there, if something happens to one parent, there's no other to look after the kids, not there, all of a sudden, not there, and that's a 
big worry, you know, sort of, what do you do if something happens to me, I break a leg, or whatever, break two arms, you know, have a car accident.

The depth of the dilemma posed by the suddenness of solo parenting is well described by Brian:

You even think, you know, the options are, look after your kids and don't go back to work and you think thank God for Commonwealth Day Care, you've got day care, and a job, whatever, and even, sort of, suicide, because I wasn't ... it goes through your mind, is it simpler. It only lasted one second in my head, its not, you know, the commitment of marriage is that you look after your kids and all that sort of thing. .... the thought of suicide goes through your mind, taking the easy way out, but of course, the commitment of marriage is that you bring up your kids and all that sort of stuff, take care of your kids and they're the priority.

Despite Mardhie's help, Brian is restricted socially, due to Mardhie's work commitments. So boozy nights out with mates don't happen anymore, with Brian limiting interactions with friends who have children, so that home entertainment with the kids can occur.

Brian is now involved with another woman: "I've got a girlfriend, and she's got two kids and her kids adore my kids and visa versa, and they get on with me very well and the boys just love Ann, so that's, that's another thing as well. Oh, probably we'll eventually marry but that's away down the track." Brian already new Ann when they were both undergraduate nursing students. When Brian returned to his home state he contacted her. This relationship started about nine months following Jenny's death.

We just hit it off. Just amazing, just amazingly quick. And whether it was sort of distance makes the heart grow fonder or anything; whilst clearly I was over in Brisbane and she was over here. I 'phoned her up a couple of times and really clicked, and I actually flew her over to Brisbane; after about three weeks, it was getting a bit ridiculous, so we had to have a face to face meeting. And she'd just divorced her husband, and you know, flew over to Brisbane for a weekend. And we got on well. The kids liked her and actually, coincidentally, it was Ricky's birthday. My friends in Brisbane also met her. Jenny's family was quite a bit for it, you know, very much the attitude of life goes on and if you meet someone else that's great. That's good.

When asked if he felt any ambiguity over this relationship starting relatively closely following Jenny's death Brian replied: 
Yeah, I just remember being, sort of after Jenny had died, you're lying in bed or you're sitting in a chair thinking, what am I going to do, and the intense feelings of marital loyalty are still there. Like, ... I'll be loyal to Jenny and her memory and all this sort of stuff. And you still can be, but still marry someone else. Life goes, as I said before, it takes two to bring up your kids. I'm really lucky I've got a sister to help me, but it does take two to bring up kids and it also, your kids have got to have other kids to play with... Ann has two daughters as well and they're the same age as my kids, virtually, within a couple of years. I think you can still stay loyal to your wife and your wife's memory, but life goes on. That's life.

Brian thought of seeking counselling in the immediate period following Jenny's death, but decided that it was not appropriate for him. Brian found solace in being able to express his feelings through conversations with Jenny's sister and brother-in-law, who he described as being a great support.

The only difficulty Brian had was reconciling Jenny's relatives' orthodox catholic that involved the concept of heaven, and that Jenny was now in a better place:

Yeah, she's gone to a better place and I said, oh, really, (chuckle) And I said quite outright that doesn't console me at all. This was during the week, just after the funeral. I'm Catholic, and I can understand, but l've been indoctrinated since grade one, and all that sort of thing. Yeah, I do have a religious belief but not that to the strengths of the Catholic faith.

Regardless of Brian's pragmatic approach to life and death issues, the experience of Jenny's death allowed him to develop empathy for others who grieve differently to him:

"And you do, you celebrate someone's life and all that sort of thing. And its very sad that they go but, you know, life goes on, and you know, you've got to, that's the way, and I can understand how, when you read someone's like a mother maybe grief stricken or their spouse has gone and they suicide afterwards or they go to alcohol or they go to drugs or whatever, I can understand that, and I can understand their feelings."

Alcohol and drug use did not increase after Jenny died, with Brian being a light drinker normally.

Brian described one of the biggest losses he experienced was not being part of a working environment, and the drudgery and social isolation of life at home:

After Jenny had died, after about three months everything was settled down, the kids were back into a routine, primary school care or day 
care or whatever. I was just going crazy. I was going home and you've got your ironing to do you've got the cleaning to do and you've still got to do the boy things, like mow the lawn and whatever, and I was going spare. And I could actually understand the housewife syndrome, where these people, you know, like housewives, women, people, lone people at home, male or female, get depressed, and they're on anti-depressants, I could easily understand it. And boring! There's only so many times you can wash the dishes, once a day or at night after everything's done. There's only so many times you can vacuum the carpet once a week, thank you very much, I'll go crazy, don't want to wear it out. Clean the tiles and all that sort of stuff, what's the point, I fucking kick the ... Now look at this, this place, now look around here, this place was spotless last night. The kids come in and it's a fucking cyclone. And so the kids clean it up after work and all that sort of stuff. But you know, its pointless bloody vacuuming the carpet more than once a week because the place is a bloody mess again. Tiles are great, there's too much carpet in this world. I can't wait to convert this house, to tiles, when this carpet wears out. I want to get tiles! But I was going spare after three months. I was going spare. It lasted to six months and then I was just getting toey to go back to work

\section{Brian described his need to be part of the work force succinctly.}

Well, it was not only that, but it was actually being socially useful again. Fulfilling my expected role and formalising this. I'd worked for, since I was aged seventeen and a half, all my adult life. Army, six years in the army; took nine months off, army reserves sort of stuff. Then university training, and then full (time work)-and I hadn't had a major break in that time, except for holiday. And it was crazy. I was just going batty. I loved going back to work. Nothing's too much to do. And I was surprised l'd found l'd lost none of my skills, too.

Brian re-entered the work force within six to seven months after Jenny's death. Brian described how he needed the mental stimulation of a working environment, and reiterated how he found being confined to home so depressing.

And I was really surprised that I just slipped back in. Whether it was the anticipation and the psychological build up to going back to work ... but I was just so social, so socially useful, I was contributing again. Not just staying at home, being locked at home. And I can understand, so easily now, how people who are housewives, say they're on anti-depressants. Its fucking depressing, ...

One of the issues that Brian had difficulty dealing with was being a male in the domestic culture that is predominantly occupied by females. He described it as being quite proprietal: "if you visit a female, you know, even though its ridiculous to think, she doesn't think anything, her husband doesn't think anything, but the gossips start, oh, its interesting." 
Brian described how it was his ability to talk with people in a mater of fact way following Jenny's death, which helped adjust to his new life. In the following passage he described what it is like telling people of his situation for the first time at work:

And then the rest, the consultants that were there, used to be junior registrars or senior residents there and so, Ah, hello, Brian, and saying what's happening and of course their faces would just fall when they found out the reason I'm back, and all that sort of stuff, but the word spread around the staff anyway. And that's all ... But then you'd get the younger staff that didn't know me. And, of course, my personality being what it is l'd tell a few rude jokes, then one of them would say, well, how does your wife put up with you, 'cause they knew I had kids, and you'd see a couple of the other girls faces fall because, they'd think ... what a thing to say! But she didn't know ... and l'd say l'll tell you later. And the poor woman, you know, after you'd had your meal, I didn't want to say anything, but my wife died two years ago. And then their face would, they'd almost go into ... "Oh, Brian, I'm sorry!" and I'd say its ok, its ok, you know. Yeah, so

Brian continued to wear his wedding ring following Jenny's death and described why he decided to remove it:

Yeah, yeah, I wore it afterwards. I didn't think l'd ever take it off. I wore a wedding ring and in fact, I had an engagement ring, as well, that I wore on my other hand. It was a small ring, better diamond ... and I wore my wedding ring, always, never, hadn't taken it off unless I swam ... unless I lose it. In fact, I wore it all the time until I came back to Perth and then when Ann and I were getting together, erm, I just said to her, look, you know, how do you feel with me wearing my wedding ring? Because we'd been talking about Jenny and all this sort of thing. And she said, oh look, you know ... does it make you feel like you're going out with a married man? And I she said, yes, sort of. And she said sometimes I feel a bit uncomfortable and so; and she said I'm not asking you to take it off or anything like that, you know, whatever. I thought about it for a week and then I took it off as a sort of a - and she noticed after that and mentioned it.

The wedding ring is now kept in his bedroom. Dealing with the possessions of the dead partner often poses problems. When asked how he dealt with Jenny's possessions, he responded:

They just stayed in our bedroom, I didn't move them around ... but that's the stuff that Jenny's sister, Mardhie and another sister, Ingrid, came over one day and - about two months, I think, after Jenny died, and said we'll pack things up and stuff that I didn't want to keep go to St Vincent's or somewhere like that and I planned - Jenny had a camphor chest and I thought l'd put things into that and of course, 
three boxes later. And, ah, there was a jumper that was sort of special, 'cos she wore that on this occasion.

Other:items of significance have been stored, so that the children can have access to them. Brain described Jenny as still being an important part of his and his children's lives:

No matter, I still think of Jenny, you know, when I say I don't think of Jenny every day, now, every second day, there's things come back, or the kids, they'll say something, like, my youngest one, Ricky, he'll say now, mummy is in heaven and he's learnt that from James or from other kids that he's playing with 'cos he hasn't got a mummy, he's got an Auntie Mardhie, and mummy's in heaven and our sister as well, cos James has picked up on Shari, our daughter ... 'cos they used to ask, you know, mummy's in heaven, mummy's in heaven,. And I certainly don't say that, don't say that, that's something they can work through themselves, and we can work through and I'm not going to repress that (I don't want to impress that on them?) Yeah, we've made sure we've been very open, Mardhie and I, Jenny's sister and I in Brisbane, or myself mainly and Mardhie, over here. The kids can talk about that, James can talk about that freely if he wants to. I'm certainly not going to say, oh, don't say that. Yeah.

During the course of the conversation, Brian often referred to the qualities of his relationship with Jenny and how it was built on, respect, trust and cooperation. Brian described how he and the children had enjoyed the last few weeks of Jenny's life:

...we never had a decent fight in our marriage, we had one or two arguments and that was always over, you know, money, how much to borrow on the house, that was my idea, but we'd never had a decent - marriage had never been closer than the three or four weeks I was looking after Jenny, and all that sort of thing, so. You know, when Jenny died, we were happy. We hadn't been divorced, we hadn't even been thinking of it or anything like that. And, heaven forbid that we'd have a fight and one of us had've been hurt in a car accident, or something like that, it would've been terrible. At least, we had a strong, happy time in the last four or five weeks. On the holidays and that. Yeah. And I remember the kids had had a nice time, you know, they'd climbed into bed and had a cuddle or a talk and jump up and down on the bed, and all that sort of thing, you know, it changed that afternoon.

Advice Brian would give to other people is very much part of his pragmatic approach to life. Brian emphasized the importance of life insurance, having current wills and arranging your financial situation so that the children would be financially secure if the remaining parent died, whilst the children were still dependent. Upon reflecting what it is like talking about his experiences, Brian had this to say: 
Yeah, well you always feel good talking about things. Something else comes up that you hadn't thought of before, and pleasant memories as well, always good to remember pleasant memories.

I have spoken to Brian a few times since the interview. His relationship with Ann lasted a few months. Brian is not in a relationship currently, but is working in a new job and living in a new situation, which is giving him and his children great satisfaction. 


\section{APPENDIX H}

Idiographic Natural Meaning Statements and Central Themes

\section{Profile}

Surviving partner - David 52 (Engineer, university researcher)

Deceased partner- Lorna was a 45 year old woman who experienced an intra cerebral haemorrhage followed by a tonic/clonic seizure, she vomited and inhaled her vomitus which resulted in hypoxic brain damage leading to brain death.

Length of Relationship - 23 years

Time since death -2.5 years

Children:

Jimmy 10 years

Kelly 8 years

\section{Relationship to self}

Natural Meaning Statements

Central Themes

\begin{tabular}{|c|c|}
\hline Reaction to the death & \\
\hline $\begin{array}{l}\text { So, yeah I mean, God that was a shock } \\
\text { of, total, I mean you're numb I know } \\
\text { what people mean by... they just feel } \\
\text { numb }\end{array}$ & $\begin{array}{l}\text { The shock following his partner's death } \\
\text { manifested itself in a feeling of } \\
\text { "numbness" and unreality. }\end{array}$ \\
\hline $\begin{array}{l}\text { You know, um unfortunately they then } \\
\text { had to keep her on ventilators etc to } \\
\text { make sure the drugs had worn off. They } \\
\text { waited eighteen hours, and then they } \\
\text { switched everything off. Twelve hours } \\
\text { later her heart stopped. Yeah it was, } \\
\text { quite a shock }\end{array}$ & $\begin{array}{l}\text { Following the diagnosis of an intra } \\
\text { cerebral bleed, Lorna had a long } \\
\text { tonic/clonic seizure, whilst she was } \\
\text { having the fit she vomited and aspirated } \\
\text { the contents of her stomach, resulting in } \\
\text { a prolonged hypoxic state leading to } \\
\text { brain death. }\end{array}$ \\
\hline $\begin{array}{l}\text { I was trying to get a handle on it and so } \\
\text { they just seemed to be so, I wouldn't say } \\
\text { cold about it, but you know it was just, } \\
\text { hmm I don't know I was in just floods of } \\
\text { tears, and they're just totally'indifferent } \\
\text { and, and I suppose that's, one of things } \\
\text { that you come to realize. When you have } \\
\text { these experiences, your responses are, } \\
\text { often totally different to what you } \\
\text { anticipated, you know... }\end{array}$ & $\begin{array}{l}\text { The surviving partner perceived the } \\
\text { medical and nursing staff to be aloof } \\
\text { and indifferent. } \\
\text { Note: Therefore medical and nursing } \\
\text { staff whom adopt a detached clinical } \\
\text { attitude at the expense of an empathetic } \\
\text { but still professional approach, could be } \\
\text { perceived as being uncaring and aloof. }\end{array}$ \\
\hline \multicolumn{2}{|l|}{ Coping strategies } \\
\hline $\begin{array}{l}\text { A friend of mine is a Doctor and, I said } \\
\text { (have) you got any sleeping pills cause } \\
\text { obviously I'm finding it difficult sleeping, } \\
\text { so she gave me a bottle of fifty sleeping } \\
\text { tablets, but there were only five left, no, } \\
\text { there were ten in there, no wouldn't have } \\
\text { been ten I think it was about eight, }\end{array}$ & $\begin{array}{l}\text { Initially the surviving partner required } \\
\text { some help with sleeping, with his Doctor } \\
\text { treating him with caution, by not giving } \\
\text { him enough tablets to harm himself. }\end{array}$ \\
\hline
\end{tabular}


sleeping tablets, two and a half years later there's still five in there. But she just thought that, I might top myself if I had a whole bottle.

Yeah so my sleeping patterns were disrupted, um, I didn't realise it at the time but I was cracking teeth and I had to go to the Dentist. Lorna died in the August, and I was still going to the Dentist in the February . I busted about three or four teeth. Apparently I was grinding my teeth at night, so there was this subconscious stress obviously. Physically I just ticked on, obviously there was a lot of, subconscious stuff oinn on

But at the moment I do have free time, in fact it's one of the things that I question as to whether or not I'm utilising my free time, in the way that I should. For example I tend to sit at home and do things during the day, rather than actually get out and do things, but occasionally Rae will look after them, the grandparents never look after them

But mainly I draw upon other kids and other parents at the school and friends of the children. So sleepovers are pretty common things these days. So the difficulty is that there's really only one family that have a boy and a girl that are similar in age and her husband works away from home, not a fair bit, but a reasonable amount, so I have her kids and she has mine so that's quite good in the sense that that gives me a break, but that's only happened in the last year. I mean even though they had sleepovers I was of the old school where I wouldn't even go to a movie by myself, it was just a really weird concept to go to a, I mean I still haven't been to dinner by myself, I just can't do it

You know there are different subtle fears, fears that run through your mind as to how it will impact on the kids, and whether or not they will start to teeter off into a certain frame of mind and, and how you can get them to come back to being normal, so to speak. On the fridge there's someone, a psychologist's name, a child psychologist's name sitting on the fridge which l've never used but it's there. It's almost like I feel that while it's there I don't need it (laughs)
The surviving partner was grinding his teeth during his sleep.

Interpretation: It could be argued that the surviving partner's "matter of fact" way of "getting on with life" was masking the distress he was experiencing, which manifested itself by the grinding and cracking of several teeth during sleep.

The surviving partner admits to doing chores at home while the children are at school, rather than doing things for himself and doing the chores when the kids are at home.

The surviving partner gets some free time at night when the kids sleep over at friends' places. Despite having the freedom to go out at night, he hásn't been able to bring himiself to dine alone.
Despite not seeing the need to seek professional counselling, the surviving partner recognised that there may be a need in the future and that by having a psychologist's details on hand gave him reassurance that help was available. 
Well to be honest, I got one pamphlet from the Funeral Directors on grief, and I read it, and, it seemed to be really just all common sense. No-one sort of tapped me on the shoulder and said, things are coming unstuck, so I felt I was probably, anticipating problems that might occur, and assessing them reasonably well and that, I wasn't really having problems. I suppose I became focused on the kids and so work wasn't a priority to me anymore, and so that didn't occupy my time and so I could actually sit at home and think about what the kids were doing and how it was impacting on them, and what I might need to do or what I had to do and how I would answer their questions etc.

l've never really, had any little problems developed into large problems and obvious some problems have dropped away. I've found I haven't entertained the thought of needing counseling. I suppose counselling in the early stages, not resolve problems but to perhaps outline the playing field you're about to go into...that would have been helpful. Rather than actually trying to resolve my issues, but to make you aware of, things like personal relationships, how they might develop or how friends might change, or, how your gonna deal with work and, being, in a domestic environment, maintenance, finance what might happen over the next few years. What Centrelink can do, all those sorts of things would have been quite helpful. Yeah but, you had to sort of go and search for them and find it for yourself
Having something concrete to such as a pamphlet about grieving, was found to be useful, because it ratified the surviving partner's "common sense" approach to his new situation.

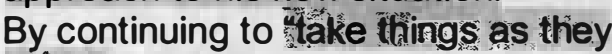
come" as the surviving partner cared for the children, he "woikked? his way through his own grieff and the kids as issues arose.

The surviving partner took a fairly matter of fact approach to his psychological well being, dealing with issues and problems as they arose.

If he had a wish for some sort of professional support it would have been some sort of guide to help deal with agencies such as Centrelink. 


\section{Relationship to others}

\begin{tabular}{|c|c|}
\hline Surviving the funeral & \\
\hline $\begin{array}{l}\text { The funeral was actually in the parkland } \\
\text { down here, right next to the lake. It } \\
\text { wasn't a funeral in a traditional sense it } \\
\text { was more of a funeral in, people being } \\
\text { able to say goodbye. Tt wasn't a formal } \\
\text { process of the parents sitting there and } \\
\text { lots of prayers, just having bit more of a } \\
\text { formal wake, and so the kids from school } \\
\text { were all running around doing their thing } \\
\text { in the trees and running up and down } \\
\text { the hill. I said to the kids that the funeral } \\
\text { wasn't really (for them), they've already } \\
\text { said goodbye to Lorna, that the funeral } \\
\text { was really for people that knew Lorna to } \\
\text { have their opportunity, to say goodbye so } \\
\text { the kids never really saw it as a funeral } \\
\text { as such they saw it as a opportunity for } \\
\text { other pnople to say goodbye }\end{array}$ & $\begin{array}{l}\text { The surviving partner took an informal } \\
\text { approach to the funeral of his deceased } \\
\text { partner, having it in the local park, which } \\
\text { allowed the children to play and } \\
\text { therefore reducing a lot of the stress } \\
\text { normally associated with formal funerals. }\end{array}$ \\
\hline \multicolumn{2}{|l|}{ Relationship with deceased partner } \\
\hline $\begin{array}{l}\text { Oh obviously it brings back feelings, you } \\
\text { know, in ways as you've seen, tears etc, } \\
\text { but, it's much easier as time goes on. } \\
\text { The thing that has hit me more today } \\
\text { than anything, is the fact that even } \\
\text { though I'm now in another relationship } \\
\text { where I feel quite strong about that } \\
\text { relationship, that I can still have tears. I } \\
\text { thought it would go away, it obviously } \\
\text { doesn't. }\end{array}$ & $\begin{array}{l}\text { Talking about the death of his partner } \\
\text { evoked strong emotions during the } \\
\text { interview eg: choking, stuttering, } \\
\text { difficulties in finding the correct words to } \\
\text { convey meaning, and tears. }\end{array}$ \\
\hline $\begin{array}{l}\text { Obviously it never will I suppose, it's } \\
\text { strange cause I always thought that time } \\
\text { would heal, and actually close in the } \\
\text { entire void and there wouldn't be that } \\
\text { feeling there. I can see how women, you } \\
\text { know fifty years after the death of their } \\
\text { babies, still have some sort of emotional } \\
\text { attachment to that child even though } \\
\text { they may have known them for only a } \\
\text { short period, that they, get an emotional } \\
\text { attachment that doesn't disappear, and } \\
\text { yet, I certainly don't have the same } \\
\text { feeling towards old girlfriends but it is for } \\
\text { Lorna, you know and I suppose it's, } \\
\text { obviously twenty two years of your life } \\
\text { just suddenly, nipped off. I suppose the } \\
\text { whole area of motorcar accidents and all } \\
\text { those sorts of deaths must be quite } \\
\text { traumatic. That healing process means } \\
\text { that it never really fully heal. }\end{array}$ & $\begin{array}{l}\text { The surviving partner described the } \\
\text { emptiness that he experiences following } \\
\text { the death of his long time partner as a } \\
\text { void, which is slowly refilling, but will } \\
\text { probably remain for ever. }\end{array}$ \\
\hline $\begin{array}{l}\text { Relationship to the health and caring } \\
\text { professions }\end{array}$ & \\
\hline
\end{tabular}


They rang me half an hour later and said that she'd had a large fit, and that she had dilated pupils, and of course that meant nothing to me, so I though oh well okay and I trundled on down there and they basically said she was brain dead By the time I got there (clears throat) she had been moved up to ICU. I met the Neurosurgeon, who was looking after her we had a chat before I went and saw her. It started to, sink in then, I mean I think he was even shocked, to a certain extend with what had happened I didn't think the Social Worker handled it very well. I asked whether or not, the children should see her. Whilst she's on the ventilator or should I just tell them she died and her response was well it really depends on the children and then went through this whole, gobble de gook of whatever and all I wanted at that point in time was a yes or no answer. If she'd actually said look let me go and have a yak with the kids and, I will make an assessment as to whether or not they're introverted or extroverted and I'll make a quick judgment on it and let you know, I mean for me to sit down and make some, sort of long term assessment on the children

I think even a brochure, to just highlight the areas you're going. Just set out the playing field, the future playing field. I mean obviously it depends on how pragmatic the person is that you're talking to, (clears throat) as to how you can set that out, (clears throat) I mean some people just won't accept the fact that they'll never overcome the emotional loss. No I was after answers but she was just too wish washy The Social Worker said you know if you ever need anything please contact me. Well, you've got so many things going on in your mind it's not a matter of you contacting them, it's a matter of them contacting you. You don't have time to be trying to think of near present and especially not future questions, you've just got so many other immediate concerns ...

So during that whole process you're wondering why this suddenly happened to Lorna and why it's even just

happened, why there would suddenly be
This news was totally unexpected, and delivered in a manner which the surviving partner had difficulty grasping.

Despite the survivirig partner being I a state of confusion he was able to detect that the neurosurgeon treating his wife was upset by the rapid decline of his wife.

The social worker involved in this case did not provide the surviving partner with the support that he wanted.

The surviving partner wanted straightfonward common sense style advice from the health professionals, to guide him in his immediate situation, unfortunately this was not forthcoming.

Information given by the social worker was not directive enough for the surviving partner. He wanted a step-bystep guide as to what most people in this situation experience.

The surviving partner believes that the social worker should have made contact with him, rather than expecting him to contact her.

He feels that the surviving partner has so much to think about, that they are swamped by life and are not capable of reaching out them-selves.

Initially the surviving partner found the information he received from the medical staff useful. The sumiving partiner responded to concrete information such 


\begin{tabular}{|c|c|}
\hline $\begin{array}{l}\text { a burst vessel in the brain and, they } \\
\text { were good in regards to just giving me } \\
\text { the stat's, which, I found quite useful, I } \\
\text { mean, having an engineering } \\
\text { background I like the statistics on the } \\
\text { probability on certain things so, I was } \\
\text { aware there was a high chance of her } \\
\text { either dying or being OK }\end{array}$ & as the probability of survival. \\
\hline $\begin{array}{l}\text { But they went to do a CAT scan and she } \\
\text { was too... I think the CAT scan is were } \\
\text { you can't have movement ....and they } \\
\text { wouldn't give her an injection to sedate } \\
\text { her to then do it ,so l'm quite sure there } \\
\text { were lots of complications within the } \\
\text { whole process...and I still never really } \\
\text { got a satisfactory answer from the } \\
\text { hospital, I'm under the impression, that } \\
\text { though she had a fit, she actually } \\
\text { vomited, and in vomiting she swallowed, } \\
\text { inhaled her vomit. Inhaled and she } \\
\text { actually drowned, and then got oxygen } \\
\text { depletion, and because they couldn't get } \\
\text { the tube down her throat when the ICU } \\
\text { people were called down to resuscitate } \\
\text { her }\end{array}$ & $\begin{array}{l}\text { The official cause of death was intra } \\
\text { cerebral haemorrhage, the surviving } \\
\text { partner felt that the main reason for her } \\
\text { death was aspiration pneumonia caused } \\
\text { by inhalation of her gastric contents. } \\
\text { The resentment towards the medical } \\
\text { profession is has been compounded by } \\
\text { lack of communication from them, } \\
\text { regarding the circumstances leading to } \\
\text { her death. }\end{array}$ \\
\hline $\begin{array}{l}\text { I mean obviously I have a very negative } \\
\text { response to the medical, environment as } \\
\text { such ... the assistance by some people } \\
\text { was excellent for example the Doctor } \\
\text { who was in charge of the ICU ward was } \\
\text { very emotive at the time, and that } \\
\text { actually, was really nice for me because } \\
\text { I felt that she was aware of the problem } \\
\text { that had occurred, that was impacting on } \\
\text { me, um, that, at the time, at the, the } \\
\text { immediacy of the situation was that I just } \\
\text { needed answers, I didn't need } \\
\text { generalisations }\end{array}$ & $\begin{array}{l}\text { Openness, honesty, empathy and } \\
\text { willingness to show and share emotions } \\
\text { are valued by the surviving partner, and } \\
\text { are not seen as admissions of guilt or } \\
\text { signs of weakness. }\end{array}$ \\
\hline $\begin{array}{l}\text {... which again you know is one of those } \\
\text { really, sort of horrific things, because } \\
\text { someone had mentioned that because of } \\
\text { some process in the past, they have to } \\
\text { take the drugs off to ensure that she is } \\
\text { brain dead, but there is still a probability, } \\
\text { that she could flip out of this, and come } \\
\text { back as a vegetable, so I mean, the next } \\
\text { two days is, as much as you want the } \\
\text { person back, you want them back as } \\
\text { they were, not, what they're going to end } \\
\text { up being, so the next couple of days } \\
\text { were just, like freaky sort of stuff in the } \\
\text { sense that I can be pushing a wheelchair } \\
\text { around for the next twenty years, now } \\
\text { whether or not they, and I don't know, } \\
\text { you never know, I mean whether or not }\end{array}$ & $\begin{array}{l}\text { The conundrum of wanting your partner } \\
\text { to live through a catastrophic brain injury } \\
\text { but not end up in a vegetitive state is } \\
\text { articulated very well in this NMS. } \\
\text { Note: The conflict and associated guilt of } \\
\text { wishing she were dead, rather than } \\
\text { ending up in a dependent state is } \\
\text { something, which would concern anyone } \\
\text { in this situation. }\end{array}$ \\
\hline
\end{tabular}


they turn it of after eighteen hours because she actually did come back out of it and she was a vegetable and they just decided to switch it off then and there, which would be great. but I'm under the impression that they got her to a level where, there was no residual drugs in her system and they made another, assessment of her, and said yes she's brain dead

Yeah, and so I think that again being a lay person you don't know but you obviously have lots of ideas in your head I would hope that what would have come out of the incident would be that someone that is in her condition is never laid on their back, but they're always laid on say their side so if they do vomit, they don't inhale it, because apparently the drugs that their on, they don't have a gag reflex

...the hospitals are so fearful of duty of care and being sued, I suppose they would never even make a comment to the fact that they may have made that error but you never hear that they've actually remedied it by implementing procedures in future such that a person should be always on their side Um, eight weeks after the autopsy I still hadn't heard anything and then when I did ring the hospital to find out again there was a great degree of insensitivity I was told that I would have to go through, Freedom of Information, which I suppose not being in the hospital environment, it inferred to me that I had to go through some process of acquiring the information because they didn't want it to be freely available to me, as the husband and so I spat the dummy over that, and went to the Newspapers, and they wrote an article about it and within two or three hours I had the information I required but otherwise I had to go through this process of you know writing out forms and filling in forms and cross checking drivers licenses and passports or whatever to get the information, so the hospital was then respectful of the fact that perhaps that wasn't a good way of having the system and apparently the Freedom of Information came about because in the past the hospitals wouldn't release that information
The surviving partner believes that the hospital had breached it's duty of care, by having his partner lying in a supine rather than coma position.

If the hospital had acknowledged that by having the deceased partner lying supine position when she vomited, then the surviving partner may have had his faith restored in the veracity and integrity of the hospital and it's staff.

The lack of freely available information in a reasonable timeframe and a perceived lack of sensitivity resulted in the surviving partner telling a newspaper of his story, resulting in the hospital giving him the information that he had requested within three hours.

Despite the release of information the surviving partner still wasn't satisfied that he knew the exact cause of death. 
anyway. So again it's a secretive process within the hospital structure that I found, and still do find to be my biggest bug bear. I never really found out, how she really died.

... and that information never had any information relating to sectioning the brain, or what they may have found or whatever, there was reference in the general Autopsy processes to no lesions in the brain, or whatever so whoever did the general autopsy had done some dissection of the brain but it certainly wasn't slicing it and trying to locate the source of the bleed

It could have been that she did actually die because she drowned rather than a haemorihage, or another haemorrhage (clears throat) caused by the drowning process. What ever for them the cause of death was an intracranial haemorrhage. Now that's what she originally went in for but I don't think she necessarily died from that, I think that she actually drowned, and she drowned because she was on her back when she shouldn't have been, and I suppose that for every ninety percent of patients that die, that there would be no legal recourse on them, but for the other ten percent, means the hospitals have to shut down on, the full one hundred percent of cases. They go into self protect mode and I just feel that for people like myself that, would not sue the hospital because she was probably better off there than she was here, and I'm appreciative of the fact that the hospital's probably at the time doing the best that they can, I then go through life wondering how she really died, so I, think that she actually died from Management fault not through her ailment at the time, and I suppose perhaps in thirty years time you know they'll have some release of information when the statue of limitations is up, and they'll actually release the information, I don't know, but when I spoke to the Doctor a year later, what he, because it had gone to the papers and then I asked for an interview to try and clarify how she died, again they came into the interview, they were very protective, of the information to the point where he arrived
The autopsy did not reveal any abnormalities with the brain, further fuelling the surviving partner's suspicions that his partner died from aspiration pneumonia related hypoxic brain damage.

Resentment of the medical profession has fuelled by the surviving partner believing that information has been hidden from him.

The loss of the deceased partner's MRI scan has also contributed to the surviving partner's feelings of being misled. 
at the interview and his first comment was, that he didn't have the MRI scans they had been lost, so I don't know, sounds a bit suss, l'll never know what was on the MRI scans, either as to whether or not they'd actually missed the clot, or an Aneurysm, or they'd missed the source of the bleed and that they could have actually operated...

Yes and I didn't have a problem with that, in fact Lorna had, that she wanted to be a organ donor, and they didn't take any of her organs because, and that's something I find reasonably strange they didn't take any of her organs like her eyes or cataracts or, whatever because she'd previously had breast Cancer, well that's what I was told. Yeah and so I didn't really have a problem with them taking the brain, in fact we had the funeral, four or five days later and I was under the impression she wouldn't have her brain because I had requested that they do a full autopsy of the brain to pinpoint the source of the bleed and why, and they had told me it would take 8 weeks. They released the body, again this was a real drama, she died on the, well she was technically dead on the Friday, I'm sorry she was physically dead on the Friday, um, and on the Monday I rang them to find out, when they would be able to release the body for the funeral which we'd organized for the Wednesday, and they said oh well you could have picked her up on Friday, they'd done the Autopsy on Friday afternoon but no-one had contacted me, I just felt, oh I must say, look I just found the hospital, um fucking useless to be honest (laughs).

Was the GP ever informed of your wife's death? No, no Never No, and they knew who the GP was. My GP lives across the road, my neighbor (laughs) so you know the hospital hadn't contacted the GP they never contacted my GP

They didn't contacted anyone, it was, it was almost like this piece of... this body's come in they do the processing on it and throw it in, the freezer over there and, someone will eventually ring to pick it up

None of this feedback process you're (the interviewer) referring to, went on at
Despite being an organ donor, Lorna did not have any tissue or organs harvested because she had been treated for breast cancer, this cuased frustration for David.

The hospital failed to contact the surviving partner to inform him that the deceased partner's body was available to be picked up by the funeral directors.

David felt that the hospital's level of competence was inadequate.
The medical consultant failed to contact the family GP, who was the referring doctor, aboult the deatti of his patient:

The ongoing poor communication further reinforced the hospital's perceived lack of sensitivity and inclusion.

The surviving partner doesn't believe that he is the only person this has ever 
all, and I should imagine that I'm not a isolated case, so yeah on the Monday they said, yes, that she was ready for, to be released

Or so I thought, but l've never been informed as to whether or not, the, I asked for an Autopsy, again this is what I find reasonably strange, if I have a Motor vehicle, and I fix it, and I drive down the street and the engine blows up, I go and I rip the engine out and find out, what went wrong, this was almost like oh she's dead, okay next, it was like there was no interest by the

Neurosurgeon as to how she died, there was no interest by the hospital to try and establish the cause of death, or if not the procedures, that may have caused the death, or any information of that nature, made no reference back to me again to say look this is what we would like to do or this is what we're now going to do, to establish the cause of death, and I suppose in hindsight they probably already knew what the cause of death was, and so they didn't want to go any further, and again I think it was because she drowned, not died from a haemorrhage,, I am not to sure even to this date, as to whether or not, they sectioned the brain, sections of the brain were meant to be taken, because they told me it would be an eight week process

They are just a waste of space, she would have been better off lying on my bed and dying, from brain pressure, from the haemorrhage, and, and not being able to do anything about it than sending her of to a institution where you thought that she was safe and then finding out, and then realising later on that it was probably, hospital management, practices that, actually killed her ... had they presented me with some sort of literature that outlined, what I might go through over the next two or three, six months, something like that, would have been better for sure. What opportunities are out there, what I would have to do? I mean why do you deregister your wife on the electoral roll I thought all of these things, the big brother syndrome that we all are fearful of doesn't exist in Australia, I had to happened to.

The surviving partner had to request an autopsy be performed; the treating neurosurgeon was satisfied that they knew what the cause of death was, and that an autopsy was not required.
Without a thorough investigation, which was completely transparent and communicated fully to the surviving partner, the hospital's trust and reputation will always be tarnished in the surviving partner's mind.

The surviving partner wanted information which was practically based, like a "what to do now", booklet, outlining how to deal with officialdom, timelines etc. 


\begin{tabular}{|c|c|}
\hline $\begin{array}{l}\text { individually go to each (department). } \\
\text { Nothing was linked. I couldn't go to, I } \\
\text { couldn't, I couldn't go to Births, Deaths } \\
\text { and Marriages and register my wife was, } \\
\text { because the hospital does it }\end{array}$ & \\
\hline $\begin{array}{l}\text {... but as far as, what institutions can } \\
\text { do... obviously there are long term } \\
\text { issues, that people need to resolve } \\
\text { because they could become problems, } \\
\text { and I suppose institutions need to be } \\
\text { able to direct the appropriate resources } \\
\text { very early on, after the loss, and I think } \\
\text { that they are, well for me anyway, it was } \\
\text { resolving the death, and setting out what } \\
\text { I could expect, what the expectations } \\
\text { are, and what the options are, and that } \\
\text { might even be a matter of sitting down } \\
\text { with someone that can go, through the } \\
\text { financial processes, and say you know if, } \\
\text { for a male anyway, could you get off } \\
\text { work or do you want to get off work and } \\
\text { if you did give up work, do you see that } \\
\text { as significant. I mean l'm quite sure } \\
\text { there are guy's that have given up work } \\
\text { to look after their children but they } \\
\text { haven't really wanted to give up work } \\
\text { and so it's actually become a, laborious } \\
\text { task looking after the kids, where as }\end{array}$ & $\begin{array}{l}\text { The surviving partner recognises that the } \\
\text { way in which he has adapted to his new } \\
\text { life may not be acceptable to other men } \\
\text { in this situation. His advice to } \\
\text { bereavement professionals, is that this } \\
\text { should be discussed early on with the } \\
\text { surviving partner, with all of the options } \\
\text { given, so that the surviving partner can } \\
\text { make a decision further down the track } \\
\text { without guilt or anxiety, regarding } \\
\text { returning to work. }\end{array}$ \\
\hline $\begin{array}{l}\text { Actually they were very good, in fact, the } \\
\text { funeral people were the only people to, } \\
\text { contact me after one month and just } \\
\text { touch base to find out how I was going } \\
\text { and they were, they were just a, I } \\
\text { shouldn't say a cheap funeral service, } \\
\text { but they, weren't a brand name sort of } \\
\text { funeral director. }\end{array}$ & $\begin{array}{l}\text { The funeral directors contacted the } \\
\text { surviving partner a month after the } \\
\text { deceased partner's death. } \\
\text { Note: It could be argued that because } \\
\text { the funeral directors are a business that } \\
\text { is profit based and therefore competitive } \\
\text { then they would provide a better, more } \\
\text { holistic approach to their clients than a } \\
\text { non-profit government hospital. This } \\
\text { argument cannot be supported because } \\
\text { hospitals now regard themselves as } \\
\text { business' and as such have client } \\
\text { charters, bills of rights etc. }\end{array}$ \\
\hline $\begin{array}{l}\text { Relationship to children, family and } \\
\text { friends }\end{array}$ & \\
\hline $\begin{array}{l}\text { They went in a couple of times when she } \\
\text { was... I mean you have to remember } \\
\text { this was just a three-day period. So the } \\
\text { first day, yes we went in when she } \\
\text { presented to emergency and the kids } \\
\text { were there then. In fact Jimmy had to } \\
\text { hold her in the back of the car so she } \\
\text { wouldn't fall off the seat, cause the } \\
\text { Ambulance didn't arrive, um that's } \\
\text { another story, the next day they went in } \\
\text { for a short period, and I suppose that }\end{array}$ & $\begin{array}{l}\text { The children were kept informed of their } \\
\text { mother's progress continuously. They } \\
\text { were taken into see her when she was } \\
\text { awake following her intra cerebral bleed, } \\
\text { and then when she was being ventilated } \\
\text { following her fit. }\end{array}$ \\
\hline
\end{tabular}


was Mum's in hospital, everything's going to be okay, we just have to really see whether or not there's any long term, sort of damage or whatever, and so, yeah the kids had school, at the time, so it was really a matter of, keeping that flowing, keeping sort of normalcy going I suppose, then when she did have dilated pupils and they had her on the ventilator in the ICU ward I just decided that the kids needed to go and see her, sorry I still get sort of choked after two years Um, so yeah we went in and I just told them that Mum, was still alive, ah and that there was a possibility that she would die, and this was their opportunity of saying goodbye, and so they did and then the next day they took off the ventilator.

The kids went straight back to school.

Cause they were already, yeah six and seven at the time and they're sort of oblivious to the concept of what death really means. Even little Kelly was saying afterwards oh well Mum's not coming back, she wasn't even aware of the concept of death
The children were informed of their mother's dire condition, and were given time to say goodbye.

The surviving partner decided to have the children return straight back to school, not disrupting they're routine. The concept of death was fairly abstract for the children, who took it in a fairly matter of fact way... "Mummy's not coming back"

Note: Children have fairly matter of fact concrete approaches to death. The impact of the loss may not be as dramatic/traumatic, because the child has not invested the time and effort into the relationship, that the partner has, and therefore the concept of a lost future with them isn't as obvious.

The surviving partner believes that the children will recover in time.

The deceased partner's family haven't been as supportive as the surviving partner would have thought. Again, the assumption is that if you need help or support we're here for you, otherwise they'll carry on as usual. l've been to dinner three times in two and a half years. They live a kilometer away, and I would have thought that in that period I would have been to their place for dinner three times in the first week, and it just never eventuated, it just didn't happen They feel, we're there if you need us, but it's almost like l've got to put my hand up and say, yes I can't do it, I need you, and it's just reversed psychology... people that need don't put 
their hand up, it's only when they get desperate they put their hand up, unless somebody else puts a hand up for them Again, there are things that you assume but then you find out later, that was just a wrong impression that you had, you know Lorna was the glue that held a dysfunctional family together, she was the one that would take the kids up to see Grandma and Grandpa, she was the one that would get her Sister around to our place and have dinner, in fact, again with her sister being single, I've been to Rae's place twice for dinner, in two and a half years, Rae's been here probably, a dozen or so times for dinner, her parents will, arrive, and for some reason they've always got to have a reason to be here they can't just drop in and say oh we've come down to see the kids, or we've come down to have a cup of tea, they've got to have a reason to come, and l'll say stay for a cup of tea, oh no, no it's okay, we've just got to.., or we're on our way shopping and if we've got to get it done, so off they go, and I for, oh probably for about two or three months thought, God have I got bad breath or something (laughs)

I just didn't know what was going on, and then I start to, to think back before Lorna died and I can remember saying to Lorna, one time, why her parents don't just come down and read with the kids or, you know bring their books down and just sit in the lounge room and read with the kids and she said oh I don't know, I take them up, I take the kids up to their place, and even at their place Grandma gets uptight because it's a six year old around the furniture, what are they going to break and so Lorna would only stay there for half an hour and I don't actually remember the

Grandparents being down here all that often and so here was this "ideal" middle of the road family, in actual fact they were dysfunctional, Lorna was the one that was holding them together and yeah took me probably, six months to come to terms with the fact that Grandma and Grandpa, although it's mainly Grandma's influence, Grandpa when they do come down here, he'll sit and talk with me over a cup of tea and, and have a yak, it will
Following the partner's death it became apparent that she was a cohesive force within the family. Since her death the family has fractured. This is demonstrated by the lack of shared meals at the parents and sister's houses, and the lack of unsolicited support from her parents.
Lorna's death and the attitude of her parents towards her family, has led to insight building of the surviving partner into the mother's personality which is probably a combination of obsessive compulsive disorder and agoraphobia. 
be Grandma that's dragging him away, and ah, l've noticed that, she does that, not just in my situation but when she visits other people, other Cousins whatever, she can't stay, she's just got this nervousness that she's just got to get back out again,

I haven't discussed it (the death) with them, and I suppose they might be waiting for...I suppose I'm the one that has to initiate it, and I can appreciate that, and I never have initiated that, but then, they don't seem to create an environment

We get together to actually have a yak about it you know, come on up to dinner, come on up to dinner or something like that you know, so I would put my hand up and claim fault for not actually discussing her death, but then it was strange because, even though they both suffered, after her death, physically, cause of their age I mean they were seventy eight and eighty at the time, her old man 1 can distinctly remembèr, didn't even have a fear, shouldn'tsay didn't even have, he didn't have a tear in his eye, all he did was Kiss Lorna on the elbow, and that was it, it was almost like he's totally internalised it. I suppose it might be that generation, 1 don't know, perhaps, but not only have they gone through a war but he is the last of all lof his friends that's still alive, so he probably experienced the death of close friends quite a lot over the last ten, fifteen years and so perthaps, they can come to terms with it a lot easier I'm trying to get a handle on it and so they just seemed to be so, I wouldn't say cold about it, I don't know, I was in floods of tears, I mean I, they're just totally different and, and I suppose that's, one of things that you come to realise that the responses are, often totally different to what you anticipated,

My Brother, there's six kids in our family and three of them came over. So they came over, they stayed for about a day, but again, my family's reasonable dysfunctional, my parents were divorced when I was about ten, and so the girls went with the Mother and the boys went with the Father, so my two Brothers came over and one of my Sister's that
In 2.5 years the death of their daughter has not been discussed with their son-inlaw.

In trying to understand his parents-inlaws' reactions to the death of their daughter the surviving partner try's to rationalise their approach to death with them having been confronted by it through war, and age, and their own impending death, as elderly people.
The surviving partner has had to accommodate different grieving styles whilst not judging people such as his parents-in-law who have a stoic approach.
Three of the surviving partner's family came for the funeral and stayed a day. $\mathrm{He}$ is able to rationalise this brief visit as being typical of his family who have not visited him in 20 years. 
I've got close to over the years, um but again there's not a lot of family

association anyway and that's probably, I mean I've been living here for twenty years and in that twenty years, ah they've never come over here to Perth, but I would, we'd, go on holidays or go skiing or whatever so, every two years we'd be in Sydney and so l'd do the relie rounds and see everybod

They were of assistance, because my brother unfortunately lost his wife about, four years before that and so he'd gone through the same sort of process

You always hear people saying, you need a disaster to really figure out who your friends are and strangely enough I would have thought that, I premised it by saying this, when you lose a partner, you lose a lifestyle which incorporates doing things together, and fitting in together and you through your friends initiate things and they through there friends initiate things and through mutual friends you initiate things, when your partner dies, the void that they leave is also their initiation of friends, and Lorna was a very, out there sort of person, a very dynamic sort of person so, in the main our friends were Loma's friends and without her there to stimulate their interest in her and therefore our activities, a lot of, Loma's friends died away, even though at the time them felt, well your our friend as well, you and Lorna were our friends, it wasn't just Lorna, it was you and Lorna, and I felt it was myself and Lorna, yeah a lot of people that I thought would be a lot closer and probably be of more assistance... I mean a lot of people are out there saying if you need me, give me a ring

But the reality is that you're so consurned doing your own thing and you don't have a lot of time to just suddenly ring up and say, look I'm really lonely can you, have a yak to me for half an hour and I suppose it's like palliative care in the sense that somebody else has to come and help you, you can't go and ask them for help , there were people saying if you need help, give me a ring, but because I didn't ring over time, there've just faded away and yet
The surviving partner's brother was able to empathise with him due to his own loss of his partner.

Following his partner's death it became apparent that the friends that he had as a couple were drifting off because they were actually his deceased partner's friends initially. This realisation was disappointing, and despite their offers of availability if he needed them, the offer obviously rang hollow.
The post bereavement period was a shakedown peñod tor his friends, resulting in some héndships deepening: and others reducing in quality and quantity of contact. The need for friends to actively reach out to the surviving partner who is often not in a position to contact the friend for support. 


\begin{tabular}{|c|c|}
\hline $\begin{array}{l}\text { they were some of Lorna's best friends } \\
\text { and other people that weren't Lorna's } \\
\text { best friends I think within their nature, } \\
\text { have come to the surface of being, really } \\
\text { nice people and it was just interesting } \\
\text { that those people that Lorna would have } \\
\text { thought would have been more helpful } \\
\text { they weren't there. }\end{array}$ & \\
\hline $\begin{array}{l}\text { The first eighteen months I just didn't } \\
\text { have any, interest and, even now, there } \\
\text { wouldn't have been a lot of interest } \\
\text { except for one of the women, at school. } \\
\text { I mean I've been approached by a } \\
\text { couple of women and a couple of } \\
\text { women, at school have introduced me to } \\
\text { other single mum's, but I suppose you } \\
\text { need some sort of chemistry there and } \\
\text { you need a situation that triggers it }\end{array}$ & $\begin{array}{l}\text { Women were actively attempting to } \\
\text { introduce the surviving partner to other } \\
\text { women in the hope that a relationship } \\
\text { would start. } \\
\text { Note: It is interesting to note that the } \\
\text { traditional "grieving times" have been } \\
\text { reduced considerably over the past } \\
\text { generation, with women actively } \\
\text { pursuing a widower within a relatively } \\
\text { short period of time, following the death } \\
\text { of his wife. }\end{array}$ \\
\hline $\begin{array}{l}\text { Whereas inviting someone around for } \\
\text { afternoon tea and having a nice chat } \\
\text { with them just doesn't, do anything, } \\
\text { whereas one woman actually invited us } \\
\text { to go down to her holiday house, and } \\
\text { that triggered a relationship and so that's } \\
\text { been going since, New Year. The kids... } \\
\text { again that package concept, our kids get } \\
\text { along really well, her children are much } \\
\text { older, but they all get along, and they get } \\
\text { along on a, very friendly basis and } \\
\text { there's no, weirdness about her kids nor } \\
\text { my kids, and that sounds strange saying } \\
\text { that but it's just that some people's } \\
\text { children irk you, and hers don't. And my } \\
\text { kids have been okay with a new, woman } \\
\text { coming on the scene, actually Kelly just } \\
\text { loves her, }\end{array}$ & $\begin{array}{l}\text { The surviving partner believes that the } \\
\text { concept of getting involved with another } \\
\text { person involves compatibility with the } \\
\text { children on both sides, in order to reduce } \\
\text { the amount of stress involved in starting } \\
\text { a new relationship. }\end{array}$ \\
\hline $\begin{array}{l}\text {...and because they're older than Kelly } \\
\text { who is eight, going on nine she sees this } \\
\text { progressive step into, adolescence so } \\
\text { she really likes it and, yeah my partner is } \\
\text { very motherly, she likes giving lots of } \\
\text { cuddles and all that sort of stuff. So } \\
\text { Kelly just likes that, Jimmy is a little bit } \\
\text { reserved, but he's reserved anyway but } \\
\text { he enjoys it, Brooke who's the thirteen } \\
\text { year old, and they swim and play cause } \\
\text { she's two or three years older, she's } \\
\text { doing, physical things that a boy likes } \\
\text { doing So, you know, she has been, } \\
\text { informed that she's, a great girl cause } \\
\text { she's a boy }\end{array}$ & $\begin{array}{l}\text { The children from both sides are getting } \\
\text { along well in the new relationship, which } \\
\text { reduces the potential friction in a } \\
\text { blended family. }\end{array}$ \\
\hline $\begin{array}{l}\text { What about her ex-partner, l've meet } \\
\text { (him) a couple of times, and that's }\end{array}$ & $\begin{array}{l}\text { There is a very real concern by the } \\
\text { surviving partner that a new partner }\end{array}$ \\
\hline
\end{tabular}


always a concern to me, because, I'm coming from a relationship where there was a loss rather than a hate, so I don't see the ex as a threat or anything of that nature. I suppose you add to their relationship with a different sort of maturity, but I suppose I feel that because she's come from a divorce situation, that she will have some sort of protective attitude towards our relationship

Bringing them in and seeing how their relationship forms with the other person, and bring them to terms with a new relationship... Because she's come from a divorced situation, and for four or five years she's had time to talk to her kids about, a new partner or whatever and her children are at a age where they're receptive of the need for a partner...

...actually it was strange really because I was the first relationship that she'd had, and I with her

It was almost like gloves, in fact it was, and it was a bit scary for both of us in a sense that it seemed to be so natural. I mean because there'd been, about two years since l'd been with anybody, and even though the memories are still there of Lorna, I mean Barb's got a totally different build, she has a similar sort of personality but she's got a totally different build and so physically it's not the same...

But I feel that had I not met her, I could have stayed in a celibate state for whatever...

But now that it has developed, it obviously triggers old needs, and desires and expectations and you realise you had something missing

You know whien you get into that sort of relationship it starts to fill in the parts of the void that the last person left behind. Her fear is getting into a relationship where, she doesn't know whether to trust the male and my getting into a relationship is, am I just going back to what my expectations were, in other words am I really having a relationship with her or am I having a relationship to fill the void that Lorna left and I suppose, it's a fear that we both sort of talk about and I suppose the having experienced the separation from a partner through divorce will have feelings of antipathy towards the ex partner and the need to protect herself from another hurtful relationship.

The surviving partner believes that there is a need to introduce the children to a new partner sensitively and with care. The new partner's children have had longer to contemplate the idea and come from a situation where the relationship was not ideal.

For both of them it was their first new relationship since widowhood/divorce.

The new relationship felt very comfortable which was unsettling that it could feel so natural.

The surviving partner was not contemplating becoming involved in a new relationship, and was settled in his celibate situation.

Only after the relationship had begun, were the longings and desires rekindled. It is then that you realize what has been missing in your life.

The conundrum for both partners is related to their previous relationship, with the new woman - will she be hurt again, with the surviving partner - "am I only getting involved because I miss my deceased partner so much?"

Having discussed their concerns with each other, they have decided to take 
more we talk about it the more we

realise that we just have needs and, and to go with it, and if it doesn't work then it doesn't work, if it does work then great, and so I think the only courting process that we are doing is really the courting of the children not, the courting of us, in that, both of us are pretty sensitive towards treading softly with our kids Yeah, how both of our kids, react, um, because we realise that at our age, you know what you physically and mentally are seeking, and, if it's going to work then you just go for it and hope it works, it's not, you know l'll take you out to dinner and buy some flowers and, she'll, come and give me a home cooked meal and all that sort of gobble de gook, we don't seem to be getting into that at all, it's just we realise we have our needs and, lets just go for it and see if it works, and if it doesn't work then, we will say goodbye to each other without any animosity but in the mean time the kids have become, receptive to the other person but we realise that there are hurdles, I suppose one of things that we realise is that although we fit together, like gloves, we can fit together with a lot of people, like a glove, you need to satisfy your needs, and there's a lot of fish out there that would satisfy those needs, and I think we're both receptive to the fact that our need for the other person, requires time and familiarity and that we need to build a relationship with them, but the sexual need could have been with anybody but you wouldn't do it with anybody cause of the other needs, they create the parameters to work within and so, it's not really a matter of, whether or not we spilt up, it's more a matter of, the impact it's going to have on the kids if we split up, and the impact of the kids if we get together so it's sort of that, you know delicate balance trying to achieve...

Relationship to the community ...these meals arrived every couple of days from the people at school, um and the school was very supportive When I showed any degree of selfsufficiency they would, quickly fall away Although I must say the meals kept on coming till, the end of school and so that the relationship as it comes, working hard to incorporate the needs of both sets of children as they progress.

Now that the children have accepted the new relationship, they are concerned about the effect them splitting up would do to the children...

Both partners are very sensitive to increasing the anymore exposure that their children have to loss experiences.
The school community was very supportive in a practical manner.

People discretely withdrew their help, as the surviving partner appeared to gain control of his life. 


\begin{tabular}{|c|c|}
\hline $\begin{array}{l}\text { was like two months, three months, very } \\
\text { helpful }\end{array}$ & \\
\hline $\begin{array}{l}\text { Yeah, and in a way, I probably didn't } \\
\text { need it in the last, month or so, but I } \\
\text { accepted it because I realised that } \\
\text { people wanted to help... I think I had a } \\
\text { freezer full of, frozen food (laughs), but it } \\
\text { was just nice to feel that these people } \\
\text { were willing to help... }\end{array}$ & $\begin{array}{l}\text { Allowing people to feel that they are } \\
\text { contributing is an important sign that the } \\
\text { surviving partner is in touch with what is } \\
\text { going on around him. }\end{array}$ \\
\hline $\begin{array}{l}\text { I could only give them a review of what } \\
\text { happened to me and what I felt like, I } \\
\text { think one of the obvious things that has } \\
\text { come out of it is, my children go to a } \\
\text { smallish school, and there's a lot of } \\
\text { parent participation, and that has } \\
\text { probably been my savior, the school } \\
\text { indirectly has provided me with, parent } \\
\text { contact which provided me with adult } \\
\text { stimulation. It's, enabled me to } \\
\text { participate with my children, like sailing } \\
\text { I'd go and do sports with the kids at } \\
\text { school, and help out around the school } \\
\text { with their bits, l'm in contact with, my } \\
\text { children and also other people's } \\
\text { children, and that indirectly means that, I } \\
\text { have contact with other adults and, if I } \\
\text { didn't have that, yeah it'd be pretty, it } \\
\text { would be pretty lonely because a lot of } \\
\text { the people that were our old friends, are } \\
\text { off working during the day, and at night } \\
\text { time they're home to do their thing, and } \\
\text { then on weekends they do social things } \\
\text { as a couple and they require another } \\
\text { couple, .Hmm, but it's an old (laughs) } \\
\text { parent of school, very few young parents } \\
\text { there, so I mean again that's been my } \\
\text { savior as I'm an old dad. I'm sure that if } \\
\text { the kids were going to, some other } \\
\text { school I mean I sure if they went to any } \\
\text { little school l'd find a similar sort of thing, } \\
\text { but if the were teenagers for example } \\
\text { where you don't participate as much in } \\
\text { the school, I wouldn't have had that } \\
\text { family contact, and I probably would } \\
\text { have had to have gone to work for the } \\
\text { social contact }\end{array}$ & $\begin{array}{l}\text { Having contact with other people through } \\
\text { his children's school has provided him } \\
\text { with community support and friendship, } \\
\text { which helped reduce the isolation and } \\
\text { loneliness that he felt. } \\
\text { If his children were older then he would } \\
\text { have to seek social contact through work } \\
\text { associated activities. }\end{array}$ \\
\hline
\end{tabular}

\section{RELATIONSHIP TO THE WORLD}

\section{Adapting to new social status/identity}

I just stopped work....So, um, I felt that l'd probably be home for about a year and then l'd go back to work and I thought that would be long enough for the kids, in actually fact I found some
The surviving partner decided to stop work immediately and has not returned to work since the death of his partner.

He feels that the children need him at 
little subtle things that the kids were doing that inferred they would, prefer quantity time rather than quality time, and so it suited me at the same time to just stay off work and pursue my own interests, um, and so l've done that, and I probably feel at this point in time I will continue doing that until they're twelve years of age, so thats another two years, and then I'll probably get housewife syndrome and, need some brain matter stimulus and disappear into the work force again, I don't know or l'll disappear into doing something that l'm interested in, not necessarily into the work force We didn't have life insurance because we did a lot of traveling; we just felt that life was pretty immediate. We paid off the house, and we didn't have any huge investments, we just felt that, paying out for life insurance, was not necessary, because you know the other person would survive and so we never went into life insurance, in fact, it was only when the kids came along we got health, medical insurance, we were too busy traveling to worry about, that sort of thing

I just really played house husband ever since, and tinkered around doing different things.

I think it was that, macho Australian male culture of you're just got to get on with it. You realise that something unfortunate has happened, and you just get on with it, and I suppose that's, probably that, the most simplistic and probably best advice that I got was, you've just got to get on with it,.

....and they said that I could either have them (meals provided from parents at school) every day or whatever I wanted, so I took it on two days a week, and I suppose not having cooking skills or domestic skills, I mean I think that's where women with children are probably fortunate when they lose there partner and go on Centrelink, their fundamentals don't change, in other words they're still looking after the children and keeping the house going whereas my fundamentals were I go to work and home to support and care for them on a full time basis.

Fortunately the family home was paid off, which allowed the surviving partner to survive on the single parent pension.

What was also revealed by this part of the conversation was that as a couple, they lived a full and active life, living for today and not putting things off to do in the future.

Even though the surviving partner recognised that his role as primary carer is important, he refers to himself as "playing" house husband, implying that the domestic role is of lesser importance that that of paid labour.

The surviving partner approached his life after his partner's death in a pragmatic manner.

Living by the maxim that you have to "get on with life".

The lack of domestic skills for a male poses significant difficulties in the immediate first few months following the death of their partner. 
come home

and that whole work, home environment is a niche that the other person looked after and Lorna being an Accountant also looked after most of the financial stuff

I drew on the experience of a friend in Britain who also had a partner die suddenly and unexpectedly, and it made more sense for me to try and keep as much stability as possible and to keep things around, and life went straight back into normalcy with the loss of a Mum.... yes so things quickly went back, to what appeared to be normalcy, and I just got on with a new way of looking at life really, I suppose it was just the pragmatism of just getting on with it I didn't really have a lot of male friends anyway and of the five I still see, three only get together occasionally because, they tend to get together with, their, partner and because I'm not partnered I don't know why it is, I mean, now is the time that I need friends and yet, there seems to be this isolation, although there's still three that I still have. They will invite me over for dinner and the kids will play and l'll go over there and have a yak, with the wife and that sort of thing and I suppose there's never been any real animosity but I do know that I will actually go and talk with the wife more than I will talk to the guy because it's female company and you have more in common with them now.

true, in fact they were going to tattoo
bvaries on to me, because of that...

Experiencing significant dates/events

It's still a bit of a drama, though we do celebrate Father's Day, again because you don't have, another adult initiating the making of cards or the buying of presents it a bit awkward. So Christmas and Father's Day and things like that I initiate, the presents and things. All that sort of stuffl wouldn't have done in the past. Lorna would have done that especially little trinkety things.

Christmas we've always had with the grandparents and Rae so we've sort of maintained that so it hasn't been, too big a drama, but it's obviously lost a lot of it's flair, probably not so much because of the loss of Lorna, but also the kids are
His deceased partner also managed the domestic finances, which added to the surviving partner's burden.

The surviving partner talks about maintaining normalcy and stability as his priorities for himself and the children, several times in the interview.

The surviving partner feels isolated from his best male friends, because of a lack of common ground, due to him being a househusband.
Without the deceased partner to help prepare for and be involved in significant days such as Father's Day Christmas don't have the same "feel" about them. 
getting older and they've lost Santa Clause now, but at the same time there isn't that dynamism that Lorna brought into the house, if anything the house has become a lot more staid and boring than it was before

\section{Relationship with officialdom}

Yeah a little bit difficult there, like a lot of things in our society it's not logical and straight forward, you do what is, manipulative and shrewd, and so in asking the questions of Centrelink and places like that it became obvious, that I was better off leaving Lorna's estate going, so even now it still exists.... Take her off Medicare, take her off I don't know just all the different bits and pieces. I'm still getting letters addressed to her from government departments and things like that and I just thought that would be an automatic flow on and it wasn't (the case), you had to actually go to individual places and I think in some cases there were time frames by which you had to register the person's death with them.

...they changed the law at the beginning of this year as to trust funds and things so fortunately because we'd paid off the house our, my biggest outgoing is no longer there and the monies that I got when I was on the pension, enabled me to just survive

\section{Memorialisation of the deceased partner}

Well because we were involved in local issues, we had the funeral in the park and the Council gave us a Tuart Tree, and so there's a tree, it's not plaqued or anything, But there's a tree in the parkland that is Lorna's Tree and so we'll go down and have a yak to the tree. The tree's been there, symbolically for them to go to if it was necessary, I suppose I put into place lots of opportunities for the kids to be able to say goodbye, or to have contact, but they very rarely go down there now, I go down there and water the tree, and say hi...

I kept the ashes, I felt they might be needed, because the kids were so young when she died, and again this is something that I talked to her parents about, and they were considerate
Informing DSS, Medicare and other government agencies is an onerous chore and not easy. If a brochure was given to the surviving partner outlining all of the things that they have to attend to and in what time frame would be very useful.
With the house paid off a single parent pension allows the surviving partner to live reasonably comfortably albeit frugally.
Having a tree that was planted in the nearby park in honour of the deceased partner allowed the surviving partner and his children to care for and watch grow, and make contact with the deceased partner as opposed to a static grave stone in a cemetery.
The surviving partner has kept the deceased partner's ashes to spread around the tree at a time that is appropriate for both him and the children. 
enough not to be... they just said you

know even through she was our

daughter, she was your wife and

therefore you have had more of an

emotional relationship with her and so

just do what you want to do, again like the tree, l've kept the ashes, thinking that, perhaps, as time went on if the kids really missed her, and we did start having problems, that they would be able to spread the ashes around the tree and perhaps that might be a mechanism for them to be able to release her, to be able to say goodbye because they were too young to say goodbye before and to be honest, the ashes to me are just probably more a box than it is Lorna, seeing we're ninety eight percent water, so having the ashes doesn't irk me or disturb me, I kept them in the box upstairs, so that if a need arises the kids have that opportunity of spreading them. So, they might stay there for another five, ten years till there fifteen and sixteen, um, they might condemn me for not having spread them beforehand but I'd rather them condemn me for not spreading them than to have some psychological problem arise, at fourteen or fifteen years of age where they felt they were never able to say good bya...

That I might even spread them earlier, but you know it was just in the back of my mind at the time, that I didn't know how the kids were going to handle it at a later age when they get into their teens, and of course you don't know what sort of partner you're going to meet, you often wonder whether or not the person that you meet will be, well your not really meeting a person your meeting a package, she come with her baggage, more than likely with her kids etc, etc, and I just felt at the time, that there might be a lot of animosity to a new partner and, again that would enable them to flip into, missing their Mother and, not having said goodbye to their Mum or, not having something symbolic of their Mother or whatever, so I just though right I'll just keep, (them) I don't have any, spiritual, emotional sort of belief in the after life so, I just felt if I kept the ashes, it's a backstop in case something happened
The surviving partner believes that there will be a time in the future when the disposal of the deceased partner's ashes will be appropriate for both him and the children.

The surviving partner does not believe in life after death, so the spreading of the ashes is more of an act of memorialisation than that of a religious nature. 


\section{Relationship with the future}

... but unfortunately, when, Lorna and I were working we shared the domestic things, there was time enough for us to work, and to play with the kids and we could share the load. But when there's only one of you, it seems more than just twice the amount of work, I suppose it's because you don't get the relaxation opportunity, rest wise. That seems to build and even though it probably isn't actually twice the amount of work, it's probably only one and a half times the amount of work, it seems like twice the amount of work cause you just don't get that opportunity to go off and have time and it's hard I think initially, to justify the time off, I mean there's so many things you need to get done and to do, I suppose it comes back to an old story that I was told once, about the axe-man, he's chopping wood and he was very productive chopping wood, but as time goes on he gets less and less productive so he has to chop faster and faster and faster until someone comes along and said why don't you just sharpen the axe, you know take time off

Without going backward into our savings, ,unlike a lot a people I just felt, my attitude towards things changed I don't live life for the moment but I do have a better appreciation of just, living now and doing the things that l'd like to do, and that's why I don't really have a drama not working, I mean a lot of people are fearful of the fact that I'm not working...

I feel that because I could be dead tomorrow too I just want to do simple things like, make sundials and sculptures and stuff, I'm getting more into doing things that I want to do...

I suppose it's death, I mean there were people at the time who went oh wow it's such a shock Lorna dying it make you suddenly realize the futility of things, a lot of the things you do in life especially going to work but they change for about two or three months, and then the system caught them again and, they were back to the old attitudes whereas, I suppose it was such an impact on me that it has actually changed the way I
Insight is shown in this passage, with the surviving partner admitting that he hasn't taken any time out for himself over the last 2.5 years, and that he probably should take some time off to rest and allow himself some space to process what has happened to him and his family.

Being at home to care for his children has taken precedence over working and having a "better" material quality of life.

Note: It is interesting that it causes concern to other people.

The surviving partner keeps himself occupied by creating sun dials, sculptures and stated that he doesn't get bored by not working in the paid work force, having plenty to keep him occupied at home.

People close to the family took the opportunity of reviewing their own lives following her death, but within months the impact wore off, with them maintaining their pre-death lives. 
see things.I haven't dropped out, but at the same time I don't see the importance of pursuing my own interests I see more importance in giving the kids a better, a good life

Obviously you get people saying oh, time will heal, but the reality is that's what happens is you have this void that's, stuck on the back of your being and you just drag it along with you through time, and eventually it gets smaller and the influences aren't there anymore and life just goes on

I can remember standing at the counter at school one day talking with these women, about there husbands, this woman just went off about her husband, spending too much time down the beach and I said some comment and she said oh yeah but you're more in touch with your female side, and I thought well I suppose I have become that way. I have a greater sensitivity to children and I'm more aware of their security, and their, failings, and the frustrations of domestic life and the taxi server process that you go through and all those sort of silly little things that just end up at the end of the day being an irritation to a lot of housewives and so I'm more appreciative of what they have to do than ever before

But it just seemed to be, God there must been something they can do you know to achieve that end, but obviously at this point in time they don't have that ability and I suppose I looked at it like someone being wounded on the battlefield back in the eighteen hundreds, they survived the battle but because they were wounded they died...later by infection, or blood loss or whatever which I suppose over the years we've improved, and I suppose, neuro-surgery is at that point where there still like the battlefield victims in that, they have a head bleed they don't actually die from the bleed at the time, they die from complications that arise after that, and it seems as though it's that same battlefield scenario we'll just have to wait and see, presumably in another fifty years, that whole area of medicine will have changed and Lorna would have lived, In a way she died
The surviving partner often talks about the death of his partner creating a void, which slowly fills with time, but not completely.

Having to adapt from his pre death life of engineer/researcher/breadwinner to that of non wage earning primary parent has resulted in a greater awareness, sensitivity and empathy towards his children's needs as well as the situation of being at home experiencing domestic life.

The surviving partner harboured a large amount of resentment regarding the manner in which his deceased partner was treated in hospital. He blamed the hospital for nursing her in a supine position when she was vulnerable, resulting in her aspirating her stomach contents, and becoming hypoxic resulting in brain death. This ingrained resentment was compounded by the difficulty in obtaining the autopsy results as discussed in another section. 


\begin{tabular}{|c|c|}
\hline $\begin{array}{l}\text { through naive hospital management not } \\
\text { through her original ailment, and I will } \\
\text { never, ever find out. And I gather there } \\
\text { is quite a large proportion of } \\
\text { questionable deaths in hospital. But it's } \\
\text { better than not having hospitals (laughs). } \\
\text { I can be philosophical about it two years } \\
\text { later but at the time I just thought fucking } \\
\text { hospitals are a waste of space. }\end{array}$ & \\
\hline $\begin{array}{l}\text {...obviously there's the immediacy after } \\
\text { the situation, being really pragmatic. Its } \\
\text { only time that has enabled me to filter } \\
\text { the information and select what I think is } \\
\text { appropriate but now l'm in a new } \\
\text { relationship, that's becoming a priority in } \\
\text { my life }\end{array}$ & $\begin{array}{l}\text { Immediately following the death of a } \\
\text { partner, the day-to-day needs of the } \\
\text { surviving partner and the children take } \\
\text { up a lot of time and space. When a new } \\
\text { relationship starts it allows the surviving } \\
\text { partner to start thinking of someone else } \\
\text { as well as acknowledging his or her own } \\
\text { needs. }\end{array}$ \\
\hline $\begin{array}{l}\text { How do I develop this relationship, } \\
\text { based on my previous experience and } \\
\text { what's happened, and her experiences } \\
\text { and what's happened to her, and how } \\
\text { my children are going into it, it's like } \\
\text { palliative care, you know the persons } \\
\text { going to die but you can't do anything } \\
\text { about the situation, you can't move on } \\
\text { until they have died, so, you're just in } \\
\text { this sort of limbo land waiting for the } \\
\text { situation to occur. When they die you } \\
\text { can then progress to the next stage, } \\
\text { Lorna's death put me into the next } \\
\text { stage, limbo land and it's only when you } \\
\text { get into the next relationship which, it } \\
\text { takes time for the emotional void to } \\
\text { close over a bit from the last person } \\
\text { before you get the openness to move } \\
\text { into the next... }\end{array}$ & $\begin{array}{l}\text { The surviving partner describes being in } \\
\text { limbo land following the death if his } \\
\text { partner, and as he has stated before, it is } \\
\text { only when the "void" is starting to close } \\
\text { up, that the surviving partner can allow } \\
\text { another person into his life. }\end{array}$ \\
\hline $\begin{array}{l}\text {... when you're in that new relationship, } \\
\text { you can then move on, but until then, } \\
\text { you're just sort of in limbo land, which is } \\
\text { in a way been okay for me because that } \\
\text { limbo land has given me time to be } \\
\text { involved with other things, because I } \\
\text { gave up work and because l'm not } \\
\text { focused on work, and l'm not focused on } \\
\text { a career, and because the children } \\
\text { haven't been a problem, I've been able } \\
\text { to do other activities that I've always } \\
\text { wanted to do that, which aren't overly } \\
\text { time consuming, also being a domestic } \\
\text { is a new experience for me, I haven't } \\
\text { become, bored, even though l'm in limbo } \\
\text { land it's all been a new experience and } \\
\text { therefore, educational (laughs) }\end{array}$ & $\begin{array}{l}\text { The surviving partner has managed to } \\
\text { gain insight over time as to the positive } \\
\text { things that have happened to him since } \\
\text { the death of his partner. }\end{array}$ \\
\hline $\begin{array}{l}\text { I initially thought, I can approach this in a } \\
\text { negative way or I can approach it in a }\end{array}$ & $\begin{array}{l}\text { By keeping himself occupied and not } \\
\text { allowing to get bored, the surviving }\end{array}$ \\
\hline
\end{tabular}


positive way, and so, make it a positive experience with the kids rather than have it be a burden. So, it has been a bigger bonding period, now, and probably a bonding period that has established a much longer term, relationship between my kids and me. If anything, I haven't become bored with it so, I haven't become frustrated and generated anxieties about being, single, I don't know how long I could stay in that situation. I know that a lot of women, after about four or five years become frustrated with domestic life, especially if they'd been out in the work force previously, so I suppose a new relationship just gives me another focus that different focus probably allows me to move on or give me different set of problems that I have to resolve...

l've had to change my emotional attributes a fair bit. I've had to become, softer, I've had to have a different perception of children's needs and children's expectations, I think it's been a matter of me giving up rather than them giving up. I suppose it's because I just felt that I would continue things as they were. I will continue trying to keep the children with their expectations and their desires going rather than me keeping mine going, so I suppose that's the sacrifice, but I don't see it as a sacrifice now, I think I initially did, but now I see a lot of benefits have come out of it. I see it as an investment. As someone once said, when your on your death bed you don't say, boy l'm glad I went to work everyilay I do see that stronger sense of family, I mean, gosh you know you go to work, to come home, so it's home that you're trying to create so why go to work if you're destroying home so I just felt that l'd rather be doing more towards home rather than going to work thinking that by being financially secure that would resolve the problems

The kids, I feel the kids at this age aren't really into the Reebok society, Nike society they, at their age, they don't appear to be as entrenched as an older child perhaps if they were fourteen, fifteen years of age it might, I may have had a different approach to it, I may partner has been able to grow and develop into his new life and by not becoming fixed upon the negative aspects of his life was able to allow someone new into his life.
The surviving partner recognises the positive outcomes he has experienced since the death of his partner, having closer relationships with his children, gaining confidence in the domestic realm, and gaining independence. The surviving parther also sees his decision to stay at home with his kids as an investment in their fúture.
The surviving partner's world-view has become much more family focussed, realizing that you work so that you can create an ideal home front; so if you can do that without working then, why work?

When the children are older and the financial drain is more, then work will be an option. 


\begin{tabular}{|c|c|}
\hline $\begin{array}{l}\text { have actually stayed at work, because } \\
\text { they would have had their own physical } \\
\text { independence, whereas these guys are } \\
\text { so young I was still bathing them, and } \\
\text { doing all their cooking, and doing all } \\
\text { their washing, and making their beds } \\
\text { and all that sort of stuff, they weren't } \\
\text { independent as teenagers, I suppose, } \\
\text { were they teenagers their drain on you } \\
\text { would be more financial. Whereas I } \\
\text { think younger kids it's more an } \\
\text { emotional drain that they put on you, so I } \\
\text { just looked over and said well that's } \\
\text { what they're needs are so that's what I'II } \\
\text { cater for Until Jimmy is twelve or } \\
\text { whatever I'll probably, stay as a } \\
\text { househusband and just find, actually my } \\
\text { problem is I find too many activities to } \\
\text { keep me busy. I don't get bored at all } \\
\text { and I enjoy my own company, and I like } \\
\text { tinkering with things. I don't find that I } \\
\text { am frustrated or have any anxieties or } \\
\text { wish I was doing something else and I } \\
\text { suppose it's just an acceptance of being } \\
\text { where I am and what's happened, and } \\
\text { just moving with it and then as the kids } \\
\text { become more independent, III probably } \\
\text { look at going back to work and making } \\
\text { the best of our next situation. }\end{array}$ & 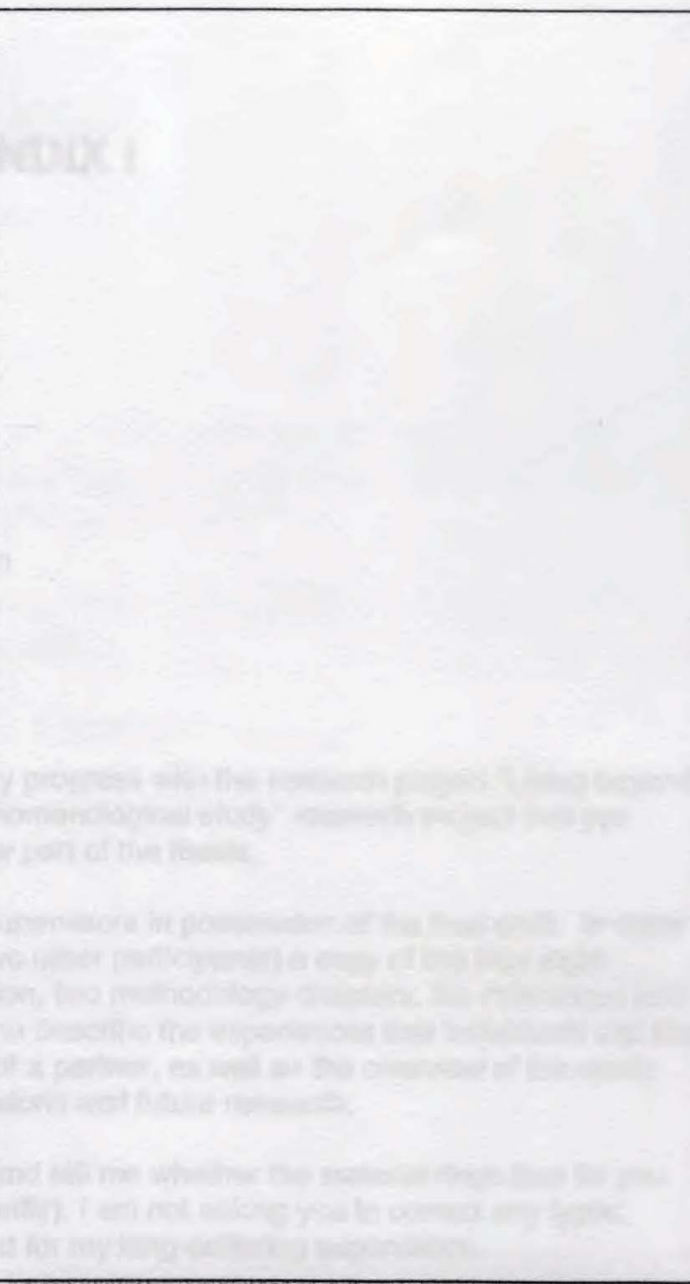 \\
\hline $\begin{array}{l}\text {.eventually it (the void) gets smaller } \\
\text { and the influences aren't there anymore } \\
\text { and life just goes on... }\end{array}$ & $\begin{array}{l}\text { The surviving partner recognises that life } \\
\text { does not stop when somebody close to } \\
\text { you dies, and that you have to go on } \\
\text { living and making the best of the } \\
\text { situation... }\end{array}$ \\
\hline $\begin{array}{l}\text { It's strange I mean you do actually end } \\
\text { up with a new life }\end{array}$ & A new life develops... \\
\hline
\end{tabular}




\title{
APPENDIX I
}

\section{Participant review of thesis}

\author{
Martin Rodger \\ Nursing Researcher \\ Personal contact details withheld for publication \\ $28^{\text {th }}$ September May 2004

\section{Dear $X x x x x x$}

I am writing to you to give you another update on my progress with the research project "Living beyond the unanticipated sudden death of a partner: a phenomenological study" research project that you participated in. Thank you for volunteering to review part of the thesis.

I am now in the final editing stages, with my three supervisors in possession of the final draft. In order to authenticate the project I am sending you (and two other participants) a copy of the final eight chapters (I have spared you the prefaces, introduction, two methodology chapters, the references and appendices). The eight chapters that I have sent you describe the experiences that individuals and the group as a whole lived through following the death of a partner, as well as the overview of the whole experience, recommendations for the health professions and future research.

What I would like you to do is read these chapters and tell me whether the material rings true for you (remembering that everyone experiences life differently). I am not asking you to correct any typos, formatting or grammatical errors, that job is reserved for my long-suffering supervisors.

What you need to consider is whether I have accurately and definitively described what life was like following the death of $X 000 x$. Again, I must emphasise that you will have to think of your life in general terms, and put yourself in others shoes, in onder to get a generalised feel for the concepts that I have created and described. Chapters four to nine are divided into the relationship that the surviving partner has had with themselves, others and the world.

I would also like your opinions as to whether I have made the appropriate recommendations in chapters ten and eleven. I have attached a cue sheet to assist you in this endeavour. If you would prefer to state your opinions via email, then please do so. I will be including your comments in the final edit of the thesis.

I understand that you may find this task both daunting and traumatic. If you no longer want to undertake this task, then don't. If this is the case, please contact me as soon as possible. Othenwise, please feel free to call me for a chat or email me anytime.

I have enclosed a stamped self-addressed envelope, for the retum of the cue sheet. I would appreciate your feedback by the middle of October. I hope to submit the thesis for examination by early November.

As promised, I will send you a copy of the completed thesis, once it has been examined and edited. Thank you for taking the time to participate further in this study. I hope that you are continuing to travel well in life.

Yours sincerely 


\section{APPENDIX J}

Participant thesis review questionnaire

"LIVING BEYOND THE UNANTICIPATED SUDDEN DEATH OF A PARTNER: A PHENOMENOLOGICAL STUDY'

A RESEARCH PROJECT FOR THE AWARD OF DOCTOR OF PHLOSOPHY (NURSING)

BY MARTIN RODGER

EDITH COWAN UNIERSITY

The aim of this research project was to describe as closely as possible what life was like for people whose partner had died suddenly and unexpectedly.

Do you believe that this aim has been achieved?

If not, why?

Do you believe that the descriptions portray as completely as possible, the experiences that you encountered and felt since your partner died?

What would you add or detract from the descriptions?

Did the descriptive chapters evoke strong emotions and/or images?

Do you think that I have captured the nature and intensity of the experienoes, feelings and emotions that affect the mind, body and soul and your 
relationship with yourself, others and the world, following the death of your partner?

What do you think of the experience pattern that I have proposed on pages 224 and 225 ? Do you have anything to add or detract?

What do you think of the recommendations that were made for health profecolonals? Do you have anything to add?

What do you think of the recommendations for future research Into griof and bereavement? Are there any other recommendations that you would have made?

Do you have any further comments?

Thank you for being an integral part in this research project. 